\title{
Evolution of Australasian Plantago (Plantaginaceae)
}

\author{
A thesis \\ submitted in part fulfillment \\ of the requirements for the degree of \\ Master of Science in Ecology and Biodiversity \\ at \\ Victoria University of Wellington \\ by
}

Mei Lin Tay

School of Biological Sciences

Victoria University of Wellington

New Zealand

CMei Lin Tay 2008 



\section{Abstract}

Phylogenetic analyses using molecular data were used to investigate biogeographic and evolutionary patterns of Australasian Plantago. The Internal Transcribed Spacers (ITS) from nuclear DNA, $n d h F-r p l 32$ from chloroplast DNA and coxl from mitochondrial DNA were selected from a primer assay of 24 primer pairs for further phylogenetic analyses. Phylogenetic reconstruction and molecular dating of a dataset concatenated from these regions comprising 20 Australasian Plantago species rejected a hypothesis of Gondwanan vicariance for the Australasian group. The phylogeny revealed three independent dispersal events from Australia to New Zealand that match expected direction because of West Wind Drift and ocean currents. Following this study, a dataset with 150 new ITS sequences from Australasian Plantago, combined with 89 Plantago sequences from previous studies, revealed that the New Zealand species appear to have a recent origin from Australia, not long after the formation of suitable habitats formed by the uplift of the Southern Alps (about 5 mya), followed by radiation. The ITS phylogeny also suggests that a single migration event of alpine species to lowland habitats has occurred and that recurrent polyploidy appears to be an important speciation mechanism in the genus. Species boundaries between New Zealand Plantago were unclear using both morphological and molecular data, which was a result of low genetic divergences and plastic morphology. The taxonomy of several New Zealand Plantago species need revision based on the ITS phylogeny. 



\section{Acknowledgements}

I am very grateful to Professor Phil Garnock-Jones for inspiration, funding and invaluable help with fieldwork; to Dr. Heidi Meudt for help with fieldwork, her patience with endless draft revisions, guidance and support during the course of my research. Thanks also to Dr. Peter Ritchie for guidance. I would also like to acknowledge Dr. Lara Shepherd, Dr. Vincent Woo, and the Victoria University Molecular Ecology lab for much valued advice and companionship in the lab over the past two years. Peter Beveridge, Barbara Briggs, Rewi Elliot, Kerry Ford, Peter Heenan, Rodney Lewington, Peter Lockhart, Bill Malcolm, Nancy Malcolm, Colin Ogle, Ines Schönberger, Leon Perrie, Dr. Lara Shepherd and Mike Thorsen for helped with sample collection. Barbara Briggs (Herbarium of New South Wales) and Landcare Research, Christchurch supplied information about geographic distributions of Plantago during the course of this research. Dr. Brian Murray at Auckland University demonstrated chromosome counting techniques for the purpose of this thesis, and Lesley Mililich provided technical support essential to my research.

For financial support, I thank the Morton family (for the Alison Morton Postgraduate Scholarship for Ecology and Marine Biology); FRST OBI Defining New Zealand's Terrestrial Biota C09X0501; the Wellington Botanical Society, VUW Post Graduate Scholarship for Masters Study and the VUW small grants scheme. I would like to acknowledge the administrative staff in the School of Biological Sciences, Victoria University of Wellington: Mary Murray; Patricia Stein; and Sandra. I also thank my family and friends for their support and patience throughout this undertaking. Finally, thank you to Zhang Te and Leah Tooman for keeping me sane. 


\section{Table of Contents}

Abstract

Acknowledgements

Table of contents iv

List of tables viii

List of figures $\quad$ ix

$\begin{array}{ll}\text { Chapter one: General introduction } & 1\end{array}$

1.1 Plant phylogenetics 1

1.1.1 Genetic markers for plant phylogenetics 9

1.2 Biogeography of Southern Hemisphere plants 11

1.3 Patterns of evolution in New Zealand plants 13

$\begin{array}{lll}1.4 & \text { Taxonomy in New Zealand plants } & 14\end{array}$

$\begin{array}{lll}1.5 & \text { Study group: Plantago } & 15\end{array}$

1.5.1 Previous phylogenetic studies 16

$\begin{array}{lll}\text { 1.5.2 Biogeography of Plantago } & 17\end{array}$

1.5.3 Taxonomy of Plantago in New Zealand 18

$\begin{array}{lll}1.6 & \text { Summary and research aims } & 19\end{array}$

Chapter two: Primer pair assays for amplification of 24 nuclear, mitochondrial or chloroplast regions in four Plantago and one Veronica (Plantaginaceae) species.

2.1 Introduction 
2.2 Materials and methods

2.2.1 Study group 26

$\begin{array}{lll}\text { 2.2.2 Molecular methods } & 27\end{array}$

2.3 Results 32

2.4 Discussion 33

2.4.1 PCR amplification results 34

2.4.2 Sequence divergence compared in ITS, $n d h F$-rpl32 and coxl 35

2.4.3 Conclusions 36

Chapter three: A three genome phylogeny for Australasian Plantago (Plantaginaceae) species reveals multiple trans-Tasman dispersal patterns

3.1 Introduction

3.2 Materials and methods 44

3.2.1 Study group $\quad 44$

3.2.2 Genetic markers 48

3.2.3 Molecular techniques $\quad 48$

3.2.4 Dataset alignment and analyses 51

3.2.5 Molecular dating 53

3.3 Results 55

3.3.1 Dataset statistics 55

3.3.2 Phylogenetic analyses $\quad 61$

$\begin{array}{lll}\text { 3.3.3 Molecular dating } & 64\end{array}$

$\begin{array}{lll}3.4 & \text { Discussion } & 65\end{array}$

3.4.1 Biogeography of Australasian Plantago 66

3.4.2 Incongruence of phylogenies from nuclear and organellar DNA 69

3.4.3 Reduced rates of mtDNA in Australasian Plantago 70

$\begin{array}{lll}\text { 3.4.4 Summary and future directions } & 71\end{array}$ 
Chapter four: Evolutionary patterns and species boundaries in New

$\begin{array}{lll}4.1 & \text { Introduction } & 73\end{array}$

4.1.1 Evolution of New Zealand plant groups 73

4.1.2 Taxonomy of New Zealand plant groups 75

$\begin{array}{lll}\text { 4.1.3 The genus Plantago } & 75\end{array}$

$\begin{array}{ll}\text { 4.1.4 New Zealand Plantago } & 79\end{array}$

4.1.5 Study aims $\quad 85$

4.2 Materials and methods 95

4.2.1 Study group 95

4.2.2 Molecular techniques 97

4.2.3 Dataset alignment and phylogenetic analyses 98

$\begin{array}{lll}4.3 & \text { Results } & 101\end{array}$

$\begin{array}{lll}4.4 & \text { Discussion } & 114\end{array}$

4.4.1 Evolution of New Zealand Plantago 114

4.4.2 Taxonomy of New Zealand Plantago 118

4.4.3 Implications of this study 123

4.4.4 Conclusions and future directions 127

$\begin{array}{lr}\text { Chapter five: General discussion } & 129\end{array}$

5.1 Choosing a suitable region for phylogenetic analyses 129

5.2 Phylogeny of Plantago 131

5.3 Biogeography of Australasian Plantago 132

5.4 Taxonomy of New Zealand Plantago 134

$\begin{array}{lll}5.5 & \text { Evolutionary patterns } & 135\end{array}$

$\begin{array}{lll}5.6 & \text { Future directions } & 137\end{array}$

$\begin{array}{lll}5.7 & \text { Conclusions } & 138\end{array}$ 
Literature cited

Appendix

169

Appendix I Details of sample collections

Appendix II Phylogenetic analyses

171

Appendix III Data statistics

190 


\section{List of Tables}

1.1 List of recent molecular phylogenetic studies that have investigated biogeography of New Zealand plant groups

2.1 PCR amplification and sequencing results for the four Plantago and Veronica species included in the primer assay

2.2 Primer sequences and references for the primer pairs in the primer assay

2.3 Comparison of sequence variation (\%) between the three sequenced regions for the primer assay

3.1 Collection details and Genbank accession numbers (ITS, $n d h F$ rpl32 and coxl) of Australasian Plantago species used in biogeographic analyses

3.2 Summary of statistics for ITS, $n d h F-r p l 32$ and coxl for the Plantago dataset used in biogeographic analyses

4.1 A comparison of previous taxonomic treatments of New Zealand Plantago

4.2 Collection details and Genbank accession numbers of Plantago samples that were included in a worldwide ITS phylogeny

4.3 Population statistics for the native New Zealand Plantago species included in the worldwide ITS phyogeny

4.4 Comparison of allopatry vs. sympatry and same vs. different chromosome numbers in New Zealand Plantago species 


\section{List of Figures}

2.1 Gel electrophoresis of PCR amplification of trnH-psbA, rps 16, rbcL and CYC for Plantago lanceolata, P. euryphylla, P. spathulata subsp. spathulata, P. triandra subsp. triandra and Veronica stricta

2.2 Gel electrophoresis of PCR amplification of microsatellite regions PCM07, JPM11 and PM6 for Plantago lanceolata, P. euryphylla, P. spathulata subsp. spathulata, $P$. triandra subsp. triandra and Veronica stricta

3.1 The distribution of Australasian Plantago and collection sites of samples used in biogeographic analyses

3.2 Phylogeny of the Australasian Plantago species using ITS, $n d h F$ rpl32 and coxl, respectively, reconstructed using Maximum Likelihood and showing branch lengths

3.3 Phylogeny of the Australasian Plantago species reconstructed using Maximum Likelihood of a concatenated dataset (ITS, $n d h F-r p l 32$ and $\operatorname{cox} 1)$

4.1 Morphological habits of cultivated samples of the New Zealand Plantago species, illustrating morphological plasticity

4.2 Distributions of the New Zealand Plantago species and collection sites of samples used in the worldwide ITS phylogeny

4.3 Simplified 50\% consensus tree of a worldwide ITS Plantago phylogeny reconstructed using Bayesian phylogeny, showing current taxonomic classifications and geographic locations of the Australasian species 
4.4 Phylogeny of a clade of: Plantago aucklandica, $P$. spathulata, $P$. “sylvester", P. raoulii, P. triantha, P. varia, P. debilis, P. hispida, P. paradoxa, $P$. cladarophylla and $P$. stauntoni reconstructed using Maximum Likelihood

4.5 Phylogeny of Plantago lanigera, $P$. aucklandica and $P$. obconica reconstructed using Maximum Likelihood

4.6 Phylogeny of Plantago unibracteata and P. triandra reconstructed using Maximum Likelihood

4.7 Splitstree analyses of three groups of Australasian Plantago species; A: Plantago aucklandica, $P$. spathulata, $P$. "sylvester", $P$. raoulii, $P$. triantha, $P$. varia, $P$. debilis, $P$. hispida, $P$. paradoxa, $P$. cladarophylla and P. stauntoni; B: Plantago lanigera, $P$. aucklandica and P. obconica; and C: Plantago unibracteata and P. triandra 


\section{Chapter One: General Introduction}

\subsection{Plant phylogenetics}

Ever since its conception, molecular phylogenetics has been increasingly used as a means of elucidating evolutionary histories and refining taxonomy where other means fail (e.g. the study group has ambiguous morphological data or an incomplete fossil record). Methods of obtaining molecular data (such as the quantity of sample needed and the amount of time needed to process the sample through to the sequencing stage) have consequently improved to the point that molecular data are now as easy to obtain for phylogenetic purposes as any other type of data. The use of molecular data for phylogenetic studies is more common in the animal kingdom, whereas its utility has only been recently applied to plant studies. However, molecular phylogenies are extremely useful for plants, for which processes such as interbreeding species complexes, hybridisation, introgression and polyploidy are fairly common (Soltis et al. 2004; Hegarty and Hiscock 2005; Vriesendorp and Bakker 2005).

In New Zealand, phylogenetic analyses using molecular data have been effectively employed for many different purposes such as dating lineages (Barker et al. 2007; Knapp et al. 2007; Perrie and Brownsey 2007), clarifying taxonomy (Albach et al. 2005a; Heenan et al. 2006; de Lange et al. 2007; Tripp 2007), investigating biogeography (Wagstaff et al. 2002; Meudt and Simpson 2006; Sanmartín et al. 2007; Shepherd et al. 2007), and investigating patterns of evolution (Meudt and Bayly 2008). 
Table 1.1. Recent molecular phylogenetic studies that have investigated biogeography of New Zealand plant groups.

\begin{tabular}{|c|c|c|c|c|}
\hline Family or genus & $\begin{array}{l}\text { Long Distance } \\
\text { Dispersal } \\
\text { (LDD) vs. } \\
\text { vicariance }\end{array}$ & $\begin{array}{l}\text { Sequencing } \\
\text { regions }\end{array}$ & References & Notes \\
\hline Abrotanella & LDD & $\begin{array}{l}\text { ITS, } \operatorname{trnK}- \\
\text { matK }\end{array}$ & $\begin{array}{l}\text { Wagstaff et al. } \\
2006\end{array}$ & $\begin{array}{l}\text { Split between sister groups in Australia and South America was } \\
\text { dated to about } 3.1 \text { million years ago (mya). }\end{array}$ \\
\hline Agathis & Vicariance & $r b c L$ & Stöckler et al. 2002 & $\begin{array}{l}\text { Closest relative of Agathis australis (the New Zealand species) } \\
\text { is not one of the three extant Australian species of Agathis. I.e. } \\
\text { presence of this species is not LDD from Australia therefore } \\
\text { vicariance was inferred. }\end{array}$ \\
\hline Asplenium & LDD & $\operatorname{trnL} L-F$ & $\begin{array}{l}\text { Perrie and } \\
\text { Brownsey } 2005\end{array}$ & $\begin{array}{l}\text { Multiple dispersals to New Zealand. Estimated divergence time } \\
\text { was } 43 \text { mya for the oldest pair of New Zealand and non-New } \\
\text { Zealand group. One frequently hybridizing austral group was } \\
\text { found. }\end{array}$ \\
\hline Atherospermataceae & LDD & $\begin{array}{l}r b c L, r p l 16, \\
\text { trnL-trnF, } \\
\text { trnT-trnL, } \\
\text { psbA-trnH, } \\
\text { atpB-rbcL }\end{array}$ & Renner et al. 2000 & $\begin{array}{l}\text { Short fossil record and small genetic divergence indicate that the } \\
\text { New Zealand species probably arrived by LDD from Australia } \\
\text { or Antarctica during the last } 30-50 \text { million years (my). }\end{array}$ \\
\hline Blechnaceae & LDD & $\operatorname{trn} L-t r n F$ & $\begin{array}{l}\text { Shepherd et al. } \\
2007\end{array}$ & $\begin{array}{l}\text { Identical sequences between species from: New Zealand and } \\
\text { Australia, New Zealand and Chile, and Australia and Hawaii. }\end{array}$ \\
\hline Caltha & Vicariance & $\begin{array}{l}\text { ITS, atpB- } \\
\operatorname{rbcL,} \text { trnL-F }\end{array}$ & $\begin{array}{l}\text { Schuettpelz and } \\
\text { Hoot } 2004\end{array}$ & $\begin{array}{l}\text { Northern Hemisphere to South America and then to } \\
\text { Australia/New Zealand. }\end{array}$ \\
\hline
\end{tabular}


Table 1.1. Recent molecular phylogenetic studies that have investigated biogeography of New Zealand plant groups.

\begin{tabular}{|c|c|c|c|c|}
\hline Family or genus & $\begin{array}{l}\text { Long Distance } \\
\text { Dispersal } \\
\text { (LDD) vs. } \\
\text { vicariance }\end{array}$ & $\begin{array}{l}\text { Sequencing } \\
\text { regions }\end{array}$ & References & Notes \\
\hline Chloranthaceae & LDD & $\begin{array}{l}\text { rbcL, rpl20- } \\
\operatorname{rps} 12, \operatorname{trnL} \\
\operatorname{trnL-F}\end{array}$ & $\begin{array}{l}\text { Zhang and Renner } \\
2003\end{array}$ & $\begin{array}{l}\text { Estimated time of divergence among extant Ascarina was } 18 \text { - } \\
19 \text { mya. }\end{array}$ \\
\hline Coriaria & LDD & $r b c L, m a t K$ & $\begin{array}{l}\text { Yokoyama et al. } \\
2000\end{array}$ & $\begin{array}{l}\text { LDD was inferred from North America to the Pacific Islands, } \\
\text { and from New Zealand to South America. }\end{array}$ \\
\hline Craspedia & LDD & $\begin{array}{l}\text { ITS, ETS, } \\
\text { psbA-trnH }\end{array}$ & Ford et al. 2007 & $\begin{array}{l}\text { Low sequence divergence between Australia and New Zealand } \\
(1.5,1.7,3.0 \% \text {; respectively). One trans-Tasman dispersal from } \\
\text { Australia to New Zealand, followed by species radiation. }\end{array}$ \\
\hline Elaeocarpaceae & LDD & ITS, $t r n L-t r n F$ & Crayn et al. 2006 & $\begin{array}{l}\text { LDD for Aristotelia (New Zealand and Australian species form } \\
\text { sister clades, with South American species sister to the } \\
\text { Australasian clade). Divergence of South American and New } \\
\text { Zealand lineages were dated to } 24-27 \text { and } 3 \text { mya, respectively. }\end{array}$ \\
\hline Gentianella & LDD & $\begin{array}{l}\text { ITS, matK, } \\
\text { morphology }\end{array}$ & $\begin{array}{l}\text { von Hagen and } \\
\text { Kadereit } 2001\end{array}$ & $\begin{array}{l}\text { Australian and New Zealand species probably dispersed only } \\
\text { once and probably from South America (suggested by } \\
\text { morphology; the relationships were not resolved with molecular } \\
\text { data). New Zealand and Australian clade diverged about } 2.7 \\
\text { mya. }\end{array}$ \\
\hline Gentianella & LDD & ITS 1 , ITS 2 & Glenny 2004 & $\begin{array}{l}\text { Gentianella appears to have arrived in New Zealand from South } \\
\text { America either once or twice, and probably dispersed once to } \\
\text { Australia. First arrived in the South Island with subsequent } \\
\text { northward expansion. }\end{array}$ \\
\hline
\end{tabular}


Table 1.1. Recent molecular phylogenetic studies that have investigated biogeography of New Zealand plant groups.

\begin{tabular}{|c|c|c|c|c|}
\hline Family or genus & $\begin{array}{l}\text { Long Distance } \\
\text { Dispersal } \\
\text { (LDD) vs. } \\
\text { vicariance }\end{array}$ & $\begin{array}{l}\text { Sequencing } \\
\text { regions }\end{array}$ & References & Notes \\
\hline Gleicheniaceae & LDD & $r b c L, \operatorname{trn} L-F$ & Perrie et al. 2007 & $\begin{array}{l}\text { All three genera have undergone LDD to/from New Zealand } \\
\text { less than } 55 \text { mya. Tasmanian and New Zealand Gleichenia share } \\
\text { identical } r b c \text { L sequences. }\end{array}$ \\
\hline Gnaphalieae & LDD & ITS & $\begin{array}{l}\text { Breitwieser et al. } \\
1999\end{array}$ & $\begin{array}{l}\text { Most Gnaphalieae groups have relatively recent arrival in New } \\
\text { Zealand, followed by rapid radiation in the group and have close } \\
\text { affinities with Australian and New Guinean taxa. }\end{array}$ \\
\hline Gunnera & Vicariance & $\begin{array}{l}\text { ITS, } r b c L, \\
r p s 16\end{array}$ & $\begin{array}{l}\text { Wanntorp and } \\
\text { Wanntorp } 2003\end{array}$ & $\begin{array}{l}\text { Vicariance of the group, with recent LDD of one species from } \\
\text { New Zealand to Tasmania. }\end{array}$ \\
\hline Herbertus & $\begin{array}{l}\text { Short distance } \\
\text { dispersal }\end{array}$ & ITS, $\operatorname{trn} L-F$ & $\begin{array}{l}\text { Feldberg et al. } \\
2007\end{array}$ & $\begin{array}{l}\text { Distribution cannot be explained by Gondwanan vicariance. } \\
\text { Could be a combination of short distance dispersal and several } \\
\text { rare LDDs. }\end{array}$ \\
\hline Korthalsella & LDD & ITS, $\operatorname{trn} L-F$ & Molvray et al. 1999 & $\begin{array}{l}\text { Possibly from Malesia (where sister genus is found) outward. } \\
\text { Direction of LDD within Australasia was unclear. }\end{array}$ \\
\hline $\begin{array}{l}\text { Lyallia and } \\
\text { Hectorella }\end{array}$ & LDD & $\begin{array}{l}\text { rbcL, trnK- } \\
\text { matK }\end{array}$ & $\begin{array}{l}\text { Wagstaff and } \\
\text { Hennion } 2007\end{array}$ & $\begin{array}{l}\text { Divergence of sister genera from sub-Antarctic Islands and New } \\
\text { Zealand was estimated to be about } 18.6 \text { mya. }\end{array}$ \\
\hline Microseris & LDD & AFLP & $\begin{array}{l}\text { Vijverberg et al. } \\
2002\end{array}$ & $\begin{array}{l}\text { Dispersals in south-east Australia, Tasmania, New Zealand, and } \\
\text { the Australian mainland. Morphological differentiation is not } \\
\text { evident in the nuclear DNA. }\end{array}$ \\
\hline
\end{tabular}


Table 1.1. Recent molecular phylogenetic studies that have investigated biogeography of New Zealand plant groups.

\begin{tabular}{|c|c|c|c|c|}
\hline Family or genus & $\begin{array}{l}\text { Long Distance } \\
\text { Dispersal } \\
\text { (LDD) vs. } \\
\text { vicariance }\end{array}$ & $\begin{array}{l}\text { Sequencing } \\
\text { regions }\end{array}$ & References & Notes \\
\hline Myosotis & LDD & $\begin{array}{l}\text { ITS, psbA- } \\
\text { trnA, matK, } \\
\text { ndhF }\end{array}$ & $\begin{array}{l}\text { Winkworth et al. } \\
\text { 2002a }\end{array}$ & $\begin{array}{l}\text { Multiple long distance dispersals events; most of these were in a } \\
\text { direction opposite to predictions of the West Wind Drift. }\end{array}$ \\
\hline Nothofagus & Vicariance & $r b c L$ & $\begin{array}{l}\text { Linder and Crisp } \\
1995\end{array}$ & Vicariance followed by extensive extinctions. \\
\hline Nothofagus & $\begin{array}{l}\mathrm{LDD}+ \\
\text { vicariance }\end{array}$ & $\begin{array}{l}\text { ITS, } r b c L \text {, } \\
a t p B-r b c L\end{array}$ & $\begin{array}{l}\text { Swenson et al. } \\
2001\end{array}$ & $\begin{array}{l}\text { LDD of one species to Tasmania and one to New Zealand. } \\
\text { Several species in New Zealand and Australia have much less } \\
\text { variation than expected from Gondwanan vicariance. }\end{array}$ \\
\hline Nothofagus & $\begin{array}{l}\mathrm{LDD}+ \\
\text { vicariance }\end{array}$ & $\begin{array}{l}\text { atpB-psaI, } \\
\text { trnL-trnF }\end{array}$ & Knapp et al. 2005 & $\begin{array}{l}\text { Vicariance can explain some transoceanic relationships among } \\
\text { Nothofagus but the relationships between the trans-Tasman } \\
\text { species (in Lophozonia and Fucospora) can only be explained } \\
\text { by mid- to late-Tertiary transoceanic dispersal. }\end{array}$ \\
\hline Oreobolus & LDD & $\begin{array}{l}\text { ITS, } t r n L, \\
\text { trnL-F }\end{array}$ & Chacón et al. 2006 & $\begin{array}{l}\text { Australasian (and Malesian, which is the closest relative) } \\
\text { relationships unclear but hypothesized LDD from } \\
\text { Australasia/Malesia to Hawaii, and from Australia to South } \\
\text { America. }\end{array}$ \\
\hline Oreomyrrhis & LDD & ITS & Chung et al. 2005 & $\begin{array}{l}\text { ITS phylogeny shows that the New Zealand Oreomyrrhis group } \\
\text { is closely related to a group that is mostly distributed in the } \\
\text { Northern Hemisphere. A molecular clock estimate is fairly } \\
\text { recent (about } 1.06 \text { mya). }\end{array}$ \\
\hline
\end{tabular}


Table 1.1. Recent molecular phylogenetic studies that have investigated biogeography of New Zealand plant groups.

\begin{tabular}{|c|c|c|c|c|}
\hline Family or genus & $\begin{array}{l}\text { Long Distance } \\
\text { Dispersal } \\
\text { (LDD) vs. } \\
\text { vicariance }\end{array}$ & $\begin{array}{l}\text { Sequencing } \\
\text { regions }\end{array}$ & References & Notes \\
\hline Ourisia & LDD & $\begin{array}{l}\text { ITS, ETS, } \\
\text { matK, rps } 16\end{array}$ & $\begin{array}{l}\text { Meudt and } \\
\text { Simpson } 2006\end{array}$ & $\begin{array}{l}\text { Tasmanian species are sister to a New Zealand clade. Ancestor } \\
\text { dispersed to Australasia from South America. }\end{array}$ \\
\hline Pachycladon & LDD & ITS & Heenan et al. 2002 & $\begin{array}{l}\text { Recent dispersal between New Zealand and Tasmania ( } 1 \text { species } \\
\text { is endemic to Tasmania, while all others endemic to South } \\
\text { Island, New Zealand). Origin of Pachycladon was estimated to } \\
\text { be about } 1.0 \text { to } 3.5 \text { mya. }\end{array}$ \\
\hline Pittosporum & LDD & ITS & $\begin{array}{l}\text { Gemmill et al. } \\
2002\end{array}$ & $\begin{array}{l}\text { Mostly about the Hawaiian lineages but LDD is suggested for } \\
\text { the group, which includes one New Zealand species. } \\
\text { Relationships to and from New Zealand are unclear. }\end{array}$ \\
\hline Plagiochila & $\begin{array}{l}\text { Vicariance } \\
\text { cannot be } \\
\text { refuted. }\end{array}$ & ITS, rps 4 & $\begin{array}{l}\text { Heinrichs et al. } \\
2006\end{array}$ & $\begin{array}{l}\text { Current distribution is a mixture of short distance dispersal, rare } \\
\text { long distance events and extinction/recolonization as a result of } \\
\text { climate changes. }\end{array}$ \\
\hline Polystichum & LDD & $\begin{array}{l}r p s 4-t r n S \\
\text { AFLP }\end{array}$ & Perrie et al. 2003 & $\begin{array}{l}\text { Appears to be from Australia to New Zealand within the last } 20 \\
\text { my. }\end{array}$ \\
\hline Proteaceae & $\begin{array}{l}\mathrm{LDD}+ \\
\text { vicariance }\end{array}$ & $\begin{array}{l}\operatorname{rbcL}, a t p B \\
\operatorname{atp} B-r b c L\end{array}$ & Barker et al. 2007 & $\begin{array}{l}\text { Gondwanan vicariance with more recent LDD. Split between } \\
\text { New Zealand and Australian species was dated to about } 45.4 \\
\text { mya. }\end{array}$ \\
\hline Pteridophytes & LDD & $r b c L$ & $\begin{array}{l}\text { Perrie and } \\
\text { Brownsey } 2007\end{array}$ & $\begin{array}{l}\text { Molecular dating shows that most ferns have undergone LDD. } \\
\text { Many of the New Zealand and non New Zealand pteridophyte } \\
\text { pairs had relatively small differences. }\end{array}$ \\
\hline
\end{tabular}


Table 1.1. Recent molecular phylogenetic studies that have investigated biogeography of New Zealand plant groups.

\begin{tabular}{|c|c|c|c|c|}
\hline Family or genus & $\begin{array}{l}\text { Long Distance } \\
\text { Dispersal } \\
\text { (LDD) vs. } \\
\text { vicariance }\end{array}$ & $\begin{array}{l}\text { Sequencing } \\
\text { regions }\end{array}$ & References & Notes \\
\hline Ranunculus & LDD & $\begin{array}{l}\text { ITS, JSA } \\
\text { (chloroplast) }\end{array}$ & $\begin{array}{l}\text { Lockhart et al. } \\
2001\end{array}$ & $\begin{array}{l}\text { Dispersal from New Zealand to Australia and to New Guinea. } \\
\text { Dispersal origin of New Zealand species is unclear from but the } \\
\text { group arose about } 5 \text { mya. }\end{array}$ \\
\hline Scaevola & LDD & ITS & $\begin{array}{l}\text { Howarth et al. } \\
2003\end{array}$ & $\begin{array}{l}\text { New Zealand species (shared by Tonga) is nested within an } \\
\text { Australian lineage. }\end{array}$ \\
\hline Scleranthus & LDD & ITS 1 , ITS 2 & Smissen et al. 2003 & $\begin{array}{l}\text { Lack of ITS sequence divergence between Australian and New } \\
\text { Zealand populations of two species. Divergence between } \\
\text { Australasian and Eurasian clade was estimated to be less than } 35 \\
\text { mya. }\end{array}$ \\
\hline Sophora & LDD & $a t p B-r b c L$ & Hurr et al. 1999 & $\begin{array}{l}\text { Long distance dispersal from Tuvalu to Lord Howe Island to } \\
\text { New Zealand and across the South Pacific within the last 2-5 } \\
\text { my. }\end{array}$ \\
\hline Stylidiaceae & LDD & ITS, $r b c L$ & $\begin{array}{l}\text { Wagstaff and Wege } \\
2002\end{array}$ & $\begin{array}{l}\text { Two dispersal events: one from Australia and the other from } \\
\text { either South America or Australia. }\end{array}$ \\
\hline $\begin{array}{l}\text { sunflower alliance } \\
\text { of families }\end{array}$ & Vicariance & $r b c L$ & $\begin{array}{l}\text { Bremer and } \\
\text { Gustafsson } 1997\end{array}$ & $\begin{array}{l}\text { Simple molecular dating estimated the age of the sunflower } \\
\text { alliance to be about } 96 \text { mya. }\end{array}$ \\
\hline Tetrachondra & LDD & $r b c L$ & $\begin{array}{l}\text { Wagstaff et al. } \\
2000\end{array}$ & $\begin{array}{l}\text { Either long-distance dispersal of Tetrachondra hamiltonii to } \\
\text { New Zealand, or short distance dispersal via stepping stones. } \\
\text { East to west direction of LDD, opposite to the direction } \\
\text { predicted by West Wind Drift. }\end{array}$ \\
\hline
\end{tabular}


Table 1.1. Recent molecular phylogenetic studies that have investigated biogeography of New Zealand plant groups.

\begin{tabular}{|c|c|c|c|c|}
\hline Family or genus & $\begin{array}{l}\text { Long Distance } \\
\text { Dispersal } \\
\text { (LDD) vs. } \\
\text { vicariance }\end{array}$ & $\begin{array}{l}\text { Sequencing } \\
\text { regions }\end{array}$ & References & Notes \\
\hline Veronica (Hebe) & LDD & ITS & $\begin{array}{l}\text { Wagstaff and } \\
\text { Garnock-Jones } \\
1998\end{array}$ & $\begin{array}{l}\text { Recent origin and rapid radiation of the New Zealand Hebe } \\
\text { group. This is followed by dispersal to the Chatham Islands, and } \\
\text { South America (at least twice). }\end{array}$ \\
\hline $\begin{array}{l}\text { Veronica } \\
\text { (Chionohebe, } \\
\text { Parahebe) }\end{array}$ & LDD & ITS & $\begin{array}{l}\text { Wagstaff and } \\
\text { Garnock-Jones } \\
2000\end{array}$ & $\begin{array}{l}\text { LDD from New Zealand to Australia and New Guinea, and also } \\
\text { from New Zealand to South America and Rapa Island. Origin of } \\
\text { New Zealand species is equivocal between Australia and } \\
\text { Northern Hemisphere }\end{array}$ \\
\hline Veronica (Hebe) & LDD & ITS, $r b c L$ & $\begin{array}{l}\text { Wagstaff et al. } \\
2002\end{array}$ & $\begin{array}{l}\text { One ancestor followed by diversification in New Zealand. } \\
\text { Two LDD events to South America, at least one to Australia and } \\
\text { one to New Guinea; plus six others across the Pacific, including } \\
\text { to Chatham Island and the subantarctic islands. }\end{array}$ \\
\hline
\end{tabular}




\subsubsection{Genetic markers for plant phylogenetics}

When working on molecular phylogenies, choosing genetic markers is an important process. Genetic markers need to be chosen based on their ability to differentiate between taxa at the level that the research requires. Currently, the most common genetic marker used for phylogenetic studies in plants is the Internal Transcribed Spacer (ITS) region, found in the nuclear genome of plants, fungi and animals. This refers to the region of $18 \mathrm{~S}, 5.8 \mathrm{~S}$ and $26 \mathrm{~S}$ ribosomal genes, along with two internal transcribed spacers. It is widely applied in phylogenetic studies, from fungi to higher land plants (White et al. 1990; Álvarez and Wendel 2003) and recently to animals (Jorgensen et al. 2007; Kuriiwa et al. 2007). In fact, it was found that out of 244 papers published between the years 1998-2004, 66\% utilized ITS data and 34\% of phylogenies were published based on ITS data alone (Álvarez and Wendel 2003). The trend of utilizing ITS as a marker for reconstructing plant phylogenies is also found in New Zealand plant studies (Table 1.1), where 27 of $44(61 \%)$ recent phylogenetic studies investigating biogeography used ITS as a marker.

The ITS region has various advantages as a marker, such as high genetic variation for most groups, concerted evolution of the region, and low functional constraints (Álvarez and Wendel 2003). In addition, the entire ribosomal DNA array region is easily amplified with universal primers (Hillis and Dixon 1991) and as a consequence of frequent use, there is a wide array of ITS sequences readily available on Genbank (http://www.ncbi.nlm.nih.gov/entrez/query.fcgi?db=nucleotide). However, markers from other regions may prove to be more useful than ITS, especially at lower taxonomic levels (Mort et al. 2007; Shaw et al. 2007). Markers from independent regions can also be used in combination with each other as long as they have gene 
histories that do not conflict. Increasing sequence length in a dataset may allow phylogenetic trees to be more accurate, whereas sampling sites from independent regions increases the power of the phylogenetic inference (Cummings et al. 1995). Additionally, the use of more than one (independent) marker will allow visualization of processes such as hybridisation, introgression, reticulation and incomplete lineage sorting if these have occurred in the past (Vriesendorp and Bakker 2005). For events such as hybridisation, parental lineages may also be revealed based on the phylogenies of the different markers (e.g. Albach and Chase 2004; Smissen et al. 2004).

Markers from different genomes are useful in this respect because the nuclear DNA (nrDNA) is independent of the organellar DNA and they have different mechanisms of inheritance. Moreover, given that organellar DNA is generally maternally inherited and non-recombining in most plant groups, DNA from the chloroplast DNA (cpDNA) and mitochondrial DNA (mtDNA) may be able to show genetic relatedness and geographic structure of genetic variation better than nrDNA, which is biparentally inherited and undergoes recombination (Mort et al. 2007). Recently, the development of markers other than ITS have shown that many previously unexplored regions are useful for plant phylogenetics (e.g. chloroplast markers developed by Shaw et al. 2007). While mtDNA is commonly used in animal studies, it is usually not a suitable marker for plant phylogenetics because it is known to evolve at an extremely slow rate (Wolfe et al. 1987) and is therefore highly conserved even at the species level. However, an unusually high rate of mtDNA evolution has been found in a few plant groups, including Plantago (Cho et al. 2004), Silene (Mower et al. 2007) and Geraniaceae (Parkinson et al. 2005). Therefore, mtDNA may have some utility for 
phylogenetic analyses within these genera and possibly other plant groups. At the population level, studies often use microsatellites, a string of one to six nucleotide sequences that are repeated multiple times (Zane et al. 2002), because they have frequent length polymorphism when compared among individuals in a population.

\subsection{Biogeography of Southern Hemisphere plants}

Molecular data have been increasingly used to reconstruct phylogenies for investigating plant biogeography. Molecular phylogenies allow for large-scale studies that would otherwise be too complex using other types of characters, such as morphology (e.g. Renner 2004; Sanmartín and Ronquist 2004; Sanmartín et al. 2007). For example, by plotting distribution information on 23 phylogenies for different Southern Hemisphere plant groups, Sanmartín et al. 2007 were able to infer that plants in the Southern Hemisphere are more likely to disperse in an eastward direction between Australia and South America, whereas they are more likely to disperse in a westward direction between South America and New Zealand.

Plant biogeography in the Southern Hemisphere has garnered much attention (Table 1.1, Setoguchi et al. 1998; Muñoz et al. 2004; Sanmartín and Ronquist 2004; Sytsma et al. 2004; Sanmartín et al. 2007). Since the conception of plate tectonics in the 1960's, distribution of Southern Hemisphere flora has been believed to be the result of vicariance from the supercontinent Gondwana (Pole 1994; de Queiroz 2005; McGlone 2005), which broke up to form the landmasses in the Southern Hemisphere. However, studies using molecular data suggest that recent long distance dispersal in Southern Hemisphere plant groups are more prevalent than previously thought (Winkworth et al. 1999; Winkworth et al. 2002b; de Queiroz 2005; McGlone 2005) (see Table 1.1). 
The New Zealand landmass has been isolated by a distance of at least $1500 \mathrm{~km}$ from its closest landmass, Australia, after the break-up of Gondwana 80 million years ago (mya) (Cooper and Cooper 1995). Recent phylogenetic analyses (Table 1.1) have revealed that divergence dates for many plant groups on different continents are too recent to be explained by vicariance (e.g. Wagstaff and Garnock-Jones 1998; Hurr et al. 1999; Lockhart et al. 2001; Radford et al. 2001; Swenson et al. 2001; von Hagen and Kadereit 2001; Heenan et al. 2002; Zhang and Renner 2003; Perrie and Brownsey 2005; Barker et al. 2007; Perrie and Brownsey 2007; Perrie et al. 2007). Evidence of long distance dispersal has also been found in plant lineages that are considered typical examples of Gondwanan relicts, such as Nothofagus (Swenson et al. 2001; Knapp et al. 2005). Some authors have gone so far as to say that the entire New Zealand flora has arrived by long distance dispersal (Pole 1994) but there is still evidence that some plant groups have origins that date back to a Gondwanan origin, e.g. Agathis (Stöckler et al. 2002; Knapp et al. 2007). Thus, the origins of the New Zealand flora may be a mixture of older vicariance and more recent long distance dispersal events.

Within Australasia, dispersal from Australia to New Zealand is commonly found in molecular studies (Wagstaff and Garnock-Jones 1998; Wagstaff et al. 1999; Wagstaff and Wege 2002; Ford et al. 2007). Dispersal in this direction is consistent with the prevailing West Wind Drift (Raven 1973; Winkworth et al. 2002b; Muñoz et al. 2004; Sanmartín et al. 2007). While not as common, there is also evidence of dispersal in the opposite direction (New Zealand to Australia) (Wagstaff and Garnock-Jones 2000; Lockhart et al. 2001; Wagstaff et al. 2002; Wanntorp and Wanntorp 2003). Other dispersal patterns can also be found, e.g. in Veronica, there has been evidence of 
dispersals from Australia to New Zealand; New Zealand to Australia; New Zealand to Papua New Guinea; New Zealand to South America; and New Zealand to Rapa (Wagstaff et al. 2002). Additionally, New Zealand plant groups are often found to have established in New Zealand following one single long distance dispersal event (Wagstaff and Garnock-Jones 1998; Winkworth et al. 1999; Perrie et al. 2003; Albach et al. 2005b; Meudt and Simpson 2006). While molecular phylogenies have been able to reveal biogeographic patterns in many New Zealand plant groups, the biogeography of many more lineages remain to be tested.

\subsection{Patterns of evolution in New Zealand plants}

Overall evolutionary patterns within New Zealand plants are not well studied and in particular, the evolution of alpine species is not well-known (Lockhart et al. 2001). Evidence for rapid radiation in many New Zealand plant groups has been found in many molecular phylogenetic studies to date (Wagstaff and Garnock-Jones 1998; Winkworth et al. 1999; Heenan et al. 2002; Perrie et al. 2003; Murray et al. 2004; Albach et al. 2005b; Meudt and Simpson 2006). These radiations are often associated with speciation after recent long distance events (Breitwieser et al. 1999), adaptation to new habitats after the uplift of the Southern Alps (Wagstaff and Garnock-Jones 1998; Lockhart et al. 2001; Trewick and Morgan-Richards 2005), and climate fluctuations (Raven 1973; Lockhart et al. 2001; Winkworth et al. 2002a). Speciation in New Zealand plant groups may also have followed separation of populations due to uplift of Southern Alps (Haase et al. 2007), adaptation to different habitats (McBreen and Heenan 2006), disruption during glacial periods, or displacement along the alpine fault (Haase et al. 2007). Cook Strait, which separates the North and South Islands of New Zealand, could act as a barrier as well, although there may have been land 
bridges connecting the North and South Islands during the glacial cycles of the Pliocene (Lewis et al. 1994). Older lineages may also have experienced population fragmentation as a result of almost total submersion of the New Zealand landmass during the Oligocene (Cooper and Cooper 1995). Additionally, a recurrent pattern within New Zealand is the dispersal of plants from the South Island to the North Island (e.g. Lockhart et al. 2001; Meudt and Simpson 2006).

Hybridisation is common in many New Zealand plant groups (Heenan et al. 2001; Lockhart et al. 2001; Albach and Chase 2004; Smissen et al. 2004), along with recurrent polyploidy (Groves and Hair 1971). Recurrent polyploidy is probably associated with hybridisation because it allows instant speciation where one or several polyploid hybrids arise sympatrically with both of (or one of) the parent populations (Petit et al. 1999).

\subsection{Taxonomy in New Zealand plant groups}

Species boundaries in New Zealand plants may be unclear using morphological characters due to recent or incomplete speciation associated with recent and rapid radiations. This often results in taxonomic problems. Many New Zealand groups are large and have high morphological variation both within and among species, such as Myosotis (Winkworth et al. 1999; Winkworth et al. 2002a) and Gnaphalieae (Smissen et al. 2004). However, these, along with many other New Zealand plant groups often have low genetic diversity (Hurr et al. 1999; Winkworth et al. 1999; Heenan et al. 2002; Mitchell and Heenan 2002; Vijverberg et al. 2002; Winkworth et al. 2002a), which makes species delimitations difficult. 
Molecular phylogenies have been used for improving plant taxonomy within New Zealand. For example, molecular data revealed that the five or six genera of the Hebe complex have evolved within Veronica, and are therefore paraphyletic (Albach and Chase 2001). Circumscription of Veronica was subsequently enlarged to include all Southern Hemisphere Hebe species (Garnock-Jones et al. 2007). Molecular phylogenies can also be used to efficiently investigate species complexes (e.g. two species of Crassula were found to have frequent interbreeding and could not be separated based on genetic, morphological or karyological data (de Lange et al. 2007).

\subsection{Introduction to study group: Plantago}

In this thesis, a phylogeny of Plantago is reconstructed using molecular data. Plantago is a large genus (ca. 210 species) with a worldwide distribution in the family Plantaginaceae (Rahn 1996). The plants are mostly small rosettes but also form woody shrubs in the Hawaiian and Juan Fernández Islands (Rock 1920). Plants in this genus are wind-pollinated. The genus has three basic chromosome numbers, $x=4,5$, and 6 (Rahn 1996; Dhar et al. 2006); diploid chromosome numbers range from $2 n=8$ (P. ovata) to $2 n=96$ ( $P$. correae and $P$. "sylvester").

Chemical properties and diverse breeding systems (e.g. self-incompatible or selfcompatible; dichogamy; cosexuality; gynodioecy or dioecy; unisexual females or hermaphrodites) within the genus have captured the attention of many researchers (see Wolff and Schaal 1992; VanDijk and Bakx-Schotman 1997; Rønsted et al. 2000; Squirrell and Wolff 2001; Hale and Wolff 2003; Rønsted et al. 2003; Nilsson and Ågren 2006; Nilsson et al. 2006). Recently, Plantago has also garnered attention as a 
result of the high evolutionary rate of mtDNA found in the genus (Cho et al. 2004; Bakker et al. 2006).

\subsubsection{Previous phylogenetic studies}

One phylogenetic study using morphological characters and two using genetic sequences have been performed on the genus so far.

\section{Morphological phylogeny}

Rahn (1996) reconstructed a phylogeny of the genus using morphological characters. Most Australasian species were included (one New Zealand and four Australian species were not included). Based on the morphological phylogeny, the ca. 210 Plantago species were classified into six subgenera, including Littorella (previously described as a genus). This morphological phylogeny suggested that the Australasian species do not form a monophyletic group. The Australasian species were grouped with species from South America, Asia, Europe, New Guinea and Tonga Islands (Rahn 1996).

\section{Molecular phylogenies}

Ronsted et al. (2002) obtained ITS and trnL-F sequences from 57 Plantago species (including two New Zealand species: $P$. spathulata, $P$. raoulii; and one from Australia: P. debilis). Phylogenetic analyses revealed that subg. Albicans was paraphyletic and circumscription of subg. Psyllium was revised to include those species. In a combined ITS and trnL-F phylogeny, the Australasian species did not form a monophyletic group and were separated by $P$. stauntonii from the Amsterdam \& St. Paul Islands (located in the Indian Ocean). 
Finally, Hoggard et al. (2003) used ITS data from 23 Plantago species (including one New Zealand species: $P$. triandra; and five Australian species: $P$. tasmanica, $P$. daltoni, P. euryphylla, P. hispida, P. paradoxa) to investigate whether Littorella should be included within Plantago or considered a separate genus. Littorella was found to form the sister clade to a clade of all the other Plantago species. The Plantago phylogeny (i.e., excluding Littorella) resolved in this study was similar to that resolved by Rønsted et al. 2002.

\subsubsection{Biogeography of Plantago}

Biogeography is interesting within Plantago because the genus is widely distributed. Some species are endemic to certain areas like the Australasian species (there are even species that are native to recently formed islands, such as Amsterdam \& St. Paul Islands), whereas many species are cosmopolitan (see Rahn 1996). Based on a morphological phylogeny, Rahn (1996) invoked a vicariance model with subsequent mass extinctions to explain Plantago distribution in the Southern Hemisphere. In contrast, Rønsted et al. (2002) suggested a prevalence of long distance dispersal worldwide based on the molecular phylogeny. However, the molecular phylogenies have only included a maximum of six Australasian species (out of a total 32). South American Plantago are represented by 13 species that have published sequences. Thus, inclusion of Australasian Plantago species in the phylogeny is crucial for understanding biogeographic patterns of Southern Hemisphere plants. A molecular phylogeny including more Australasian species can be used to compare the biogeographic hypotheses of the Southern Hemisphere species as suggested by Rahn (1996) and Rønsted et al. (2002) and may also shed light on several lineages of the phylogeny that are unclear. 


\subsubsection{Taxonomy of Plantago in New Zealand}

Plantago is placed in the family Plantaginaceae, which was traditionally classified with three genera: Bougueria Decne., Littorella P. Bergius and Plantago L. These were combined to form a monogeneric family based on morphology (Rahn 1996), although a molecular phylogeny has since shown evidence for recognizing Littorella at the generic level (Hoggard et al. 2003). Individuals within the genus have high morphological plasticity, which results in difficulties when circumscribing the plants into taxonomic groups, particularly at the species level (Sykes in Webb et al. 1988, Rahn 1996). While relationships of subgenera and sections within Plantago are reasonably well-resolved (in Rønsted et al. 2002), inter-specific relationships are still largely unclear.

In this thesis, I focus on the taxonomy of Plantago species that are native to New Zealand. So far there have been several taxonomic treatments for the New Zealand species (e.g. Moore in Allan 1961; Sykes in Webb et al. 1988) but no recent, comprehensive taxonomic monograph. Eight species of Plantago were accepted in the most recent Flora of New Zealand: P. raoulii, P. spathulata, P. triandra, P. obconica, P. lanigera, P. unibracteata, P. aucklandica and P. triantha (Sykes in Webb et al. 1988). In addition, there is a purported polyploid of $2 n=96$ given the tag name $P$. "sylvester" (Groves and Hair 1971), which is still undescribed. Like the rest of the genus, morphological differences between New Zealand species are not easily defined, resulting in problems with species delimitation and identification. Thus, genetic data may be more useful in elucidating species boundaries and relationships in the New Zealand species of Plantago. Discrepancies between the five most recent taxonomic treatments (Hooker 1864; Cheeseman 1906; Cheeseman 1936; Moore in Allan 1961; 
Sykes in Webb et al. 1988) represent hypotheses of species boundaries that are investigated in this study. To date, molecular phylogenetic studies in Plantago have included only three out of the eight New Zealand species.

\subsection{Summary and research aims}

In summary, obtaining DNA sequences from multiple independent genetic markers has many advantages in phylogenetic studies. For Plantago, Australasian species should be integrated into the molecular phylogeny in order to make inferences about the biogeography of Southern Hemisphere Plantago species. A molecular phylogeny including Australasian species can also be used to look at species relationships within the group, many of which are still largely unclear. Genetic data may be useful for the genus because morphological characters are extremely plastic in the group and do not appear to be very useful for species delimitations.

For this thesis, DNA sequences from the three different genomes are obtained to reconstruct a molecular phylogeny of Australasian Plantago species. Selection of molecular markers from the three different plant genomes is based on an assay of various primer pairs. The molecular phylogeny is then used to: 1) investigate phylogeny and biogeography of Australasian species of Plantago; and 2) elucidate phylogeny, evolutionary patterns and species boundaries of the New Zealand species. In particular, I investigate if the current distribution of native Australasian Plantago species can be explained by vicariance or long distance dispersal. While this study cannot include a taxonomic monograph due to time constraints, I address several taxonomic issues at species rank that have plagued researchers in the past. 


\title{
Chapter Two: Primer pair assays for amplification of 24 nuclear, mitochondrial, or chloroplast regions in four Plantago and one Veronica (Plantaginaceae) species
}

\begin{abstract}
Combining DNA sequences from all three plant genomes provides a powerful phylogenetic tool because the genomes have different modes of inheritance. DNA sequences from the chloroplast and nucleus are most often used for reconstructing the evolutionary history of plants, whereas mitochondrial DNA is not often used because of extremely low evolution rates within the mitochondrial genome. The aim of this study was to find markers with good phylogenetic signals for future studies on the genus Plantago (Plantaginaceae). A total of 23 different sequence regions in all three genomes were tested for amplification in four Plantago and one Veronica species. This survey revealed that primers for ITS, coxl, ndhF-rpl32, trnK-psbA, trnE-trnTr, $\operatorname{trn} L c$-trnLf, trnC-trnD, rps16 (using both sets of primers tested) and trnH-psbA produced consistently clean amplification of their targeted regions and were of good sequence length (about 700-1k base pairs in length each). These regions are recommended for future studies in Plantago or related groups. DNA microsatellites developed specifically for Plantago major, P. coronopus and $P$. intermedia were also trialed but they did not amplify or were not genotyped successfully. Of the regions that were sequenced, ITS and $n d h F-r p l 32$ had the highest sequence variation between New Zealand and Australian species (an average of $2.5 \%$ for each) and were chosen for further phylogenetic analyses of Plantago.
\end{abstract}




\subsection{Introduction}

Nuclear DNA (nrDNA) sequences are the most often used molecular markers in plant phylogenetic studies, whereas chloroplast DNA (cpDNA) has recently gained recognition as a useful marker (since the 1990's). The single most commonly used genetic marker in plant molecular phylogenetics is the Internal Transcribed Spacer (ITS) region, which is located in the nrDNA. Out of 244 plant phylogenetic papers published between the years 1998-2004, it was found that $66 \%$ utilized ITS data and $34 \%$ of these presented phylogenies based on ITS data alone (Álvarez and Wendel 2003).

DNA sequence regions from cpDNA and mtDNA, however, may prove to be more useful for phylogenetic studies than some well-established nrDNA markers. Sequence regions from cpDNA and mtDNA can also be used in conjunction with nrDNA markers to improve understanding of the evolutionary history of a plant or plant groups. Utilising genetic markers from the three different genomes may reveal different lineage histories because mtDNA and cpDNA are typically uniparentally inherited, whereas nrDNA is biparentally inherited. These contrasting modes of inheritance are especially useful for plant studies, in which polyploidy, hybridisation and introgression are fairly common processes (Soltis et al. 2004). For example, hybridisation events have been inferred and parent species have been elucidated from conflicting signals presented by nrDNA and organelle DNA in several phylogenetic studies (Lockhart et al. 2001; Albach and Chase 2004; Smissen et al. 2004). Where there is no conflict among lineages, combining sequences from all three plant genomes is able to provide a powerful tool for phylogenetic analysis. Concatenated 
datasets have increased dataset size compared to a single region, which allows building methods to construct more robust trees, whereas analyzing data from multiple independent sources has been shown to improve the power of analyses (Cummings et al. 1995). Analyses of concatenated datasets may thus provide further insight into an organism's evolutionary history than can be achieved by markers from the one genome alone or even several markers from the same genome.

Mitochondrial DNA (mtDNA) is rarely found to be a suitable marker for plant phylogenetic studies. Unlike mtDNA in animals, plant mtDNA is generally assumed to evolve at an extremely slow rate (Wolfe et al. 1987) and is therefore highly conserved even at species level. However, an unusually high rate of mtDNA evolution has recently been reported in Plantago (Cho et al. 2004) and several other plant groups such as Silene (Houliston and Olson 2006) and Geraniaceae (Bakker et al. 2006). In the case of Plantago, this accelerated rate even exceeds the rate of animal mtDNA evolution by an order of magnitude (Cho et al. 2004), which is highly suprising. More phylogenetic work needs to be carried out on the mtDNA in the group to explore this high rate of evolution.

The genus Plantago (Plantaginaceae) comprises more than 200 species of windpollinated plants with a worldwide distribution that includes many cosmopolitan species. Plants within the genus have variable chromosome numbers. Rahn (1996) reports values from from $2 n=8$ ( $P$. ovata) to $2 n=96$ ( $P$. correae and $P$. "sylvester") within the genus) and diverse breeding systems (such as self-compatibility, dichogamy, cosexuality, gynodioecy, dioecy, unisexual females or hermaphrodites), which have captured the attention of many researchers (see Wolff and Schaal 1992; 
VanDijk and BakxSchotman 1997; Squirrell and Wolff 2001; Hale and Wolff 2003; Nilsson and Ågren 2006; Nilsson et al. 2006). The plants in the genus also have interesting chemical properties, which have been investigated in various studies (Rønsted et al. 2000; Rønsted et al. 2003; Kozan et al. 2006; Barton 2007). Several species, such as $P$. ovata, are cultivated for medicinal uses (Dagar et al. 2006). Recent studies that investigate the phylogeny of Plantago using the nrDNA Internal Transcribed Spacer (ITS) and the cpDNA $\operatorname{trn} L-F$ region have created a framework for the evolutionary history of the group. However, these studies included sequences for only three or six Australasian species (Rønsted et al. 2002; Hoggard et al. 2003), respectively.

In this study, the usefulness of several primer pairs from each of the three plant genomes is tested for plants in the genus Plantago. The study group comprises two New Zealand species, one Australian and one cosmopolitan Plantago species. A species from a different genus in the same family, Veronica stricta from New Zealand, was included in the assays to establish the applicability of the primer pairs outside of the genus. The unexpected rate of evolution in Plantago mtDNA may be useful for phylogenetic studies involving the genus and warrants further investigation. For this reason, mtDNA primers have been included in this study. Several microsatellite primers were also included. Microsatellites are regions in any given genome, which have multiple repeats of a string of one to six nucleotides (Zane et al. 2002). Microsatellite regions have frequent length polymorphism, and are more variable than other types of sequence markers at the population level. 
Table 2.1. Primer sequences and references for the primer pairs included in this study.

\begin{tabular}{|c|c|c|c|c|c|}
\hline & Region & Genome & Primer sequences & Reference & Designed for \\
\hline 1 & ITS & Nuclear & $\begin{array}{l}\text { ITS28CC CGCCGTTACTAGGGGAATCCTTGTAAG } \\
\text { ITS5 GGAAGTAAAAGTCGTAACAAGG }\end{array}$ & $\begin{array}{l}\text { Wagstaff and Garnock-Jones } 1998 \\
\text { White et al. } 1990\end{array}$ & Universal \\
\hline 2 & $C Y C$ & Nuclear & Primers are unpublished & Wang, UBC (pers. comm.) & $\mathrm{N} / \mathrm{A}$ \\
\hline 3 & $C A M$ & Nuclear & $\begin{array}{l}\text { CAMX1F AGCCTNTTCGACAAGGATGG } \\
C A M X 2 R \text { AGTGANCGCATCACAGTT }\end{array}$ & Strand et al. 1997 & angiosperms \\
\hline 4 & Waxy & Nuclear & $\begin{array}{l}\text { Waxy7F GYYTTSTGCATCCACAACATTGC } \\
\text { Waxy13R GGAGTGGCRACGTTTTCCTT }\end{array}$ & Olmstead et al. unpubl. & Lamiales \\
\hline 5 & $\mathrm{CHS}$ & Nuclear & $\begin{array}{l}\text { CHSX1F AGGAAAAATTCAAGCGCATG } \\
\text { CHSX2RN TTCAGTCAAGTGCATGTAACG }\end{array}$ & Strand et al. 1997 & angiosperms \\
\hline 6 & LFY & Nuclear & $\begin{array}{l}\text { LFY.F2 CGTGGSAAAAAGAAYGGYYTDGATTA } \\
\text { LFY.R3 CATTTTDGGYTTGTTKATGTA }\end{array}$ & Howarth and Baum 2005 & angiosperms \\
\hline 7 & G3pdH & Nuclear & $\begin{array}{l}\text { GPDX7F GATAGATTTGGAATTGTTGAGG } \\
\text { GPDX9R AAGCAATTCCAGCCTTGG }\end{array}$ & Strand et al. 1997 & angiosperms \\
\hline 8 & $\operatorname{cox} 1$ & Mitochondrial & $\begin{array}{l}\operatorname{cox} 1 F 4 \text { GGATATCTAGGYATGGTTTATGC } \\
\operatorname{cox} 1 R 3 \text { AAGCTGGAGGACTTTGTAC }\end{array}$ & Cho et al. 2004 (pers. comm.) & Plantago \\
\hline 9 & nad1 & Mitochondrial & $\begin{array}{l}\text { nad1b GCATTACGATCTGCAGCTCA } \\
\text { nad1c GGAGCTCGATTAGTTTCTGC }\end{array}$ & Demesure et al. 1995 & land plants \\
\hline 10 & NIA3 & Mitochondrial & $\begin{array}{l}\text { NIA-i3F AARTAYTGGTGYTGGTGYTTYTGGTC } \\
\text { NIA-i3R GAACCARCARTTGTTCATCATDCC }\end{array}$ & Howarth and Baum 2002 & $\begin{array}{l}\text { Scaevola, and } \\
\text { angiosperms }\end{array}$ \\
\hline 11 & $\begin{array}{l}\text { ndhF- } \\
\text { rpl32 }\end{array}$ & Chloroplast & $\begin{array}{l}n d h F \text { GAAAGGTATKATCCAYGMATATT } \\
r p / 32-R \text { CCAATATCCCTTYYTTTTCCAA }\end{array}$ & Shaw et al. 2007 & angiosperms \\
\hline 13 & rp/32-trnL & Chloroplast & $\begin{array}{l}\text { trnL CTGCTTCCTAAGAGCAGCGT } \\
\text { rp/32-F CAGTTCCAAAAAAACGTACTTC }\end{array}$ & Shaw et al. 2007 & angiosperms \\
\hline 12 & $\operatorname{trnK-psbA}$ & chloroplast & $\begin{array}{l}\text { trnK3F CCGACTAGTTCCGGGTTCGAAT } \\
\text { PSBAR CGCGTCTCTCTAAAATTGCAGTCAT }\end{array}$ & Winkworth et al. 2002a & Myosotis \\
\hline 14 & $\operatorname{trn} E-\operatorname{trn} T r$ & chloroplast & $\begin{array}{l}\text { trnE GCC TCC TTG AAA GAG AGA TG } \\
\text { trnT-r TAC CAC TGA GTT AAA AGG GC }\end{array}$ & Doyle et al. 1992 & Poaceae \\
\hline
\end{tabular}


Table 2.1. Primer sequences and references for the primer pairs included in this study.

\begin{tabular}{|c|c|c|c|c|c|}
\hline & Region & Genome & Primer sequences & Reference & Designed for \\
\hline 15 & $\operatorname{trnLc}-t r n L f$ & chloroplast & $\begin{array}{l}\text { c CGAAATCGGTAGACGCTACG } \\
f \text { ATTTGAACTGGTGACACGAG }\end{array}$ & Taberlet et al. 1991 & land plants \\
\hline 16 & $\operatorname{trn} C-\operatorname{trn} D$ & chloroplast & $\begin{array}{l}\text { trnC CCAGTTCAAATCTGGGTGTC } \\
\text { trnD GGGATTGTAGTTCAATTGGT }\end{array}$ & Demesure et al. 1995 & land plants \\
\hline 17 & rps 16 & chloroplast & $\begin{array}{l}\text { rps16F AAA CGA TGT GGT ARA AAG CAA C } \\
\text { rps16R AAC ATC WAT TGC AAS GAT TCG ATA }\end{array}$ & Shaw et al. 2005 & Angiosperms \\
\hline 18 & $r b c L$ & chloroplast & $\begin{array}{l}\text { aF ATGTCACCACAAACAGAGACTAAAGC } \\
c R \text { GCAGCAGCTAGTTCCGGGCTCCA }\end{array}$ & Hasebe et al. 1994 & Ferns \\
\hline 19 & $\operatorname{trnH}-p s b A$ & chloroplast & $\begin{array}{l}\text { trnH2 CGCGCATGGTGGATTCACAATCC } \\
\text { psbAF GTTATGCATGAACGTAATGCTC }\end{array}$ & $\begin{array}{l}\text { Tate } 2002 \\
\text { Sang et al. } 1997\end{array}$ & $\begin{array}{l}\text { Tarasa and } \\
\text { Paeonia }\end{array}$ \\
\hline 20 & rps16 & chloroplast & $\begin{array}{l}r p s F \text { GTGGTAGAAAGCAACGTGCGACTT } \\
r p s R 2 \text { TCGGGATCGAACATCAATTGCAAC }\end{array}$ & Oxelman et al. 1997 & $\begin{array}{l}\text { angiosperms (designed } \\
\text { from Sileneae) }\end{array}$ \\
\hline 21 & $\begin{array}{c}\text { trnLb- } \\
\operatorname{trnTa}\end{array}$ & chloroplast & $\begin{array}{l}a \text { CATTACAAATGCGATGCTCT } \\
\text { b TCTACCGATTTCGCCATATC }\end{array}$ & Taberlet et al. 1991 & land plants \\
\hline 22 & PCM07 & microsatellite & $\begin{array}{l}\text { PCM07F GAGCGTCCGATCTAAACGAT } \\
\text { PCM07R GACTAACGTGCATTGCCTAGC }\end{array}$ & Koorevaar et al. 2002 & Plantago coronopus \\
\hline 23 & PM6 & microsatellite & $\begin{array}{l}\text { PM6F ATATGAATTAGCCAACAAA } \\
\text { PM6R CCAGCTCCAAGTCAAAGTA }\end{array}$ & Squirrell and Wolff 2001 & P. major, P. intermedia \\
\hline 24 & Jpm11 & microsatellite & $\begin{array}{l}\text { Jpm11F ATGGCATGAGTGGACCAGAT } \\
\text { Jpm11R AAAAGCTGGGCACCTACAAA }\end{array}$ & Squirrell and Wolff 2001 & P. major, P. intermedia \\
\hline
\end{tabular}


The primers used here have been previously published (Table 2.1) and were chosen based on their previous usefulness in other plant phylogenetic studies. Many of these were designed for universal use throughout land plants, including ITS regions (White et al. 1990; Wagstaff and Garnock-Jones 1998), trnL-trnF (Taberlet et al. 1991) and the rps16 intron (Shaw et al. 2005). Other primers have been developed for specific group studies, such as $r b c L$ for ferns (Hasebe et al. 1994), trnE-trnTr for Poaceae (Doyle et al. 1992) and trnK-psbA for Myosotis (Winkworth et al. 2002a). The microsatellite markers have been designed for specific species within Plantago; PCM07 for P. coronopus (Koorevaar et al. 2002), and JPM11 and PM6 for P. major and P. intermedia (Squirrell and Wolff 2001). Prior to this study, all of the primer pairs (with the exception of ITS and trnLc$\operatorname{trnLf}$ ) have not been amplified in any native New Zealand or Australian Plantago species. Several regions with successful amplification are then scrutinized in more detail by comparing amplified length and sequence variation between the Plantago samples. The regions which show successful amplification and good sequence variation can be recommended for use in future studies.

\subsection{Materials and Methods}

\subsubsection{Study group}

Within Plantago, two native New Zealand species ( $P$. spathulata subsp. spathulata and $P$. triandra subsp. triandra), one native Australian species ( $P$. euryphylla) and one cosmopolitan species that has established in New Zealand (P. lanceolata) were included in this study. $P$. lanceolata and $P$. spathulata subsp. spathulata represent the furthest 
divergence between taxa in the genus and are placed in distant clades in the phylogeny (Rønsted et al. 2002), thereby covering a wide range of the molecular variation in the genus. For the microsatellites, the Plantago species that the primers were designed for were included as positive controls. Thus, $P$. coronopus was included as the positive control for PCM07, and P. major was included as the positive control for both JPM11 and PM6.

In addition, Veronica stricta was included to see if the primers had phylogenetic utilities beyond the genus Plantago, especially for primers that were designed for specific use, e.g. the microsatellite primer pairs. Sample collection details for the species included in this study are given in Appendix I (A).

\subsubsection{Molecular methods}

Total DNA was extracted from silica-dried leaves or whole plants with either the QIAGEN DNeasy Plant Mini Extraction Kit (Hilden, Germany) or a cetyltrimethylammonium bromide (CTAB) extraction method modified from Doyle and Doyle (1990). PCR amplification was performed using Eppendorf Mastercycler ep gradient S (Hamburg, Germany) in a final volume of $25 \mu \mathrm{l}$ of the following: $16.35 \mu \mathrm{l}$ water, 10X ThermoPol reaction buffer $\left(10 \mathrm{mM} \mathrm{KCl}, 10 \mathrm{mM}\left(\mathrm{NH}_{4}\right) 2 \mathrm{SO}_{4}, 20 \mathrm{mM}\right.$ Tris$\mathrm{HCl}$ (pH8.8), $2 \mathrm{mM} \mathrm{MgSO}$, $0.1 \%$ Triton X-100)(New England BioLabs), $0.4 \mathrm{mg} / \mathrm{mL}$ BSA, $250 \mu \mathrm{mol}$ dNTPs, 10 pmol each primer, $0.75 \mathrm{U}$ of Taq DNA polymerase (New England BioLabs) and $0.4 \mu \mathrm{l}$ DNA template. Products were amplified with a thermocycling profile of an initial 3 minutes at $95^{\circ} \mathrm{C}$; then 35 cycles of 30 seconds at 
Table 2.2. PCR amplification and sequencing results for the four Plantago and one Veronica species included in this study.

\begin{tabular}{|c|c|c|c|c|c|c|c|c|c|}
\hline & Region & $\begin{array}{c}\text { Veronica } \\
\text { stricta }\end{array}$ & $\begin{array}{c}\text { Plantago } \\
\text { lanceolata }\end{array}$ & $\begin{array}{c}\text { Plantago } \\
\text { euryphylla }\end{array}$ & $\begin{array}{c}\text { Plantago } \\
\text { spathulata }\end{array}$ & $\begin{array}{c}\text { Plantago } \\
\text { triandra }\end{array}$ & $\begin{array}{c}\text { Annealing } \\
\text { temperature }\end{array}$ & $\begin{array}{c}\text { No. of base } \\
\text { pairs }\end{array}$ & Sequencing \\
\hline 1 & ITS & $\mathrm{S}$ & $\mathrm{S}$ & $\mathrm{S}$ & $S$ & $\mathrm{~S}$ & $50^{\circ} \mathrm{C}$ & $\sim 800$ & + \\
\hline 2 & $C Y C$ & $M$ & - & $M$ & $M$ & $M$ & $40^{\circ} \mathrm{C}$ & $\sim 500-600$ & + \\
\hline 3 & CAM & $M$ & - & - & - & - & $40^{\circ} \mathrm{C}$ & $\sim 200-1300^{*}$ & $N / A$ \\
\hline 4 & Waxy & - & - & - & - & - & $\mathrm{N} / \mathrm{A}$ & $?$ & $\mathrm{~N} / \mathrm{A}$ \\
\hline 5 & $\mathrm{CHS}$ & - & - & - & - & - & $\mathrm{N} / \mathrm{A}$ & $\sim 150-1200^{*}$ & $\mathrm{~N} / \mathrm{A}$ \\
\hline 6 & LFY & - & - & - & - & - & $N / A$ & $\sim 500^{*}$ & $\mathrm{~N} / \mathrm{A}$ \\
\hline 7 & G3pdH & - & - & - & - & - & $N / A$ & $\sim 150-1600^{*}$ & $N / A$ \\
\hline 8 & $\operatorname{cox} 1$ & $S$ & $\mathbf{S}$ & $\mathbf{S}$ & $\mathbf{S}$ & $\mathbf{S}$ & $55^{\circ} \mathrm{C}$ & $\sim 800$ & + \\
\hline 9 & nad1 & $S$ & S & - & - & - & $50^{\circ} \mathrm{C}$ & $\sim 200$ & $\mathrm{~N} / \mathrm{A}$ \\
\hline 10 & NIA3 & - & - & - & - & - & $N / A$ & $\sim 85-1646^{*}$ & $\mathrm{~N} / \mathrm{A}$ \\
\hline 11 & $n d h F-r p / 32$ & S & $\mathbf{S}$ & $\mathbf{S}$ & $\mathbf{S}$ & $\mathbf{S}$ & $50^{\circ} \mathrm{C}$ & $\sim 900-1000$ & + \\
\hline 13 & rp/32-trnL & $S$ & $S$ & $S / M$ & $S$ & $S / M$ & $50^{\circ} \mathrm{C}$ & $\sim 800-900$ & + \\
\hline 12 & $\operatorname{trnK}$-psbA & $S$ & $S$ & $\mathbf{S}$ & S & $\mathbf{S}$ & $50^{\circ} \mathrm{C}$ & $\sim 300$ & + \\
\hline 14 & $\operatorname{trn} E-\operatorname{trn} T r$ & $S$ & $S$ & S & $S$ & S & $50^{\circ} \mathrm{C}$ & $\sim 500-700$ & + \\
\hline 15 & trnLc-trnLf & S & S & $S$ & $\mathbf{S}$ & $\mathbf{S}$ & $50^{\circ} \mathrm{C}$ & $\sim 1000$ & + \\
\hline 16 & $\operatorname{trn} C-\operatorname{trn} D$ & S & S & s & s & s & $50^{\circ} \mathrm{C}$ & $>2000$ & + \\
\hline 17 & rps16 & $S$ & $S$ & $\mathbf{S}$ & $S$ & $\mathbf{S}$ & $50^{\circ} \mathrm{C}$ & $\sim 1000$ & $N / A$ \\
\hline 18 & $r b c L$ & $\mathrm{~S} / \mathrm{M}$ & $S / M$ & $S / M$ & $S$ & $S / M$ & $50^{\circ} \mathrm{C}$ & $\sim 1400$ & $\mathrm{~N} / \mathrm{A}$ \\
\hline 19 & $\operatorname{trnH}-p s b A$ & $S$ & $S$ & $S$ & $S$ & $S$ & $50^{\circ} \mathrm{C}$ & $\sim 400$ & + \\
\hline 20 & rps16 & S & S & S & $\mathbf{S}$ & $\mathbf{S}$ & $50^{\circ} \mathrm{C}$ & $\sim 1000$ & $N / A$ \\
\hline 21 & $\operatorname{trn} \mathrm{Lb}-\operatorname{trnTa}$ & $S$ & - & - & - & - & $50^{\circ} \mathrm{C}$ & $\sim 700^{*}$ & $\mathrm{~N} / \mathrm{A}$ \\
\hline 22 & PCM07 & $M$ & $M$ & $M$ & $M$ & $M$ & $55^{\circ} \mathrm{C}$ & $\sim 190^{*}$ & + \\
\hline 23 & PM6 & - & - & - & - & - & $N / A$ & $\sim 100^{*}$ & $\mathrm{~N} / \mathrm{A}$ \\
\hline 24 & JPM11 & $\mathrm{M}$ & $\mathrm{M}$ & $\mathrm{M}$ & M & $\mathrm{M}$ & $55^{\circ} \mathrm{C}$ & $\sim 200$ & 0 \\
\hline
\end{tabular}

$\mathrm{S}=$ single banded amplified product, $\mathrm{M}=$ multiple banded amplified product, $\mathrm{S} / \mathrm{M}=$ multiple banded product but band of amplified region much brighter, $-=$ no amplified product, $*$ estimated length from previous studies, $+=$ successful sequencing or genotyping, $0=$ sequencing or genotyping failed, $\mathrm{N} / \mathrm{A}=$ data not available (i.e. not sequenced). 
$95^{\circ} \mathrm{C}, 30$ seconds at $50^{\circ} \mathrm{C}$, and 2 minutes at $72^{\circ} \mathrm{C}$; and a final extension period of 10 minutes at $72^{\circ} \mathrm{C}$ on an Eppendorf Mastercycler ep gradient $\mathrm{S}$ (Hamburg, Germany). The same PCR protocol was used for all primer pairs but some of the primer pairs needed optimization of annealing temperatures for successful single band amplification of the targeted region (Table 2.2).

The microsatellite regions were amplified using the same PCR cocktail as above, with the following modifications: 2 pmol of the forward primer with an M13 tail was added, and 8 pmol of a reverse complement of the tail labeled with a fluorescent 6FAM dye was added to the cocktail. The method used here follows the PCR protocol as described in Schuelke (2000). These regions were amplified using a two-step thermocycling profile of: an initial 5 minutes at $94^{\circ} \mathrm{C}$; then 30 cycles of 30 seconds at $94^{\circ} \mathrm{C}, 30$ seconds at $55-57^{\circ} \mathrm{C}$, and 2 minutes at $72^{\circ} \mathrm{C}$; followed by 8 cycles of 30 seconds at $94^{\circ} \mathrm{C}, 30$ seconds at $53^{\circ} \mathrm{C}$, and 2 minutes at $72^{\circ} \mathrm{C}$; and a final extension period of 10 minutes at $72^{\circ} \mathrm{C}$.

Amplified lengths for all samples were checked using a 100 base pair (bp) DNA ladder (Roche, Penzberg, Germany) on a $1.5 \%$ agarose gel. The amplified products of Plantago species of ITS, CYC, coxl, ndhF-rpl32, rpl32-trnL, trnK-psbA, trnE-trnTr, trnLc-LF, trnC-trnD, trnH-psbA, PCM07 and JPM11 were cleaned using ROCHE High Pure PCR Product Purification Kit (Manheim, Germany) and these were sequenced/genotyped using an ABI3730 Genetic Analyzer by the Allan Wilson Centre Genome Service (Massey University, Palmerston North, New Zealand). Genetic sequences were aligned and sequence variation was calculated using 

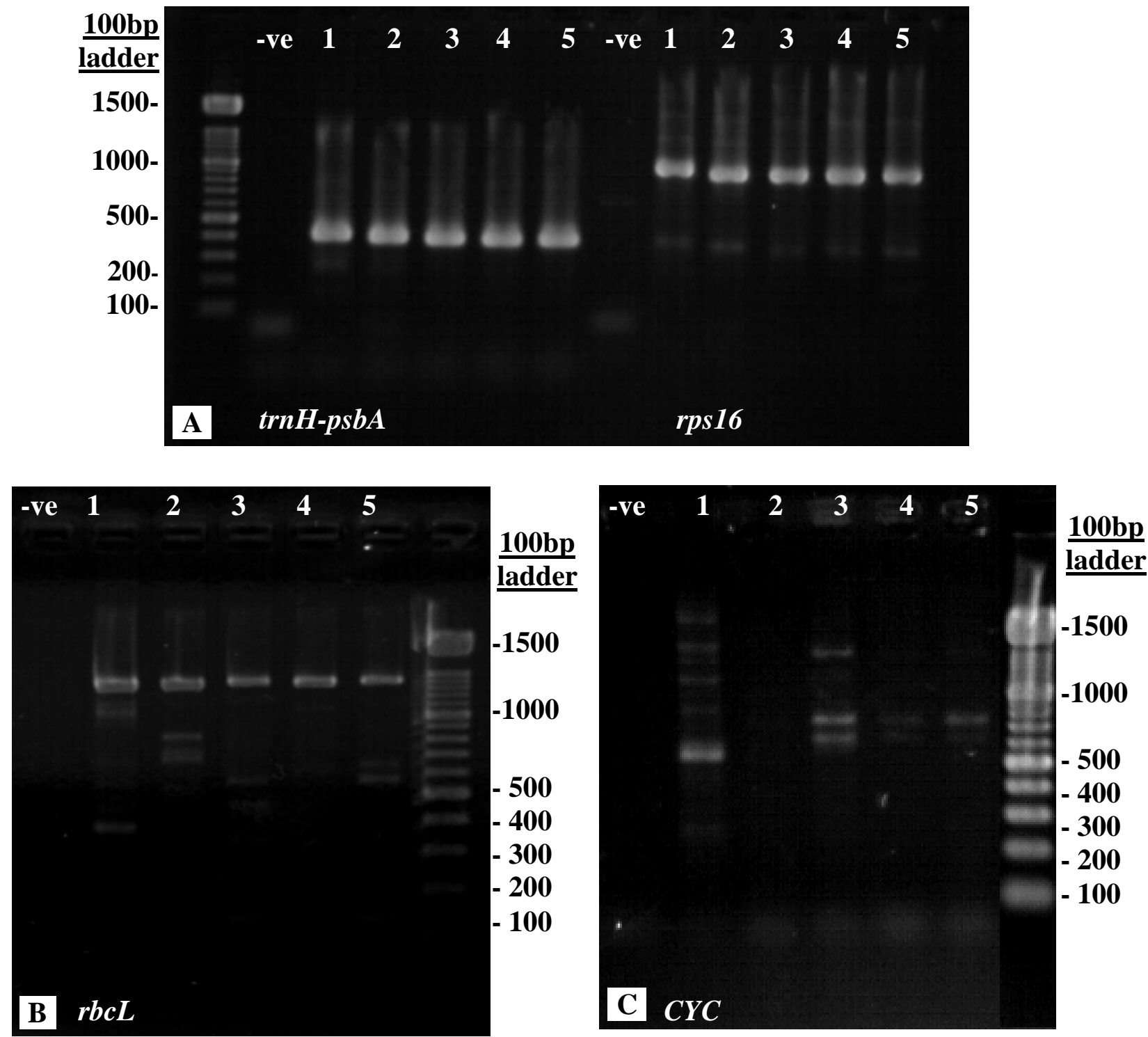

Figure 2.1. Gels illustrating various PCR products. Lanes: $1-5=$ Veronica stricta, Plantago lanceolata, P. euryphylla, P. spathulata subsp. spathulata and P. triandra subsp. triandra for each region; A: trnH-psbA and rpsl6 (amplified using primers from Oxelman et al. 1997), B: rbcL and C: CYC. Products in A show single banded amplification of targeted area (referred to as $\mathrm{S}$ in Table 2.2) whereas B and C are a mix of multiple bands (S/M and $\mathrm{M}$ in Table 2.2). 

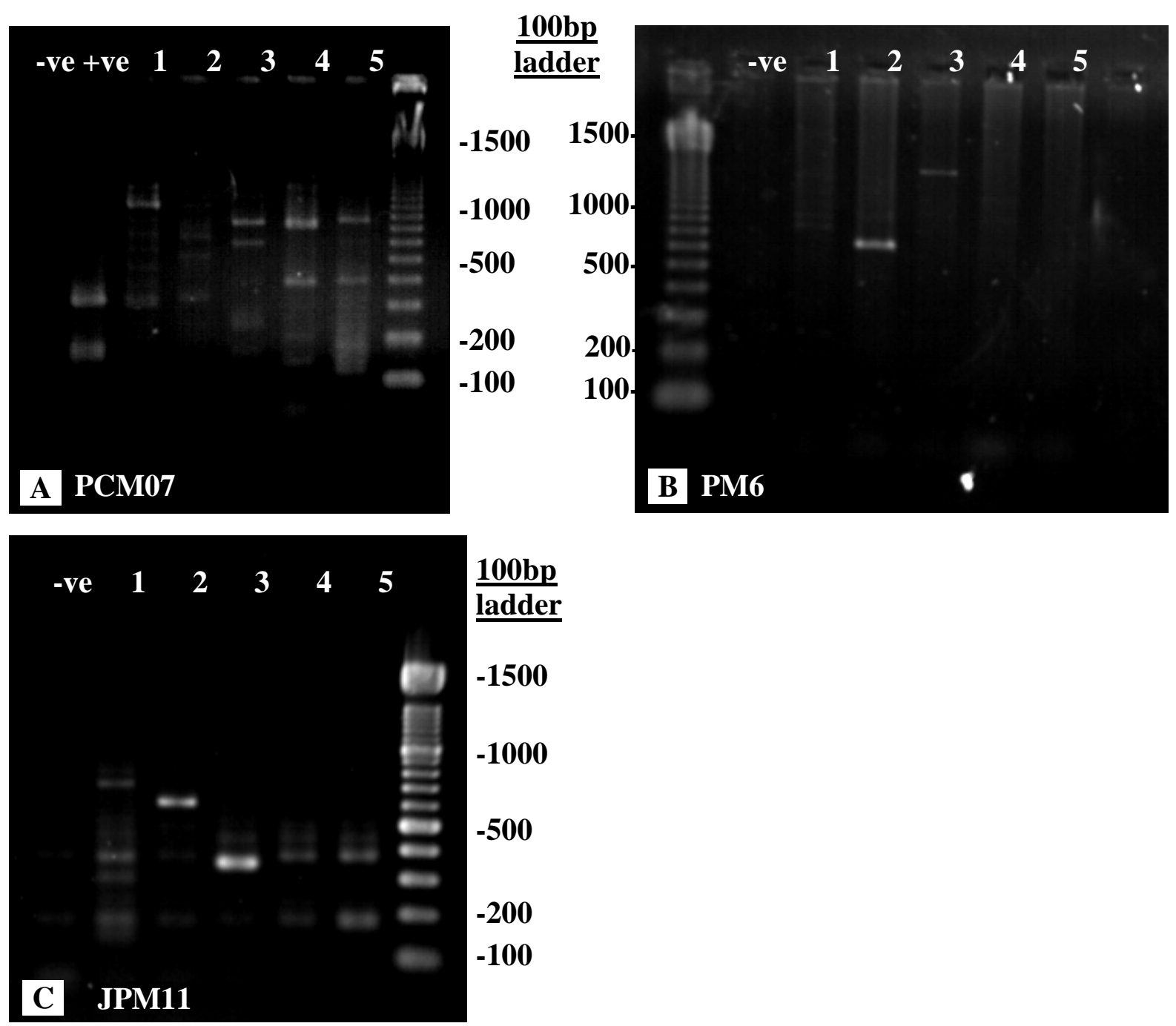

Figure 2.2. Gels illustrating the amplification of the microsatellite regions. Lanes: 1-5 = Veronica stricta, Plantago lanceolata, P. euryphylla, P. spathulata subsp. spathulata and P. triandra subsp. triandra for each region; A: PCM07, B: PM6, C: JPM11. Positive controls for B and C were run on a separate gel (not shown). PCM07 and JPM11 yielded product with multiple bands, whereas PM6 failed to amplify the targeted area. 
MEGA3.1 (Kumar et al. 2004). Microsatellites were analysed using GeneMapper v3.7 (Applied Biosystems). DNA sequences were deposited into Genbank (http://www.ncbi.nlm.nih.gov/entrez/query.fcgi?db=nucleotide).

\subsection{Results}

Different primer pairs amplified with various results (see Figs. 2.1 and 2.2) and the optimal temperatures for each region varied from $40^{\circ} \mathrm{C}$ to $55^{\circ} \mathrm{C}$ (Table 2.2). Primer pairs that resulted in single band amplifications for all samples trialed were: ITS, coxl, $n d h F-r p l 32, \operatorname{trnK}-p s b A, \operatorname{trnE}$-trnTr, trnLc-trnLf, trnC-trnD, rps16 (using both sets of primers) and trnH-psbA. CAM yielded amplified products only for Veronica stricta, whereas nadl amplified successfully in the Veronica stricta and the cosmopolitan Plantago species (P. lanceolata) but not in the Australasian Plantago species. CYC amplified multiple banded products in all samples but did not amplify in P. lanceolata. Primers that consistently failed to amplify any product despite several attempts were Waxy, Leafy, CHS and G3pdH and NIA3.

Table 2.3. Comparison of sequence variation (\%) between the three sequenced regions, which represent the three plant genomes. Each of the values presented here is the sequence variation as compared with Plantago spathulata subsp. spathulata.

\begin{tabular}{lccc} 
& \multicolumn{2}{|c}{ Australasian } & Cosmopolitan \\
\hline \hline & $\begin{array}{l}\text { Plantago triandra } \\
\text { subsp. triandra }\end{array}$ & P. euryphylla & P. lanceolata \\
\hline ITS & 2.84 & 2.09 & 9.12 \\
ndhF-rp/32 & 2.13 & 3.32 & 11.49 \\
Cox1 & 0.17 & 0.17 & 17.98 \\
\hline
\end{tabular}


Several of the amplified products were sequenced but these are not directly comparable because products from different species were sequenced for each region. However, sequences were obtained from all four Plantago species for ITS, $n d h F$ rpl32 and coxl, representing one region from each genome. Percentages of sequence variation among the Plantago species for these regions (Table 2.3) showed that the interspecific genetic divergence found in ITS and $n d h F-r p l 32$ are quite similar but there was relatively lower interspecific genetic divergence found in coxl among Australasian species. However, coxl displayed higher sequence divergence between the New Zealand $P$. spathulata subsp. spathulata and the cosmopolitan P. lanceolata than ITS and $n d h F-r p l 32$.

The microsatellite primers PCM07 and JPM11 yielded multiple-banded product for all Plantago and Veronica samples, whereas PM6 did not amplify the targeted region (Fig. 2.2). PCM07 and JPM11 amplified the targeted product in the positive control but PM6 failed to amplify in its positive control. For PCM07 and JPM11, which had successful amplification, we analyzed the product for length and heterogeneity in the samples. Genotyping was unsuccessful for PCM07, whereas the JPM11 microsatellites failed to show heterogeneity in the Plantago samples.

\subsection{Discussion}

Primer pairs for amplification of regions from all three plant genomes were included in this study to test their usefulness for future phylogenetic studies focusing on Plantago or related genera. Regions from all three plant genomes were tested, including several regions that are not usually utilised in plant phylogenetic studies, e.g. 
regions in the short single copy of the cpDNA and the mtDNA regions. With the exception of ITS and $\operatorname{trn} L c-t r n L f$, the primers included in this study have never been tested in Plantago.

\subsubsection{PCR amplification results}

Most of the primers tested here amplified products for all Plantago and Veronica species, including a few that were designed specifically for other plant groups (such as $a F$ and $c R$ from Hasebe et al. (1994), which were designed for Leptosporangiate ferns). Surprisingly, other primers such as those for Leafy and $C A M$, which were designed for universal use among angiosperms, consistently failed to amplify PCR products (Leafy) or only produced PCR products for Veronica stricta $(C A M)$. The primers for the nadl region, shown to have worked in previous studies involving Plantago species (Bakker et al. 2006), amplified DNA from the cosmopolitan $P$. lanceolata and from the outgroup (V. stricta) but failed to amplify DNA from native New Zealand and Australian species. Poor primer specificity or differences in the quality of the DNA used in PCR could be the cause for non-amplification of the targeted region. However, the latter seems less probable as the method of DNA extraction was the same for all of the samples and the quality of DNA for all samples were similar when checked on a gel.

Nine regions amplified consistently with good PCR product across all samples: ITS, cox1, ndhF-rpl32, trnK-psbA, trnE-trnTr, trnLc-trnLf, trnC-trnD, rps16 (using both sets of primers) and trnH-psbA (Table 2.2). Among these, one is from nrDNA, one from mtDNA and seven are from cpDNA. This result may simply be proportional to the number of cpDNA markers included in this study but appears to suggest that 
regions from the cpDNA have easier amplification compared to nrDNA or mtDNA. Microsatellites failed to amplify using PCR (Fig. 2.2), or failed genotyping (Table 2.2), suggesting that primers for these regions cannot be extended to other species in the genus.

While the nadl region has been previously reported as $>1 \mathrm{kbp}$ in sequence length, the amplified nadl product in Plantago lanceolata was about $200 \mathrm{bp}$. This finding is consistent with previous studies reporting a loss of this mtDNA intron in Plantago (Bakker et al. 2006). This deletion also occurs in Pelargonium, Geranium, and Sarcocaulon (Bakker et al. 2000).

\subsubsection{Sequence divergence compared in ITS, $n d h F-r p l 32$ and coxI}

Usefulness of ITS, $n d h F-r p l 32$ and coxl are compared in this study using sequence divergence. Among these, the nuclear ITS region is the most commonly used marker in plants whereas the mtDNA coxl is the most commonly used marker used in animal phylogenetics. The cpDNA $n d h F$-rpl32 intergenic spacer is a fairly new marker that has not yet been utilised in plant phylogenetics but was found to have the most variation among other primers designed by Shaw et al. (2007) for universal angiosperm use. Among the three regions, coxl had much higher sequence divergence between the native New Zealand species $P$. spathulata subsp. spathulata and the introduced P. lanceolata (Table 2.3). This may be support for the fast evolutionary rate of mtDNA in Plantago as reported by Cho et al. 2004. However, the same rate does not seem to extend to within the New Zealand species, where coxl has the least amount of variation (only one nucleotide substitution between the two New Zealand species) compared with ITS or $n d h F-r p l 32$. Further studies are needed to determine 
the extent of the elevated mtDNA rate in Plantago. The $n d h F-r p l 32$ region appears to have the fastest rate between Australasian species (Australian P. euryphylla and New Zealand $P$. spathulata subsp. spathulata), whereas coxl and ITS did not have as much variation per sequence length for these species. Thus, different primers may be better suited to different research objectives. For example, the fast evolving cpDNA marker $n d h F-r p l 32$ may be appropriate when working with lower taxonomic levels, while the mtDNA coxl may be better suited when analyzing taxa at higher taxonomic levels.

\subsubsection{Conclusions}

In this study, amplification of regions from nuclear, mitochondrial and chloroplast genomes in four species of Plantago and one Veronica (more than 10,000 bp in total) have shown that several regions are more easily amplified than others. Crossamplification of microsatellites designed for other species in Plantago failed to amplify or sequence for these four Plantago and one Veronica species. The thermocycling profile and optimal annealing temperatures reported here can also be further optimized for each individual primer to achieve cleaner amplification product.

ITS had the most sequence variation between the New Zealand species in this study. This region is the most commonly used marker in most plant phylogenetic studies and has proven to be reliable in studies despite several drawbacks (see Feliner and Rosselló 2007). However, researchers have now been looking for alternative markers that may be more useful for phylogenetic analyses (e.g. Shaw et al. 2007). It is shown in this study that there may be more information in markers in the nrDNA (such as ITS) or in the other two genomes, depending on the needs of the researcher. Researchers intending to work on Plantago and any closely related group such as 
Veronica should be able to use the primer pairs that consistently amplified the targeted products (Tables 2.1 and 2.2). Based on results from this study, it is not recommended to use the microsatellite primers tested here for species other than those they were developed for.

For further phylogenetic analyses of Australasian Plantago species (Chapters three and four), I chose to use ITS and $n d h F-r p l 32$ because these markers appear to have substantial variation and are a reasonable length (about 800-1000 bp long). Coxl had the best result out of all the mitochondrial regions tested and is therefore also selected for further phylogenetic analyses. The sequence divergence observed among Australasian species here indicates that the elevated rate of evolution is inconsistent across the genus and sequencing of $\operatorname{cox} 1$ for more Australasian species will allow for testing of this hypothesis (Cho et al. 2004 only included a few Plantago species and no Australasian species). 


\title{
Chapter Three: A three genome phylogeny for Australasian Plantago (Plantaginaceae) species reveals multiple trans-Tasman dispersal patterns ${ }^{1}$
}

\begin{abstract}
Recent phylogenetic studies have shown that the occurrence of recent long distance dispersal in Southern Hemisphere plants is far more prevalent than the expected distribution pattern of ancient Gondwanan vicariance. The phylogeny of New Zealand and Australian Plantago (Plantaginaceae) was reconstructed using DNA sequences from the Internal Transcribed Spacers, $n d h F-r p l 32$ and coxl from the nrDNA, cpDNA and mtDNA, respectively. The resolved phylogeny shows evidence for at least three long distance directional dispersal events, which does not support a Gondwanan vicariance origin for Southern Hemisphere Plantago species. Molecular dating also showed support for the conclusion that the distribution of Australasian Plantago was influenced by relatively recent long distance dispersal and not vicariance events. A concatenated ITS, $n d h F-r p l 32$ and coxl phylogeny indicated that the three trans-Tasman dispersals have occurred from Australia to New Zealand, consistent with the direction of the West Wind Drift. The finding of three dispersal events to New Zealand differs from the common pattern of a single origin followed by rapid radiation in many New Zealand plant groups. The apparent success of this group in New Zealand may be attributed to the fact that the plants were pre-adapted to the environments they established in.

\footnotetext{
${ }^{1}$ Note: This chapter has been prepared as a manuscript for submission in a journal and has been retained in this format. Co-authors of this paper are Phil Garnock-Jones, Heidi Meudt and Peter Ritchie, whose roles were supervision and advice. Mei Lin Tay collected sequence data and wrote the manuscript. Mei Lin Tay, Phil Garnock-Jones, and Heidi Meudt collaborated for the collection of Plantago samples
} 


\subsection{Introduction}

For the last ca. 45 years, it has been the common view that Southern Hemisphere flora is a relic of the supercontinent Gondwana and that their current distributions are the result of vicariance (see Pole 1994; de Queiroz 2005; McGlone 2005). However, recent studies using molecular data revealed that most plant groups in the Southern Hemisphere have instead achieved their current distributions through more recent long distance dispersal events (Winkworth et al. 1999; Winkworth et al. 2002b; de Queiroz 2005; McGlone 2005). This paradigm shift is an element that is reflected in New Zealand plant biogeography. New Zealand has always been featured in studies about Southern Hemisphere biogeography because of its unique geologic history. New Zealand has been separated by at least $1500 \mathrm{~km}$ from its closest landmass (Australia) since the breakup of the supercontinent Gondwana about 80 million years ago (mya) (Cooper and Cooper 1995). In spite of this, there is evidence that even plant groups regarded as classic examples of "ancient New Zealand lineages" (Cooper and Millener 1993) have previously undergone long distance dispersal. For example, it has been found that several lineages of southern beeches (Nothofagus) have arrived relatively recently through long distance dispersal (Swenson et al. 2001; Knapp et al. 2005). Molecular dating has shown that many plant lineages have diversified recently and are probably the result of long distance dispersal, not relicts of Gondwana (Hurr et al. 1999; Lockhart et al. 2001; Heenan et al. 2002; Zhang and Renner 2003; Perrie and Brownsey 2005; Barker et al. 2007; Perrie and Brownsey 2007). Some authors have gone as far as to say that the entire New Zealand flora arrived by long distance dispersal (Pole 1994), but there are still examples appearing in the literature of plant groups that date back to a Gondwanan origin, e.g. Agathis (Stöckler et al. 2002; 
Knapp et al. 2007). Thus, the origins of the New Zealand flora may be the result of a mixture of older vicariance and more recent long distance dispersal events.

A common observation among New Zealand plant groups with a history of long distance dispersal is a lack of DNA sequence divergence between species from Australia and species from New Zealand (Hurr et al. 1999; Renner et al. 2000; Swenson et al. 2001; Wagstaff et al. 2002; Smissen et al. 2003; Ford et al. 2007; Sanmartín et al. 2007) and a recurrent pattern of New Zealand and Australian species being sister groups (Linder and Crisp 1995; Sanmartín and Ronquist 2004; Perrie and Brownsey 2005; Crayn et al. 2006; Meudt and Simpson 2006). A brief survey of recent phylogenetic studies involving Australasian plants revealed that many New Zealand plant groups have arrived from Australia (e.g. Wagstaff et al. 1999; Wagstaff and Wege 2002; Ford et al. 2007). This asymmetric West to East direction of dispersal is consistent with expectations of the West Wind Drift, which predicts more dispersal events from west to east because of westerly winds and ocean currents (Raven 1973; Winkworth et al. 2002b; Muñoz et al. 2004; Sanmartín et al. 2007). Another pattern that is frequently found is a single dispersal to New Zealand followed by rapid species radiation (Wagstaff and Garnock-Jones 1998; Winkworth et al. 1999; Perrie et al. 2003; Albach et al. 2005b; Meudt and Simpson 2006). Other dispersal biogeographic patterns also exist (Winkworth et al. 2002b). However, these patterns can be difficult to elucidate because species relationships are often unresolved polytomies in large scale studies (i.e. at the genus level or higher) (Swenson et al. 2001; von Hagen and Kadereit 2001). Species relationships have previously been found to be unclear in studies focusing on Australasian groups, e.g. Radford et al. 
A

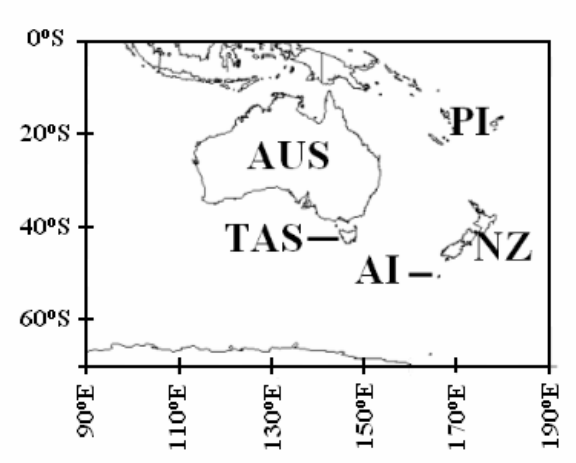

B NZ

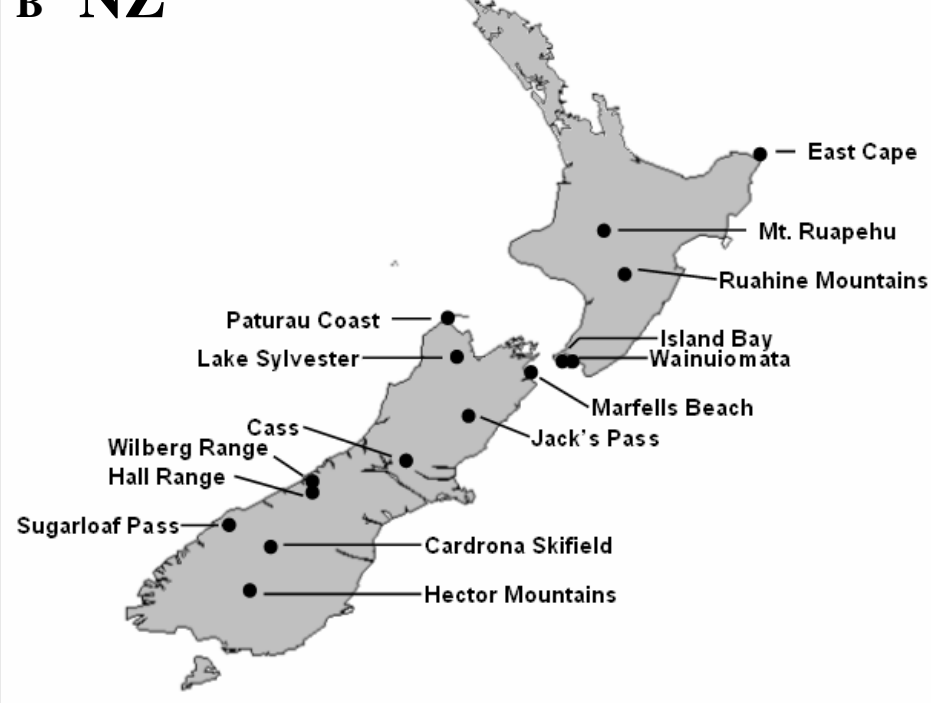

- Auckland Islands

C AUS

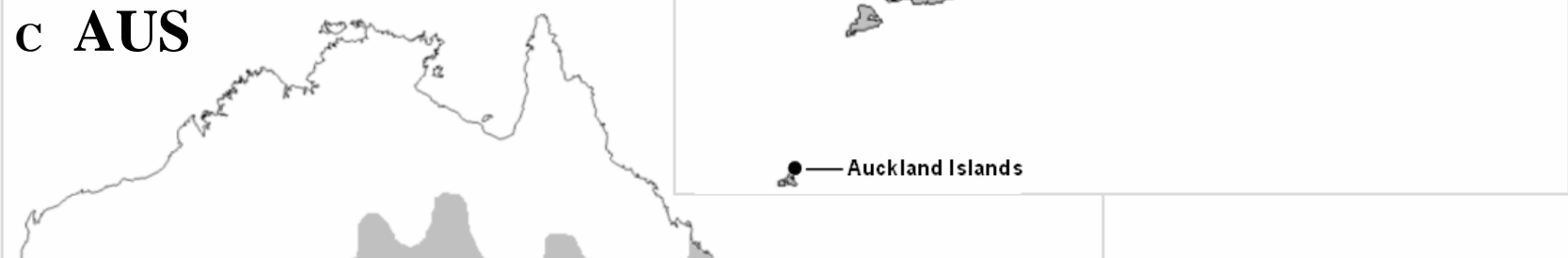

Figure 3.1. $A$ : The Australasian region $A I=$ Auckland Islands, $A U S=$ Australia, $N Z$ $=$ New Zealand, PI $=$ Pacific Islands and TAS $=$ Tasmania. B: Distribution of native species of New Zealand Plantago from the databases of the Allan Herbarium (Landcare Research, Christchurch, NZ) and Victoria University of Wellington (Wellington, NZ). C: Distribution of native Australian Plantago species from the Australian Virtual Herbarium (http://www.flora.sa.gov.au/avh/). For B and C, shaded areas illustrate the distribution of native Australasian species and black circles represent the localities where native Australasian species were sampled for this molecular study 
(2001); Perrie et al. (2007). Thus, more studies focused on lower taxonomic levels are needed to fully understand the historical biogeography of Australasian plants.

The molecular phylogeny of Australasian Plantago species was reconstructed in order to resolve species relationships and to investigate regional biogeographic patterns, e.g. to test the occurrence of long distance dispersal versus vicariance in the evolutionary history of the group. Plantago is a large worldwide genus in the family Plantaginaceae with six subgenera and more than 200 species (Rahn 1996). There are eight native Plantago species in New Zealand (Sykes in Webb et al. 1988), and an undescribed polyploid species (P. "sylvester") (Groves and Hair 1971). There are 24 species that are native to Australia (Briggs 1992), all of which are placed in subg. Plantago (Rahn 1996). New Zealand species of Plantago are distributed widely over both the North and South Islands (Fig. 3.1). In Australia, they are found on the mainland below $25^{\circ} \mathrm{S}$ and in Tasmania. Australasian Plantago also occur on offshore islands; $P$. aucklandica is endemic to the Auckland Islands, and $P$. triantha is endemic to the Auckland Islands and Tasmania. The plants are mostly small rosette herbs and are usually found in damp areas (such as seepage areas and near bogs, tarns, and river edges) from alpine regions to lowland herbfields and coastal areas. Morphological differences between taxa are not easily defined, which has resulted in problems with species delimitation and identification in the past. Classification of subgenera and sections in this paper follows Rahn (1996), whereas classification of Australasian species follows Sykes (in Webb et al. 1988) and Briggs (1992).

When Rahn reconstructed the phylogeny of Plantago using morphological characters, the New Zealand species were paraphyletic to multiple South American, Australian 
and other Pacific species. It was suggested that Plantago had a distribution consistent with vicariance with subsequent extinctions (Rahn 1996). Molecular phylogenetics can often form a robust and well-resolved evolutionary history where morphological characters and the fossil record cannot. In a worldwide phylogenetic study of Plantago, Rønsted et al. (2002) inferred that the distribution of the species was largely influenced by long distance dispersal. However, only three Australasian species were included in the study. Six Australasian species were included in another molecular phylogenetic study by Hoggard et al. (2003) but these studies were not focused on species relationships of the Australasian species and thus provided no further resolution among them.

Including all the Southern Hemisphere Plantago species is key to testing dispersal vs. Gondwanan vicariance. In a Gondwanan vicariance scenario, three clades are expected: a South American clade that is sister to an Australian clade, and a New Zealand clade that is sister to (and with a node that is basal to) the South AmericanAustralian group. In addition, the node of the New Zealand clade should be at least 80 mya according to the break-up sequence of Gondwana. Since this study is focused on the Australasian Plantago species, we can conclude that long distance dispersal has occured if: (1) the New Zealand and Australian groups are not reciprocally monophyletic, (2) the New Zealand species are in a clade that is derived from the Australian species (concordant with the direction of wind flow but does not match the pattern expected from Gondwanan vicariance) and/or (3) the split between New Zealand and Australian groups is found to be less than 80mya. 
The Internal Transcribed Spacers (ITS) from nuclear DNA (nrDNA), ndhF-rpl32 spacer from chloroplast DNA (cpDNA) and coxl from mitochondrial DNA (mtDNA) were chosen to elucidate the evolutionary history of the Australasian Plantago. The coxl marker is particularly interesting for Plantago because unprecendented elevated rates of mtDNA evolution, even several times higher than human mtDNA evolution rates, have been reported in the genus (Cho et al. 2004). This is surprising because mtDNA in plants is normally characterized by slow evolving rates (Wolfe et al. 1987). A mtDNA marker would also provide good phylogenetic resolution if the elevated rate was present in the Australasian species. Using markers from the three genomes will allow a comparison of evolutionary patterns in the three plant genomes, and also an investigation of whether the mtDNA of Australasian Plantago has a faster rate of evolution than nrDNA and cpDNA. The aims of this study are thus to test for evidence of either Gondwanan vicariance or long distance dispersal in the evolutionary history of this plant group, to investigate Australasian biogeographic patterns, and to examine if fast evolving mtDNA is present in Australasian Plantago.

\subsection{Materials and Methods}

\subsubsection{Study group}

Samples for this study were collected from wild populations across the North and South Islands of New Zealand from previously known locations in order to cover the 
Table 3.1: Collection details and Genbank accession numbers for species included in this study.

\begin{tabular}{|c|c|c|c|c|c|c|c|}
\hline \multirow{2}{*}{ Species } & \multirow{2}{*}{$\begin{array}{l}\text { Indigenous } \\
\text { distribution }\end{array}$} & \multirow{2}{*}{ Collected from } & \multirow{2}{*}{$\begin{array}{c}\text { Collection } \\
\text { number }\end{array}$} & \multicolumn{3}{|c|}{ Genbank accession number } & \multirow{2}{*}{$\begin{array}{c}\text { Herbarium } \\
\text { voucher }\end{array}$} \\
\hline & & & & ITS & ndhF-rpl32 & $\operatorname{cox} 1$ & \\
\hline Plantago alpestris & AUS & Kosciuszko National Park, NSW, AUS & $B G B 9748$ & & & & NSW742962 \\
\hline P. aucklandica & AI & AI, NZ (cult. Otari-Wilton Bush) & N/A & & & & WELTU20185 \\
\hline P. australis & America & Hunua Ranges, Auckland, NZ & MLT019 \& PGJ & & & & WELTU20181 \\
\hline P. cladarophylla & AUS & Barrington Tops National Park, NSW, AUS & JRHosking 2682 & & & & WELTU20189 \\
\hline P. coronopus & $\begin{array}{l}\text { Mediterranean, } \\
\text { Europe }\end{array}$ & Island Bay, Wellington, NZ & PGJ2549 & & & & WELTU20183 \\
\hline P. cunninghamii & AUS & Brigalow Park Nature Reserve, NSW, AUS & JRHosking 2752 & & & & WELTU20186 \\
\hline P. daltonii & AUS & St. Clair National Park, AUS, Tasmania & BGB9782 & & & & NSW743874 \\
\hline P. debilis & AUS & Barrenjoey Headland, NSW, AUS & $B G B 9738$ & & & & NSW 742894 \\
\hline P. euryphylla & AUS & Kosciuszko National Park, NSW, AUS & $B G B 9743$ & & & & NSW742956 \\
\hline P. glacialis & AUS & Kosciuszko National Park, NSW, AUS & $B G B 9753$ & & & & NSW743813 \\
\hline P. lanceolata & cosmopolitan & Karori, Wellington, NZ & PGJ2551 & & & & WELTU20184 \\
\hline P. lanigera (1) & $\mathrm{NZ}$ & Sugar Loaf Pass, Aspiring National Park, NZ & Mike Thorsen & & & & WELTU20133 \\
\hline P. lanigera (2) & NZ & Sugar Loaf Pass, Aspiring National Park, NZ & $\begin{array}{c}\text { s.n. } \\
\text { Mike Thorsen } \\
\text { s. } n .\end{array}$ & & & & WELTU20133 \\
\hline P. lanigera (3) & NZ & Hall Range, Canterbury, NZ & PBH s.n. & & & & WELTU20143 \\
\hline P. lanigera (4) & NZ & Wilberg Range, Westland, NZ & MLT027 et al. & & & & WELTU20147 \\
\hline P. lanigera (5) & $\mathrm{NZ}$ & Wilberg Range, Westland, NZ & MLT027 et al. & & & & WELTU20147 \\
\hline P. major & cosmopolitan & Ben Burn Park, Karori, NZ & PGJ2550 & & & & WELTU20180 \\
\hline P. muelleri & AUS & Kosciuszko National Park, NSW, AUS & $B G B 9752$ & & & & NSW743812 \\
\hline P. obconica (1) & NZ & Hector Mountains, Otago, NZ & N/A & & & & CHR573261 \\
\hline P. obconica (2) & NZ & Cardrona Ski Field, Wanaka, NZ & PGJ2600 et al. & & & & WELTU20121 \\
\hline P. paradoxa & AUS & St. Clair National Park, AUS, Tasmania & BGB9781 & & & & WELTU20187 \\
\hline P. raoulii (1) & $\mathrm{NZ}$ & Lake Sarah, Cass, NZ & PGJ2559 & & & & WELTU20153 \\
\hline P. raoulii (2) & NZ & Wainuiomata Valley, Wellington, NZ & $P B \& R L$ s.n. & & & & WELTU20155 \\
\hline P. sp.* & $?$ & Pukerua Bay, Wellington, NZ & $P G J 2566 \& M L T$ & & & & WELTU20178 \\
\hline
\end{tabular}


Table 3.1: Collection details and Genbank accession numbers for species included in this study.

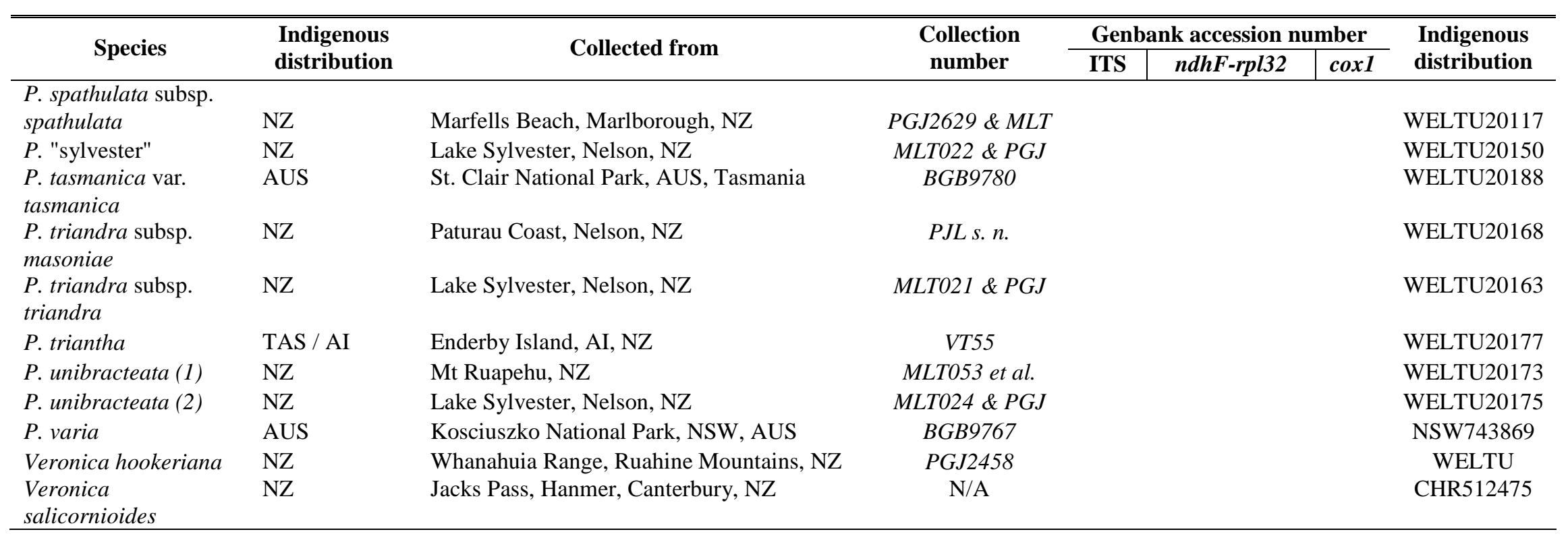

Locations: $\mathrm{AI}=$ Auckland Islands, AUS = Australia, NSW = New South Wales, NZ = New Zealand and TAS $=$ Tasmania. Collectors: $B G B=$ Barbara Briggs, $M L T=$ Mei Lin Tay, $P B H=$ Peter Heenan, $P G J=$ Phil Garnock-Jones, $P B=$ Peter Beveridge, $P J L=$ Peter Lockhart, $R L=$ Rodney Lewington and $V T=$ Vanessa Thorne. Herbarium vouchers: CHR = Allan Herbarium, Landcare Research, Christchurch, New Zealand; NSW = National Herbarium of New South Wales, Australia; WELT = Herbarium of Museum of New Zealand, Te Papa Tongarewa, Wellington, New Zealand; and WELTU = H. D. Gordon Herbarium in Victoria University of Wellington, New Zealand.

*The taxon referred to as $P$. sp. in this study is an introduced species that has never been reported in New Zealand. The ITS sequence for this species was identical to a $P$. asiatica sequence downloaded from Genbank (http://www.ncbi.nlm.nih.gov/entrez/query.fcgi?db=nucleotide) but further morphological work is needed to clarify the identity of this sample.

Note: Accession numbers will be inserted into table before publication of the paper. 
range of species distributions, and also from Australia (Fig. 3.1). Location of samples, along with voucher information and Genbank accession numbers are presented in Table 3.1. Multiple individuals were obtained for several of the Australasian species. DNA sequences were obtained from all eight known native New Zealand Plantago species, including the recently described New Zealand species, P. obconica (Sykes 1988) and the undescribed New Zealand polyploid specimen, tag-named $P$. "sylvester" (Groves and Hair 1971). The chromosome number of $2 n=96$ reported by Groves and Hair (1971) was confirmed using one sample from the populations referred to as $P$. "sylvester" in this study. DNA sequences were also obtained for 12 of the 24 native Australian species including P. triantha, which is also found in New Zealand. Introduced Plantago species that have established in New Zealand $(P$. coronopus, $P$. lanceolata, $P$. major and $P$. australis) were included in this study. $P$. major and $P$. australis are in the same subgenus as the Australasian species (subg. Plantago). P. coronopus and P. lanceolata are in subg. Coronopus and Albicans, respectively (following Rahn 1996).

$P$. coronopus and $P$. lanceolata were used as close outgroups as they represent the sister groups of subg. Plantago (Rønsted et al. 2002), whereas Veronica hookeriana and $V$. salicornioides are used as distant outgroup species for Plantago because Veronica is a close relative and has been used as an outgroup in the past (Rønsted et al. 2002; Cho et al. 2004). The dataset of one region ( $n d h F-r p l 32)$ contained only $V$. hookeriana as a distant outgroup due to sequencing difficulties. 


\subsubsection{Genetic markers}

In order to reconstruct the molecular phylogeny, the following genetic markers were chosen. ITS, found in the nuclear genome of plants and animals, has various advantages as a marker (Álvarez and Wendel 2003) and is widely applied; 66\% of published plant phylogenetic papers at the genus level or below between 1998 and 2002 utilised this marker (Feliner and Rosselló 2007). The second molecular marker used is the $n d h F-r p l 32$ intergenic spacer. This region is located in the small single copy region of the chloroplast and universal primers for this region have been published recently (Shaw et al. 2007), where this marker was found to have the highest variation among sequences out of many other amplified chloroplast regions. Thirdly, cox1, a gene in mtDNA that codes for the cyclooxygenase enzyme was used. The three regions described above each come from a different genome. By combining sequences from different independent sources (at least between the biparentally inherited ITS and the other two maternally inherited regions), incongruences (if any) in the evolutionary history of the different genomes may be visualised. Additionally, it has been shown that the increased length of variable sequences and sampling from different sites both increase accuracy and support for phylogenetic analyses (Cummings et al. 1995) and thus, concatenation of these three regions will be useful if they do not present conflicting signals.

\subsubsection{Molecular techniques}

Tissue samples were either preserved in silica gel from field collections, or were obtained from existing herbarium specimens. DNA extractions were performed using the DNEasy Plant Mini kit (Qiagen, Hilden, Germany) or using a cetyltrimethylammonium bromide $(\mathrm{CTAB})$ protocol modified from Doyle and Doyle 
(1990), after manual disruption of dried tissue using a pestle and mortar. The primers used to amplify the various DNA regions are: ITS28CCCGCCGTTACTAGGGGAATCCTTGTAAG (Wagstaff and Garnock-Jones 1998) and ITS5-GGAAGTAAAAGTCGTAACAAGG (White et al. 1990); $n d h F-$ AAAGGTATKATCCAYGMATATT and $r p l 32 R$-AATATCCCTTYYTTTTCCAA from (Shaw et al. 2007); and coxlF4-GGATATCTAGGYATGGTTTATGC and coxlR3-AAGCTGGAGGACTTTGTAC (Cho et al. 2004 pers. comm.) These primers amplify the ITS region (ITS1, 5.8s nuclear rDNA and ITS2), ndhF-rpl32 spacer region, and coxl mitochondrial gene, respectively.

PCR amplification was performed using Eppendorf Mastercycler ep gradient S (Hamburg, Germany) in a final volume of $25 \mu \mathrm{l}$ of the following: $16.35 \mu \mathrm{l}$ water, 10X ThermoPol reaction buffer $\left(10 \mathrm{mM} \mathrm{KCl}, 10 \mathrm{mM}\left(\mathrm{NH}_{4}\right) 2 \mathrm{SO}_{4}, 20 \mathrm{mM}\right.$ Tris- $\mathrm{HCl}$ (pH8.8), $2 \mathrm{mM} \mathrm{MgSO} 4,0.1 \%$ Triton X-100)(New England BioLabs), $0.4 \mathrm{mg} / \mathrm{mL}$ BSA, $250 \mu \mathrm{mol}$ dNTPs, 10 pmol each primer, $0.75 \mathrm{U}$ of Taq DNA polymerase (New England BioLabs), and $0.4 \mu$ DNA template. The amplification was carried out with a thermocycling profile of an initial 2 minutes at $94^{\circ} \mathrm{C}$, followed by 30 cycles of 1 minute at $94^{\circ} \mathrm{C}, 1.5$ minutes at $50^{\circ} \mathrm{C}, 1$ minute at $72^{\circ} \mathrm{C}$, and ending with a final extension time of 5 minutes at $72^{\circ} \mathrm{C}$. This PCR protocol was used to successfully amplify regions for all primers pairs. PCR products were visualised on $1.5 \%$ agarose gels before being purified with the High Pure PCR Purification Kit (Roche Diagnostics, Manheim, Germany). The purified PCR products were sequenced in both directions using an ABI3730 Genetic Analyzer by the Allan Wilson Centre Genome Service (Massey University, Palmerston North, New Zealand). 
Table 3.2: Summary of statistics for each dataset used in this study.

\begin{tabular}{|c|c|c|c|c|c|c|c|c|}
\hline \multirow[b]{2}{*}{ Base frequencies of all sites $(\%)$} & \multicolumn{2}{|c|}{ ITS (nuclear) } & \multicolumn{2}{|c|}{ ndhF-rpl32 (chloroplast) } & \multicolumn{2}{|c|}{$\operatorname{cox} 1$ (mitochondrial) } & \multicolumn{2}{|c|}{ concatenated } \\
\hline & $\begin{array}{l}\text { T- } 23.0 \\
\text { A- } 22.2\end{array}$ & $\begin{array}{l}\text { C- } 26.4 \\
\text { G- } 28.4\end{array}$ & $\begin{array}{l}\text { T- } 37.0 \\
\text { A- } 37.3\end{array}$ & $\begin{array}{l}\text { C- } 12.5 \\
\text { G- } 13.2\end{array}$ & $\begin{array}{l}\text { T- } 32.8 \\
\text { A- } 23.3\end{array}$ & $\begin{array}{l}\text { C- } 23.2 \\
\text { G- } 20.6\end{array}$ & $\begin{array}{l}\text { T- } 31.2 \\
\text { A- } 28.0\end{array}$ & $\begin{array}{l}\text { C- } 20.4 \\
\text { G- } 20.4\end{array}$ \\
\hline Base frequencies of variable sites $(\%)$ & $\begin{array}{l}\text { T- } 31.6 \\
\text { A- } 22.5\end{array}$ & $\begin{array}{l}\text { C- } 26.2 \\
\text { G- } 19.6\end{array}$ & $\begin{array}{l}\text { T- } 33.0 \\
\text { A- } 25.4\end{array}$ & $\begin{array}{l}\text { C- } 19.0 \\
\text { G- } 22.5\end{array}$ & $\begin{array}{l}\text { T- } 26.1 \\
\text { A- } 25.5\end{array}$ & $\begin{array}{l}\text { C- } 34.1 \\
\text { G- } 14.3\end{array}$ & $\begin{array}{l}\text { T- } 30.5 \\
\text { A- } 24.7\end{array}$ & $\begin{array}{l}\text { C- } 25.1 \\
\text { G- } 19.7\end{array}$ \\
\hline $\begin{array}{l}\text { Range of sequence length (aligned length) in bp } \\
\text { including outgroups }\end{array}$ & \multicolumn{2}{|c|}{$577-622(639)$} & \multicolumn{2}{|c|}{$548-737(942)$} & \multicolumn{2}{|c|}{$613(613)$} & \multicolumn{2}{|c|}{$1774-1972$ (2194) } \\
\hline $\begin{array}{l}\text { No. of recoded gaps appended and aligned } \\
\text { length (with recoded gaps) }\end{array}$ & \multicolumn{2}{|c|}{$26(665)$} & \multicolumn{2}{|c|}{$36(978)$} & \multicolumn{2}{|c|}{$0(613)$} & \multicolumn{2}{|c|}{$61(2255)$} \\
\hline $\begin{array}{l}\text { No. of variable sites and parsimony informative } \\
\text { sites including outgroups }(\%)\end{array}$ & \multicolumn{2}{|c|}{$211(20 \%)$} & \multicolumn{2}{|c|}{$286(10 \%)$} & \multicolumn{2}{|c|}{$150(19 \%)$} & \multicolumn{2}{|c|}{$638(13 \%)$} \\
\hline $\begin{array}{l}\text { No. of variable sites and parsimony informative } \\
\text { sitesfor ingroup sequences }(\%)\end{array}$ & \multicolumn{2}{|c|}{$78(6 \%)$} & \multicolumn{2}{|c|}{$95(6 \%)$} & \multicolumn{2}{|c|}{$39(2 \%)$} & \multicolumn{2}{|c|}{$212(5 \%)$} \\
\hline Modeltest model (AIC) & \multicolumn{2}{|c|}{$\mathrm{GTR}+\mathrm{G}$} & \multicolumn{2}{|c|}{$\mathrm{TVM}+\mathrm{G}$} & \multicolumn{2}{|c|}{$\mathrm{TVM}+\mathrm{G}$} & \multicolumn{2}{|c|}{$\mathrm{TIM}+\mathrm{I}+\mathrm{G}$} \\
\hline Gamma shape estimate & \multicolumn{2}{|c|}{0.4645} & \multicolumn{2}{|c|}{2.0817} & \multicolumn{2}{|c|}{0.2834} & \multicolumn{2}{|c|}{0.9143} \\
\hline Pinvar & \multicolumn{2}{|c|}{0} & \multicolumn{2}{|c|}{0} & \multicolumn{2}{|c|}{0} & \multicolumn{2}{|c|}{0.2309} \\
\hline No. of transitions (all sites included) & \multicolumn{2}{|c|}{17} & \multicolumn{2}{|c|}{14} & \multicolumn{2}{|c|}{10} & \multicolumn{2}{|c|}{38} \\
\hline No. of transversions (all sites included) & \multicolumn{2}{|c|}{10} & & & & & 3 & 8 \\
\hline Transition/transversion ratio (all sites included) & 1 & 6 & & & & & 1 & 0 \\
\hline$\%$ missing data & 0.4 & $3 \%$ & & $4 \%$ & 0.4 & $4 \%$ & 0.5 & $2 \%$ \\
\hline
\end{tabular}




\subsubsection{Dataset alignment and analyses}

The program MEGA v3.1 (Kumar et al. 2004) was used to assemble and align sequences for each accession. Before alignment, the sequences were submitted to BLAST (http://www.ncbi.nlm.nih.gov/blast/) to check that they were the correct region. The aim of this study is to look at the overall biogeographic patterns of the different austral species and not to analyse samples at the population level. Therefore, population replicates were removed according to the availability of sequences in all three regions. This was done to improve the efficiency of analyses and to visually simplify the analyses, as well as to allow for concatenation of the datasets where a different number of taxa was sequenced for each region. There were 35 individuals included in the $n d h F-r p l 32$ dataset, whereas the ITS and coxl datasets included sequences from 36 individuals (Veronica salicornioides was not included in the $n d h F$ rpl32 dataset). For the concatenated dataset, we used the 35 taxa included in the $n d h F-r p l 32$ dataset. Exploration of sequence datasets was performed using functions provided in MEGA v3.1 and DAMBE v4.5.9 (Xia and Xie 2001).

Analyses were first performed individually for each of the datasets and then on a concatenated dataset. Gaps were coded using modified complex indel coding (MCIC) method as implemented in SeqState v1.32 (Müller 2005) and these were included in the dataset. Preliminary analyses of our datasets suggested that gaps are informative and should be included, and previous analyses have found that MCIC coded gaps often outperform analyses in which gaps are treated as missing data or excluded (Simmons et al. 2007). Datasets with gaps coded resulted in 26 indel characters added onto the end of the ITS and 36 onto the chloroplast sequence matrix. There were no indels in the coxl dataset, as expected, because it is a coding region. An indel was 
present in the aligned ITS sequence of Veronica salicornioides, one of the distant outgroups, but the sequence was not included in the concatenated dataset because of sequencing problems. Therefore, the concatenated dataset had 61 indel characters added onto the end of the alignment (Table 3.2). Ambiguous characters present in the datasets were excluded from phylogenetic analyses.

Maximum parsimony (MP) and maximum likelihood (ML) analyses were conducted using PAUP* v4.0b10 (Swofford 2002). A heuristic search was conducted under a MP criterion using 10,000 replicates of random sequence addition and tree-bisectionreconnection (TBR) branch swapping. A maximum of 10,000 trees was set for the MP analysis. A heuristic search was also conducted under a ML criterion, with 100 replicates of random sequence addition, and TBR branch swapping. The substitution model was selected by Modeltest v3.7 (Posada and Crandall 1998), which tests the fit among 56 different models of different complexity using a hierarchical likelihood ratio test. Models were selected using Akaike Information Weights criterion (AIC) because it has advantages over the hierarchical likelihood ratio test (Posada and Buckley 2004). Chosen models and parameter estimates are presented in Table 3.2. Nonparametric bootstrap support was assessed using 200 replicates for both MP and ML analyses, with random sequence addition and TBR branch swapping.

MrBayes v3.1.1 (Huelsenbeck and Ronquist 2001) was used to conduct heuristic searches, also implementing the AIC model that was selected by Modeltest. Each dataset was initially analysed with four chains and 500,000 generations. Additional generations were added if necessary in order to reach a standard deviation of split frequencies of less than 0.01 , which ensures that the runs have converged on a 
stationary distribution. For the concatenated dataset, two analyses were run. First one model was used across the whole dataset, and then a partitioned dataset was used such that separate models were used for each dataset as recommended by Modeltest for each individual dataset. For each run, $25 \%$ of the trees were excluded as burn-in.

Topological congruence was examined firstly by visually comparing trees generated from each of the datasets for each analysis. A partition-homogeneity test was also run in PAUP* (1000 replicates, TBR branch swapping, 100 random replicates of random taxa addition, and MaxTrees $=10,000$ ) for all combinations of datasets. Additionally, supertree networks were constructed from ML trees from the three datasets using Splitstree v4.8 (Huson and Bryant 2006). The ITS, cpDNA and mtDNA datasets were then concatenated and characters (e.g. geographic distributions and habitats) were mapped onto a concatenated tree in order to infer evolutionary patterns.

\subsubsection{Molecular dating}

An ITS dataset consisting of representatives from each Australasian Plantago species, several Veronica sequences, and sequences of Aragoa and Littorella obtained from Genbank (http://www.ncbi.nlm.nih.gov/entrez/query.fcgi?db=nucleotide) were used to date nodes for testing the hypothesis of a Gondwanan origin for the Australasian (see Appendix I (B) for details of the dataset). ITS sequences were used because only ITS sequences for Litorella and Aragoa are readily available. Rate heterogeneity of the dataset was checked by estimating the likelihood score of a tree with a molecular clock constraint and comparing this to the likelihood score of a tree obtained without this constraint using a likelihood ratio test (Felsenstein 1981). It was found that the ITS sequences did not evolve in a clock-like manner. Therefore, a relaxed clock 
model was implemented in the following molecular dating analyses. It has also been shown through simulations of different datasets that a relaxed-clock approach is more accurate and more precise than other models at reconstructing phylogenies (Drummond et al. 2006). BEAST v1.4.6 (Drummond et al. 2006) was used to implement a relaxed-clock model within a Bayesian framework to estimate divergence times for the lineages in our dataset. The program BEAUti v1.4.6 (Drummond et al. 2006) was used to set up groups that were used for dating nodes. Only monophyletic groups with high support in the ML tree were set up. These were: 1) a clade containing Plantago and Aragoa sequences, 2) a clade of the Plantago species, 3) a clade with all Plantago but excluding $P$. coronopus and $P$. lanceolata, and 4) Clade I, excluding $P$. cunninghamii. Analyses in BEAST were set up with $10,000,000$ runs initially, with additional 10,000,000 runs until estimated sample sizes (ESS) for each parameter were large enough, resulting in $20,000,000$ to $40,000,000$ runs for each analysis. A GTR $+\mathrm{I}+\mathrm{G}$ model was implemented for each analysis as recommended by Modeltest. A gamma distribution of rates is preferable in molecular dating (Sanderson and Doyle 2001). TRACER v1.4 (Rambaut and Drummond 2007) was used to analyse results. Exploration of the trees reconstructed by BEAST showed identical topology of the ITS tree reconstructed using ML analysis in all cases.

\section{Testing Gondwanan origin of Australasian species}

The hypothesis of Gondwanan origin for the Australasian species was tested in two separate analyses. First, a divergence date for a group was estimated to obtain a substitution rate for the sequences. The divergence date for the node of the Australasian Plantago, P. major, $P$. sp. and P. australis clade is expected to be at least 80 mya if the New Zealand species were present before New Zealand split from 
Gondwana. Thus, the node of this clade was constrained at 80mya. Secondly, substitution rates were applied to estimate divergence of the nodes. The slowest rate reported across all herbaceous angiosperms lineages in a study by Kay et al. (2006) of $1.72 \times 10^{-9}$ substitutions/site/year was chosen in order to be conservative.

The resulting substitution rates and node dates were then subjected to a t-test to compare it to the expected values. The test involves calculating a 99\% confidence interval for the expected value and determining if the obtained value from BEAST is within that $99 \%$ interval. If values obtained from BEAST are found outside the interval, then the values are significantly different at the $1 \%$ level. Estimated substitution rates were then compared with the lowest substitution rate found in herbaceous angiosperms and estimated divergence dates were compared to 80mya.

Estimating age of the Australasian species

We used the dates 5.47 MYA for the radiation of the Plantago-Littorella group and 7.1 MY since the divergence of this group and Aragoa (see Rønsted et al. 2002) to calibrate the tree to obtain an estimate for the divergence dates of Australasian species.

\subsection{Results}

\subsubsection{Dataset statistics}

Exploration of the three datasets revealed that the $n d h F-r p l 32$ dataset had more variable sites relative to the ITS and coxl datasets, but a lower percentage of parsimony-informative sites than the ITS dataset (Table 3.2). When gaps were coded 
as separate indel characters, the ITS and $n d h F-r p l 32$ datasets had slightly more parsimony informative sites than when gaps were ignored. In comparison to these two regions, the coxl dataset had fewer variable sites but a higher percentage of parsimony informative sites than the $n d h F-r p l 32$ dataset, and a similar percentage of parsimony informative sites as the ITS dataset. The variable sites in coxl provided little resolution within the Australasian Plantago clade, but were useful in delimiting the clade and separating Plantago from Veronica.

All ITS and $n d h F$-rpl32 sequences were unique, whereas the coxl dataset only had 15 unique sequences. This result illustrates the lack of coxl sequence divergence between members of Australasian Plantago. In fact, some Australian species had identical coxl sequence to some New Zealand species (P. muelleri was identical to $P$. triandra and $P$. unibracteata; $P$. debilis and $P$. triantha were identical to $P$. raoulii and $P$. spathulata subsp. picta; and $P$. euryphylla and $P$. glacialis were identical to $P$. lanigera, P. novae-zelandiae, P. obconica and P. aucklandica).

Chi-squared tests of all base frequencies only showed significant base heterogeneity for the $n d h F$-rpl32 dataset and among variable sites for the coxl dataset. In all three datasets, average G-C (guanine and cytosine) content was slightly less than A-T (adenine and thymine). This could be explained by transversions from $\mathrm{A} / \mathrm{T}$ to $\mathrm{C} / \mathrm{G}$ events, which are common in chloroplast genomes and is caused by oxidative damage (GuhaMajumdar and Sears 2005). In the coxl dataset, the third codon position had less $\mathrm{G}-\mathrm{C}$ content than the first and second positions. The $\mathrm{G}-\mathrm{C}$ content in plant genomes has been found to vary substantially although the implications of this are still unknown (Carels and Bernardi 2000). 
Within the coxl dataset, the substitution rate was higher in the third codon position than the other two codon positions, as expected because the third codon position is functionally redundant for many amino acids. Transition and transversion rates differed among the three regions, with transitions being more frequent than transversions in the ITS dataset but the other way around for the $n d h F$-rpl32 and the coxl datasets (Table 3.2). Transitions may have a bias over transversions because of the different molecular structures of purines $(A, G)$ and pyrimidines $(C, T)$ (DeckerWalters et al. 2004) but Keller et al. (2007) report that the bias is not universal and the results from the organellar DNA datasets support the latter situation. The transition/ transversion ratio was higher in the third codon position for the coxl gene.

Homogeneity partition (HP) tests indicated that the datasets were not congruent (pvalue $=0.001,0.002,0.001,0.016$ for ITS $+n d h F-r p l 32+\operatorname{cox} 1$, ITS + cox 1, ITS + $n d h F-r p l 32$, and $n d h F-r p l 32+\operatorname{coxl}$, respectively). While the organellar DNA datasets (ndhF-rpl32 and coxl) showed the least conflict, they were still significantly different. Visual analysis of the topology and Splitstree analyses (appendix II (N)) indicated that only four species (Plantago muelleri, $P$. paradoxa, $P$. triandra and $P$. unibracteata) provided conflicting signal and may be the cause of the low p-values of the HP test. However, the three datasets were still significantly incongruent when HP tests were run with these four species removed. Although traditionally used to check congruence of phylogenies from different regions, the HP test has been shown to be highly inaccurate even when the topologies of trees are congruent (Reeves et al. 2001; Yoder et al. 2001) and may continue to indicate conflict even after the incongruent taxa are 


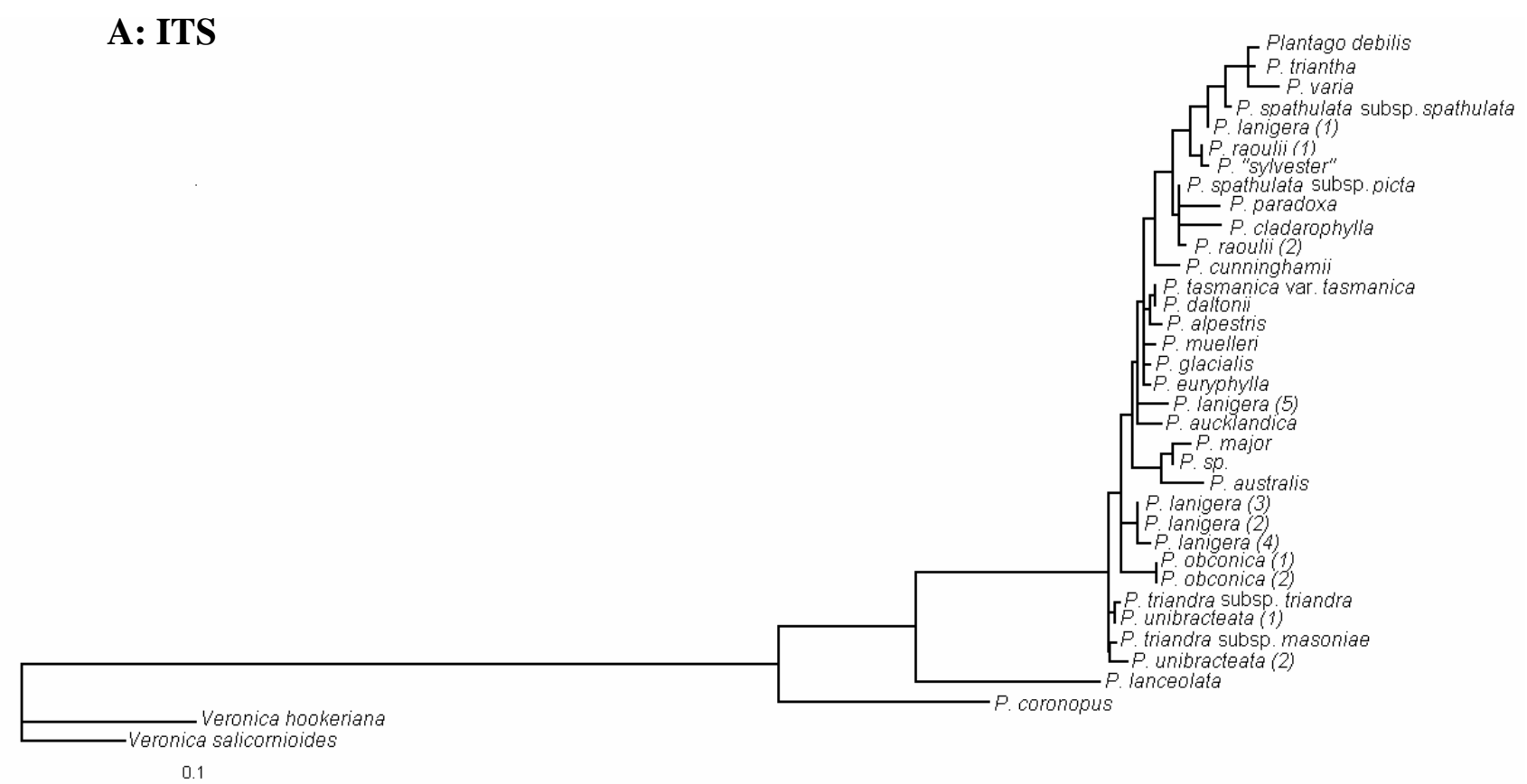

B: $n d h F-r p l 32$

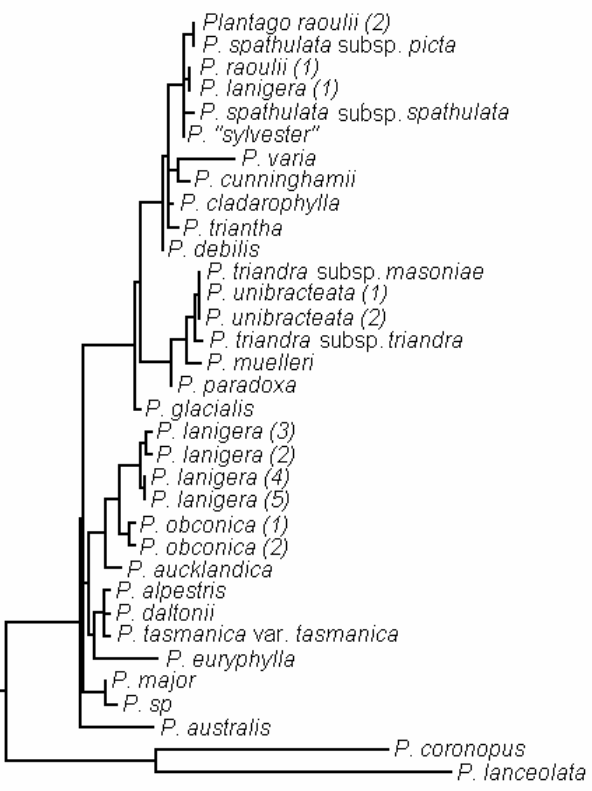

Figure 3.2: Maximum Likelihood phylogenies with branch lengths for each of the three datasets (A, ITS; B, ndhF-rpl32; C, coxl). The coxl tree displays a short branch length from the outgroup Plantago species ( $P$. coronopus and P. lanceolata) to the Veronica species, and a long branch between the Australasian and outgroup Plantago species. In contrast, the ITS and $n d h F$-rpl32 phylogenies have long branches from the outgroup Plantago to the Veronica species and a short branch between Australasian and outgroup Plantago species. Likelihood scores for these trees are -2513.31, 3045.43, and -8393.42 , respectively. 


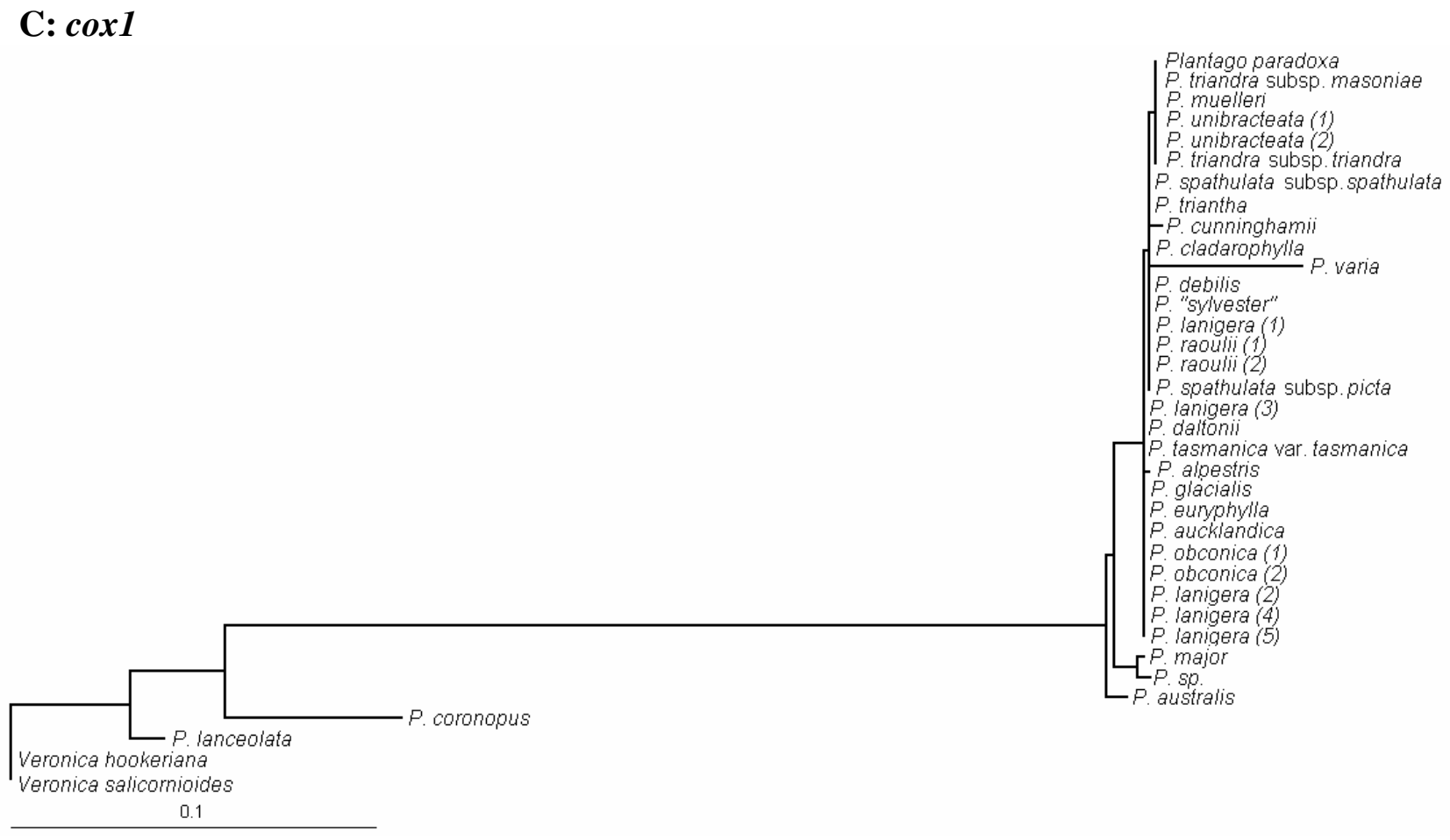

Figure 3.2 (continued): Maximum Likelihood phylogenies with branch lengths for each of the three datasets (A, ITS; B, ndhF-rpl32; C, coxl). The coxl tree displays a short branch length from the outgroup Plantago species ( $P$. coronopus and $P$. lanceolata) to the Veronica species, and a long branch between the Australasian and outgroup Plantago species. In contrast, the ITS and $n d h F$-rpl32 phylogenies have long branches from the outgroup Plantago to the Veronica species and a short branch between Australasian and outgroup Plantago species. Likelihood scores for these trees are $-2513.31,-3045.43$, and -8393.42 , respectively. 


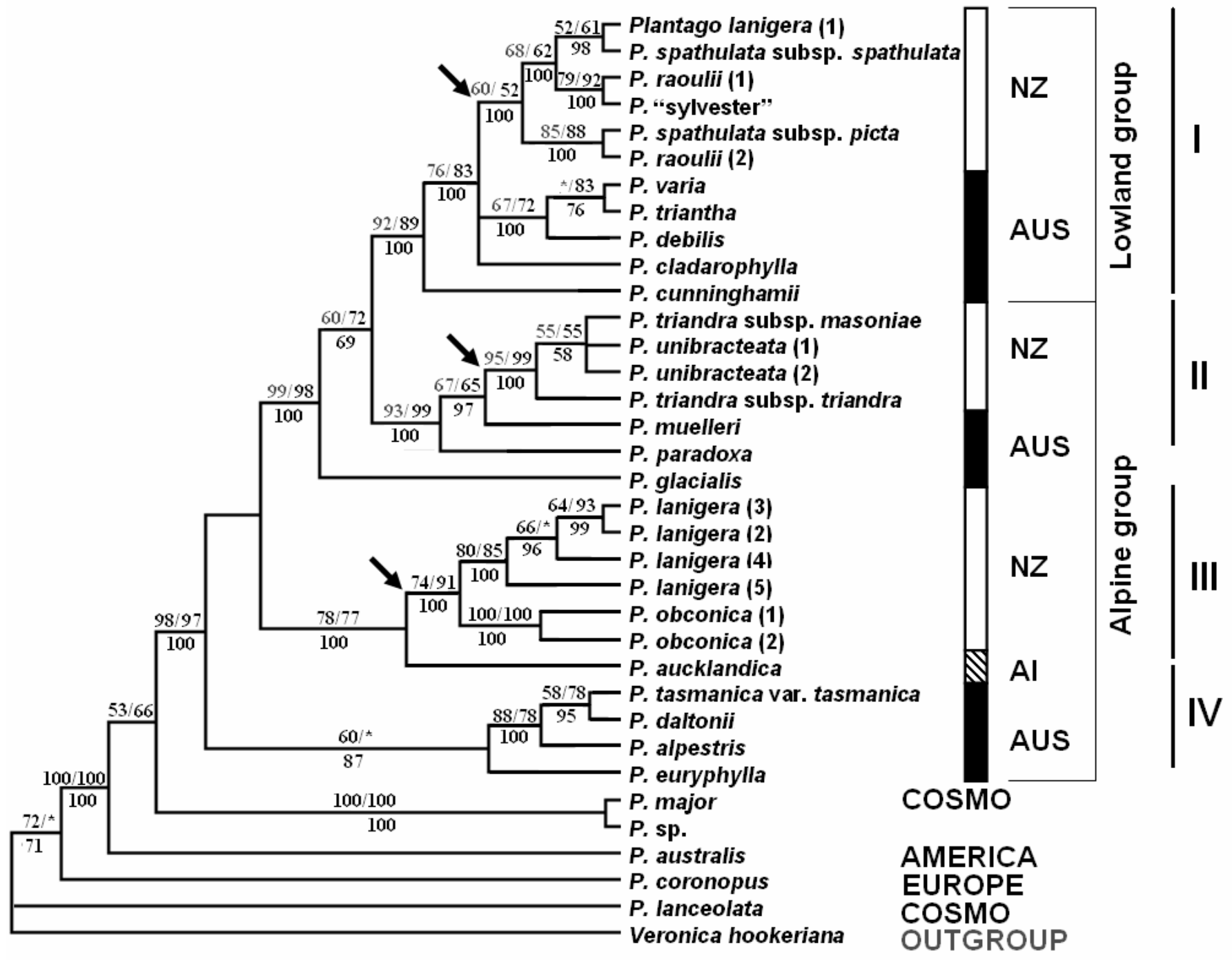

Figure 3.3. Maximum Likelihood (ML) tree reconstructed using concatenated data (ITS, $n d h F-r p l 32$ and coxl) showing indigenous distributions and habitats of native and introduced Australasian Plantago species (likelihood score $=-7738.89$ ). Values displayed above branches are from Maximum Parsimony/ML bootstrap analyses, whereas values presented below branches are posterior probabilities from MrBayes analyses (* indicates less than $50 \%$ support for the node). Arrows indicate a transTasman dispersal event to New Zealand from an ancestral Australian population. AUS $=$ Australia, $\mathrm{AI}=$ Auckland Islands, $\mathrm{COSMO}=$ cosmopolitan and $\mathrm{NZ}=\mathrm{New}$ Zealand. 
removed (Manos et al. 1999). Thus, analyses of a concatenated dataset were carried out because the tree topologies were not vastly incongruent in this case and there was no support for the placement of the conflicting species in the ITS tree. In the ITS dataset, some sequences had a few ambiguous sites that may result from multiple copies of the rDNA array in the genome. All ambiguous sites in the dataset were ignored during tree reconstruction analyses.

\subsubsection{Phylogenetic analyses}

The topologies of trees reconstructed using different tree construction methods were very similar for the ITS, $n d h F-r p l 32$ and coxl datasets (see appendix II (A-M)). Using one model versus individual models for each marker in MrBayes resulted in trees with the same topology. Posterior probabilities for trees made under Bayesian inference of phylogeny were higher compared to MP bootstrap values, and were similar to bootstrap support values obtained using ML. Therefore, only trees made using ML are presented here, with support values from all three analyses displayed on the concatenated tree (Fig. 3.3). ML trees for the individual datasets are displayed as phylograms in Fig. 3.2.

\section{Concatenated dataset}

In the tree reconstructed from the concatenated dataset (Fig. 3.3), the distant outgroup species Veronica hookeriana is in a polytomy with Plantago lanceolata. The nodes of these species are basal to the node of $P$. coronopus, which is in turn basal to the node of $P$. australis, followed by a clade containing $P$. major and $P$. sp. The Australasian species group into the clade following $P$. australis, within which there are four highly

supported monophyletic groups. Clade IV is Australian and has a node that is basal to 
the rest of the clades. Clade III comprises species from New Zealand, and $P$. aucklandica from the Auckland Islands. This clade is sister to P. glacialis (Australian), and Clades I and II, which are a mix of New Zealand and Australian species. Clade I and Clade II both contain a grade of Australian species at the base of a New Zealand clade. Thus, the pattern here is that there are multiple clades containing both New Zealand and Australian species, where the node of the New Zealand species appears in more derived positions in the tree than the node of the Australian species. In addition, Clade I is a group of Australasian Plantago found in lowland areas whereas Clades II, III, IV, along with $P$. glacialis are found in alpine and sub-alpine areas.

Individuals of Plantago raoulii, P. lanigera, and subspecies of $P$. spathulata and $P$. triandra do not form monophyletic groups, respectively, in the tree resolved using the concatenated dataset. This is discussed further in a separate paper focused on taxonomic issues and relationships of individuals at the population level (Chapter four). Supernetwork analysis using Splitstree shows support for the topology of the concatenated tree (appendix II (N)). The same four distinct groups are visible, with some uncertainties regarding the placement of $P$. muelleri, $P$. paradoxa, $P$. triandra subs. triandra and $P$. unibracteata, which was expected due to conflict between datasets.

A peculiar pattern found in the ML trees (Fig. 3.2) is a long branch separating the ingroup Plantago species from the outgroup Plantago species and an unexpectedly short branch length between Plantago as a whole and the Veronica outgroup in coxl (Fig. 3.2). In contrast, the ITS and $n d h F-r p l 32$ datasets have short branch lengths 
between the ingroup species but a long branch between Plantago as a whole and the Veronica species.

ITS

In the ITS ML tree (Fig. 3.2A), the close outgroups differed in placement from the concatenated tree (Plantago lanceolata and P. coronopus have switched positions). P. major, $P$. sp. and $P$. australis form a clade that is nested within the Australasian species as opposed to having a node at the base of the tree in the concatenated phylogeny. The ingroup clades were similar but $P$. muelleri and $P$. paradoxa do not form a clade with $P$. unibracteata and $P$. triandra. Instead, $P$. unibracteata and $P$. triandra are placed at the base of the tree, whereas $P$. muelleri and $P$. paradoxa are placed as sister species to other Australian species further up in the tree. Furthermore, P. debilis, P. varia and P. triantha form a clade with $P$. spathulata subsp. spathulata. These results are incongruent with the concatenated tree and both organellar DNA trees.

$n d h F-r p l 32$

The close outgroups ( $P$. lanceolata and $P$. coronopus) form a clade, in contrast to the concatenated tree, where these species do not form a clade (Fig. 3.2B). When the dataset is analysed after concatenation, the topology of the reconstructed trees most resembled that of the $n d h F$-rpl32 trees. This outcome may be because there is more signal in the $n d h F-r p l 32$ dataset. 


\section{$\operatorname{Cox} 1$}

The coxl dataset resulted in very little resolution in the ML analysis (Fig. 3.2C), with two Australasian nodes resolved and only one with good bootstrap support (81\% BP). Interestingly, the well supported clade is also present in the $n d h F-r p l 32$ dataset, and in the concatenated dataset, and is the clade that causes conflict between the ITS tree and the organelle trees. Poorly resolved nodes within the Australasian group may suggest a recent separation of Australian and New Zealand taxa, or unsuitability of this marker for reconstructing the phylogeny of this group of plants.

\subsubsection{Molecular Dating}

\section{Testing Gondwanan origin of Australasian species}

Molecular dating using ITS sequences rejected the hypothesis of Gondwanan vicariance for Australasian Plantago. When the divergence of the node including Australasian species, P. major, $P$. sp. and $P$. australis was set to $80 \mathrm{mya}$, the final substitution rate estimated by BEAST was $5.806 \quad( \pm 0.240) \times 10^{-10}$ substitutions/site/year. This rate is extremely low; more than ten times slower than the lowest substitution rate found in the literature for herbaceous angiosperms $\left(1.72 \times 10^{-9}\right.$ (Kay et al. 2006)). When compared, the slowest rate and the observed rate were significantly different at the $1 \%$ level. Secondly, when the substitution rate was estimated at the lowest substitution rate found in herbaceous angiosperms, BEAST gave a divergence date of $24.804( \pm 0.663)$ mya for a clade of the Australasian species, P. major, $P$. sp. and P. australis. The node for the genus Plantago was estimated to be $57.717( \pm 0.700)$ mya. This is not consistent with the expectation that the Australasian Plantago group arose before New Zealand broke off from Gondwana (at least 80mya) 
and the expected and observed values are significantly different. Thus, the Gondwanan hypothesis is rejected for Southern Hemisphere Plantago.

\section{Estimating age of Australasian species}

Molecular dating of the ITS dataset using BEAST provided a date of $2.291( \pm 0.0039)$ mya for the divergence a clade comprising the Australasian Plantago species, $P$. major, and $P$. sp. Unfortunately, there was not enough support in the tree to separate the Australasian clades from $P$. major and $P$. sp. in the ITS tree. However, the node of Clade I (excluding P. cunninghamii) (Fig. 3.3) was dated to $1.520( \pm 0.030)$ mya, which provides a range of possible dates of origin for the Australasian species.

\subsection{Discussion}

The aim of this study was primarily to investigate whether the distribution of the Australasian Plantago was the result of Gondwanan vicariance or long distance dispersal (or a mixture of both), and to elucidate biogeographic patterns for the Australasian species of Plantago. Even though Rahn (1996) attributed geographic disjunctions in the genus to vicariance and subsequent extinctions, the topology of the morphological phylogeny could also be attributed to multiple more recent dispersal events, and it was inferred from a recent molecular phylogeny that long distance dispersal is extremely common within the group (Rønsted et al. 2002). Subsequently, if dispersal was found to be the process behind the biogeography of Australasian Plantago, the goal of this study was to determine the number of and direction of dispersal events between Australia and New Zealand. This is important because many 
large scale or austral (Swenson et al. 2001; von Hagen and Kadereit 2001) and even Australasian-focused plant phylogenetic studies (Radford et al. 2001; Perrie et al. 2007) lack signal in molecular markers between closely related Australasian taxa. This lack of signal often results in ambiguous relationships between Australasian taxa. The dataset used in this study was $2194 \mathrm{bp}$ in length (2255 when indel characters are included as coded characters) and is able to resolve most of the relationships among Australasian Plantago.

\subsubsection{Biogeography of Australasian Plantago}

The hypothesis of Gondwanan vicariance can be rejected for Australasian Plantago. The concatenated tree (Fig. 3.3) reveals that multiple New Zealand clades are nested within the Australian species, which is consistent with a dispersal scenario; but not vicariance, as the cause of current distribution. There is also a lack of sequence divergence among the Australasian species, which we would not expect from a long isolation of the New Zealand species. Additionally, the nodes of the New Zealand clades are placed in a more derived position than nodes of the Australian species in the tree. Rønsted et al. (2002) estimated an Australasian clade of $P$. spathulata and $P$. debilis to be 0.5-0.7 mya (this clade was not found in the phylogeny presented here) and estimated 5.47 mya for the genus Plantago as a whole. All of this suggests that the genus is too young to be a remnant of Gondwana. This view is supported by our own molecular dating. Statistical tests rejected the hypothesis of Gondwanan vicariance for the Australasian species for both tests of: 1) when the node of the Australasian clade was set to 80mya (as would be expected for a Gondwanan vicariance hypothesis), or 2) when rates used for dating was set to the lowest known rate across herbaceous angiosperm lineages. Thus, both tree topology and molecular 
dating strongly suggest that the Australasian Plantago group achieved their current distribution through long distance dispersal and not Gondwanan vicariance.

The clades formed by the Australasian species in the molecular phylogeny presented in this study can be interpreted as multiple directional, long distance trans-Tasman events. This is consistent with other plant phylogenetic studies that report Australian and New Zealand species as sister groups (Linder and Crisp 1995; Sanmartín and Ronquist 2004; Perrie and Brownsey 2005; Crayn et al. 2006; Meudt and Simpson 2006). The lack of sequence divergence between Australian and New Zealand species is especially evident in analysis of the coxl dataset, where several Australian and New Zealand species share identical sequences, suggesting recent diversification/speciation of the trans-Tasman species. The timing of arrival and diversification of the New Zealand species matches the geological dates of the uplift of the New Zealand mountains (5-2mya) (Winkworth et al. 2002b).

At least three independent long distance dispersal events to New Zealand, followed by speciation are evident in the reconstructed phylogeny (Fig. 3.3). All three dispersals appear to be directional from Australia to New Zealand. There also appears to be two dispersal events from Australia to the Auckland Islands. Dispersal in this direction is congruent with expectations because prevailing winds from the West would result in frequent west to east direction of dispersals (refered to as West Wind Drift) (Raven 1973; Winkworth et al. 2002b; Sanmartín et al. 2007). The finding of multiple dispersals across the Tasman differs from the common pattern of one dispersal followed by rapid radiation found in many other New Zealand plant groups (Wagstaff and Garnock-Jones 1998; Winkworth et al. 1999; Perrie et al. 2003; Albach et al. 
2005b; Meudt and Simpson 2006). However, the fact that there are many cosmopolitan species in Plantago and even small oceanic islands have a mixture of native and introduced species from the genus indicates that the plants are able to disperse over long distances fairly frequently. Within the Australasian taxa, species are commonly distributed across geographic barriers that often separate other plants, like the Cook Strait in New Zealand, which separates the North and South Islands, and Bass Strait, which separates Tasmania from Australia.

The three dispersal events from Australia reflect two independent dispersals to the alpine/sub-alpine region in New Zealand (and the subantarctic islands) and one to the lowlands, where the closest Australian relative is also from similar habitats (Fig. 3.3). One explanation for this pattern is that the New Zealand species may have evolved from a common ancestor that had already established in that bioclimatic zone (i.e., alpine to alpine, lowland to lowland), which may have increased the success of establishment in New Zealand. This has been suggested previously (e.g. Winkworth et al., 2002), albeit in the other direction. For example, it was suggested that Craspedia radiated from only one successful dispersal event because of establishment difficulties (Ford et al. 2007). Further, many New Zealand genera that contain mostly alpine species also contain lowland species, although patterns of habitat colonization are not clear (Buckley and Simon 2007). The lowland New Zealand species form a clade that is nested within an alpine clade, which suggests that alpine groups have subsequently dispersed to coastal regions (Fig. 3.3). In this study, we show that in the Australasian species, the alpine species appear to have one migration to lowland habitats, followed by an additional dispersal across the Tasman. More studies regarding the New Zealand alpine species are needed to determine patterns in habitat preferences. 
Multiple dispersals across the Tasman appear fitting for Plantago, which is widely distributed. However, dispersal mechanisms of the group are largely unknown. Many Plantago seeds produce mucilage when wet and it has been hypothesized that a method of dispersal is by sticking to oceanic birds (Rønsted et al. 2002). Another New Zealand plant group that has also undergone multiple dispersals is Lepidium (Mummenhoff et al. 2001), which also has mucilaginous seeds. Other Plantago species, such as $P$. lagopus, have hairs on their capsules, which have been shown to facilitate overland dispersal by sticking to the coat of migrating ungulates (Manzano and Malo 2006). Seeds may also be dispersed by wind or water but there is no evidence for this.

We have shown that Australasian Plantago have undergone long distance dispersal but we are unable to make inferences about the relationships between South American and Australasian species of Plantago due to a lack of South American material. However, ITS sequences for 13 South American Plantago species were obtained from GenBank. Inclusion of these sequences in phylogenetic analyses (data not shown here; see Chapter 4) still shows support for long distance dispersal throughout the Southern Hemisphere, i.e. South American, Australian and New Zealand species do not form monophyletic groups in the tree, and the Australian species are more closely related to the New Zealand species than they are to South American species. Thus, inferences made from this study remain valid.

\subsubsection{Incongruence of phylogenies from nuclear DNA and organellar DNA}

In this study, trees reconstructed from the different genomes yielded similar topologies but there were a few discrepancies. The Australian species P. muelleri and 
P. paradoxa and the New Zealand species of $P$. triandra and $P$. unibracteata appear to have conflicting evolutionary histories of nuclear and organellar genomes. While the four species form a clade in the $n d h F$-rpl32 tree and the tree of the concatenated dataset, they are interspersed between other Australasian species in the ITS tree. One explanation for this conflict may be hybridisation, which is not surprising because the group is relatively young. Although trans-Tasman hybridisation appears unlikely, it has been reported to occur in plants (Perrie and Brownsey 2005). The conflict may also be a result of very little sequence divergence in the ITS sequences, which does not resolve the placement of $P$. triandra and $P$. unibracteata in the tree. Further analysis of the ITS dataset suggests that lack of resolution may be the most likely explanation for the conflict (see Chapter four).

\subsubsection{Reduced rates of mtDNA in Australasian Plantago}

Finally, the elevated rates of mtDNA substitutions in Plantago that were reported by Cho et al. (2004) were not evident in the Australasian species. There was a long branch between close Plantago outgroups and ingroup Plantago but a short branch between Plantago and Veronica in the coxl marker. The opposite was found in the other two genomic markers. Any long branch is again reduced in the Australasian species, which may be a result of recent rapid radiations, a process not uncommon in endemic New Zealand groups (Wagstaff and Garnock-Jones 1998; Heenan et al. 2002; Murray et al. 2004) or a decrease in substitution rate, which has been found in other lineages of Plantago (Cho et al. 2004). The latter is more plausible, as there is no evidence of reduced substitution rates in ITS or $n d h F-r p l 32$ sequences in the Australasian species, which would be expected if the reduction in the coxl substitution rates was a result of recent rapid radiations of the Australasian species. 


\subsubsection{Summary and future directions}

In summary, this study has shown evidence for long distance dispersal between Australia and New Zealand for the native Australasian Plantago. This study revealed an uncommon pattern of three independent directional dispersals across the Tasman Sea from Australia to New Zealand. In all cases, the ancestors of the dispersed species appear to have been pre-adapted to the habitats they established in. It was shown through molecular dating that the node of the Australian clade is about 2.291 to 1.520 mya. Further studies are needed to clarify if there are any more trans-Tasman dispersals and if trans-Tasman hybridisation is possible, if the high rate of mtDNA evolution has slowed down in Plantago from other locations, and to determine the dispersal mechanism of this group. Lastly, the dataset could be expanded to include all known Southern Hemisphere species in order to reveal other Southern Hemisphere patterns and relationships. 


\title{
Chapter Four: Evolutionary patterns and species boundaries in New Zealand Plantago (Plantaginaceae) species using ITS
}

\begin{abstract}
Major geological and climatic changes in New Zealand have affected the evolution of plants and are linked to events such as recent speciation. Recent speciation in many New Zealand plant lineages may have given rise to large groups with high morphological variation, for which taxonomy is difficult. In this study, phylogenetic analyses were carried out for the Australasian species of Plantago (Plantaginaceae) using Internal Transcribed Spacer (ITS) regions from nuclear DNA to investigate evolutionary patterns and species boundaries. An ITS phylogeny suggests that the Plantago species are separated allopatrically corresponding to habitat type and altitude (e.g. coastal, lowland or alpine/subalpine). Sympatric separation may also have occurred in the past and is influenced by various factors including polyploidy and different flowering times. The phylogeny also revealed that the species boundaries of several New Zealand species, including P. spathulata, P. triandra, and classifications of $P$. obconica, $P$. triantha and $P$. aucklandica may need revision. Low sequence divergence but high morphological variation was found in this study and could be caused by various factors, including recent speciation, presence of species complexes, hybridisation, and/or interbreeding.
\end{abstract}




\subsection{Introduction}

\subsubsection{Evolution of New Zealand plant groups}

Since its separation from Gondwana, New Zealand has undergone major geological and climatic changes, which have affected the evolutionary history and distribution of its biota (McDowall 2008). The main large-scale climatic and geological events that may have had an impact on speciation patterns of groups with recent origins are: 1) Pleistocene glaciation cycles (Trewick and Morgan-Richards 2005; McDowall 2008) and 2) final uplift of the Southern Alps ca. 5mya (Cox and Findlay 1995; Batt et al. 2000; Haase et al. 2007). These events may have had a dramatic effect on speciation patterns by causing physical separation of populations or through the creation of new habitats, which allow for divergence of populations as adaptations to these new habitats take place. Over time, the separation of populations could have led to speciation. Cook Strait, which separates the North and South Islands, may also have been a barrier to gene exchange in the past, although there may have been land bridges connecting the North and South Islands during the Pliocene glacial cycles (Lewis et al. 1994). Other phylogeographic hypotheses leading to speciation include glacial refugia (Wright et al. 2000; Greaves et al. 2007), displacement along the alpine fault (Buckley and Simon 2007), or separation by distance. Sympatric speciation is possible as well; a common pattern in New Zealand plant groups is recurrent polyploidy (Connor 1985), which may lead to rapid speciation of polyploids (i.e. when they are sympatric with parental lineages). 
Molecular data have been used successfully to investigate patterns of evolution of New Zealand biota. For example, phylogenetic analyses using molecular data showed evidence that the Hebe sensu lato (Veronica) complex had two radiations: one coinciding with uplift of the Southern Alps and the other with Pleistocene glaciation cycles (Wagstaff and Garnock-Jones 1998). In addition, it has been found that many groups have dispersed from the South Island (S. I.) to the North Island (N. I.), and that lowland species often have a different origin from the alpine species (e.g. Lockhart et al. 2001).

Recent molecular studies found that many New Zealand plant groups show evidence of recent radiations. These events occurred either following long distance dispersal (Breitwieser et al. 1999; Winkworth et al. 1999; McGlone et al. 2001; Winkworth et al. 2002b; Sanmartín and Ronquist 2004), or are associated with physical changes such as uplift of mountain ranges and climate fluctuations (Raven 1973; Lockhart et al. 2001; Winkworth et al. 2002a). Due to recent or incomplete speciation, species boundaries in New Zealand plants may be unclear using morphological characters and this often results in taxonomic problems. Many New Zealand genera are large and have high morphological variation both within and among species, such as Myosotis (Winkworth et al. 1999) and multiple genera within Gnaphalieae (Smissen et al. 2004). However, most genera studied to date are also found to have little genetic variation in contrast to morphology (Winkworth et al. 1999; Heenan et al. 2002; Vijverberg et al. 2002; Winkworth et al. 2002a). 


\subsubsection{Taxonomy of New Zealand plant groups}

The increasing use of molecular data has also helped with the systematics of many New Zealand plant groups (e.g. Heenan et al. 2002; Glenny 2004; Perrie and Brownsey 2005; Ford et al. 2007). Molecular data led to the conclusion that Veronica (previously circumscribed to exclude the Southern Hemisphere Hebe complex) was paraphyletic (Albach and Chase 2001) and the genus was subsequently enlarged by addition of Hebe and its relatives (Garnock-Jones et al. 2007). Molecular data (along with karyological information) also revealed that two species of Crassula (C. hunua and $C$. ruamahanga) were actually a species complex with interspecific hybridisation and polyploidy and these were reduced to one species (de Lange et al. 2007). Additionally, molecular data have been shown in several studies to provide better resolution when morphology and molecular data are congruent (Winkworth et al. 2002a; Meudt and Simpson 2007).

\subsubsection{The genus Plantago}

The aim of this study was to reconstruct a molecular phylogeny for the genus Plantago (Plantaginaceae), focusing on species relationships between and delimitations within the Australasian species. Plantago is a large genus of windpollinated plants, with over 200 species distributed worldwide. The genus has three basic chromosome numbers ( $x=4,5$, and 6) (Rahn 1996; Dhar et al. 2006), and diploid chromosome numbers range from $2 n=8$ (P. ovata) to $2 n=96$ ( $P$. correae and $P$. "sylvester"). While extensive morphological variation can occur within each species because of the plasticity of characters in some species, at the same time there may be few morphological differences between some species (Rock 1920; Sykes in Webb et al. 1998). 
Phylogenetic relationships, species boundaries and evolutionary patterns among Australasian Plantago species in particular are not well understood. To date, one morphological and two molecular studies have reconstructed Plantago phylogeny with the inclusion of some Australasian species. The morphological phylogeny of all Plantago species was the first phylogenetic study of the genus and included most of the Australasian species (one New Zealand and four Australian species were not included) (Rahn 1996).

In the first study using genetic sequences, Rønsted et al. (2002) combined ITS (Internal Transcribed Spacer) and trnL-F sequences to reconstruct the phylogeny of 57 Plantago species (including $P$. spathulata and $P$. raoulii from New Zealand, and $P$. debilis from Australia/Tasmania). In the second molecular phylogenetic study, Hoggard et al. (2003) obtained ITS sequences for 23 Plantago species (including $P$. tasmanica, $P$. daltonii, $P$. euryphylla, $P$. hispida and $P$. paradoxa, which are endemic to Australia/Tasmania, and P. triandra from New Zealand). The latter focused on the relationships of Littorella, which was included as a subgenus within Plantago by Rahn (1996).

These molecular phylogenies conflict with the morphological phylogeny mainly in the circumscription of several subgenera, e.g. it was found that subg. Albicans was paraphyletic (Rønsted et al. 2002). Species of Littorella were found to be in a sister clade to a clade of all other Plantago species and it was subsequently suggested that Littorella be recognised at genus rank (Hoggard et al. 2003). The recent molecular 
Table 4.1. A comparison of previous taxonomic treatments of New Zealand Plantago. Shaded areas indicate species and subspecies accepted in the most recent Flora of New Zealand (Webb et al. 1988) and are also the classifications that are used in this study.

\begin{tabular}{|c|c|c|c|c|c|c|}
\hline Name & Type & $\begin{array}{l}\text { Hooker } \\
1864\end{array}$ & $\begin{array}{l}\text { Cheeseman } \\
1906\end{array}$ & $\begin{array}{l}\text { Cheeseman } \\
1925\end{array}$ & $\begin{array}{l}\text { Moore (in } \\
\text { Allan 1961) }\end{array}$ & $\begin{array}{l}\text { Sykes (in } \\
\text { Webb 1988) }\end{array}$ \\
\hline $\begin{array}{l}\text { Plantago aucklandica Hook.f. } \\
1844\end{array}$ & Auckland Islands (K) & aucklandica & aucklandica & aucklandica & aucklandica & aucklandica \\
\hline $\begin{array}{l}\text { P. triantha Spreng. } 1825, \equiv P . \\
\text { carnosa } \text { R.Br., non Lam., } \equiv P \text {. } \\
\text { subantarctica Cockayne } 1928 \\
\text { nom. illeg. (superfl. ) } \\
=(\equiv ?) \text { P. brownii Rapin (1827) }\end{array}$ & $\begin{array}{l}\text { (K/BM?) the name } \\
\text { should be based on } \\
\text { R.Br. specimens }\end{array}$ & $\begin{array}{l}\text { As brownii } \\
\text { Rapin }\end{array}$ & $\begin{array}{l}\text { As brownii } \\
\text { Rapin }\end{array}$ & $\begin{array}{l}\text { As brownii } \\
\text { Rapin }\end{array}$ & triantha & triantha \\
\hline P. triandra Bergg. 1877 & Kelly Range (Lund?) & - & triandra & triandra & triandra & $\begin{array}{l}\text { triandra } \\
\text { subsp. } \\
\text { triandra }\end{array}$ \\
\hline P. hamiltonii Kirk 1879 & Greymouth (WELT) & - & triandra & triandra & triandra & $\begin{array}{l}\text { triandra } \\
\text { subsp. } \\
\text { triandra }\end{array}$ \\
\hline $\begin{array}{l}\text { P. masoniae Cheesem. } 1921 \\
\text { (as masonae) }\end{array}$ & Manaia (AK) & - & - & $\begin{array}{l}\text { masoniae (as } \\
\text { masonae) }\end{array}$ & triandra & $\begin{array}{l}\text { triandra } \\
\text { subsp. } \\
\text { masoniae }\end{array}$ \\
\hline P. spathulata Hook.f. 1854 & $\begin{array}{l}\text { Pahawa (Pahaoa) (K; } \\
\text { iso WELT?) }\end{array}$ & spathulata & spathulata & spathulata & spathulata & $\begin{array}{l}\text { spathulata } \\
\text { subsp. } \\
\text { spathulata }\end{array}$ \\
\hline
\end{tabular}


Table 4.1. A comparison of previous taxonomic treatments of New Zealand Plantago. Shaded areas indicate species and subspecies accepted in the most recent Flora of New Zealand (Webb et al. 1988) and are also the classifications that are used in this study.

\begin{tabular}{|c|c|c|c|c|c|c|}
\hline Name & Type & $\begin{array}{l}\text { Hooker } \\
1864\end{array}$ & $\begin{array}{l}\text { Cheeseman } \\
1906\end{array}$ & $\begin{array}{l}\text { Cheeseman } \\
1925\end{array}$ & $\begin{array}{l}\text { Moore (in } \\
\text { Allan 1961) }\end{array}$ & $\begin{array}{l}\text { Sykes (in } \\
\text { Webb 1988) }\end{array}$ \\
\hline P. picta Colenso 1890 & $\begin{array}{l}\text { Tolaga Bay (WELT \& } \\
\text { K) }\end{array}$ & - & $\begin{array}{l}\text { In syn of } P \text {. } \\
\text { brownie }\end{array}$ & $\begin{array}{l}\text { In syn of } P \text {. } \\
\text { brownie }\end{array}$ & picta & $\begin{array}{l}\text { spathulata } \\
\text { subsp. picta }\end{array}$ \\
\hline P. raoulii Decne 1852 & Banks Pen. (P) & raoulii & raoulii & raoulii & raoulii & raoulii \\
\hline P. dasyphylla Colenso 1892 & Dannevirke (WELT) & - & raoulii & raoulii & raoulii & raoulii \\
\hline $\begin{array}{l}\text { P. novae-zelandiae Moore } \\
1961\end{array}$ & Mt Hikurangi (WELT) & - & $\begin{array}{l}P . \text { brownii } \\
\text { auctt. NZ non } \\
\text { Rapin }\end{array}$ & $\begin{array}{l}\text { P. brownii } \\
\text { auctt. NZ non } \\
\text { Rapin }\end{array}$ & $\begin{array}{l}\text { novae- } \\
\text { zelandiae }\end{array}$ & lanigera \\
\hline P. lanigera Hook.f. 1864 & $\begin{array}{l}\text { Otago Lake Distr., (K } \\
\text { \&WELT) }\end{array}$ & lanigera & lanigera & lanigera & lanigera & lanigera \\
\hline $\begin{array}{l}\text { P. lanigera var. petriei } \\
\text { Cheesem. } 1906\end{array}$ & Mt Kyeburn (AK) & - & $\begin{array}{l}\text { lanigera var. } \\
\text { petriei }\end{array}$ & $\begin{array}{l}\text { lanigera var. } \\
\text { petriei }\end{array}$ & lanigera & lanigera \\
\hline $\begin{array}{l}\text { P. unibracteata } \text { Rahn } 1996, \equiv \\
\text { P. uniflora Hook.f. non } \mathrm{L} . \equiv P \text {. } \\
\text { triandra var. uniflora } \\
\text { (Hook.f.) Pilger }\end{array}$ & Ruahine Mts (K) & $\begin{array}{l}\text { uniflora } \\
\text { Hook.f. }\end{array}$ & $\begin{array}{l}\text { uniflora } \\
\text { Hook.f. }\end{array}$ & $\begin{array}{l}\text { uniflora } \\
\text { Hook.f. }\end{array}$ & $\begin{array}{l}\text { uniflora } \\
\text { Hook.f. }\end{array}$ & $\begin{array}{l}\text { uniflora } \\
\text { Hook.f. }\end{array}$ \\
\hline P. obconica Sykes 1988 & (CHR) & - & - & - & - & obconica \\
\hline
\end{tabular}


phylogenies indicate that Australasian Plantago species cluster together and that $P$. stauntoni from Amsterdam \& St. Paul Islands is nested within the Australasian group (Rønsted et al. 2002; Hoggard et al. 2003). However, relationships among the Australasian species and the placement of $P$. stauntoni were either unsupported or unresolved. Little is known regarding the evolutionary history of Australasian species because few Australasian species were included in these molecular phylogenies.

\subsubsection{New Zealand Plantago}

In New Zealand, eight native species of Plantago were accepted in the most recent Flora (Sykes in Webb et al. 1998; Table 4.1) and one ( $P$. "sylvester") is an undescribed polyploid (Groves and Hair 1971). The chromosome number of $2 n=96$ reported by Groves and Hair (1971) was confirmed using one sample from $P$. "sylvester" populations obtained in this study. Twenty four species are native to Australia (Briggs 1992). All of the Australasian species are placed in subg. Plantago and mainly in sect. Oliganthos and sect. Mesembrynia; one species from the Auckland Islands (P. aucklandica) is placed in sect. Plantago (Rahn 1996).

Out of the eight native New Zealand species, Plantago lanigera, P. obconica, P. unibracteata, $P$. aucklandica and $P$ triandra subsp. triandra are found in the alpine/subalpine region, whereas $P$. triantha, $P$. triandra subsp. masoniae and $P$. spathulata subsp. picta are found in lowland coastal areas (although sea level is considered sub-alpine in the Auckland Islands where $P$. triantha is found). $P$. spathulata subsp. spathulata and P. raoulii are found in both lowland and subalpine areas from coastal regions to altitudes of ca. 1000 and 1500m, respectively (Sykes in Webb et al. 1988). 

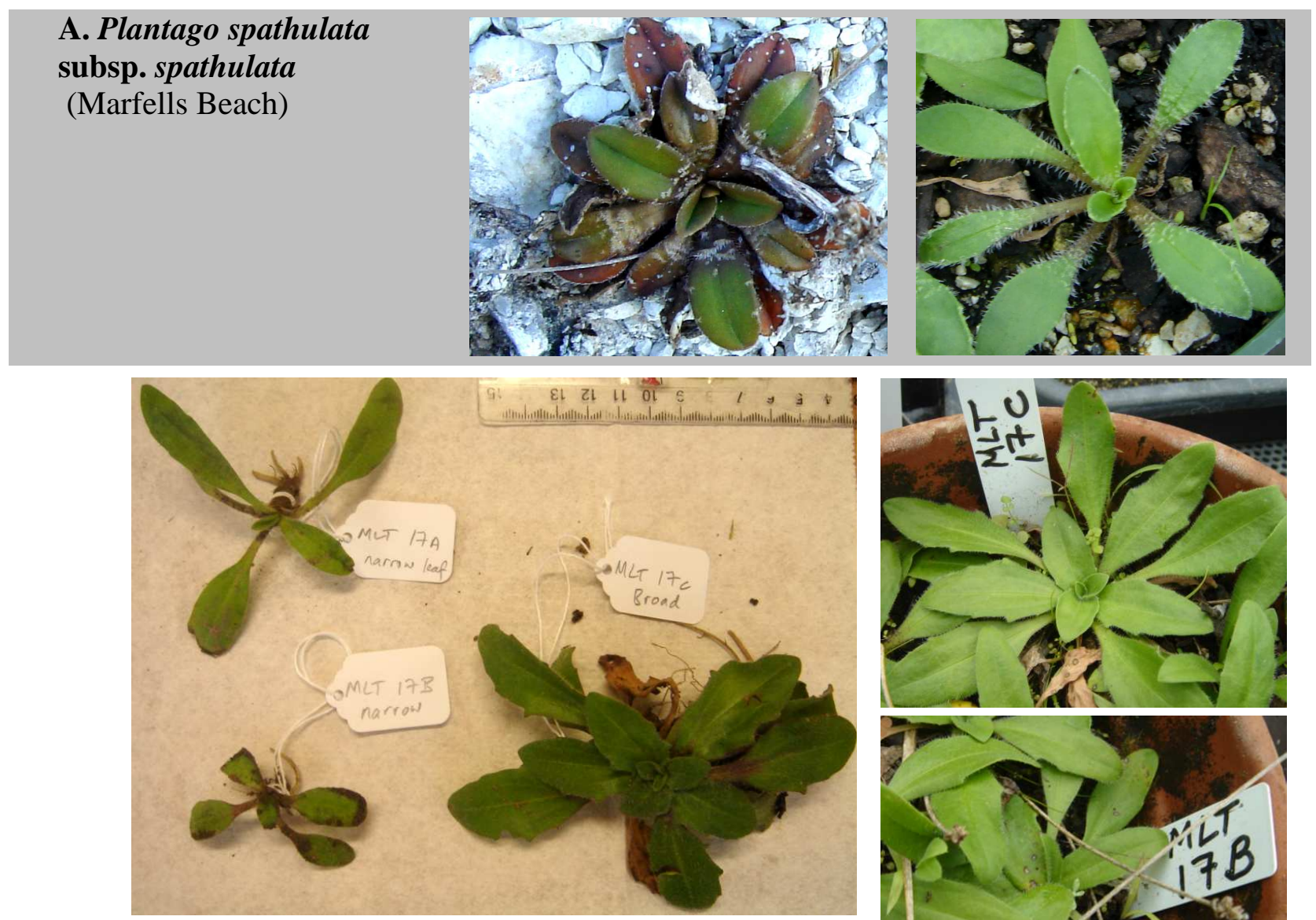

B. P. raoulii (Owhiro Bay)

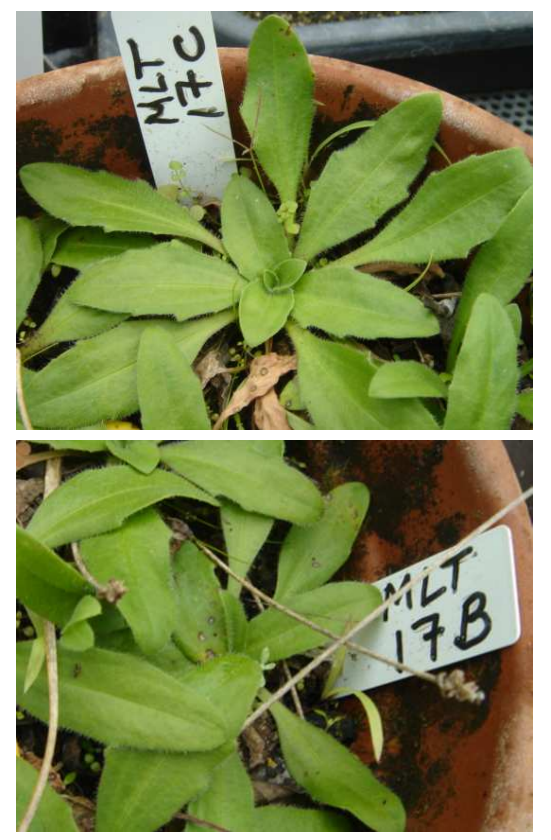

C. P. "sylvester" (Lake Sylvester)
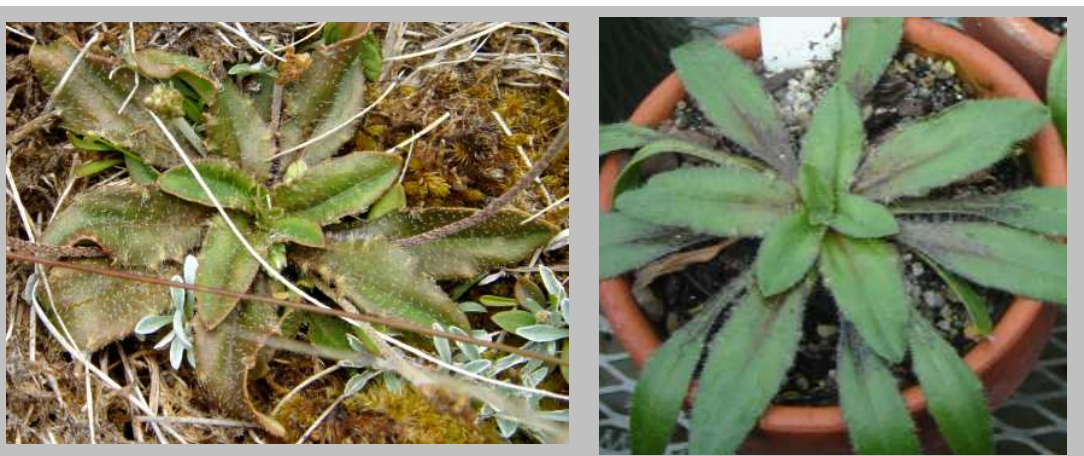

D. P. lanigera (Shotover Saddle)
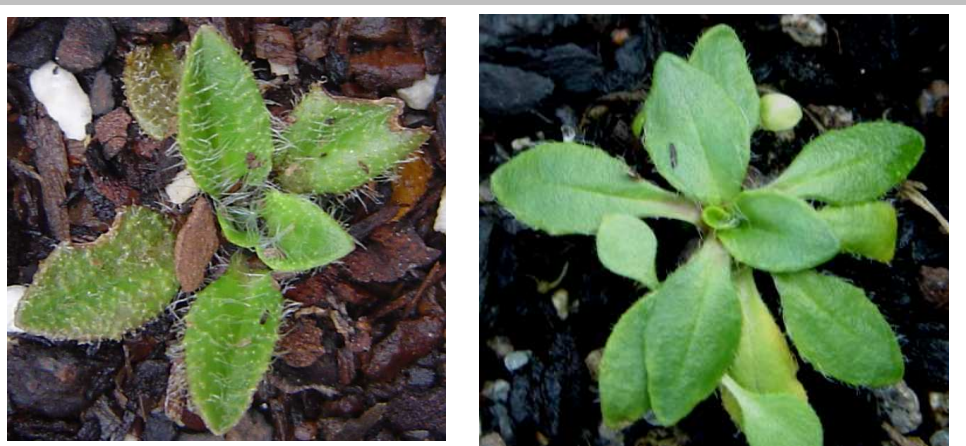

Figure 4.1. Morphological habits of cultivated samples of the New Zealand Plantago species, illustrating morphological plasticity of the plants. Figures on the left were photographed in February 2007, whereas the figures on the right were taken in cultivation in November 2007. 


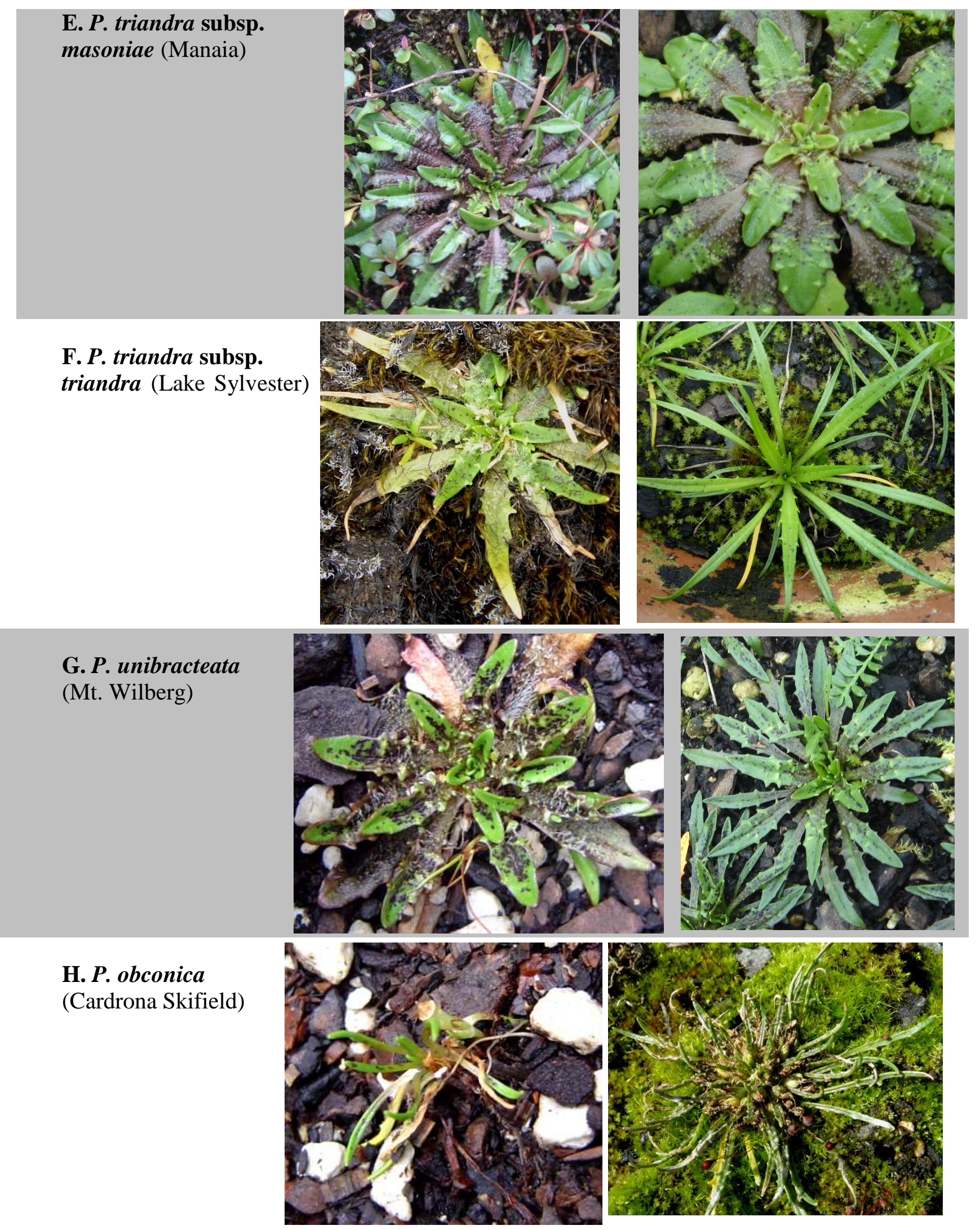

Figure 4.1. Morphological habits of cultivated samples of the New Zealand Plantago species, illustrating morphological plasticity of the plants. Figures on the left were photographed in February 2007, whereas the figures on the right were taken in cultivation in November 2007. 
Like all Plantago, morphological differences in the New Zealand species are not easily defined, resulting in problems with species delimitation and identification. Although Rahn (1996) reported that hair and seed morphology appeared to be the most useful characters for the genus, characters such as leaf size, shape, hairiness and teeth, scape length, and the number of flowers may vary within a population according to environmental factors (Sykes in Webb et al. 1988; see also Fig. 4.1). Taxonomic discrepancies are therefore common between previous Flora treatments (Table 4.1) and are used to represent hypotheses of species boundaries in this study using a molecular phylogenetic approach. Below, I discuss the taxonomy of the New Zealand Plantago species according to the order that they later appear in the ITS phylogeny and the specific hypotheses that will be tested in each case, including testing species and subspecies delimitations ( $P$. spathulata, $P$. raoulii, $P$. lanigera and $P$. triandra) and closest relatives ( $P$. "sylvester" and $P$. obconica $)$.

\section{Species and subspecies delimitations}

\section{Plantago spathulata}

Sykes (in Webb et al. 1988) included two subspecies under P. spathulata, subsp. spathulata (found on southern N. I. coasts, and both coasts and inland in the S. I.) and subsp. picta (endemic to the coastal Poverty Bay region and East Cape in Gisborne). These were previously treated as two species, $P$. spathulata and P. picta (Table 4.1). Separation of the two was based on morphological characters, such as a persistent taproot with no adventitious roots and scapes up to $7 \mathrm{~cm}$ long (P. picta), whereas $P$. spathulata only had adventitious roots and scapes of 3-12-(22) cm long. Sykes (in Webb et al. 1988) recognized these entities at the lower rank of subspecies because populations of the two were found close to one another geographically, and the 
characters used to distinguish the two species by Moore (in Allan 1961) were inconsistent due to plastic morphology within populations. Molecular data can be

used to test the hypothesis that these two are conspecific by reconstructing a population level phylogeny that includes representatives of both groups.

\section{Plantago raoulii}

$P$. raoulii has been noted to have two different forms, with one form widespread on both the North and South Islands, and the other common in Taranaki and around the Cook Strait (Sykes in Webb et al. 1988). The latter is described as having thicker leaves that are also wider and shorter. Both forms can be found in coastal regions and in altitudes of up to $1500 \mathrm{~m}$. The hypothesis of whether the narrow-leaved and broadleaved individuals can be separated based on DNA sequence data is tested in this group using a population level phylogeny for both forms.

\section{Plantago lanigera}

P. lanigera as circumscribed by Sykes (in Webb et al. 1988) was previously considered to be two distinct species (e.g. Moore in Allan 1961 treated the group as as P. lanigera and P. novae-zelandiae, see Table 4.1). Various morphological characters were used to differentiate between the two forms, such as crowded long hairs, rhomboid shaped lamina, and bracts $<2 \mathrm{~mm}$ long in $P$. lanigera vs. sparse long hairs, elliptic lamina, and bracts $2.5-3 \mathrm{~mm}$ long in P. novae-zelandiae. Sykes (in Webb et al. 1988) recognized only one species ( $P$. lanigera) because these morphological characters were inconsistent and the ranges of populations of the two forms overlap. It was found in a separate study that plants identified as P. lanigera had a chromosome number of $2 n=12$, whereas plants identified as $P$. novae-zelandiae exhibit both $2 n=$ 
12 and $2 n=24$ (Spence and Sykes 1989). While the means of morphological characters such as seed size, shape and weight, ovule numbers, number of leaves per plant, number of capsules per inflorescence, number of seeds per capsule, and inflorescence height were significantly different between the two forms, the measurement ranges of most of these characters overlap (and therefore cannot conclusively be used to separate one species from the other); only seed weight and size were found to be useful in this respect (Spence and Sykes 1989). The hypothesis that these two forms (both found in alpine regions) are conspecific is tested using a population level phylogeny that includes multiple representatives of both forms.

\section{Plantago triandra}

Two subspecies of $P$. triandra were recognized by Sykes (in Webb et al. 1988). Subsp. masoniae (found in coastal areas) is described as having fleshier leaves with smaller sessile flowers compared to subsp. triandra (which are mostly found on inland mountains). Only one species (P. triandra) was recognised by Moore (in Allan 1961) because morphological characters used to distinguish between the coastal and inland forms were regarded as inconsistent and also very plastic. P. triandra has also been previously treated as three species (P. triandra, P. masoniae and P. hamiltonii) based on morphology, but $P$. hamiltonii sensu lato was regarded as synonymous with P. triandra subsp. triandra in the most recent Flora (Sykes in Webb et al. 1988). Molecular data will be used to test the hypothesis that two different forms exist in $P$. triandra using a population level molecular phylogeny to evaluate if sequence divergence is present between subsp. triandra and subsp. masoniae. 
$\underline{\text { Species relationships }}$

Plantago "sylvester"

Moore (in Allan 1961) and Sykes (in Webb et al. 1988) both mention several plants in northwest Nelson with several different morphological characters in the description for $P$. raoulii. Based on morphology, Moore included the plants in $P$. spathulata, whereas Sykes grouped them with $P$. raoulii. Chromosome counts made for the plants (given the tag name $P$. "sylvester") suggest that they are 16-ploids with a chromosome number of $2 n=96$, whereas $P$. raoulii and $P$. spathulata have a chromosome number of $2 n=48$ (Groves and Hair 1971). Thus, using a molecular phylogeny, the relationship of $P$. "sylvester" is tested (i.e. is it more closely related to $P$. raoulii or $P$. spathulata?)

\section{Plantago obconica}

P. obconica is a recently described species found in alpine regions. It is suggested to be closely related to $P$. triandra subsp. triandra because of morphological similarities such as fine subulate leaves and a calyx that is shorter than the capsule (Sykes 1988). The species has not previously been included in any phylogenetic studies. The hypothesis that $P$. obconica is closely related to $P$. triandra is tested by examining relationships in a species level phylogeny.

\subsubsection{Study aims}

In this chapter, an ITS phylogeny of Australasian Plantago species, integrated with other Plantago species for which ITS sequences are readily available, is presented. 
Table 4.2. Details of Plantago samples that were included in the ITS phylogeny. Samples that were collected and sequenced (DNA) for this study are indicated in bold, with details of collection location.

\begin{tabular}{|c|c|c|c|c|c|}
\hline $\begin{array}{l}\text { Ref. in } \\
\text { Rahn } \\
\text { (1996) }\end{array}$ & Species & $\begin{array}{l}\text { Indigenous } \\
\text { distribution }\end{array}$ & Collection location & $\begin{array}{c}\text { Accession } \\
\text { number }\end{array}$ & Reference or voucher \\
\hline 155 & Plantago afra & S Africa & & AY101892 & Rønsted et al. 2002 \\
\hline 184 & P. albicans & Mediterranean & & AY101905 & Rønsted et al. 2002 \\
\hline 75 & P. alpestris & Australia & Kosciuszko National Park, NSW, AUS & & $\begin{array}{l}\text { NSW742962 (BGB9748) / } \\
\text { NSW742963 (BGB9749) }\end{array}$ \\
\hline 132 & P. alpine & Europe & & AY101877 & Jensen et al. 1996 \\
\hline 175 & P. amplexicaulis & Mediterranean & & AY101900 & Rønsted et al. 2002 \\
\hline 146 & P. arborescens & Macaronesia & & $\begin{array}{l}\text { AY101886 / } \\
\text { AJ548954 }\end{array}$ & $\begin{array}{l}\text { Rønsted et al. } 2000 \text { / } \\
\text { Hoggard et al. } 2003\end{array}$ \\
\hline 154 & P. arenaria & Mediterranean & & $\begin{array}{l}\text { AY101891 / } \\
\text { AY692082 }\end{array}$ & $\begin{array}{l}\text { Rønsted et al. } 2002 \text { / } \\
\text { Dhar et al. } 2006\end{array}$ \\
\hline 210 & P. aristata & E USA & & $\begin{array}{l}\text { AY101911 / } \\
\text { AJ548983 }\end{array}$ & $\begin{array}{l}\text { Rønsted et al. } 2002 \text { / } \\
\text { Hoggard et al. } 2003\end{array}$ \\
\hline 29 & P. asiatica & S \& E Asia & & $\begin{array}{l}\text { AY101862 / } \\
\text { AJ548977 }\end{array}$ & $\begin{array}{l}\text { Rønsted et al. } 2002 \text { / } \\
\text { Hoggard et al. } 2003\end{array}$ \\
\hline 166 & P. atrata & Europe, W Asia & & AY101895 & Rønsted et al. 2002 \\
\hline 15 & P. aucklandica & Auckland Islands & $\begin{array}{l}\text { Auckland Islands (cult. in Otari-Wilton Bush, } \\
\text { Wellington, NZ) }\end{array}$ & & Otari cult. (2003.2037) \\
\hline 108 & P. australis & America & $\begin{array}{l}\text { Hunua Ranges, Auckland, NZ } \\
\text { Waverly, NZ (cult. population) }\end{array}$ & & $\begin{array}{l}\text { WELTU20181 (MLT019 \& PGJ) } \\
\text { WELTU20182 (Colin Ogle s. n.) }\end{array}$ \\
\hline & & & & $\begin{array}{l}\text { AY101874 / } \\
\text { AF313038 / }\end{array}$ & $\begin{array}{l}\text { Rønsted et al. } 2000 \text { / } \\
\text { Albach \& Chase } 2001\end{array}$ \\
\hline 178 & P. bellardii & Mediterranean & & AY101902 & Rønsted et al. 2000 \\
\hline 52 & P. camtschatica & E Asia & & AJ548971 & Hoggard et al. 2003 \\
\hline 190 & P. ciliata & Mediterranean & & AY101906 & Rønsted et al. 2002 \\
\hline 67 & P. cladarophylla & Australia & Barrington Tops National Park, NSW, AUS & & NSW744803 (J. R. Hosking 2682) \\
\hline 23 & P. cornuti & S Europe & & AY101859 & Rønsted et al. 2002 \\
\hline 140 & P. coronopus & $\begin{array}{l}\text { Mediterranean, } \\
\text { Europe }\end{array}$ & Island Bay, Wellington, NZ & & WELTU20183 (PGJ2549) \\
\hline
\end{tabular}


Table 4.2. Details of Plantago samples that were included in the ITS phylogeny. Samples that were collected and sequenced (DNA) for this study are indicated in bold, with details of collection location.

\begin{tabular}{|c|c|c|c|c|c|}
\hline $\begin{array}{l}\text { Ref. in } \\
\text { Rahn } \\
\text { (1996) }\end{array}$ & Species & $\begin{array}{l}\text { Indigenous } \\
\text { distribution }\end{array}$ & Collection location & $\begin{array}{c}\text { Accession } \\
\text { number }\end{array}$ & Reference or voucher \\
\hline 140 & P. coronopus & $\begin{array}{l}\text { Mediterranean, } \\
\text { Europe }\end{array}$ & Island Bay, Wellington, NZ & $\begin{array}{l}\text { AY101882 / } \\
\text { AJ548987 }\end{array}$ & $\begin{array}{l}\text { Rønsted } \text { et al. } 2002 \text { / } \\
\text { Hoggard } \text { et al. } 2003\end{array}$ \\
\hline 137 & P. crassifolia & Mediterranean, S Africa & & AY101881 & Rønsted et al. 2002 \\
\hline 176 & P. cretica & E Mediterranean & & AY101901 & Rønsted et al. 2002 \\
\hline 57 & P. cunninghamii & Australia & Brigalow Park Nature Reserve, NSW, AUS & & NSW744804 (J. R. Hosking 2752) \\
\hline 74 & P. daltonii & Tasmania & St. Clair National Park, AUS, Tasmania & AJ548968 & $\begin{array}{l}\text { NSW743874 (BGB9782) } \\
\text { Hoggard } \text { et al. } 2003\end{array}$ \\
\hline 60 & P. debilis & Australia & Barrenjoey Headland, NSW, AUS & AY101868 & $\begin{array}{l}\text { NSW } 742894 \text { (BGB9738) } \\
\text { Rønsted } \text { et al. } 2002\end{array}$ \\
\hline 46 & P. elongata & W USA & & AJ548974 & Hoggard et al. 2003 \\
\hline 207 & P. erecta & W USA & & $\begin{array}{l}\text { AY101909 / } \\
\text { AJ548982 }\end{array}$ & $\begin{array}{l}\text { Rønsted } \text { et al. } 2002 \text { / } \\
\text { Hoggard } \text { et al. } 2003\end{array}$ \\
\hline 72 & P. euryphylla & Australia & Kosciuszko National Park, NSW, AUS & AJ548966 & $\begin{array}{l}\text { NSW743824 (BGB9760) / } \\
\text { NSW743822 }(\text { BGB9758) / } \\
\text { NSW742956 }(\text { BGB9743) / } \\
\text { NSW (BGB9741) } \\
\text { Hoggard et al. } 2003\end{array}$ \\
\hline 148 & P. famarae & Macaronesia & & AY101888 & Rønsted et al. 2002 \\
\hline 129 & P. glacialis & Australia & Kosciuszko National Park, NSW, AUS & & $\begin{array}{l}\text { NSW742960 (BGB9746) / } \\
\text { NSW743813 (BGB9753) }\end{array}$ \\
\hline 45 & P. heterophylla & SE USA & & AJ548975 & Hoggard et al. 2003 \\
\hline 77 & P. hispida & Tasmania, E Australia & & AJ548967 & Hoggard et al. 2003 \\
\hline 212 & P. hookeriana & S USA & & AY101913 & Rønsted et al. 2002 \\
\hline 169 & P. lagopus & Mediterranean & & $\begin{array}{l}\text { AY101897 / } \\
\text { AY692078 }\end{array}$ & $\begin{array}{l}\text { Rønsted et al. } 2002 \text { / } \\
\text { Dhar et al. } 2006\end{array}$ \\
\hline 170 & P. lanceolata & cosmopolitan & Karori, Wellington, NZ & $\begin{array}{l}\text { AY101898 / } \\
\text { AF313036 / } \\
\text { AJ548984 / } \\
\text { AY692077 }\end{array}$ & $\begin{array}{l}\text { WELTU20184 (PGJ2551) } \\
\text { Albach \& Chase } 2001 \text { / } \\
\text { Rønsted } \text { et al. } 2002 \text { / } \\
\text { Hoggard } \text { et al. } 2003 \text { / } \\
\text { Dhar } \text { et al. } 2006\end{array}$ \\
\hline
\end{tabular}


Table 4.2. Details of Plantago samples that were included in the ITS phylogeny. Samples that were collected and sequenced (DNA) for this study are indicated in bold, with details of collection location.

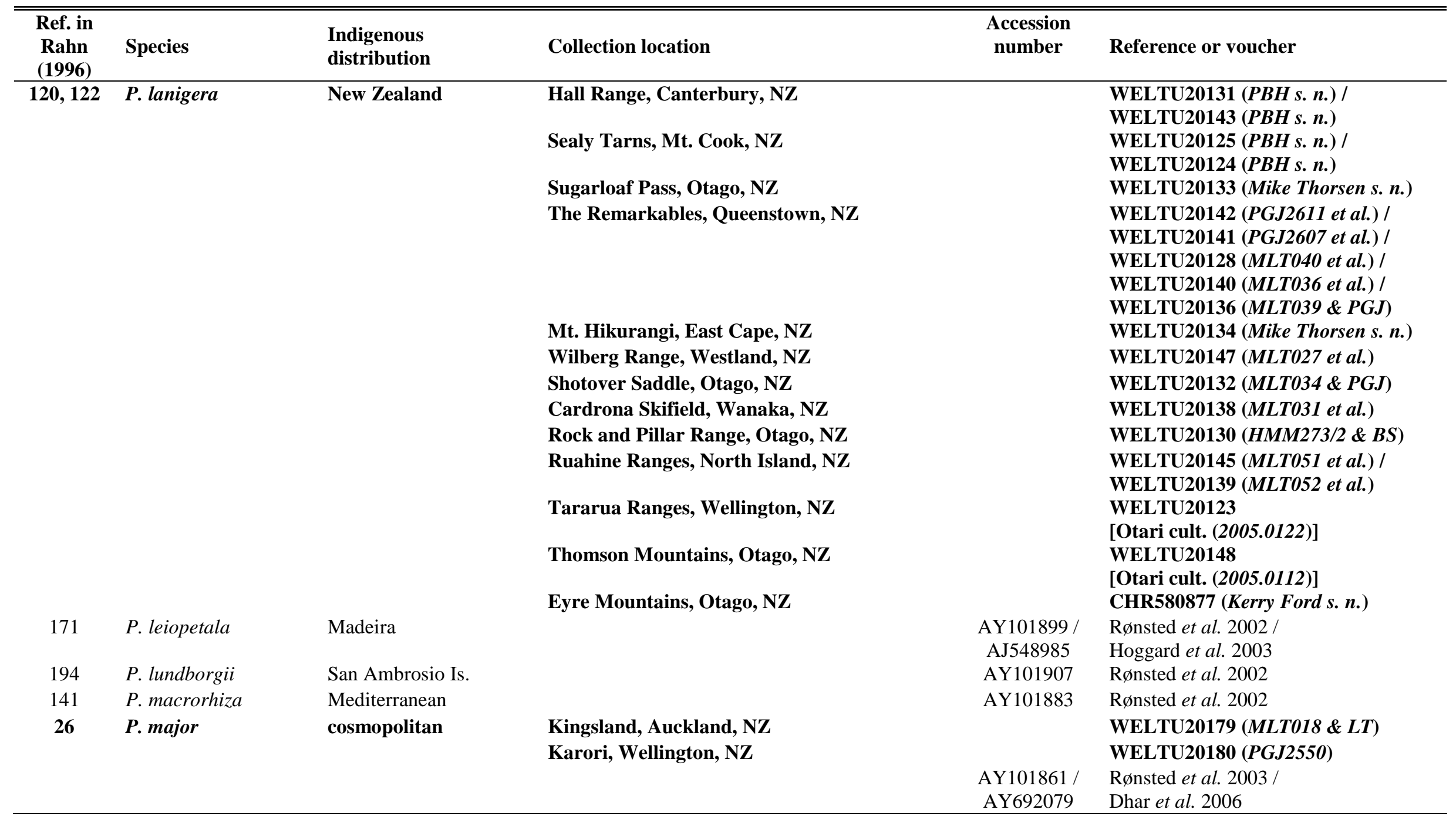


Table 4.2. Details of Plantago samples that were included in the ITS phylogeny. Samples that were collected and sequenced (DNA) for this study are indicated in bold, with details of collection location.

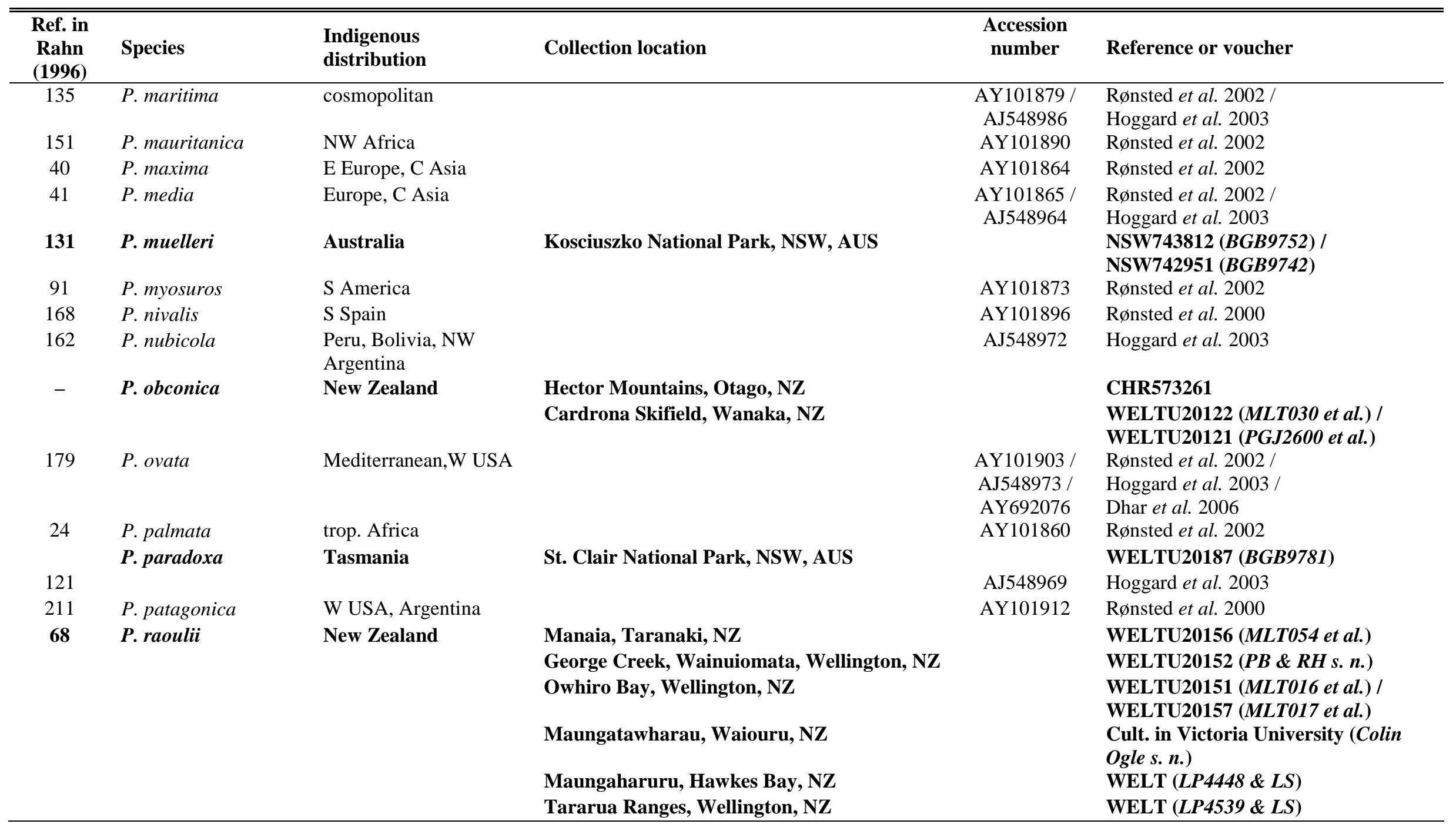


Table 4.2. Details of Plantago samples that were included in the ITS phylogeny. Samples that were collected and sequenced (DNA) for this study are indicated in bold, with details of collection location.

\begin{tabular}{|c|c|c|c|c|c|}
\hline $\begin{array}{l}\text { Ref. in } \\
\text { Rahn } \\
(1996)\end{array}$ & Species & $\begin{array}{l}\text { Indigenous } \\
\text { distribution }\end{array}$ & Collection location & $\begin{array}{c}\text { Accession } \\
\text { number }\end{array}$ & Reference or voucher \\
\hline 68 & P. raoulii & New Zealand & $\begin{array}{l}\text { Cape Palliser, Wairarapa, Wellington, NZ } \\
\text { Lake Sarah, Cass, NZ }\end{array}$ & & $\begin{array}{l}\text { WELT }(L P 4996 \& L S) \\
\text { WELTU20153 (PGJ2559) }\end{array}$ \\
\hline 22 & P. reniformis & SE Europe & & $\begin{array}{l}\text { AY101858 / } \\
\text { AJ548978 }\end{array}$ & $\begin{array}{l}\text { Rønsted et al. } 2002 \text { / } \\
\text { Hoggard } \text { et al. } 2003\end{array}$ \\
\hline 94 & P. rhodosperma & S USA, N Mexico & & $\begin{array}{l}\text { AJ548976 / } \\
\text { AY692081 }\end{array}$ & $\begin{array}{l}\text { Hoggard et al. } 2003 \text { / } \\
\text { Dhar } \text { et al. } 2006\end{array}$ \\
\hline 118 & P. rigida & Andes & & $\begin{array}{l}\text { AY101876 / } \\
\text { AF313037 / } \\
\text { DQ006026 }\end{array}$ & $\begin{array}{l}\text { Rønsted et al. } 2002 \text { / } \\
\text { Albach \& Chase } 2001 \text { / } \\
\text { Kress et al. } 2005\end{array}$ \\
\hline 35 & P. rugelii & E N America & & $\begin{array}{l}\text { AY101863 / } \\
\text { AY692080 }\end{array}$ & $\begin{array}{l}\text { Rønsted et al. } 2002 \text { / } \\
\text { Dhar } \text { et al. } 2006\end{array}$ \\
\hline 160 & P. sarcophylla & E Mediterranean & & AY101893 & Rønsted et al. 2002 \\
\hline 149 & P. sempervirens & SW Europe & & AY101889 & Rønsted et al. 2002 \\
\hline 200 & P. sericea & Andes & & AY101910 & Rønsted et al. 2003 \\
\hline \multirow[t]{2}{*}{136} & P. serraria & Mediterranean & & AY101880 & Rønsted et al. 2002 \\
\hline & $P$. sp. & $?$ & Pukerua Bay, Wellington, NZ & & WELTU20178 (PGJ2566 \& MLT) \\
\hline 20 & P. sparsiflora & SE USA & & AJ548979 & Hoggard et al. 2003 \\
\hline 56 & $\begin{array}{l}\text { P. spathulata subsp. } \\
\text { picta }\end{array}$ & New Zealand & East Cape, Gisborne, NZ & & CHR439486 \\
\hline \multirow[t]{3}{*}{76} & $\begin{array}{l}\text { P. spathulata subsp. } \\
\text { spathulata }\end{array}$ & New Zealand & Cass, NZ & & WELTU20118 (PGJ2557) \\
\hline & & & Cape Palliser, Wairarapa, Wellington, NZ & & $\begin{array}{l}\text { WELTU20120 (PGJ2567 \& MLT) } / \\
\text { WELTU20119 (PGJ2568\& MLT) }\end{array}$ \\
\hline & & & Marfells Beach, Marlborough, NZ & & WELTU20117 (PGJ2629 \& MLT) \\
\hline 161 & P. squarrosa & E Mediterranean & & AY101894 & Rønsted et al. 2002 \\
\hline 78 & P. stauntoni & $\begin{array}{l}\text { Amsterdam \& St. Paul } \\
\text { Is. }\end{array}$ & & AY 101870 & Rønsted et al. 2000 \\
\hline 182 & P. stocksii & W Asia & & AY101904 & Rønsted et al. 2002 \\
\hline 142 & P. subspathulata & Madeira & & AY101884 & Rønsted et al. 2002 \\
\hline 133 & P. subulata & Mediterranean & & AY101878 & Rønsted et al. 2000 \\
\hline
\end{tabular}


Table 4.2. Details of Plantago samples that were included in the ITS phylogeny. Samples that were collected and sequenced (DNA) for this study are indicated in bold, with details of collection location.

\begin{tabular}{|c|c|c|c|c|c|}
\hline $\begin{array}{l}\text { Ref. in } \\
\text { Rahn } \\
(1996)\end{array}$ & Species & $\begin{array}{l}\text { Indigenous } \\
\text { distribution }\end{array}$ & Collection location & $\begin{array}{c}\text { Accession } \\
\text { number }\end{array}$ & Reference or voucher \\
\hline \multirow[t]{2}{*}{-} & P. "sylvester" & New Zealand & Lake Sylvester, Nelson, NZ & & WELTU20150 (MLT022) \\
\hline & & & & & WELTU20149 (MLTO23) \\
\hline \multirow[t]{2}{*}{205} & P. tandilensis & E Argentina & & AY101908 & Rønsted et al. 2002 \\
\hline & P. tasmanica & Tasmania & St. Clair National Park, NSW, AUS & & NSW743928 (BGB9780) \\
\hline 73 & & & & AJ548970 & Hoggard et al. 2003 \\
\hline 43 & P. tenuiflora & E Europe, C Asia & & AY101866 & Rønsted et al. 2002 \\
\hline 84 & P. tomentosa & S America & & AY101872 & Rønsted et al. 2002 \\
\hline \multirow[t]{6}{*}{124} & $\begin{array}{l}\text { P. triandra subsp. } \\
\text { triandra }\end{array}$ & New Zealand & Kettlehole Tarn, Cass, NZ & & WELTU20158 (PGJ2558) \\
\hline & & & St. Arnaud, Nelson, NZ & & WELTU20162 (MLTO25 \& PGJ) \\
\hline & & & Lake Sylvester, Nelson, NZ & & WELTU20163 (MLT021 et al.) \\
\hline & & & Harihari, Westland, NZ & & WELTU20164 (MLT029 et al.) \\
\hline & & & $\begin{array}{l}\text { Waipapa River, Northland, NZ (cult. in } \\
\text { Otari-Wilton Bush, Wellington, NZ) }\end{array}$ & & $\begin{array}{l}\text { WELTU20165 } \\
\text { [Otari cult. }(1005.0115)]\end{array}$ \\
\hline & & & & AJ548965 & Hoggard et al. 2003 \\
\hline \multirow[t]{2}{*}{-} & $\begin{array}{l}P . \text { triandra subsp. } \\
\text { masoniae }\end{array}$ & New Zealand & Paturau Coast, Nelson, NZ & & WELTU20160 (PJL s. n.) \\
\hline & & & Manaia, Taranaki, NZ & & WELTU20167 (MLT055 et al.) \\
\hline 109 & P. triantha & $\begin{array}{l}\text { Tasmania, } \\
\text { Subantarctic Islands }\end{array}$ & Enderby Island, Auckland Islands & & WELTU20177 (VT55) \\
\hline 81 & P. trinitatis & Ilha Trinidade & & AY101871 & Rønsted et al. 2002 \\
\hline \multirow[t]{6}{*}{119} & P. unibracteata & New Zealand & Cardrona Skifield, Wanaka, NZ & & WELTU20171 (PGJ2603 \& MLT) \\
\hline & & & Wilberg Range, Westland, NZ & & $\begin{array}{l}\text { WELTU20160 (PGJ2599 et al.) / } \\
\text { WELTU20172 (MLT028 et al.) }\end{array}$ \\
\hline & & & Lake Sylvester, Nelson, NZ & & WELTU20175 (MLT024 \& PGJ) \\
\hline & & & Rainbow Skifield, Nelson, NZ & & WELTU20174 (MLT026 \& PGJ) \\
\hline & & & The Remarkables, Queenstown, NZ & & WELTU20176 (MLT038 \& PGJ) \\
\hline & & & Ruapehu Skifield, Mt. Ruapehu, NZ & & WELTU20173 (MLT053 \& PGJ) \\
\hline 114 & P. uniglumis & S America & & AY101875 & Rønsted et al. 2002 \\
\hline
\end{tabular}


Table 4.2. Details of Plantago samples that were included in the ITS phylogeny. Samples that were collected and sequenced (DNA) for this study are indicated in bold, with details of collection location.

\begin{tabular}{|c|c|c|c|c|c|}
\hline $\begin{array}{l}\text { Ref. in } \\
\text { Rahn } \\
\text { (1996) }\end{array}$ & Species & $\begin{array}{l}\text { Indigenous } \\
\text { distribution }\end{array}$ & Collection location & $\begin{array}{c}\text { Accession } \\
\text { number }\end{array}$ & Reference or voucher \\
\hline 65 & P. varia & Australia & Kosciuszko National Park, Australia & & $\begin{array}{l}\text { NSW } 743869(B G B 9766) / \\
\text { NSW743869 }(B G B 9767)\end{array}$ \\
\hline 147 & P. webbii & Macaronesia & & AY101887 & Rønsted et al. 2002 \\
\hline 143 & Litorella uniflora & Europe & & $\begin{array}{l}\text { AJ548962 / } \\
\text { AJ548960 / } \\
\text { AJ548963 / } \\
\text { AJ548961 / } \\
\text { AF515218 }\end{array}$ & $\begin{array}{l}\text { Hoggard et al. } 2003 \text { / } \\
\text { Hoggard et al. } 2003 \text { / } \\
\text { Hoggard et al. } 2003 \text { / } \\
\text { Hoggard et al. } 2003 \text { / } \\
\text { Albach et al. } 2004 \text { / }\end{array}$ \\
\hline 144 & Litorella americana & North America & & $\begin{array}{c}\text { AJ548956 / } \\
\text { AJ548958 / } \\
\text { AJ548957 / } \\
\text { AJ548955 }\end{array}$ & $\begin{array}{l}\text { Hoggard et al. } 2003 \text { / } \\
\text { Hoggard et al. } 2003 \text { / } \\
\text { Hoggard et al. } 2003 \text { / } \\
\text { Hoggard et al. } 2003\end{array}$ \\
\hline 145 & Litorella australis & South America & & AJ548959 & Hoggard et al. 2003 \\
\hline- & $\begin{array}{l}\text { Aragoa } \\
\text { corrugatifolia }\end{array}$ & Colombia & & AJ548980 & Hoggard et al. 2004 \\
\hline - & Aragoa cupressina & Northern Andes & & AJ459402 & Bello et al. 2002 \\
\hline _ & Veronica hookeriana & New Zealand & Whanahuia Range, Ruahine Mts, NZ & & WELTU (PGJ2458) \\
\hline - & $\begin{array}{l}\text { Veronica } \\
\text { salicornioides }\end{array}$ & New Zealand & Jacks Pass, Hanmer, Canterbury, NZ & & CHR512475 \\
\hline
\end{tabular}

Collectors: $B G B=$ Barbara G. Briggs, $H M M=$ Heidi Meudt, $L P=$ Leon Perrie, $L S=$ Lara Shepherd, $L T=$ Leah Tooman, $M L T=$ Mei-Lin Tay, $P B H=$ Peter Heenan, $P G J=$ Phil Garnock-Jones, $P B=$ Peter Beveridge, $P J L=$ Peter J. Lockhart, $R L=$ Rodney Lewington and $V T=$ Vanessa Thorn. Herbarium vouchers: CHR $=$ Allan Herbarium, Landcare Research, Christchurch, New Zealand; NSW = National Herbarium of New South Wales, Australia; WELT = Herbarium of Museum of New Zealand, Te Papa Tongarewa, Wellington, New Zealand; and WELTU = H. D. Gordon Herbarium in Victoria University of Wellington, New Zealand. Samples in bold are new samples collected and sequenced for this study.

Note: Genbank accession numbers will be inserted into the table at before publication of papers. 


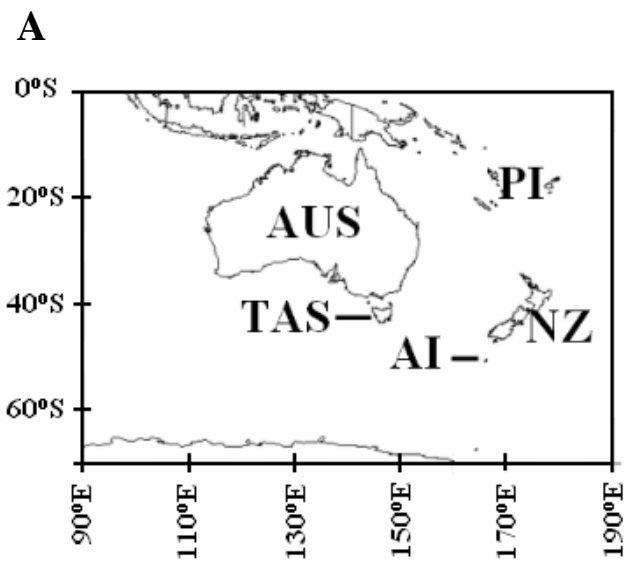

C

- P. raoulii (C/S)
$\bullet$ P. "sylvester"

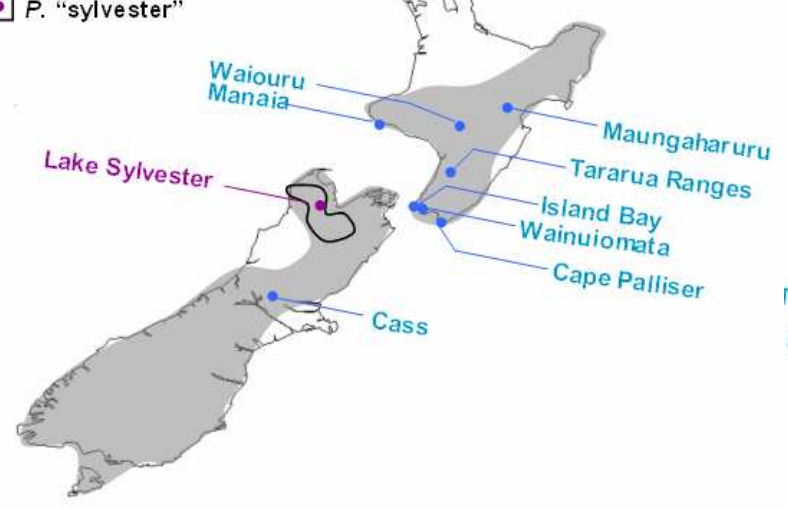

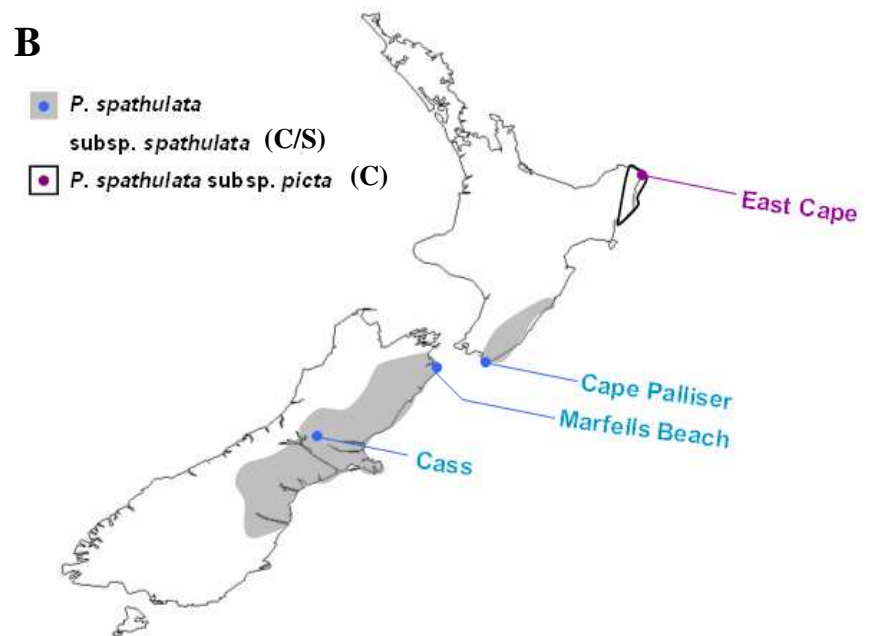

B

subsp. spathulata $(\mathrm{C} / \mathrm{S})$

P. spathulata subsp. picta (C)

\&

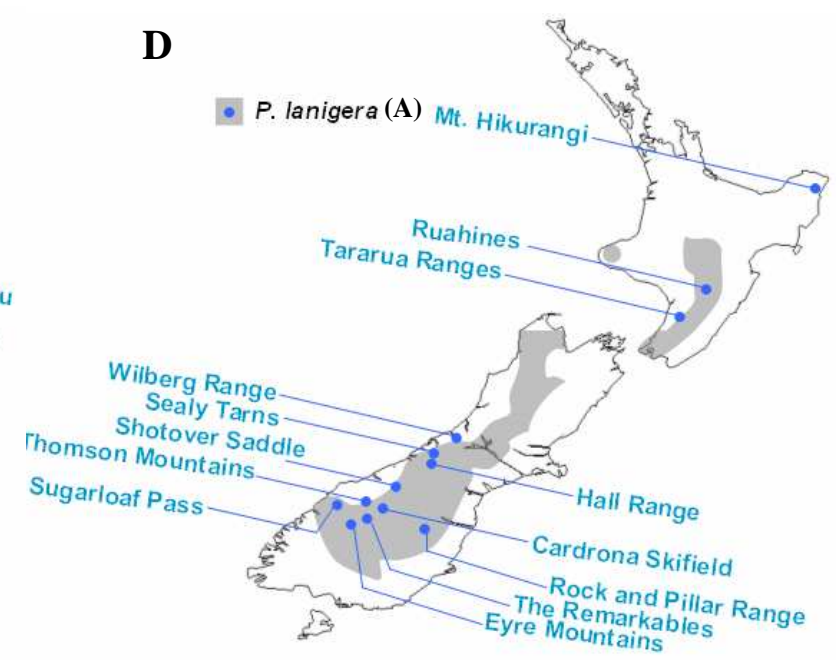

\&

Figure 4.2: Distributions of New Zealand Plantago species based on collection of previous herbarium specimens (from Allan Herbarium, Landcare Research, Christchurch, New Zealand) and locations of samples collected for this study. A: The Australasian region $(\mathrm{AI}=$ Auckland Islands, $\mathrm{AUS}=$ Australia, $\mathrm{NZ}=$ New Zealand, $\mathrm{PI}$ $=$ Pacific Islands, and TAS $=$ Tasmania); B: P. spathulata $\mathrm{C}:$ P. raoulii and $P$. “sylvester"; D: P. lanigera (A = alpine/subalpine habitats; $\mathrm{C}=$ coastal; $\mathrm{C} / \mathrm{S}=$ coastal to altitudes of $1000-1500 \mathrm{~m})$. 
$\mathbf{E}$

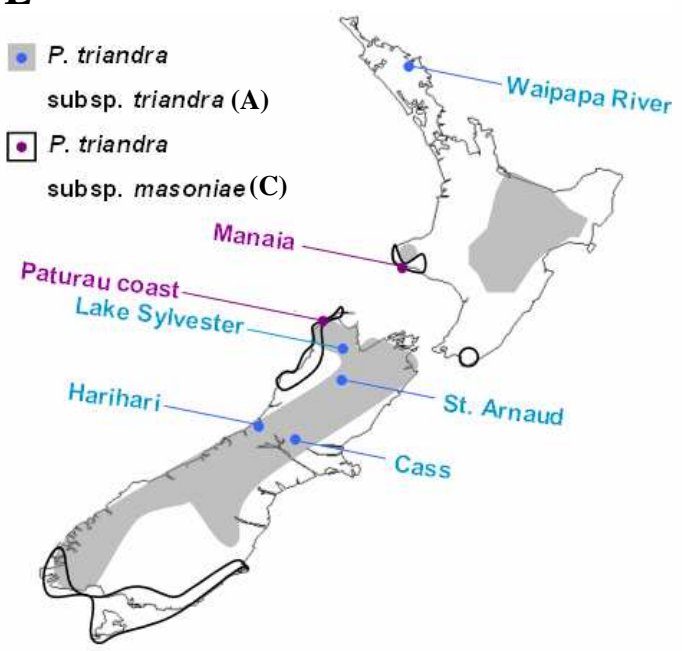

$\mathbf{F}$

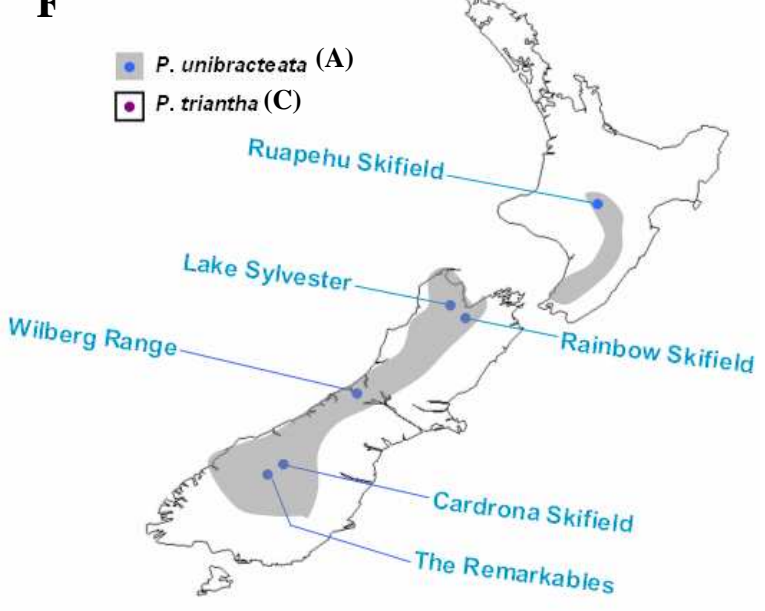

Enderby Island

(2)

\&

G

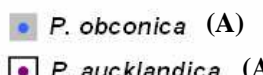

- P. aucklandica (A)
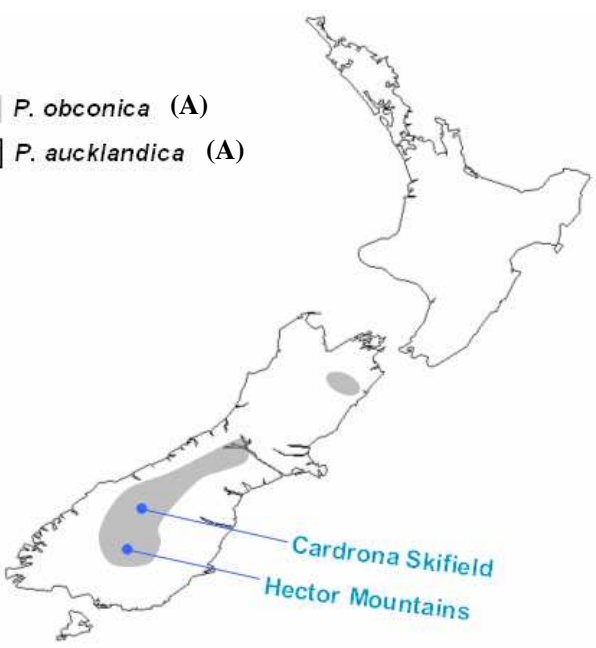

Aucklandislands

Figure 4.2 (continued): Distributions of New Zealand Plantago species based on collection of previous herbarium specimens (from Allan Herbarium, Landcare Research, Christchurch, New Zealand) and locations of samples collected for this study. E: P. triandra; F: P. unibracteata and P. triantha; and G: P. obconica and P. aucklandica $(\mathrm{A}=$ alpine/subalpine habitats; $\mathrm{C}=$ coastal; $\mathrm{C} / \mathrm{S}=$ coastal to altitudes of $1000-1500 \mathrm{~m})$. 
The inclusion of a comprehensive set of New Zealand Plantago population samples and representatives of Australasian species is essential for determining overall species relationships and biogeographic patterns of the genus in the Southern Hemisphere. In the previous chapter, I discussed the implications of new molecular data of Australasian Plantago for Southern Hemisphere biogeography. The aims of this chapter are to use ITS sequences: 1) to place the Australasian species within a larger phylogenetic framework, and 2) to examine delimitation and relationships, taxonomy and evolutionary patterns of the native New Zealand species using a molecular phylogeny (i.e. testing presence of different species or subspecies in $P$. spathulata, $P$. raoulii, $P$. lanigera and $P$. triandra; and elucidating species relationships of two undescribed or recently described species ( $P$. "sylvester" and $P$. obconica).

\subsection{Materials and Methods}

\subsubsection{Study group}

Collection locations of samples, along with voucher information and Genbank accession numbers are presented in Table 4.2. Samples were collected from the wild across the North and South Islands of New Zealand (Fig. 4.2) from previously known locations, and from Australia.

Multiple individuals (ranging from one to ten) from several populations (ranging from one to fourteen) were obtained for each species. All eight native New Zealand Plantago species were included in the phylogeny, including the recently described Plantago obconica (Sykes 1988) and the undescribed New Zealand polyploid $P$. "sylvester" (Groves and Hair 1971). Twelve out of the 24 native Australian species 
were obtained (including $P$. triantha, which is also found in New Zealand). In addition, introduced Plantago species, which have established in New Zealand $(P$. coronopus, P. lanceolata, P. major, P. australis and an unidentified specimen referred to as $P$. sp. in this study) were also inlcuded. $P$. major and $P$. australis are in the same subgenus as the Australasian species (subg. Plantago), whereas $P$. coronopus and $P$. lanceolata are in subg. Coronopus and subg. Albicans, respectively (following Rahn 1996). Additional sequences from previous studies were obtained from GenBank.

Plantago lanigera and P. novae-zelandiae are both referred to as $P$. lanigera here following Sykes (in Webb et al. 1988) but the ITS phylogeny is scrutinised to see if two groups are evident. Both forms were collected, including specimens with larger leaves and sparser hairs thought to be $P$. novae-zelandiae and specimens with smaller leaves that were densely covered with hair thought to represent $P$. lanigera as defined by Moore (in Allan 1961).

Several Veronica and Aragoa species were used as outgroups in the phylogeny. Veronica is used as a distant outgroup to Plantago because it is a close relative and has been used as an outgroup in the past (Rønsted et al. 2002; Hoggard et al. 2003; Cho et al. 2004), whereas Aragoa is the sister group to the Plantago-Littorella clade (Bello et al. 2002). For the purpose of this paper, the Littorella clade is treated as an outgroup as it has been shown to form the sister clade to a clade of all other Plantago species (Rønsted et al. 2002; Hoggard et al. 2003). 


\subsubsection{Molecular techniques}

Tissue samples were mostly preserved in silica gel from field collections, but a few were obtained from existing herbarium specimens. DNA extractions were performed using the DNEasy Plant Mini kit (Qiagen, Hilden, Germany) or using a cetyltrimethylammonium bromide $(\mathrm{CTAB})$ protocol modified from Doyle and Doyle (1990), after manual disruption of dried tissue using a pestle and mortar. The primers used to amplify the ITS DNA region are: ITS28CC: CGCCGTTACTAGGGGAATCCTTGTAAG (Wagstaff and Garnock-Jones 1998) and ITS5: GGAAGTAAAAGTCGTAACAAGG (White et al. 1990). Only ITS is used in this study because ITS sequences for Plantago are available on Genbank (http://www.ncbi.nlm.nih.gov/entrez/query.fcgi?db=nucleotide). Additionally, apart from a few conflicts, the ITS phylogeny is identical to the phylogeny reconstructed using chloroplast and mitochondrial DNA. The ITS region has also been used for everything from fungi to higher plants (White et al. 1990, Álvarez and Wendel 2003) to animals (Jorgensen et al. 2007; Kuriiwa et al. 2007), and often provides good resolution even at shallow phylogenetic levels (Álvarez and Wendel 2003). Thus, the ITS phylogeny will be used to explore taxonomic issues and evolutionary patterns of the native New Zealand Plantago species in this study.

PCR amplification was performed using Eppendorf Mastercycler ep gradient S (Hamburg, Germany) in a final volume of $25 \mu \mathrm{l}$ of the following: $16.35 \mu \mathrm{l}$ water, 10X ThermoPol reaction buffer $\left(10 \mathrm{mM} \mathrm{KCl}, 10 \mathrm{mM}\left(\mathrm{NH}_{4}\right)_{2} \mathrm{SO}_{4}, 20 \mathrm{mM}\right.$ Tris- $\mathrm{HCl}$ (pH8.8), $2 \mathrm{mM} \mathrm{MgSO}_{4}, 0.1 \%$ Triton X-100)(New England BioLabs), $0.4 \mathrm{mg} / \mathrm{mL}$ BSA, $250 \mu \mathrm{mol}$ dNTPs, 10 pmol each primer, and $0.75 \mathrm{U}$ of Taq DNA polymerase (New England BioLabs) and $0.4 \mu \mathrm{l}$ DNA template. The amplification was carried out 
with a thermocycling profile of: an initial 2 minutes at $94^{\circ} \mathrm{C}$, followed by 30 cycles of 1 minute at $94^{\circ} \mathrm{C}, 1.5$ minutes at $50^{\circ} \mathrm{C}, 1$ minute at $72^{\circ} \mathrm{C}$, and ending with a final extension time of 5 minutes at $72^{\circ} \mathrm{C}$. This PCR protocol was used to successfully amplify regions for all the primers. PCR products were visualised on $1.5 \%$ agarose gels before being purified with the High Pure PCR Purification Kit (Roche Diagnostics, Manheim, Germany). The purified PCR products were sequenced in both directions using an ABI3730 Genetic Analyzer by the Allan Wilson Centre Genome Service (Massey University, Palmerston North, New Zealand).

\subsubsection{Dataset alignment and phylogenetic analyses}

The program MEGA v3.1 (Kumar et al. 2004) was used to assemble and align sequences for each sample. The final ITS dataset consisted of 252 sequences from 239 species of Plantago, 10 sequences from Littorella, one sequence from Aragoa and two sequences from Veronica. Of these, 152 sequences (25 Plantago species and 2 Veronica species) were obtained for this study, and 100 sequences were obtained from GenBank. Identical sequences were combined in order to improve efficiency of analyses. Thus, the final dataset had 177 sequences of length $656 \mathrm{bp}$ including inferred gaps, with 321 (48.9\%) variable sites and 269 (41\%) parsimony-informative sites. Gaps were coded using modified complex indel coding (MCIC) method as implemented in SeqState v1.32 (Müller 2005) and were included in the dataset because the gaps may contain informative characters (shown in Chapter three). There were 733 characters in the dataset when indels were coded as characters concatenated onto the end of the sequences. The gapcoded dataset was then explored using MEGA v3.1 and DAMBE v4.5.9 (Xia and Xie 2001) and used for subsequent analyses. 
The substitution model was selected using Modeltest v3.7 (Posada and Crandall 1998), which tests the fit among 56 different models of different complexity using a hierarchical likelihood ratio test. Models were chosen using Akaike Information Weights criterion (AIC) because it has advantages over the hierarchical likelihood ratio test (Posada and Buckley 2004). Thus, the model implemented for the ITS dataset was a GTR $+\mathrm{I}+\mathrm{G}$ model, with base frequencies of variable sites: $\mathrm{T}=26.3 \%$, $\mathrm{C}=29.4 \%, \mathrm{~A}=20.1 \%, \mathrm{G}=24.3 \%\left(\mathrm{p}\left(\chi^{2}\right)=0.5560\right)$, scaled transition and transversion substitutions in the dataset: $\mathrm{AC}=0.7695, \mathrm{AG}=1.6289, \mathrm{AT}=1.2942, \mathrm{CG}=0.2850$, $\mathrm{CT}=4.0783, \mathrm{GT}=1.000, \mathrm{a}$ gamma shape parameter $=0.8876$ and a proportion of invariable sites (pinvar) $=0.3241$.

MrBayes v3.1.1 (Huelsenbeck and Ronquist 2001) was used to conduct heuristic searches under a Maximum Likelihood (ML) criterion. The analysis was conducted using 1,000,000 generations, resulting in 10,000 trees, and run until the standard deviation was less than 0.01 to ensure that the runs had converged on a stationary distribution ( $25 \%$ of the runs were discarded as burn-in). Branches with posterior probabilities less than $50 \%$ were collapsed in the phylogeny. Current taxonomical classifications were then plotted on the branches of the resolved phylogeny to check if the molecular phylogeny agreed with the phylogeny based on morphological characters (Rahn 1996). One of the Plantago spathulata subsp. picta sequences was removed from further analyses, because DNA was extracted from some leaves that were not in very good condition and was from a herbarium specimen more than 20 years old. The resulting sequence had multiple ambiguous sites and was placed in a different position from a more recently dried sample of $P$. spathulata subsp. picta with a clearer sequence (Appendix II (O)). 
The Bayesian phylogeny resulted in several well-supported clades but these had poor internal resolution. In order to clarify these internal relationships, each group was analysed separately in three groups to resolve parts of the full phylogeny that did not resolve because these species had a relatively lower rate of evolution than species in other parts of the tree. These phylogenies were used to investigate relationships between the New Zealand species in more detail. A model for each dataset was estimated using Modeltest v3.7 and these are presented in Appendix III (A), along with other data statistics. MrBayes was used to conduct heuristic searches for each of the three New Zealand datasets to check initial topology. The analyses were run with 1,000,000 generations, yielding 10,000 trees, and each analysis had a final standard deviation that was less than 0.01 ( $25 \%$ of the trees were discarded as burn-in). Replicates of the same population that clustered in the same clade in the resulting MrBayes phylogeny were removed and ML analyses were run on the reduced datasets to improve efficiency. ML analyses were conducted using PAUP* version $4.0 \mathrm{~b} 10$ (Swofford 2002) with 100 replicates of random sequence addition and TBR branch swapping. Nonparametric bootstrap support was assessed using 200 replicates, with random sequence addition and TBR branch swapping.

Complex evolutionary patterns, such as those arising from hybridisation, introgression and species radiations, cannot be properly displayed on traditional bifurcating trees (Lockhart et al. 2001; Huson and Bryant 2006). Therefore, Splitstree v4.8 (Huson and Bryant 2006) was used to conduct neighbour net analyses on each of the datasets in order to better visualise relationships between the New Zealand species. Splitstree uses genetic distances to compute split networks, which allows conflicting signals of species similarities to be visualised if they are present in a dataset. 


\subsection{Results}

During alignment of the dataset, several pairs of identical sequences were found (presented here with Genbank accession numbers): Plantago debilis (NSW 742894) and $P$. hispida (AJ548967); P. sp. (WELTU (PGJ2566 \& MLT)) and P. asiatica (AY101862); and P. daltonii (AJ548968) and P. tasmanica (AJ548970).

In general, there was very little intraspecific genetic variation within Australasian Plantago species sampled more than once; most of the species have less than $1 \%$ sequence divergence (Table 4.3). The highest intraspecific sequence divergence, found in $P$. raoulii and in $P$. lanigera, is still low (about 2.1-2.5\%). Uncorrected pdistances between all pairwise comparisons of Australasian species range from $0 \%$ to only $4.3 \%$ (results not shown).

Table 4.3. Population statistics for the native New Zealand Plantago species (with more than one DNA sequence) included in the ITS phylogeny.

\begin{tabular}{lccccc}
\hline \hline Species & $\begin{array}{l}\text { No. of } \\
\text { sequences }\end{array}$ & $\begin{array}{l}\text { No. of } \\
\text { localities }\end{array}$ & $\begin{array}{l}\text { No. of } \\
\text { haplotypes }\end{array}$ & $\begin{array}{l}\text { No. of } \\
\text { variable } \\
\text { sites }\end{array}$ & $\begin{array}{l}\text { Average \% } \\
\text { sequence } \\
\text { difference }\end{array}$ \\
\hline Plantago spathulata & 15 & 4 & 4 & 5 & 0.76 \\
$\quad$ P. spathulata subsp. spathulata & 14 & 3 & 3 & 1 & 0.15 \\
P. raoulii & 18 & 9 & 14 & 14 & 2.13 \\
P. "sylvester" & 12 & 1 & 6 & 1 & 0.15 \\
P. lanigera & 28 & 14 & 20 & 19 & 2.90 \\
P. obconica & 6 & 2 & 2 & 0 & 0.00 \\
P. triandra & 19 & 7 & 7 & 5 & 0.76 \\
$\quad$ P. triandra subsp. triandra & 13 & 5 & 4 & 3 & 0.46 \\
P. triandra subsp.masoniae & 6 & 2 & 4 & 4 & 0.61 \\
P. unibracteata & 10 & 7 & 8 & 5 & 0.76 \\
\hline
\end{tabular}


subgenus

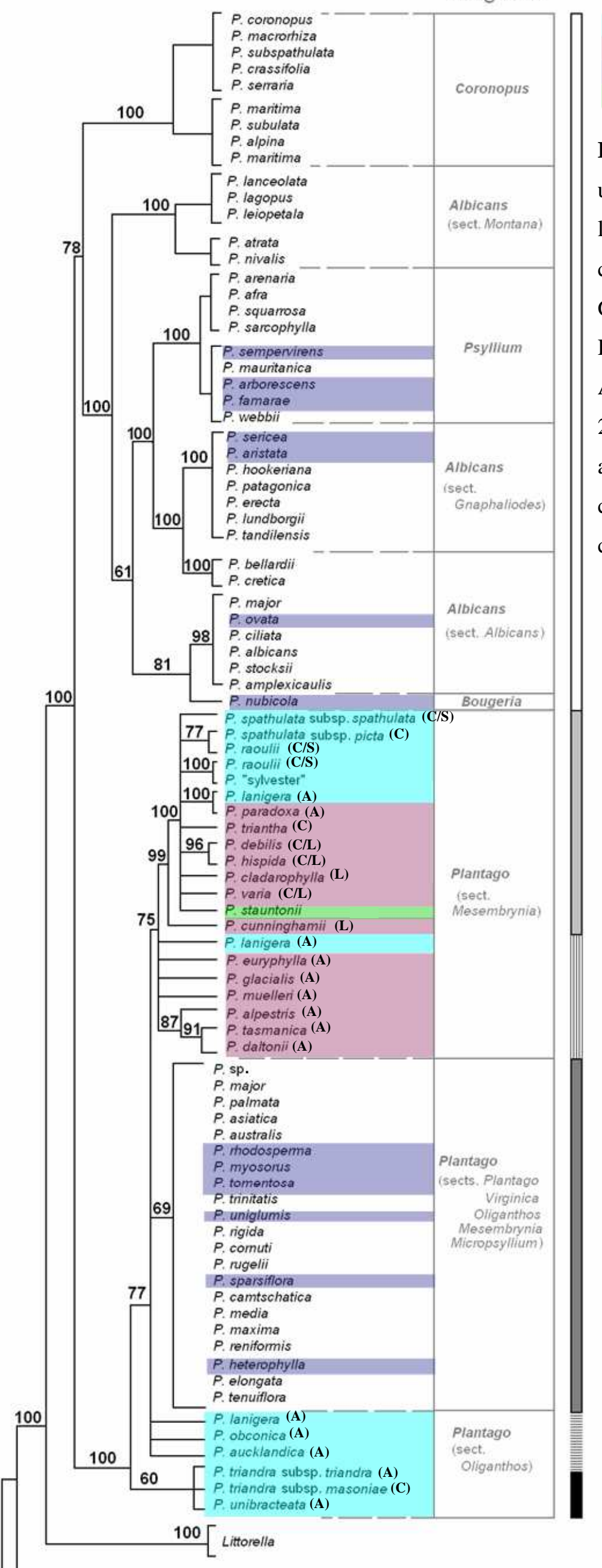

Key:

New Zealand

Australia

South America

Amsterdam \&

St. Paul Islands

Figure 4.3: Simplified 50\% consensus tree using Bayesian analysis (average tree likelihood score $=-7531.24)$, with classifications according to Rahn (1996). Geographic locations of Southern Hemisphere species are indicated. Each Australasian species in the tree represents 125 individual sequences $(\mathrm{A}=$ alpine/subalpine habitats; $\mathrm{C}=$ coastal $; \mathrm{C} / \mathrm{S}=$ coastal to altitudes of $1000-1500 \mathrm{~m} ; \mathrm{C} / \mathrm{L}=$ coastal/lowlands; $\mathrm{L}=$ lowland habitats).

\section{Clade I}

Clade II (See Fig. 4.3)

\section{Grade A}

\section{Clade III}

Grade B (See Fig. 4.4)

Clade IV (See Fig. 4.5) 
Phylogeny using ITS

The 50\% MrBayes consensus phylogeny reconstructed using the complete dataset was divided into four clades and two grades (Fig. 4.3). The focus of this paper is on the placement of Australasian species within a larger phylogeny, and species relationships within native New Zealand species. New Zealand species relationships are elucidated separately in the reduced ML analyses, thus, only the main structures of the clades are displayed in this figure for easier visual interpretation. Further resolved structure in of the clades can be found in the original tree, which is appended (Appendix II (O)).

Two main clades are resolved within Plantago. The first (Clade I) contains subg. Coronopus, subg. Albicans, subg. Psyllium, and subg. Bougeria (Fig. 4.3). In this clade, Plantago nubicola (subg. Bougeria) is nested within a paraphyletic Albicans. Most of the $P$. major replicates cluster together in Plantago Clade II, one sequence is placed within Plantago Clade I. This suggests a probable misidentification of the latter specimen, with Genbank number AY692079. Clade I contains no native New Zealand species and is not discussed further.

The second resolved clade represents subg. Plantago (sect. Mesembrynia, sect. Oliganthos and sect. Virginica) and includes all the Australasian species (1.0 PP). Subg. Plantago can be further divided to form three clades (Clades II, III and IV) and two grades (Grades A and B). Of the grades, Grade A contains only Australian species and is not further explored in this study. Previous analyses with a larger sequence dataset of three different genetic regions provided strong support that Grade B is a clade, even though in analyses of ITS alone the group appears to be a grade. Grade B is further explored in this study. The Australasian species do not form a clade 
in the ITS phylogeny, with the widely distributed Clade III and P. stauntoni (from the Amsterdam \& St. Paul Islands) nested within the Australasian species. However, there is low support for this finding ( $\leq 0.7 \mathrm{BP}$ for all resolved groups). Clade III contains species that are native to the Mediterranean, Europe, Africa, America and Asia, and is a mix of sect. Oliganthos, sect. Mesembrynia and sect. Virginica. South American species are present in Clade I and Clade III.

There is not much resolution at species level for the Australasian species (Clade II, IV and Grade A, B). Sect. Mesembrynia and sect. Oliganthos are polyphyletic in the phylogeny. Clade II and Grade A are classified as sect. Mesembrynia, and Clade IV and Grade B are sect. Oliganthos. Individuals identified as P. lanigera did not form a clade and were placed in Clade II, Grade A and Grade B. P. paradoxa forms a clade with samples from New Zealand that were identified to $P$. lanigera from Eyre Mountains. Plantago paradoxa, P. glacialis, P. muelleri and P. triantha, which were classified in sect. Oliganthos by Rahn (1996) are clustered among species from sect. Mesembrynia. P. aucklandica is classified in sect. Plantago but is not placed with other species from that section (in Clade III). P. aucklandica, placed by Rahn (1996) in sect. Plantago, is only loosely associated with Clade III, which contains all the other species of sect. Plantago. Plantago triantha is classified in sect. Oliganthos (Rahn 1996) but is placed with species from sect. Mesembrynia in the resolved ITS phylogeny (Fig. 4.3). It thus seems likely that reduction to solitary flowers, one of the defining characteristics of sect. Oliganthos, has occurred several times in the clade (e.g. P. obconica, P. triantha and Littorella uniflora). 


\section{A : Clade II}

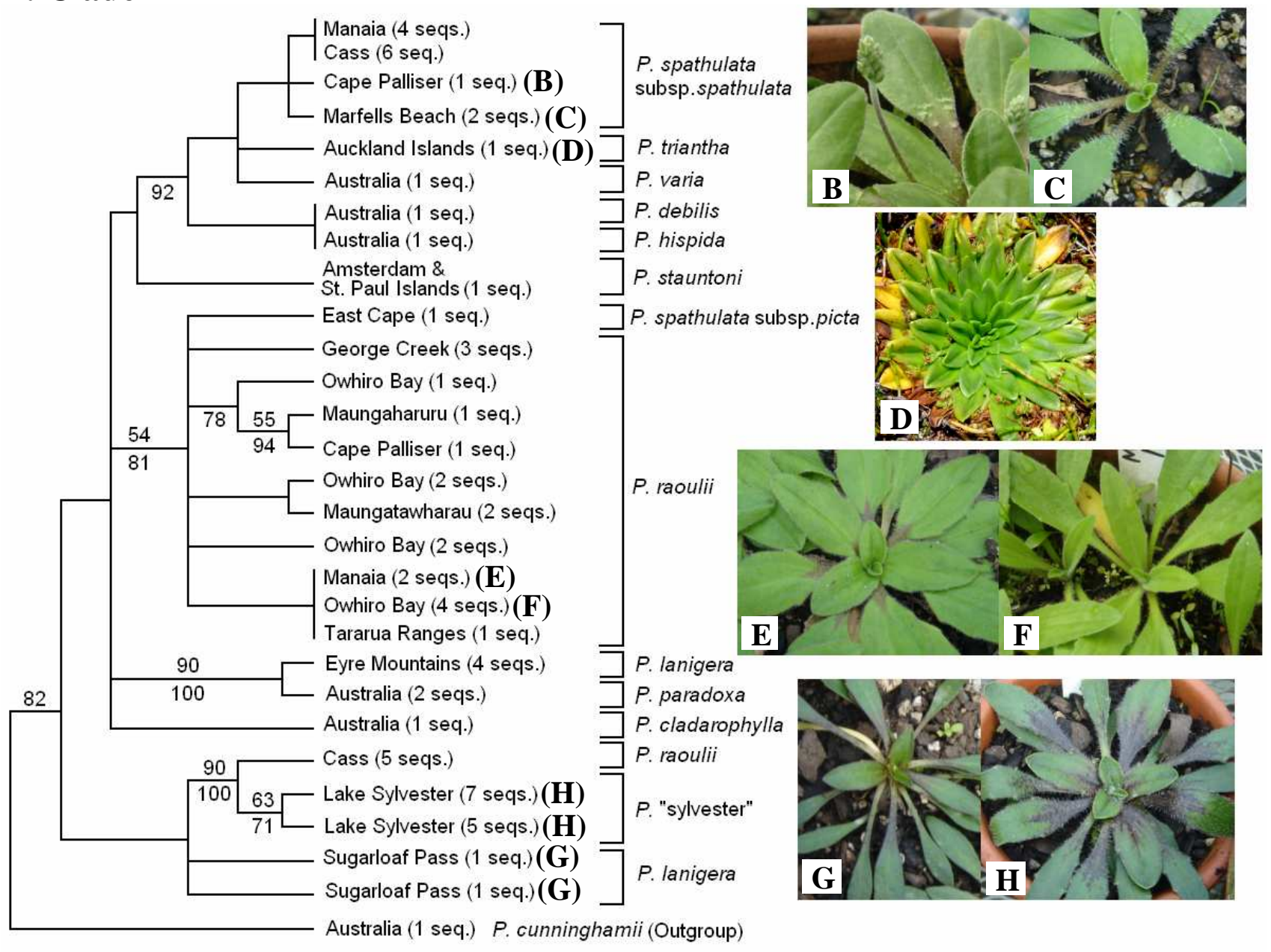

Figure 4.4. A: One of the reconstructed Maximum Likelihood (ML) trees of Clade II, which comprises lowland (including coastal) and alpine/subalpine species (tree score $=1087.60)$. Each sequence in A represents an individual plant. $\mathrm{B}$ and $\mathrm{C}$ : habit of $P$. spathulata subsp. spathulata; D: P. triantha from the Auckland Islands; E and F: two different forms of $P$. raoulii; G: specimen identified as $P$. lanigera from Sugarloaf Pass; and F: specimen from Lake Sylvester. ML bootstrap values are displayed above branches, whereas MrBayes posterior probabilities are displayed below branches (only support values $>50 \%$ are shown). Plant pictures presented here are from plants that have been cultivated in the greenhouse for about a year. 


\section{A: Grade B}

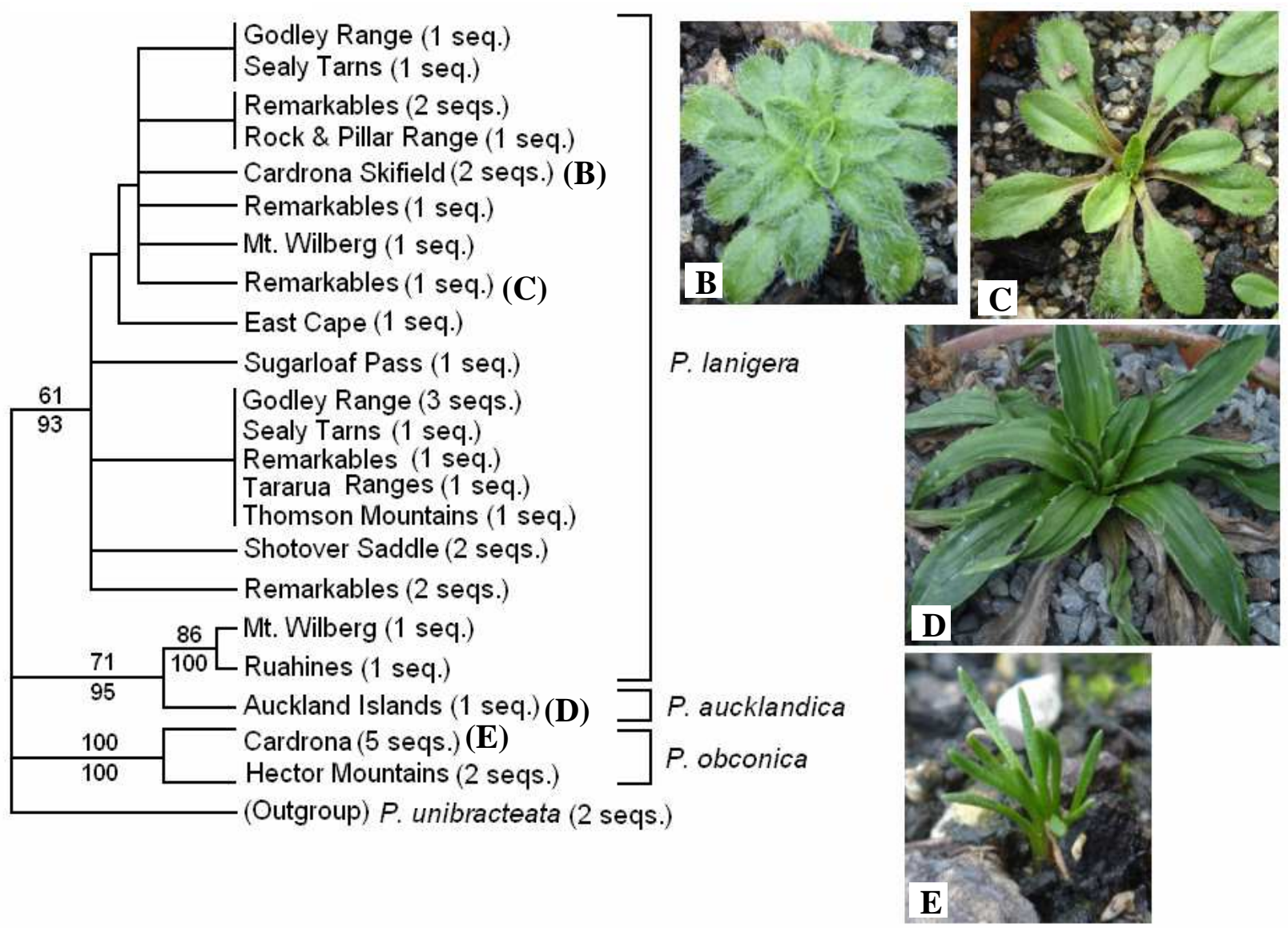

Figure 4.5. A: One of the reconstructed Maximum Likelihood (ML) trees of Grade B, which is a clade of alpine/subalpine species (tree score $=1065.00$ ). Each sequence in A represents an individual plant. B and C: two different forms currently classified under $P$. lanigera (previously $P$. lanigera and $P$. novae-zelandiae respectively); D: $P$. aucklandica, endemic to the Auckland Islands; E: habit of P. obconica. ML bootstrap values are displayed above branches, whereas MrBayes posterior probabilites are displayed below branches (only support values $>50 \%$ are shown). Plant pictures presented here are from plants that have been cultivated in the greenhouse for about a year. 


\section{A: Clade IV}

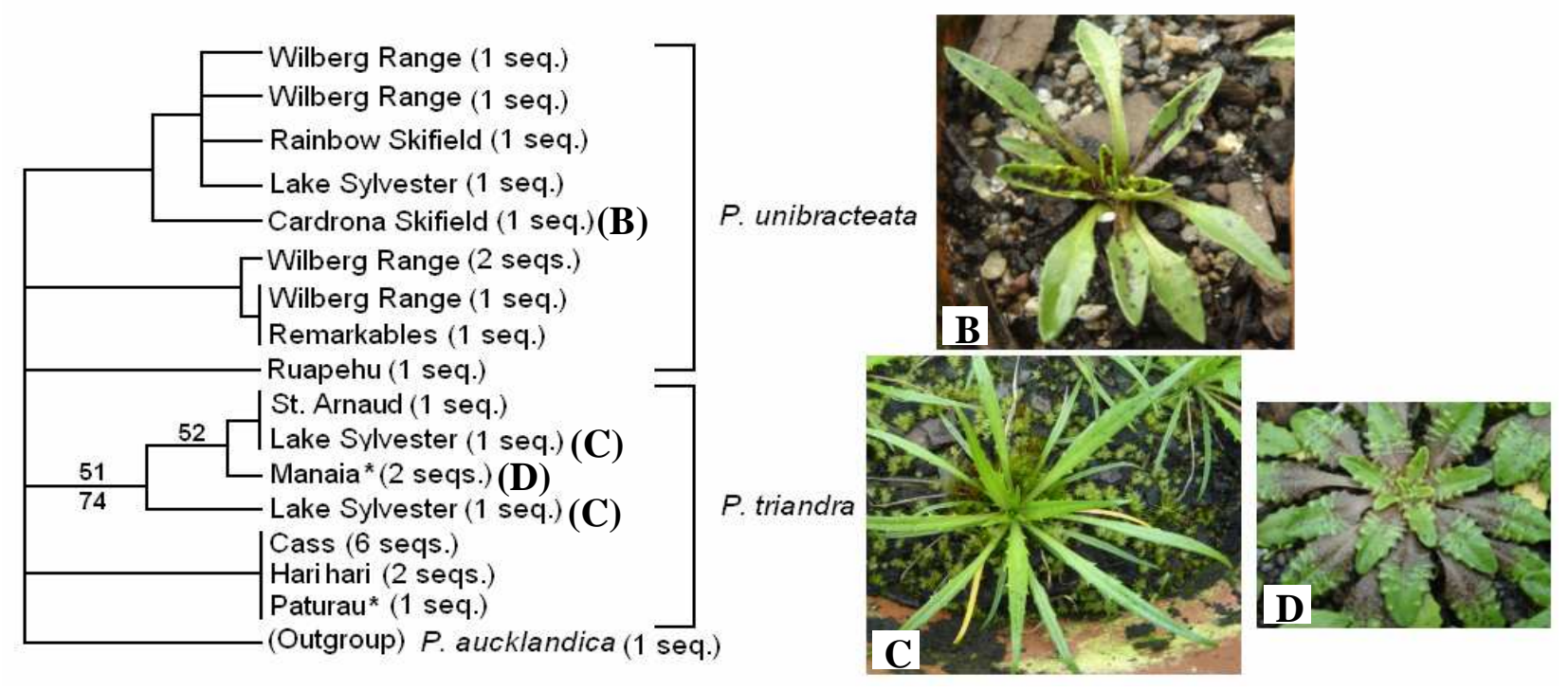

Figure 4.6. A: One of the reconstructed Maximum Likelihood (ML) trees of Clade IV, a clade of alpine/subalpine and coastal ( $P$. triandra subsp. masoniae) species (tree score $=976.76)$. Each sequence in $\mathrm{A}$ represents an individual plant. B: $P$. unibracteata; C: P. triandra subsp. triandra; D: $P$. triandra subsp. masoniae. Samples of $P$. triandra marked with a * indicate populations of $P$. triandra subsp. masoniae, whereas the others are subsp. triandra. ML bootstrap values are displayed above branches, whereas MrBayes posterior probabilites are displayed below branches (only support values $>50 \%$ are shown). Plant pictures presented here are from plants that have been cultivated in the greenhouse for about a year. 
When the dataset was partitioned into the three Australasian groups of interest (Clade II, Grade B and Clade IV) and analysed separately, the reconstructed phylogenies were able to provide slightly better resolution of species. Proportions of nucleotide bases were equivalent among all sites in the three datasets (Appendix III (A)), but bases were heterogenous among variable sites for Clade IV and Grade B. Bayesian analyses have greater time efficiency over ML for large datasets like the large ITS dataset, but ML trees are preferred for smaller datasets because MrBayes generates numerous trees (10,000 in these analyses). The Bayesian and ML analyses of the datasets had congruent topologies and equivalent support values. Therefore, results of the reduced analyses are discussed using the phylogenies recovered using ML (Figs. 4.3A, 4.4A, 4.5A).

\section{Clade II (sect. Oliganthos)}

Clade II includes the two subspecies of Plantago spathulata (four localities, 15 individuals), $P$. raoulii (four localities, 18 individuals), and $P$. "sylvester" (one locality, 12 individuals) from New Zealand; five Australian species ( $P$. varia, $P$. debilis, $P$. hispida, P. paradoxa and P. cladarophylla); one species ( $P$. stauntoni) from the Amsterdam \& St. Paul Islands in the South Indian Ocean; and one species, $P$. triantha (one locality, one individual), native to both New Zealand and Australia. The clade also contains several individuals that were identified as $P$. lanigera but do not form a clade with the other samples of P. lanigera, which are placed in Grade B.

ML analysis suggests that the two subspecies of $P$. spathulata as currently circumscribed are not sister taxa (Fig. 4.4A). P. spathulata subsp. spathulata forms a clade with $P$. triantha, $P$. varia, $P$. debilis and $P$. hispida (<50BP, 0.92PP). 


\section{A: Clade II}
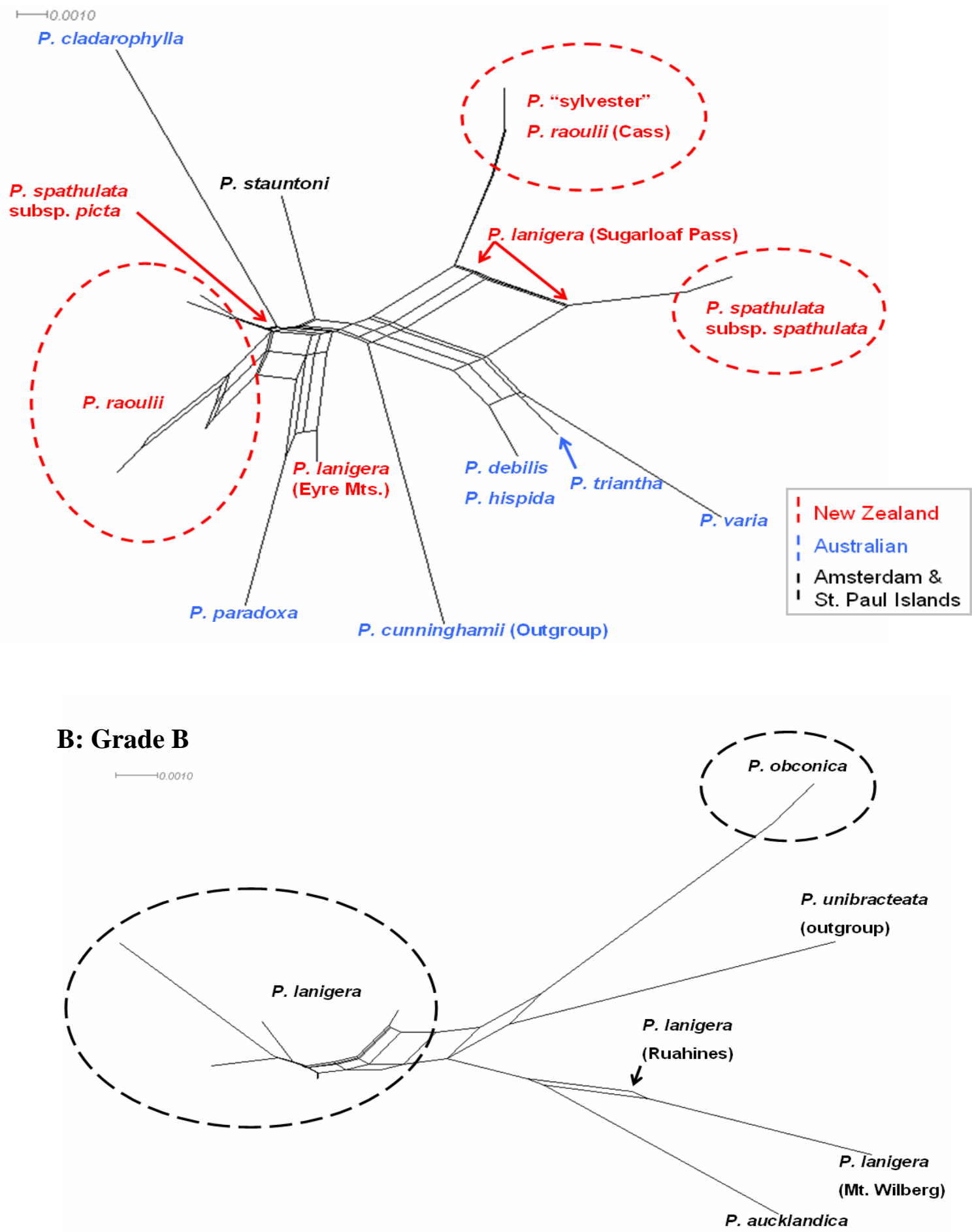

Figure 4.7. Neighbour-net analyses using Splitstree. A: Clade II; B: Grade B; and C:

Clade IV. Dotted circles indicate the different species. In A colours indicate geographic location $($ red $=$ New Zealand; blue $=$ Australian; black $=$ Amsterdam $\&$ St . Paul Islands). 


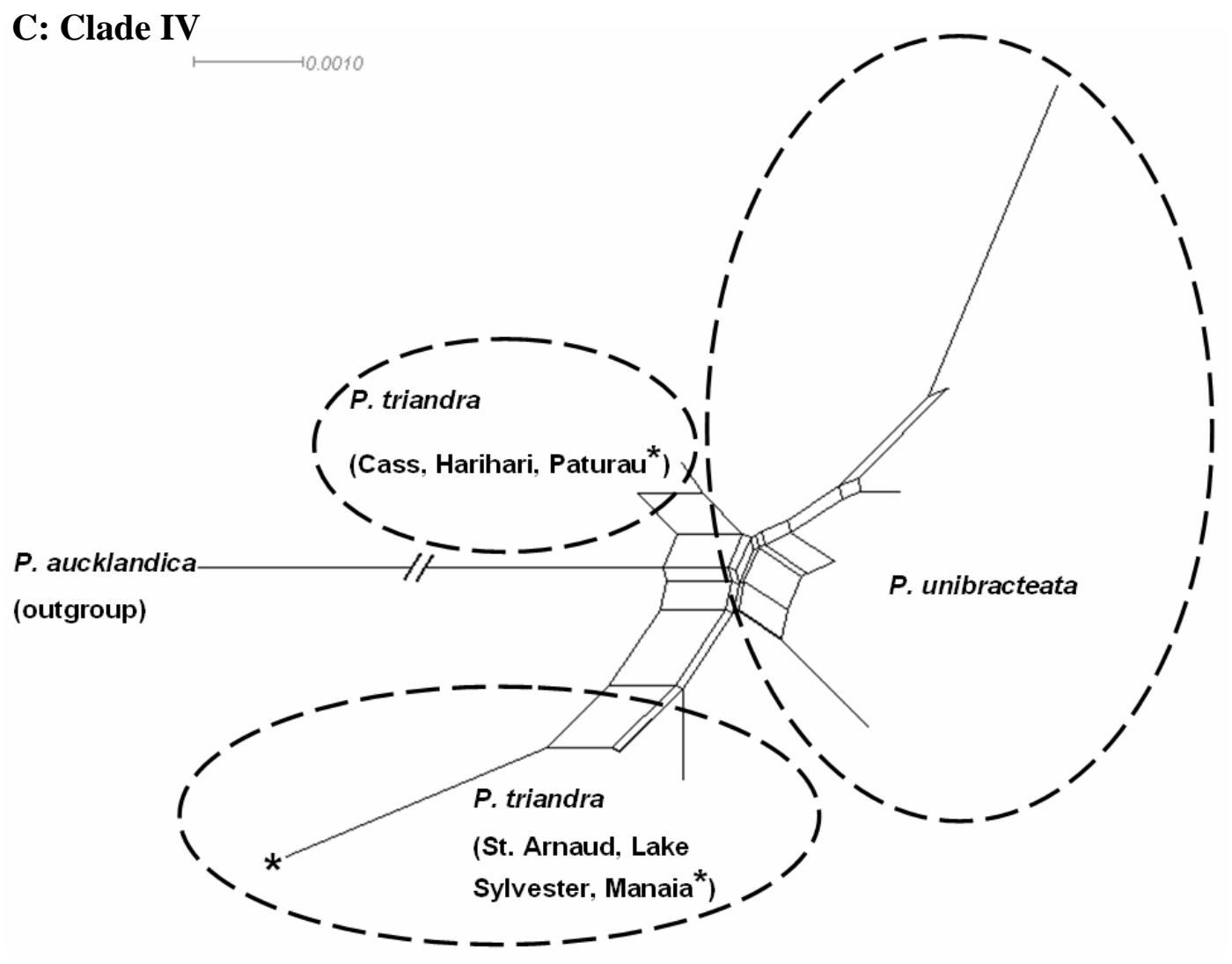

Figure 4.7 (continued). Neighbour-net analyses using Splitstree. A: Clade II; B: Grade B; and C: Clade IV. Dotted circles indicate the different species. * in C indicate populations of $P$. triandra subsp. masoniae. 
The sister to this clade is $P$. stauntoni but there is low support for this relationship. $P$. raoulii is separated into two groups based on geographic locations. The N. I. $P$. raoulii are grouped together in a clade with $P$. spathulata subsp. picta (54BP, 0.81PP), whereas the sole sample of the S. I. P. raoulii forms a clade with $P$. "sylvester" (90BP, 1.0PP). One of the populations identified as P. lanigera from Sugarloaf Pass also clusters with the sample of S. I. $P$. raoulii and $P$. "sylvester" but there is low support for this group $(<50 \mathrm{BP}$ and $\mathrm{PP})$. The other P. lanigera population in this group is from the Eyre Mountains and forms a clade with the Australian P. paradoxa (90BP, 1.0PP). ML analyses yielded six trees, which differed only by rearrangements in the $P$. raoulii- $P$. spathulata subsp. picta clade. In one of the trees, the node of the branch leading to $P$. spathulata subsp. spathulata and the node of the $P$. raoulii clade were placed in a polytomy. $P$. raoulii had the most sequence divergence within Clade I (2.13\%), P. "sylvester" only had $0.15 \%$ sequence divergence, and there was $0.76 \%$ sequence divergence between the two subspecies of $P$. spathulata.

Splitstree analysis of Clade II (Fig. 4.7A) revealed two groups. Each group contained both New Zealand and Australian species. Plantago spathulata subsp. picta is connected by a box to both $P$. cladarophylla and the N.I. P. raoulii, whereas the sample of $P$. triantha (from Auckland Islands) is attached to boxes connecting Australian species $P$. debilis, $P$. hispida and $P$. varia; but species relationships among these are not well-defined. Further, branches of one of the specimens of $P$. lanigera from Sugarloaf Pass is connected to P. spathulata subsp. spathulata, while the other specimen is connected to the branch leading to P. raoulii from Cass and $P$. "sylvester". Placement of $P$. stauntoni is uncertain; it is placed between the two Australasian groups, but closest to $P$. cladarophylla. 


\section{Grade B}

Grade B contains Plantago lanigera (14 localities, 28 individuals), P. obconica (two localities, six individuals) and P. aucklandica (one locality, one individual). This grade was not resolved in the ITS phylogeny (Fig. 4.3) but there was high support for a clade comprising these species in previous combined analyses (see Fig. 3.2). Three main clades were resolved within the group (Fig. 4.5A), although relationships among them were not well-resolved. The first contains most of the P. lanigera samples (61BP, 93PP) with poorly supported ( $\angle 50 \mathrm{BP}$ and $\mathrm{PP})$ resolution of relationships within the clade. Secondly, there is a clade of two populations of P. lanigera (86BP, 100PP), which together are sister to $P$. aucklandica (71BP, 95PP). The third clade contains the two populations of $P$. obconica (100BP, 1.0PP). ML analyses resulted in 24 trees, where the only differences were rearrangements within the larger $P$. lanigera clade. Samples thought to represent $P$. novae-zelandiae are inseparable from the other $P$. lanigera samples based on ITS sequences, i.e. clustering within the large $P$. lanigera clade does not match either morphological differences or geographic location. There also does not appear to be geographical difference in the samples of $P$. lanigera. Among all the Australasian species, $P$. lanigera had the highest intraspecies sequence divergence: $2.90 \%$ (Table 4.3 ) but this value is still low.

The distinction between species in Grade B (Fig. 4.7B) is clear aside from the two populations of $P$. lanigera that do not cluster with the other $P$. lanigera. The neighbour-net of $P$. lanigera indicates possible reticulation in the past, which may be a result of complex history perhaps involving hybridisation or incomplete lineage sorting. 
Clade IV (sect. Oliganthos)

Clade IV consists of $P$. unibracteata (seven localities, ten individuals) and the two subspecies of $P$. triandra (seven populations, 19 individuals). ML analyses provided very little resolution for this clade (Fig. 4.6A). There were two resolved but poorly supported clades of $P$. unibracteata (both with $<50 \mathrm{BP}$ ), and one resolved clade for $P$. triandra (51BP). These, along with other samples from both species, form a polytomy at the base of Clade IV. The only difference among the three resulting ML trees was the placement of an individual $P$. unibracteata sequence from Mt. Wilberg. This sequence was placed alternatively as (1) sister to the other populations of the $P$. unibracteata clade, (2) at the most derived position in the $P$. unibracteata clade, and (3) in a polytomy with the $P$. unibracteata clade.

The two subspecies of $P$. triandra do not group according to the classification of Sykes (in Webb et al. 1988), which was based on morphology. The two clades within P. triandra do not appear to group according to geographic location. In fact, several populations from $P$. triandra subsp. triandra share an identical ITS sequence with a population of $P$. triandra subsp. masoniae. $P$. unibracteata populations also did not group according to geographic locations (e.g. replicates from a Mt. Wilberg population were placed in separate clades). Intraspecific and interspecific sequence divergence was low for both species. Sequences within each species differed by only 5 nucleotide substitutions out of 656 bp of ITS sequence (uncorrected p-distances range from 0.002-0.008). Sequence divergence between the two species was represented by 9 nucleotide substitutions and an extremely low range of uncorrected p-distances of 0.002-0.008. 
In the Splitstree analysis of Clade IV (Fig. 4.7C), P. unibracteata and the two subspecies of $P$. triandra are inseparable genetically. The length of the branches connecting $P$. triandra and $P$. unibracteata show that $P$. triandra forms two groups that are more divergent genetically than either is from $P$. unibracteata. Further, representatives from both subspecies are present in each of the two groups of $P$. triandra.

\subsection{Discussion}

The aim of this study was firstly to integrate Australasian species of Plantago into a framework of an ITS phylogeny that included species representatives from around the world. This phylogeny was then used to evaluate the current taxonomy of the genus and overall relationships of the Australasian species. Secondly, phylogenetic analyses of multiple population samples per species were used to investigate evolutionary patterns and to address taxonomic issues in the New Zealand species of Plantago.

\subsubsection{Evolution of New Zealand Plantago}

Separation of groups according to elevation is evident in the ITS phylogeny presented here (Fig. 4.3), and also in the concatenated (ITS, $n d h F-r p l 32$ and coxl) phylogeny in Chapter three (Fig. 3.2), where the Australasian lowland species are separated from the alpine/subalpine species. The lowland species appear to have one more recent migration event into lowland habitats from alpine/subalpine groups. A similar pattern is found in alpine Ranunculus species (Lockart et al. 2001) and New Zealand Veronica sect. Hebe (Wagstaff and Garnock-Jones 1998; Wagstaff et al. 2002). The distribution of the New Zealand Plantago species also suggests that physical 
separation because of adaptations to different habitats may be an important speciation mechanism for some taxa in the group. For example., within Plantago triandra, subsp. triandra is distributed on inland mountains and sometimes low altitudes in the S. I., whereas subsp. masoniae grows in coastal areas that are separate from populations of P. triandra subsp. triandra (Sykes in Webb et al. 1988).

Although the processes and mechanisms involved in the evolution of alpine species in New Zealand are not well known (Winkworth et al. 2005), the origin of the New Zealand species of Plantago was dated to be in the range of 2.3 to 1.5 mya in the previous chapter, which is within the period of uplift of the Southern Alps (starting about 5 mya). Speciation of the alpine and subalpine Plantago species following the uplift of these mountain ranges agrees with previous observations in other plant groups (Lockhart et al. 2001; Winkworth et al. 2002a). The Southern Alps may also present a physical barrier that limits the distribution of some species, such as $P$. spathulata subsp. spathulata, which is reportedly found only east of the main divide (Sykes in Webb et al. 1988).

The ITS phylogeny of Clade II suggests that Cook Strait may be a physical barrier for P. raoulii populations because N.I. populations of $P$. raoulii are separated from the S.I. population in the ML phylogeny (Fig. 4.4A), which is also evident in the Splitstree analysis (Fig. 4.7A). However, only one population of $P$. raoulii from S. I. was included and testing of this hypothesis would benefit from wider sampling. Cook Strait does not appear to present a barrier for the other species because closely related populations occur on both sides of the strait (Figs. 4.4A, 4.5A, 4.6A). 
Table 4.4. Comparison of allopatry vs. sympatry and same vs. different chromosome numbers in New Zealand Plantago species.

\begin{tabular}{|c|c|c|c|c|c|c|c|c|c|c|c|}
\hline & $\begin{array}{l}\text { Plantago } \\
\text { aucklandica }\end{array}$ & $\begin{array}{l}P . \\
\text { lanigera }\end{array}$ & $\begin{array}{l}P . \\
\text { obconica }\end{array}$ & $\begin{array}{l}P . \\
\text { raoulii }\end{array}$ & $\begin{array}{l}\text { P. spathulata } \\
\text { subsp. } \\
\text { spathulata }\end{array}$ & $\begin{array}{l}\text { P. spathulata } \\
\text { subsp. picta }\end{array}$ & $\begin{array}{l}P . \\
\text { "sylvester" }\end{array}$ & $\begin{array}{l}\text { P. triandra } \\
\text { subsp. } \\
\text { triandra }\end{array}$ & $\begin{array}{l}\text { P. triandra } \\
\text { subsp. } \\
\text { masoniae } \\
\end{array}$ & $\begin{array}{l}P . \\
\text { triantha }\end{array}$ & $\begin{array}{l}P . \\
\text { unibracteata }\end{array}$ \\
\hline $\begin{array}{l}\text { Plantago } \\
\text { aucklandica }\end{array}$ & - & A & A & A & A & A & A & A & A & $\mathrm{S}$ & A \\
\hline P. lanigera & N/A & - & $\mathrm{S}$ & A & $\mathrm{S}$ & A & $\mathrm{S}$ & $\mathrm{S}$ & A & A & $\mathrm{S}$ \\
\hline P. obconica & N/A & $X$ & - & A & $\mathrm{S}$ & A & A & $\mathrm{S}$ & A & A & $\mathrm{S}$ \\
\hline P. raoulii & N/A & $X$ & $X$ & - & S & A & $\mathrm{S}$ & $\mathrm{S}$ & $\mathrm{S}$ & A & $\mathrm{S}$ \\
\hline $\begin{array}{l}\text { P. spathulata } \\
\text { subsp. } \\
\text { spathulata }\end{array}$ & N/A & $X$ & $X$ & I & - & A & A & $\mathrm{S}$ & A & A & $\mathrm{S}$ \\
\hline $\begin{array}{l}\text { P. spathulata } \\
\text { subsp. picta }\end{array}$ & N/A & $X$ & $X$ & I & I & - & A & A & A & A & A \\
\hline P. "sylvester" & N/A & $X$ & $X$ & $X$ & $X$ & $X$ & - & $\mathrm{S}$ & $\mathrm{S}$ & A & $\mathrm{S}$ \\
\hline $\begin{array}{l}\text { P. triandra } \\
\text { subsp. } \\
\text { triandra }\end{array}$ & N/A & $X$ & $X$ & I & I & I & $X$ & - & A & A & $\mathrm{S}$ \\
\hline $\begin{array}{l}\text { P. triandra } \\
\text { subsp. } \\
\text { masoniae }\end{array}$ & N/A & $X$ & $X$ & I & I & I & $X$ & I & - & A & A \\
\hline P. triantha & N/A & $\mathrm{I} / \mathrm{X}$ & I & $X$ & $X$ & $X$ & $X$ & $X$ & $X$ & - & A \\
\hline $\begin{array}{l}P . \\
\text { unibracteata }\end{array}$ & N/A & $X$ & $\mathrm{X}$ & $X$ & $X$ & $\mathrm{X}$ & $\mathrm{X}$ & $\mathrm{X}$ & $X$ & $\mathrm{X}$ & - \\
\hline
\end{tabular}

Upper right side is a comparision of whether the species are allopatric or sympatric (A = populations are allopatric, $\mathrm{S}=$ populations are sympatric). Lower left side is a comparison of chromosome numbers $(\mathrm{X}=$ different chromosome numbers, $\mathrm{I}=$ identical chromosome numbers, $\mathrm{I} / \mathrm{X}=$ one of the chromosome numbers is the same $(P$. lanigera has two chromosome numbers $2 n=12,24)$ ). Colours represent different combinations; yellow boxes are sympatric species with different chromosome numbers; orange boxes are sympatric species with identical chromosome numbers; red boxes are allopatric species with same chromosome numbers; blue boxes are allopathic species with identical chromosome numbers. N/A = data not available (chromosome numbers for P. aucklandica unknown). Chromosome numbers from Groves and Hair (1971) and Rahn (1996). 
Some of the New Zealand Plantago species occur in sympatric populations. The species have variable chromosome numbers $(2 n=12,24,48,60$ and 96$)$ which may act as a reproductive barrier where distributions overlap. Most species that have sympatric populations have different chromosome numbers (Table 4.4). For example, $P$. unibracteata and $P$. lanigera can be found growing at the same location but they have different chromosome numbers $(2 n=60$ and $2 n=12 / 24$, respectively). Polyploidy may have allowed rapid speciation within the group, e.g. P. "sylvester" $(2 n=96)$, which is suggested to be a hybrid of $P$. spathulata subsp. spathulata and $P$. raoulii (both $2 n=48$ ) (see below). Different flowering times, along with the limited dispersal of pollen and seeds may also present a biological barrier to genetic exchange, and therefore may promote speciation.

\section{Possible hybrids}

Within the ITS dataset, several populations with unexpected relationships were found in a basal polytomy in Clade II. The samples (a few per population) were identified as Plantago lanigera but they do not group with the other $P$. lanigera populations, which are placed in Grade B. The morphology of these individuals is certainly peculiar; the habits of both $P$. lanigera from Eyre Mountains and P. lanigera from Sugarloaf Pass resemble the specimens collected from Lake Sylvester ( $P$. "sylvester") with respect to coloration, leaf shape and plant size (see Fig. 4.4E \& F). Their positions are also odd in the Splitstree analyses (Fig. 4.7). P. lanigera from the Eyre Mountains is closest to $P$. paradoxa, whereas $P$. lanigera from Sugarloaf Pass are attached between $P$. spathulata subsp. spathulata and a clade of $P$. "sylvester" and $P$. raoulii (from Cass). These populations could represent misidentifications but the unexpected placements 
in the ML and Splitstree analyses could also suggest hybridisation. Further sampling and a study of morphology characters may help clarify relationships of these species.

\subsubsection{Taxonomy of New Zealand Plantago}

\section{Circumscription of subgenera and sections}

In the ITS phylogeny, the Australasian species fall into a clade of subg. Plantago, which is sister to a clade containing the other four subgenera (subg. Albicans, subg. Bougeria, subg. Psyllium and subg. Coronopus). The ITS phylogeny also shows that most of the subgenera identified by Rahn (1996) form monophyletic groups (Fig. 4.3) and the topology of the tree does not contradict the topology recovered from previous phylogenetic studies (Rønsted et al. 2002; Hoggard et al. 2003).

While there is some resolution in Clade I, there is not much resolution among Australasian species (Clades II and IV, and Grades A and B). This is probably because of low sequence divergence within and between the Australasian species (Table 4.3, Appendix III (B)). This finding is consistent with the long branch lengths found in Plantago coronopus and $P$. lanceolata, but short branch lengths in Australasian species were formed when phylogeny was reconstructed in the previous chapter (Fig. 3.3). Slightly better resolution of species relationships within Australasian groups was obtained when species with relatively high substitution rates were removed to form three reduced Australasian datasets. The ML phylogenies of these smaller datasets are used to address taxonomic issues and to look at the evolution of Plantago species in New Zealand below. 
Circumscription of New Zealand species and subspecies

\section{Plantago spathulata}

In the ML tree (Fig. 4.4A), Plantago spathulata subsp. picta appears to be more divergent from $P$. spathulata subsp. spathulata and closer to $P$. raoulii than expected based on morphology and previous classifications. Sykes (1988) noted that the main difference is a persistent taproot in subsp. picta, although they may also be differentiated by hairs either on the keels of bracts and sepals (subsp. spathulata) or only on the margins of bracts and sepals (subsp. picta) (Moore in Allan 1961). This is mirrored in Rahn's (1996) morphological phylogeny, where subsp. picta is separated from subp. spathulata by only 5 steps (3 characters) which are: absence/presence of adventitious roots, whether or not the sepals are glabrous abaxially, and 1-4 ovules per ovary with a rudiment of an upper compartment on the adaxial side of the placenta. This suggests that although the two taxa are genetically divergent, they may share many plesiomorphic character states. The divergence of the two subspecies and the placement of subsp. picta as closely related to the population of $P$. raoulii from Cass is also evident in the Splitstree analysis of Clade II (Fig. 4.7A). They are allopatric: subsp. picta is endemic to East Cape and the Poverty Bay Coast in the N. I. (Sykes in Webb et al. 1988), whereas subsp. spathulata is found in the Wairarapa coast and throughout the S. I. Phylogenetic analyses suggest that the two taxa are not each other's closest relatives. However, additional samples of subsp. picta should be sequenced and although these results suggest that they are distinct species, it would be impractical to recognise them taxonomically without reliable and consistent morphological differences. 


\section{Plantago raoulii}

There are reportedly two sympatric forms of P. raoulii (Sykes in Webb et al. 1988, C. Ogle pers. comm.) distinguished by broad vs. narrow leaves. These two distinct forms were collected for this study (Figs. 4.1B, 4.4E \& F). However, both ML and Splitstree analyses indicated that there was no genetic differentiation between populations of $\mathrm{N}$. I. $P$. raoulii found here that are consistent with morphology, i.e., there was no difference in the morphology of the plants that formed the separate poorly supported clades, and there were individuals from the same population that occurred in separate clades (but again no difference in morphology). Thus, it appears that the two forms of P. raoulii may simply be ecotypes or represent simple polymorphisms.

The phylogenetic analyses also show that $P$. raoulii is separated by geographic location (i.e. N. I. and Cass populations were in different groups). It is possible that the $P$. raoulii population from Cass may be related to $P$. "sylvester" because they group together with high support. The habitats of the Cass and Lake Sylvester samples were similar (flush among Schoenus) and their morphology and flowering times in cultivation are very similar (Garnock-Jones pers. comm.), but $P$. raoulii from a location near to Cass has been found to have $2 n=48$ (Groves and Hair 1971). Further studies and additional samples of $P$. raoulii from S. I. are needed to clarify this observation.

\section{Plantago lanigera}

In agreement with Sykes (in Webb et al. 1988), there was not enough molecular evidence to distinguish between the two forms previously known as P. lanigera and $P$. novae-zelandiae (e.g. Moore in Allan 1961) in the dataset. There was weak support 
for a $P$. lanigera clade that included the two different forms (excluding two samples of $P$. lanigera) but no support for any difference between populations within the group (Fig. 4.5A). Thus, there is no evidence to refute the conspecificity of $P$. lanigera and P. novae-zelandiae (Sykes in Webb et al. 1988). There appears to be no barrier to genetic interchange among populations, although some reticulation in the history of $P$. lanigera is suggested from Splitstree analysis (Fig. 4.7B). An odd finding in the ML phylogeny is that some but not all individuals from two populations (Mt. Wilberg and Ruahines) were placed in a clade with $P$. aucklandica, which is sister to the larger $P$. lanigera clade. Samples from Mt. Wilberg were present in both clades, which indicate that they are not grouped according to geographic location. Two scenarios may explain this finding: that there were two different species collected in both locations, or that more variation exists within populations than between populations. The latter appears to be more plausible as samples collected from either population were morphologically indistinguishable.

\section{Plantago triandra}

Sampling in this study included populations referable to both $P$. triandra subsp. triandra and subsp. masoniae based on morphology. Although two clades of $P$. triandra were resolved, each contained both samples from both subsp. triandra and subsp. masoniae (Fig. 4.6A). Populations of the two were also not separated in the Splitstree analysis (Fig. 4.7C). Sykes (1988) distinguished subsp. masoniae from $P$. triandra subsp. triandra by fleshier leaves that differ in size. Morphological differences between coastal and inland plants appear to be cosistent (see Fig. 4.1E \& F), but unfortunately, some components relating to the thickness of leaves, size, shape and even whether the leaves are toothed or entire appear to be plastic depending on 
environment and seasonal changes (personal observation from plants in the greenhouse). Thus, although two morphological groups can be distinguished, there is no genetic evidence for separation of these two into separate subspecies. Several populations of subsp. triandra even share identical ITS sequences with individuals from a population of subsp. masoniae. These two morphological forms appear to be ecotypes and recognition at a lower rank (i.e. variety) might be more appropriate.

\section{Species relationships}

Plantago "sylvester"

The 16-ploid $P$. "sylvester" may be an allopolyploid between $P$. raoulii and $P$. spathulata subsp. spathulata. There are morphological characteristics that link it to these two species: $P$. "sylvester" plants resemble $P$. spathulata by having two long seeds in each locule, and broad glabrous corolla lobes (Moore in Allan 1961); whereas they resemble $P$. raoulii in only having four vertical seeds, and the habit of the plants appear to resemble $P$. raoulii morphologically (Sykes in Webb et al. 1988). $P$. "sylvester" has a chromosome number of $2 n=96$, while both $P$. spathulata and $P$. raoulii have chromosome numbers of $2 n=48 . P$. "sylvester" is sister to a sample of P. raoulii from Cass (S. I.) in the ML analysis (Figs. 3A) and these are at almost equal distances from the N. I. P. raoulii and P. spathulata subsp. spathulata in the Splitstree analysis (Fig. 4.7A). Until the morphological recognition and geographic range of $P$. "sylvester" are better known, it would be imprudent to recognise it as a new species.

\section{Plantago obconica}

The ITS phylogeny reconstructed in this study (Fig. 4.3) and a three genome phylogeny discussed previously (Fig. 3.2) both show that $P$. obconica is closely 
related to $P$. lanigera and not $P$. triandra as previously suggested based on morphology (Sykes in Webb et al. 1988). Thus, morphological similarities between $P$. obconica and P. triandra appear to have arisen convergently. P. obconica should be classified within sect. Oliganthos.

\section{Plantago triantha and Plantago aucklandica}

Plantago triantha is currently placed within sect. Oliganthos (Rahn 1996). However, it is placed with species from sect. Mesembrynia in the ITS phylogeny (Fig. 4.3) because it is very similar to $P$. spathulata subsp. spathulata genetically. $P$. aucklandica is placed in sect. Plantago (Rahn 1996) but groups with other species from sect. Oliganthos (Fig. 4.3 and Fig. 3.2). P. triantha and P. aucklandica should be reclassified in those groups.

\subsubsection{Implications of this study}

The reconstructed ITS phylogeny presented here using ITS sequences did not match the concatenated ML tree presented in the previous chapter (the latter resembles and is strongly influenced by the tree of the cpDNA spacer $n d h F-r p l 32)$. This outcome was also encountered in the previous chapter comparing trees of the ITS and organellar regions. Plantago triandra, P. unibracteata, P. muelleri and P. paradoxa showed conflicting organellar and nuclear DNA signals. The phylogeny presented in Chapter three had many branches with high BP support compared to the ITS phylogeny presented here where support values (PP) were mostly quite low. Thus, this conflict might simply be a result of poor sequence divergence among the four species, i.e. phylogenetic analyses may not be able to place them in the tree and they are placed as a polytomy at the base of the clade instead. Trans-Tasman hybridisation 
events in the past may also have caused the incongruence, but this is a less likely explanation because migration, hybridisation, and extinctions must all be postulated. All four species are currently placed in sect. Oliganthos but if placement of $P$. paradoxa and $P$. muelleri follows that as indicated by the ITS phylogeny, they may have to be reclassified to sect. Mesembrynia.

The South American species are found in two groups in the ITS phylogeny (in Clade I and Clade III). Thus, the South American species are not showing patterns consistent with those expected as a result of Gondwanan vicariance, i.e. one clade each of New Zealand, South American and Australian species, with an expected relationship of $(($ Australia + South America) New Zealand) according to breakup sequence or multiple paralogous repeats of this pattern. In addition, Plantago stauntoni from the Amsterdam \& St. Paul Islands (Southern Indian Ocean) is nested within the Australasian species. The phylogeny suggests that the ancestor of $P$. stauntoni dispersed there from Australasia but it is unclear from Fig. 4.3 exactly where it dispersed from.

For the three Australasian clades, there is little resolution and low support for any resolved clades with ITS alone (Figs. 4.3 - 4.5) but it was shown in Chapter three that a concatenated dataset, including organellar DNA sequences were able to resolve species relationships (Fig. 3.2). Splitstree analyses back up the topology reconstructed by ML analyses but the neighbour net analyses revealed several additional reticulate relationships that were not illustrated in the ML trees (Fig. 4.7). However, analysis using Splitstree also showed difficulty in delineating species within the group. The lack of resolution and low support for clades may be a result of the low sequence 
divergence among Australasian species (Table 4.3, Appendix III (B)). For example, the interspecific p-distance range $(0.002-0.008)$ between Plantago triandra and $P$. unibracteata is extremely low and results in no resolution between the two in the ML phylogeny. The low sequence divergence coupled with variable morphology is consistent with the pattern found in most New Zealand plants that have undergone recent speciation (e.g. Winkworth et al. 1999; Winkworth et al. 2002a); changes in relatively few loci may result in huge morphological differences (Winkworth et al. 1999). It may also be that the ITS region is not the best marker to capture genetic variation at this level. Other molecular data such as amplified fragment length polymorphism (AFLP) and randomly amplified polymorphic DNA (RAPD) are increasingly being applied for plant groups with low genetic variability and thus, use of these resources, along with wider sampling, may be able to improve resolution of species relationships in Australasian Plantago (e.g. Wolff and Morgan-Richards 1999; Meudt and Bayly 2008). If the New Zealand species have had a recent origin and not much genetic divergence, concatenation of multiple independent loci may also be helpful as long as little hybridisation in the group has occurred.

It was found during phylogenetic analyses that samples of $P$. triandra and $P$. unibracteata were inseparable genetically (Figs. 4.6A, 4.7C). It is interesting to note that $P$. unibracteata has previously been treated as a variety of $P$. triandra (Table 4.1). Wider population sampling of both species will be able to clarify if this observation stands, which may lead to reclassification of $P$. unibracteata.

It is also interesting to note that Plantago aucklandica appears to have a recent origin from within P. lanigera (Fig. 4.5A). P. aucklandica is found in Auckland Islands and 
the subantarctic islands, and could be classified as a megaherb. Thus, if this relationship is true, then $P$. aucklandica appears to have a different history from that suggested by Wagstaff et al. (2007), which is that subantarctic megaherb lineages are old and are sister to large New Zealand clades.

Plantago sp. might represent a recent addition to the naturalised flora of New Zealand because it does not match any of the reported species in Sykes (in Webb et al. 1988). While P. asiatica is common and widespread in Asia, it has never been found in New Zealand. The taxonomic status of $P$. tasmanica and $P$. daltonii were discussed by Brown (1981), who mentioned that morphologies of the two species are very similar. Field and glasshouse experiments revealed that differences in leaf morphology remain consistent between species, although there is some degree of plasticity in leaf morphology. There were two sequences each of $P$. daltonii and $P$. tasmanica and they were all identical (except for a few ambiguous sites in the sequences). Their close genetic similarity mirrors their close morphological similarity. This suggests that the two may not be isolated from one another but there is not enough sampling to clarify their taxonomic status in this study.

Additionally, it was found that genetic divergence in New Zealand Plantago is highest within populations, followed by between populations. There is the least amount of variation between species. This pattern is also not expected because the ITS region undergoes concerted evolution (Álvarez and Wendel 2003), which should reduce genetic divergence within populations. Explanations for this unexpected pattern could be incomplete speciation within many lineages, or that the plants are undergoing dispersal around the North and South Islands. Additionally, Plantago 
plants are wind-pollinated, which suggests that genetic exchange could occur over long distances and it also appears that biotic seed dispersal is not limited, as evidenced by widespread dispersal and presence of many cosmopolitan species in the genus.

\subsubsection{Conclusions and future directions}

In summary, this study is important because it shows the placement of most of the Australasian species in a worldwide Plantago phylogeny. DNA sequences for 13 Australasian species were added to the Plantago phylogeny, which now includes about 80 Plantago species out of ca. 210 so far, excluding Littorella. Analysis of the ITS dataset revealed that the Australasian species have very little interspecific genetic differences, even though extensive morphological variation may exist. Taxonomy has been difficult for the genus because of plastic morphological characters and flower reduction associated with wind pollination. The New Zealand Plantago species are no exception; the morphology of plants in cultivation changes dramatically according to environmental and seasonal change (see Fig. 4.1) The complex evolutionary history in the New Zealand Plantago species as indicated by Splitstree analyses require further investigation because processes such as hybridisation or incomplete lineage sorting may be involved in this group. In addition to reticulation, recurrent polyploidy appears to be a common speciation mechanism in the group, suggested by variable chromosome numbers and demonstrated by the Australasian species and is probably associated with hybrid speciation. The groups are also separated by altitude: whether plants are found in alpine/subalpine or lowland habitats appears to relate to the separation of the New Zealand groupings. 
Additionally, it is evident from the ITS phylogeny presented in this study that the current taxonomic classifications of many New Zealand species (i.e. $P$. spathulata, $P$. triandra, P. obconica, P. aucklandica and P. triantha) need revision.

It is shown here that while ITS is the most commonly used marker in plant studies (Álvarez and Wendel 2003) and also in Plantago phylogenetic studies (Rønsted et al. 2002; Hoggard et al. 2003), it may not be the most suitable marker for investigating genetic variation in recently diverged species. Resolution in the phylogeny of Australasian species may be increased with wider population sampling and utilising markers from faster evolving regions such as from the cpDNA or non-sequence markers such as RAPD or AFLP. The relationships between the two subspecies currently classified under $P$. spathulata require further studies, with increased sampling of $P$. spathulata subsp. picta.

Additional chromosome counts should be made, especially for the $P$. raoulii from the S. I., which appears to be closely related to the 16-ploid $P$. "sylvester". Also, $P$. lanigera in the ITS phylogeny included samples within two populations that were widely separated in the phylogenetic tree (Fig. 4.5A) and in the Splitstree analysis (Fig. 4.7B). Given that two chromosome numbers are known within this complex (Grove and Hair 1971; Sykes 1988), chromosome counts would also be interesting for these samples. 


\section{Chapter Five: General Discussion}

The aim of this thesis was to generate molecular sequence data to: 1) elucidate the phylogeny and biogeography of the Australasian species of Plantago (Plantaginaceae) and 2) investigate evolutionary patterns and taxonomy of the New Zealand Plantago species. One region each from nuclear DNA, chloroplast DNA and mitochondrial DNA were chosen for amplification and sequencing of DNA from 20 Australasian Plantago species. Phylogenies for markers from each of the three genomes (ITS, $n d h F-r p l 32$, and coxl) were reconstructed for the Australasian species to examine biogeographic patterns of the group in the Southern Hemisphere. Following this, new ITS sequences of 150 Plantago individuals were integrated into a larger phylogeny of Plantago, which included published sequences of other species distributed worldwide to investigate placement of the Australasian species. Phylogenetic analyses of the three New Zealand clades that were resolved in the ITS and concatenated phylogenies revealed several evolutionary patterns and assist species delimitations of the New Zealand species, which are outlined in this chapter.

\subsection{Choosing a suitable region for phylogenetic analyses}

The most commonly used region for plant phylogenetic analyses is the Internal Transcribed Spacer (ITS) from nuclear DNA. Despite its advantages, markers from other regions may sometimes prove to be more useful for reconstructing phylogenies, either by themselves or in conjunction with ITS. In this thesis, amplification and sequencing using 24 primer pairs from all three plant genomes was tested on four Plantago species (P. spathulata subsp. spathulata and P. triandra subsp. triandra from New Zealand; P. euryphylla from Australia; and the cosmopolitan P. lanceolata) 
and a relative from the same family (Veronica stricta from New Zealand). Out of eleven primer pairs with consistent, clean amplification across all species (Table 2.1), the ITS from the nuclear genome and the intergenic spacer $n d h F$-rpl32 from the chloroplast genome were chosen for further phylogenetic studies because of their ease of amplification and adequate sequence diversity (2.8\% for ITS and $2.1 \%$ for $n d h F$ rpl32, comparing the two New Zealand species). While mitochondrial DNA (mtDNA) substitution rates are traditionally regarded as very slow in plants (Wolfe et al. 1987), a high rate of mtDNA evolution has been found in Plantago (Cho et al. 2004). Therefore, coxl from the mtDNA was also chosen to compare rates found in Australasian mtDNA with rates found in previous studies, and for phylogeny reconstruction in this study.

Comparisons between the two New Zealand species revealed that ITS and $n d h F-r p l 32$ had relatively higher sequence variation than coxl, whereas coxl had more variation when comparing the Australasian species with the cosmopolitan Plantago lanceolata (Table 2.3). In Chapter Four, phylogenetic analyses indicated that ITS is not a suitable marker for investigating New Zealand species relationships because very little genetic differences were found between species. In Chapter Three, the $n d h F$-rpl32 region was found to have better variation between species, and higher resolution in the phylogeny compared to the ITS region. It was also shown that the coxl marker provided very little resolution in the Australasian group. Thus, the use of fast evolving chloroplast markers is recommended for further studies involving Australasian Plantago. 


\subsection{Phylogeny of Plantago}

Previous molecular phylogenies reconstructed for Plantago included only three and six species (Rønsted et al. 2002 and Hoggard et al. 2003, respectively) out of a total of 32 Australasian species. Inclusion of the Australasian species is essential for elucidating biogeographic patterns of Southern Hemisphere Plantago, and to investigate unclear Australasian species relationships. In this thesis, inclusion of sequences from 20 Australasian species in the worldwide ITS phylogeny revealed that all the Australasian species are placed in a clade of subg. Plantago (Fig. 4.2). The subg. Plantago clade is separate from a clade comprising the four other subgenera (subg. Psyllium, subg. Albicans, subg. Bougeria, and subg. Coronopus). This clade also includes a clade of species that are native to America (including South America), Africa, Asia, Ilha Trindade, Europe, and several cosmopolitan species. P. stauntoni from the Amsterdam \& St. Paul Islands was nested within the Australasian species.

There was some incongruence between phylogenies reconstructed using the ITS dataset and either of the organelle datasets caused by different placements of sequences of $P$. triandra and $P$. unibracteata (New Zealand species), and $P$. muelleri and $P$. paradoxa (Australian species) in the phylogenies. Explanations for this incongruence included low resolution in the ITS phylogeny within the Australasian group, or reticulation in the evolutionary history of these species (e.g. trans-Tasman hybridisation). The lack of resolution in the ITS phylogeny is most likely because there was low support for the placement of these species in the ITS phylogeny (Fig. 4.3) but high support in the concatenated phylogeny (Fig. 3.2). 
The phylogeny displaying branch lengths of the coxl region for the Australasian species (Fig. 3.3C) revealed that while there is an elevated rate of mitochondrial evolution between Australasian species and the two introduced species ( $P$. lanceolata and $P$. coronopus) that were included, the elevated rate is not present among Australasian species. This could be due to recent radiations in the group, which is not uncommon in endemic New Zealand groups (Heenan et al. 2002; Murray et al. 2004; Wagstaff and Garnock-Jones 1998). However, different Plantago lineages have also been found to have either substitution rate increases or rate decreases (Cho et al. 2004) and the branch lengths could simply indicate that there has been a decrease in substitution rate in the Australasian Plantago species. The latter situation is more likely to be true, as there was no decrease in substitution rate evident in the other markers (ITS or $n d h F-r p l 32$ ), which is expected if speciation was the result of more recent rapid radiations.

\subsection{Biogeography of Australasian Plantago}

Reconstructions of molecular phylogenies for Southern Hemisphere plant groups have revealed that long distance dispersal has been an important process in most plant groups (Radford et al. 2001; Swenson et al. 2001; von Hagen and Kadereit 2001; Heenan et al. 2002; Hurr et al. 1999; Lockhart et al. 2001; Winkworth et al. 2002; Zhang and Renner 2003; Perrie and Brownsey 2005; Barker et al. 2007; Perrie and Brownsey 2007; Perrie et al. 2007; Sanmartín et al. 2007) but there is still evidence of Gondwanan vicariance in a few plant lineages (Stöckler et al. 2002, Knapp et al. 2007). Most New Zealand plant groups also have one dispersal event to New Zealand, followed by speciation (Wagstaff and Garnock-Jones 1998; Winkworth et al. 1999; Perrie et al. 2003; Albach et al. 2005; Meudt and Simpson 2006). A meta-analysis of 
plant phylogenetic studies has shown that dispersal between Australia and New Zealand is asymmetrical, and most dispersal events have occurred in the direction of West to East due to West Wind Drift and oceanic currents (Sanmartín et al. 2007).

In this thesis, the hypothesis of Gondwanan vicariance for the Southern Hemisphere Plantago was rejected because there was no evidence of monophyletic groups of Australian, New Zealand and South American species, respectively, in the phylogeny. Further, New Zealand clades and species are more closely related to Australian groups than to South American clades and species. Molecular dating techniques provided evidence for long distance dispersal within the Australasian Plantago. It was found that there was too little genetic divergence among the Australasian species to infer a Gondwanan origin for the group. The origin for the Australasian clade was estimated to be within 1.5 to 2.2 million years ago, which is consistent with the uplift of the Southern Alps in the South Island of New Zealand.

The phylogeny of the concatenated dataset (ITS $+n d h F-r p l 32+\operatorname{coxl})$ suggests at least three long distance dispersal events to New Zealand from Australia (Fig. 3.2). This direction of dispersal is consistent with patterns influenced by the West-Wind Drift and ocean currents (Sanmartín et al. 2007) but differs from the common pattern of one origin of most New Zealand groups. These long distance events also reflect dispersal of species that were already adapted to the alpine/subalpine or lowland environment in Australian lineages before establishment in New Zealand. One habitat shift event from the alpine/subalpine zone to lowland habitats in Australasian Plantago can be postulated from the phylogeny. Additionally, the ancestor of $P$. 
stauntoni, which is native to the Amsterdam \& St. Paul Islands, appears to have dispersed from within Australasia.

\subsection{Taxonomy of New Zealand Plantago}

Taxonomy of plant groups in New Zealand has been difficult because of extreme morphological variation but a common pattern of low genetic divergence, which is associated with the recent origin or recent radiations of many plant lineages in New Zealand (Winkworth et al. 1999; Smissen et al. 2004). Taxonomy within the genus Plantago has also been difficult because plants in the genus have extremely plastic morphological characters (Sykes in Webb et al. 1988; Rahn 1996). Difficult species delimitations in the New Zealand species of Plantago have resulted in multiple taxonomic changes in the past (Moore in Allan 1961; Sykes in Webb et al. 1988). These changes were used to represent hypotheses of species questions in this study. No previous molecular studies have included more than two New Zealand species when reconstructing the phylogeny of the genus (Rønsted et al. 2002; Hoggard et al. 2003).

In this thesis, phylogenetic analyses using ITS sequences were able to show that there was no genetic difference between morphological forms recognized within each of Plantago lanigera, $P$. triandra and $P$. raoulii. Therefore, the rank of $P$. lanigera and $P$. raoulii should be maintained; in addition, the two subspecies described under $P$. triandra are not supported by molecular data. Genetic distinctions between $P$. triandra and $P$. unibracteata were also unclear. P. spathulata subsp. picta and $P$. spathulata subsp. spathulata did not group together in the phylogeny, which indicates that the two are not as closely related as previously thought based on similarity of 
morphological characters. However, only one sample of $P$. spathulata subsp. picta was obtained for this study. With more sampling, there may be substantial evidence for P. spathulata subsp. picta to be restored to species rank (P. picta as in (Moore in Allan 1961). The placement of $P$. obconica in the phylogeny of a concatenated ITS, $n d h F-r p l 32$ and coxl dataset (Fig. 3.2) clearly indicated that $P$. obconica is closely related to $P$. lanigera, not $P$. triandra as previously suggested (Sykes 1988) and should therefore be classified within sect. Oliganthos. Additionally, Plantago triantha perhaps should be placed in sect. Mesembrynia and P. aucklandica in sect. Oliganthos.

Low resolution found in phylogenies might be a result of low genetic divergence found among Australasian species using the ITS marker (Table 4.2, appendix 4.4), and the $n d h F-r p l 32$ and coxl markers (Table 2.3). The highest genetic divergence among New Zealand Plantago species $(2.8401 \%)$ was found in ITS, which is also low.

Splitstree analyses (Fig. 4.7) and the ML phylogeny using ITS sequences (Fig. 4.4) revealed that the placement of several specimens of $P$. lanigera (from the Eyre Mountains and Sugarloaf Pass) were not well-defined (Fig. 4.6). Further studies should include more specimens of these, along with nearby samples, to determine if these could be hybrids, which could explain their ambiguous placements in the phylogenetic analyses.

\subsection{Evolutionary patterns}

Phylogenetic analyses suggest that adaptation to different habitats and altitudes (i.e. alpine/subalpine, lowland or coastal) may have played an important role in speciation within New Zealand Plantago. There are eight native New Zealand species: $P$. 
lanigera, $P$. obconica, $P$. unibracteata, $P$. aucklandica and $P$ triandra subsp. triandra can be found in the alpine/subalpine region; $P$. triantha, $P$. triandra subsp. masoniae and P. spathulata subsp. picta can be found in coastal areas; and P. spathulata subsp. spathulata and $P$. raoulii can be found from coastal regions to altitudes of ca. 1000 and 1500m, respectively (Sykes in Webb et al. 1988). Separation of species according to altitude is backed up by the ITS phylogeny (Fig. 4.3), and also in the concatenated (ITS, ndhF-rpl32 and coxl) phylogeny (Fig. 3.2), where the New Zealand lowland species are separated from the alpine/subalpine species. The molecular phylogeny also suggests that the New Zealand species were pre-adapted to the alpine/subalpine and lowland habitats, with a more recent origin for the lowland species. There appears to have been a single migration event into lowland habitats from alpine/subalpine groups.

The New Zealand species have variable chromosome numbers $(2 n=12,24,48,60$ and 96) which may act as a reproductive barrier where distributions overlap. For example, $P$. unibracteata and $P$. lanigera can be found growing at the same location but have different chromosome numbers $(2 n=60$ and $2 n=12 / 24$, respectively). Polyploidy may be a mechanism of rapid speciation within the group. A good example is $P$. "sylvester" $(2 n=96)$, which is suggested to be a hybrid of $P$. spathulata subsp. spathulata and $P$. raoulii (both $2 n=48$ ). Different flowering times, along with the limited dispersal of pollen and seeds may also present a biological barrier to genetic exchange, which may promote speciation. 


\subsection{Future directions}

One of the problems encountered in this thesis is that the New Zealand Plantago species have very little intra- and interspecific genetic divergence, resulting in little resolution within the group in all three markers. Wider population sampling within New Zealand or the addition of further independent genetic markers may help overcome this problem. Other genetic data such as randomly amplified polymorphic DNA (RAPD) and Amplified Fragment Length Polymorphism (AFLP) are often used for lineages that have little genetic divergence (e.g. Wolff and Morgan-Richards 1999; Meudt and Bayly 2008) and may be able to provide further resolution within the New Zealand groups. Wider population sampling throughout New Zealand and addition of genetic material would also help to clarify identities of ambiguously placed populations or individuals, such as the $P$. lanigera populations from Sugarloaf Pass and Eyre Mountains.

Additional chromosome counts to those reported by Groves and Hair (1971) would be invaluable in future studies for specimens suspected of being hybrids, like the South Island specimens of $P$. raoulii (i.e. chromosome counts will be able to determine if they are 16-ploids like $P$. "sylvester"). Additional counts and sampling should be made for $P$. "sylvester" specimens, including morphologically similar plants that have been reported in the Gouland Downs (Moore in Allan 1961). In addition, the two chromosome races within the $P$. lanigera complex also require further sampling and their relationship to morphological variation, habitats, distributions, and sympatry needs further work to clarify the taxonomic status of the individuals currently placed under P. lanigera. 
For Plantago phylogeny reconstruction and biogeographic analyses, the ITS and $n d h F-r p l 32$ datasets could be expanded to include all of the Australian species, some samples of species distributed around the Pacific (such as Hawaii, Tonga, Juan Fernández, and New Guinea), and additional South American species. This would contribute to the understanding of distribution patterns, especially in the Southern Hemisphere. Additionally, genetic data could also be used to investigate unclear species relationships for Australian Plantago.

\subsection{Conclusions}

It was shown here that the Plantago phylogeny reconstructed using sequences from all three plant genomes, along with some molecular dating work, rejected the hypothesis of vicariance from Gondwana. Instead, the origin of the Australasian species appears to be through three long distance dispersal events of pre-adapted lineages. In addition, a phylogram of the coxl region suggests that the high rate of mtDNA evolution observed in Plantago by Cho et al. (2004) has slowed down in the Australasian group. In regard to New Zealand Plantago taxonomy, phylogenetic analyses in the Australasian group has shown that $P$. lanigera, $P$. raoulii and $P$. triandra should remain as species, with abolition of the subspecies within P. triandra, and that the two subspecies of $P$. spathulata should be recognised at species rank (as in Moore in Allan 1961). P. obconica, P. triantha and P. aucklandica need to be reclassified. Additionally, ITS may not be a suitable marker for investigating species boundaries within this group. NdhF-rpl32 from the fast-evolving chloroplast region may be more useful for future phylogenetic work. Chromosome counts, utilization of additional genetic markers, and expansion of the molecular datasets (both within New 
Zealand and outside) will be able to provide more answers, particularly for taxonomic work on the genus. 


\section{Literature cited}

Albach, D. C. and M. W. Chase (2001). Paraphyly of Veronica (Veroniceae; Scrophulariaceae): Evidence from the internal transcribed spacer (ITS) sequences of nuclear ribosomal DNA. Journal of Plant Research 114(1113): $9-18$.

Albach, D. C. and M. W. Chase (2004). Incongruence in Veroniceae (Plantaginaceae): evidence from two plastid and a nuclear ribosomal DNA region. Molecular Phylogenetics and Evolution 32(1): 183-197.

Albach, D. C., H. M. Meudt and B. Oxelman (2005a). Piecing together the "new" Plantaginaceae. American Journal of Botany 92(2): 297-315.

Albach, D. C., T. Utteridge and S. J. Wagstaff (2005b). Origin of Veroniceae (Plantaginaceae, formerly scrophulariaceae) on New Guinea. Systematic Botany 30(2): 412-423.

Allan, H. H. (1961). Flora of New Zealand. Vol I. Indigenous tracheophyta. Wellington, Government Printer.

Álvarez, I. and J. F. Wendel (2003). Ribosomal ITS sequences and plant phylogenetic inference. Molecular Phylogenetics and Evolution 29(3): 417-434. 
Bakker, F. T., F. Breman and V. Merckx (2006). DNA sequence evolution in fast evolving mitochondrial DNA nad1 exons in Geraniaceae and Plantaginaceae. Taxon 55(4): 887-896.

Bakker, F. T., A. Culham, C. E. Pankhurst and M. Gibb (2000). Mitochondrial and cloroplast DNA-based phylogeny of Pelargonium (Geraniaceae) (vol 87, pg 727, 2000). American Journal of Botany 87(7): 933-933.

Barker, N. P., P. H. Weston, F. Rutschmann and H. Sauquet (2007). Molecular dating of the 'Gondwanan' plant family Proteaceae is only partially congruent with the timing of the break-up of Gondwana. 34: 2012-2027.

Barton, K. E. (2007). Early ontogenetic patterns in chemical defense in Plantago (Plantaginaceae): Genetic variation and trade-offs. American Journal of Botany 94(1): 56-66.

Batt, G. E., J. Braun, B. P. Kohn and I. McDougall (2000). Thermochronological analysis of the dynamics of the Southern Alps, New Zealand. Geological Society of America Bulletin 112(2): 250-266.

Bello, M. A., M. W. Chase, R. G. Olmstead, N. Ronsted and D. Albach (2002). The paramo endemic Aragoa is the sister genus of Plantago (Plantaginaceae; Lamiales): Evidence from plastid $r b c L$ and nuclear ribosomal ITS sequence data. Kew Bulletin 57(3): 585-597. 
Breitwieser, I., D. S. Glenny, A. Thorne and S. J. Wagstaff (1999). Phylogenetic relationships in Australasian Gnaphalieae (Compositae) inferred from ITS sequences. New Zealand Journal of Botany 37(3): 399-412.

Bremer, K. and M. H. G. Gustafsson (1997). East Gondwana ancestry of the sunflower alliance of families. Proceedings of the National Academy of Sciences of the United States of America 94(17): 9188-9190.

Briggs, B. G. (1992). Plantago. Sydney, Royal Botanic Gardens \& Domain Trust.

Brown, M. J. (1981). An Experimental Taxonomic Study of Plantago Tasmanica Hook. F. and P. Daltonii Dene. Australian Journal of Botany 29(4): 441-452.

Buckley, T. R. and C. Simon (2007). Evolutionary radiation of the cicada genus Maoricicada Dugdale (Hemiptera : Cicadoidea) and the origins of the New Zealand alpine biota. Biological Journal of the Linnean Society 91(3): 419435.

Carels, N. and G. Bernardi (2000). Two classes of genes in plants. Genetics 154(4): 1819-1825.

Chacón, J., S. Madriñan, M. W. Chase and J. J. Bruhl (2006). Molecular phylogenetics of Oreobolus (Cyperaceae) and the origin and diversification of the American species. Taxon 55(2): 359-366. 
Cheeseman, T. F. (1906). Manual of the New Zealand flora. Wellington, Government Printer.

Cheeseman, T. F. (1925). Manual of the New Zealand flora. Wellington, Government Printer.

Cho, Y., J. P. Mower, Y. L. Qiu and J. D. Palmer (2004). Mitochondrial substitution rates are extraordinarily elevated and variable in a genus of flowering plants. Proceedings of the National Academy of Sciences of the United States of America 101(51): 17741-17746.

Chung, K. F., C. I. Peng, S. R. Downie, K. Spalik and B. A. Schaal (2005). Molecular systematics of the trans-Pacific alpine genus Oreomyrrhis (Apiaceae): Phylogenetic affinities and biogeographic implications. American Journal of Botany 92(12): 2054-2071.

Connor, H. E. (1985). Biosystematics of Higher Plants in New Zealand 1965-1984. New Zealand Journal of Botany 23(4): 613-643.

Cooper, A. and R. A. Cooper (1995). The Oligocene Bottleneck and New-Zealand Biota: Genetic Record of a Past Environmental Crisis. Proceedings of the Royal Society of London Series B-Biological Sciences 261(1362): 293-302. 
Cooper, R. A. and P. R. Millener (1993). The New Zealand Biota: Historical Background and New Research. Trends in Ecology \& Evolution 8(12): 429433.

Cox, S. C. and R. H. Findlay (1995). The Main Divide Fault Zone and its role in formation of the Southern Alps, New Zealand. New Zealand Journal of Geology and Geophysics 38(4): 489-499.

Crayn, D. M., M. Rossetto and D. J. Maynard (2006). Molecular phylogeny and dating reveals an Oligo-Miocene radiation of dry-adapted shrubs (former Tremandraceae) from rainforest tree progenitors (Elaeocarpaceae) in Australia. American Journal of Botany 93(9): 1328-1342.

Cummings, M. P., S. P. Otto and J. Wakeley (1995). Sampling Properties of DNA Sequence Data in Phylogenetic Analysis. Molecular Biology and Evolution 12(5): $814-822$.

Dagar, J. C., Y. Kumar and O. S. Tomar (2006). Cultivation of medicinal isabgol (Plantago ovata) in alkali soils in semiarid regions of Northern India. Land Degradation \& Development 17(3): 275-283.

de Lange, P. J., P. B. Heenan, D. J. Keeling, B. G. Murray, R. Smissen and W. R. Sykes (2007). Biosystematics and Conservation: A Case Study with Two Enigmatic and Uncommon Species of Crassula from New Zealand: mcm294. 
de Queiroz, A. (2005). The resurrection of oceanic dispersal in historical biogeography. Trends in Ecology \& Evolution 20(2): 68-73.

Decker-Walters, D. S., S. M. Chung and J. E. Staub (2004). Plastid sequence evolution: A new pattern of nucleotide substitutions in the Cucurbitaceae. Journal of Molecular Evolution 58(5): 606-614.

Demesure, B., N. Sodzi and R. J. Petit (1995). A Set of Universal Primers for Amplification of Polymorphic Noncoding Regions of Mitochondrial and Chloroplast DNA in Plants. Molecular Ecology 4(1): 129-131.

Dhar, M. K., B. Friebe, S. Kaul and B. S. Gill (2006). Characterization and physical mapping of ribosomal RNA gene families in Plantago. Annals of Botany 97(4): $541-548$.

Doyle, J. J., J. I. Davis, R. J. Soreng, D. Garvin and M. J. Anderson (1992). Chloroplast DNA Inversions and the Origin of the Grass Family (Poaceae). Proceedings of the National Academy of Sciences of the United States of America 89(16): 7722-7726.

Doyle, J. J. and J. D. Doyle (1990). Isolation of plant DNA from fresh tissue. Focus 12: $13-15$.

Drummond, A. J., S. Y. W. Ho, M. J. Phillips and A. Rambaut (2006). Relaxed phylogenetics and dating with confidence. Plos Biology 4(5): 699-710. 
Feldberg, K., J. Hentschel, R. Wilson, D. S. Rycroft, D. Glenny and J. Heinrichs (2007). Phylogenetic biogeography of the leafy liverwort Herbertus (Jungermanniales, Herbertaceae) based on nuclear and chloroplast DNA sequence data: correlation between genetic variation and geographical distribution. Journal of Biogeography 34(4): 688-698.

Feliner, G. N. and J. A. Rosselló (2007). Better the devil you know? Guidelines for insightful utilization of nrDNA ITS in species-level evolutionary studies in plants. Molecular Phylogenetics and Evolution 44(2): 911-919.

Felsenstein, J. (1981). Evolutionary Trees from DNA-Sequences - a MaximumLikelihood Approach. Journal of Molecular Evolution 17(6): 368-376.

Ford, K. A., J. M. Ward, R. D. Smissen, S. J. Wagstaff and I. Breitwieser (2007). Phylogeny and biogeography of Craspedia (Asteraceae : Gnaphalieae) based on ITS, ETS and psbA-trnH sequence data. Taxon 56(3): 783-794.

Garnock-Jones, P., D. Albach and B. G. Briggs (2007). Botanical names in Southern Hemisphere Veronica (Plantaginaceae): sect. Detzneria, sect. Hebe, and sect. Labiatoides. Taxon 56(2): 571-582.

Gemmill, C. E. C., G. J. Allan, W. L. Wagner and E. A. Zimmer (2002). Evolution of insular Pacific Pittosporum (Pittosporaceae): Origin of the Hawaiian radiation. Molecular Phylogenetics and Evolution 22(1): 31-42. 
Glenny, D. (2004). A revision of the genus Gentianella in New Zealand. New Zealand Journal of Botany 42(3): 361-530.

Greaves, S. N. J., D. G. Chapple, D. M. Gleeson, C. H. Daugherty and P. A. Ritchie (2007). Phylogeography of the spotted skink (Oligosoma lineoocellatum) and green skink (O. chloronoton) species complex (Lacertilia : Scincidae) in New Zealand reveals pre-Pleistocene divergence. Molecular Phylogenetics and Evolution 45(2): 729-739.

Groves, B. E. and J. B. Hair (1971). Contributions to a chromosome atlas of the New Zealand flora - 15 Miscellaneous families. New Zealand Journal of Botany 9: $569-575$.

GuhaMajumdar, M. and B. B. Sears (2005). Chloroplast DNA base substitutions: an experimental assessment. Molecular Genetics and Genomics 273(2): 177-183.

Haase, M., B. Marshall and I. Hogg (2007). Disentangling causes of disjunction on the South Island of New Zealand: the Alpine fault hypothesis of vicariance revisited. Biological Journal of the Linnean Society 91(3): 361-374.

Hale, M. L. and K. Wolff (2003). Polymorphic microsatellite loci in Plantago lanceolata. Molecular Ecology Notes 3(1): 134-135. 
Hasebe, M., T. Omori, M. Nakazawa, T. Sano, M. Kato and K. Iwatsuki (1994). Rbcl Gene-Sequences Provide Evidence for the Evolutionary Lineages of Leptosporangiate Ferns. Proceedings of the National Academy of Sciences of the United States of America 91(12): 5730-5734.

Heenan, P. B., P. J. de Lange and A. D. Wilton (2001). Sophora (Fabaceae) in New Zealand: taxonomy, distribution, and biogeography. New Zealand Journal of Botany 39(1): 17-53.

Heenan, P. B., P. J. Lockhart, K. McBreen and D. Havell (2006). Relationships in the alpine Ranunculus haastii (Ranunculaceae) complex and recognition of $R$. piliferus and $R$. acraeus from southern New Zealand. New Zealand Journal of Botany 44(4): 425-441.

Heenan, P. B., A. D. Mitchell and M. Koch (2002). Molecular systematics of the New Zealand Pachycladon (Brassicaceae) complex: generic circumscription and relationship to Arabidopsis sens. lat. and Arabis sens. lat. New Zealand Journal of Botany 40(4): 543-562.

Hegarty, M. J. and S. J. Hiscock (2005). Hybrid speciation in plants: new insights from molecular studies. New Phytologist 165: 411-423. 
Heinrichs, J., M. Lindner, H. Groth, J. Hentschel, K. Feldberg, C. Renker, J. J. Engel, M. von Konrat, D. G. Long and H. Schneider (2006). Goodbye or welcome Gondwana? insights into the phylogenetic biogeography of the leafy liverwort Plagiochila with a description of Proskauera gen. nov (Plagiochilaceae, Jungermanniales). Plant Systematics and Evolution 258(3-4): 227-250.

Hillis, D. M. and M. T. Dixon (1991). Ribosomal DNA - Molecular Evolution and Phylogenetic Inference. Quarterly Review of Biology 66(4): 410-453.

Hoggard, R. K., P. J. Kores, M. Molvray, G. D. Hoggard and D. A. Broughton (2003). Molecular systematics and biogeography of the amphibious genus Littorella (Plantaginaceae). American Journal of Botany 90(3): 429-435.

Hooker, J. D. (1864). Handbook of the New Zealand flora: a systematic description of the native plants of New Zealand and the Chatham, Kermadecs, Lord Auckland's, Campbell's, and Macquarrie's Islands. London, Reeve \& Co.

Houliston, G. J. and M. S. Olson (2006). Nonneutral evolution of organelle genes in Silene vulgaris. Genetics 174(4): 1983-1994.

Howarth, D. G. and D. A. Baum (2002). Phylogenetic utility of a nuclear intron from nitrate reductase for the study of closely related plant species. Molecular Phylogenetics and Evolution 23(3): 525-528. 
Howarth, D. G. and D. A. Baum (2005). Genealogical evidence of homoploid hybrid speciation in an adaptive radiation of Scaevola (goodeniaceae) in the Hawaiian Islands. Evolution 59(5): 948-961.

Howarth, D. G., M. H. G. Gustafsson, D. A. Baum and T. J. Motley (2003). Phylogenetics of the genus Scaevola (Goodeniaceae): Implication for dispersal patterns across the Pacific Basin and colonization of the Hawaiian Islands. American Journal of Botany 90(6): 915-923.

Huelsenbeck, J. P. and F. Ronquist (2001). MRBAYES: Bayesian inference of phylogenetic trees. Bioinformatics 17(8): 754-755.

Hurr, K. A., P. J. Lockhart, P. B. Heenan and D. Penny (1999). Evidence for the recent dispersal of Sophora (Leguminosae) around the Southern Oceans: molecular data. Journal of Biogeography 26(3): 565-577.

Huson, D. H. and D. Bryant (2006). Application of phylogenetic networks in evolutionary studies. Molecular Biology and Evolution 23(2): 254-267.

Jorgensen, A., T. K. Kristensen and J. R. Stothard (2007). Phylogeny and biogeography of African Biomphalaria (Gastropoda : Planorbidae), with emphasis on endemic species of the great East African lakes. Zoological Journal of the Linnean Society 151(2): 337-349. 
Kay, K. M., J. B. Whittall and S. A. Hodges (2006). A survey of nuclear ribosomal internal transcribed spacer substitution rates across angiosperms: an approximate molecular clock with life history effects. Bmc Evolutionary Biology 6: 36 .

Keller, I., D. Bensasson and R. A. Nichols (2007). Transition-transversion bias is not universal: A counter example from grasshopper pseudogenes. Plos Genetics 3(2): 185-191.

Knapp, M., R. Mudaliar, D. Havell, S. J. Wagstaff and P. J. Lockhart (2007). The drowning of New Zealand and the problem of Agathis. Systematic Biology 56(5): $862-870$.

Knapp, M., K. Stöckler, D. Havell, F. Delsuc, F. Sebastiani and P. J. Lockhart (2005). Relaxed molecular clock provides evidence for long-distance dispersal of Nothofagus (southern beech). Plos Biology 3(1): 38-43.

Koorevaar, G. N., S. Ivanovic, J. M. M. Van Damme, H. P. Koelewijn, W. P. C. Van't Westende, M. J. M. Smulders and B. Vosman (2002). Dinucleotide repeat microsatellite markers for buck's-horn plantain (Plantago coronopus). Molecular Ecology Notes 2(4): 524-526.

Kozan, E., E. Küpeli and E. Yesilada (2006). Evaluation of some plants used in Turkish folk medicine against parasitic infections for their in vivo anthelmintic activity. Journal of Ethnopharmacology 108(2): 211-216. 
Kumar, S., K. Tamura and M. Nei (2004). MEGA3: Integrated software for molecular evolutionary genetics analysis and sequence alignment. Briefings in Bioinformatics 5(2): 150-163.

Kuriiwa, K., N. Hanzawa, T. Yoshino, S. Kimura and M. Nishida (2007). Phylogenetic relationships and natural hybridisation in rabbitfishes (Teleostei : Siganidae) inferred from mitochondrial and nuclear DNA analyses. Molecular Phylogenetics and Evolution 45(1): 69-80.

Lewis, K. B., L. Carter and F. J. Davey (1994). The Opening of Cook Strait Interglacial Tidal Scour and Aligning Basins at a Subduction to Transform Plate Edge. Marine Geology 116(3-4): 293-312.

Linder, H. P. and M. D. Crisp (1995). Nothofagus and Pacific biogeography. Cladistics-the International Journal of the Willi Hennig Society 11(1): 5-32.

Lockhart, P. J., P. A. McLenachan, D. Harell, D. Glenny, D. Huson and U. Jensen (2001). Phylogeny, radiation, and transoceanic dispersal of New Zealand alpine buttercups: Molecular evidence under split decomposition. Annals of the Missouri Botanical Garden 88(3): 458-477.

Manos, P. S., J. J. Doyle and K. C. Nixon (1999). Phylogeny, biogeography, and processes of molecular differentiation in Quercus subgenus Quercus (Fagaceae). Molecular Phylogenetics and Evolution 12(3): 333-349. 
Manzano, P. and J. E. Malo (2006). Extreme long-distance seed dispersal via sheep. Frontiers in Ecology and the Environment 5(5): 244-248.

McBreen, K. and P. B. Heenan (2006). Phylogenetic relationships of Pachycladon (Brassicaceae) species based on three nuclear and two chloroplast DNA markers. New Zealand Journal of Botany 44(4): 377-386.

McDowall, R. M. (2008). Process and pattern in the biogeography of New Zealand - a global microcosm? Journal of Biogeography 35(2): 197-212.

McGlone, M. S. (2005). Goodbye Gondwana. Journal of Biogeography 32(5): 739740.

McGlone, M. S., R. P. Duncan and P. B. Heenan (2001). Endemism, species selection and the origin and distribution of the vascular plant flora of New Zealand. Journal of Biogeography 28(2): 199-216.

Meudt, H. M. and M. J. Bayly (2008). Phylogeographic patterns in the Australasian genus Chionohebe (Veronica s.1., Plantaginaceae) based on AFLP and chloroplast DNA sequences. Molecular Phylogenetics and Evolution In Press, Accepted Manuscript. 
Meudt, H. M. and B. B. Simpson (2006). The biogeography of the austral, subalpine genus Ourisia (Plantaginaceae) based on molecular phylogenetic evidence: South American origin and dispersal to New Zealand and Tasmania. Biological Journal of the Linnean Society 87(4): 479-513.

Meudt, H. M. and B. B. Simpson (2007). Phylogenetic analysis of morphological characters in Ourisia (Plantaginaceae): Taxonomic and evolutionary implications. Annals of the Missouri Botanical Garden 94(3): 554-570.

Mitchell, A. D. and P. B. Heenan (2002). Sophora sect. Edwardsia (Fabaceae): further evidence from nrDNA sequence data of a recent and rapid radiation around the Southern Oceans. Botanical Journal of the Linnean Society 140(4): 435-441.

Mitchell, A. D., C. J. Webb and S. J. Wagstaff (1998). Phylogenetic relationships of species of Gingidia and related genera (Apiaceae, subfamily Apioideae). New Zealand Journal of Botany 36(3): 417-424.

Molvray, M., P. J. Kores and M. W. Chase (1999). Phylogenetic relationships within Korthalsella (Viscaceae) based on nuclear ITS and plastid trnL-F sequence data. American Journal of Botany 86(2): 249-260.

Mort, M. E., J. K. Archibald, C. P. Randle, N. D. Levsen, T. R. O'Leary, K. Topalov, C. M. Wiegand and D. J. Crawford (2007). Inferring phylogeny at low taxonomic levels: Utility of rapidly evolving cpDNA and nuclear ITS loci. American Journal of Botany 94(2): 173-183. 
Mower, J. P., P. Touzet, J. S. Gummow, L. F. Delph and J. D. Palmer (2007). Extensive variation in synonymous substitution rates in mitochondrial genes of seed plants. Bmc Evolutionary Biology 7(1): 135.

Müller, K. (2005). SeqState: Primer Design and Sequence Statistics for Phylogenetic DNA Datasets. Applied Bioinformatics 4(1): 65-69.

Mummenhoff, K., H. Bruggemann and J. L. Bowman (2001). Chloroplast DNA phylogeny and biogeography of Lepidium (Brassicaceae). American Journal of Botany 88(11): 2051-2063.

Muñoz, J., A. M. Felicísimo, F. Cabezas, A. R. Burgaz and I. Martínez (2004). Wind as a long-distance dispersal vehicle in the Southern Hemisphere. Science 304(5674): 1144-1147.

Murray, B. G., P. M. Datson, E. L. Lai, K. M. Sheath and E. K. Cameron (2004). Polyploidy, hybridisation and evolution in Pratia (Campanulaceae). New Zealand Journal of Botany 42(5): 905-920.

Nilsson, E. and J. Ågren (2006). Population size, female fecundity, and sex ratio variation in gynodioecious Plantago maritima. Journal of Evolutionary Biology 19(3): 825-833.

Nilsson, E., N. Gyllenstrand and K. Wolff (2006). Six polymorphic microsatellite markers for Plantago maritima. Molecular Ecology Notes 6(4): 1093-1095. 
Oxelman, B., M. Liden and D. Berglund (1997). Chloroplast rps16 intron phylogeny of the tribe Sileneae (Caryophyllaceae). Plant Systematics and Evolution 206(1-4): 393-410.

Parkinson, C. L., J. P. Mower, Y. L. Qiu, A. J. Shirk, K. M. Song, N. D. Young, C. W. dePamphilis and J. D. Palmer (2005). Multiple major increases and decreases in mitochondrial substitution rates in the plant family Geraniaceae. Bmc Evolutionary Biology 5: 12.

Perrie, L. and P. Brownsey (2007). Molecular evidence for long-distance dispersal in the New Zealand pteridophyte flora. 34: 2028-2038.

Perrie, L. R., M. J. Bayly, C. A. Lehnebach and P. J. Brownsey (2007). Molecular phylogenetics and molecular dating of the New Zealand Gleicheniaceae. Brittonia 59(2): 129-141.

Perrie, L. R. and P. J. Brownsey (2005). Insights into the biogeography and polyploid evolution of new Zealand Asplenium from chloroplast DNA sequence data. American Fern Journal 95(1): 1-21.

Perrie, L. R., P. J. Brownsey, P. J. Lockhart, E. A. Brown and M. F. Large (2003). Biogeography of temperate Australasian Polystichum ferns as inferred from chloroplast sequence and AFLP. Journal of Biogeography 30(11): 1729-1736. 
Petit, C., F. Bretagnolle and F. Felber (1999). Evolutionary consequences of diploidpolyploid hybrid zones in wild species. Trends in Ecology \& Evolution 14(8): 306-311.

Pole, M. (1994). The New-Zealand Flora - Entirely Long-Distance Dispersal. Journal of Biogeography 21(6): 625-635.

Posada, D. and T. R. Buckley (2004). Model selection and model averaging in phylogenetics: Advantages of akaike information criterion and Bayesian approaches over likelihood ratio tests. Systematic Biology 53(5): 793-808.

Posada, D. and K. A. Crandall (1998). MODELTEST: testing the model of DNA substitution. Bioinformatics 14(9): 817-818.

Radford, E. A., M. F. Watson and J. Preston (2001). Phylogenetic relationships of species of Aciphylla (Apiaceae, subfamily Apioideae) and related genera using molecular, morphological, and combined data sets. New Zealand Journal of Botany 39(2): 183-208.

Rahn, K. (1996). A phylogenetic study of the Plantaginaceae. Botanical Journal of the Linnean Society 120(2): 145-198.

Rambaut, A. and A. J. Drummond (2007). Tracer v1.4. 
Raven, P. H. (1973). Evolution of Subalpine and Alpine Plant Groups in New Zealand. New Zealand Journal of Botany 11: 177-200.

Reeves, G., M. W. Chase, P. Goldblatt, P. Rudall, M. F. Fay, A. V. Cox, B. Lejeune and T. Souza-Chies (2001). Molecular systematics of Iridaceae: Evidence from four plastid DNA regions. American Journal of Botany 88(11): 20742087.

Renner, S. (2004). Plant dispersal across the tropical Atlantic by wind and sea currents. International Journal of Plant Sciences 165(4): S23-S33.

Renner, S. S., D. B. Foreman and D. Murray (2000). Timing transantarctic disjunctions in the Atherospermataceae (Laurales): Evidence from coding and noncoding chloroplast sequences. Systematic Biology 49(3): 579-591.

Rock, J. F. (1920). The genus Plantago in Hawaii. American Journal of Botany 7(5): 195-U11.

Rønsted, N., M. W. Chase, D. C. Albach and M. A. Bello (2002). Phylogenetic relationships within Plantago (Plantaginaceae): evidence from nuclear ribosomal ITS and plastid trnL-F sequence data. Botanical Journal of the Linnean Society 139(4): 323-338. 
Rønsted, N., H. Franzyk, P. Mølgaard, J. W. Jaroszewski and S. R. Jensen (2003). Chemotaxonomy and evolution of Plantago L. Plant Systematics and Evolution 242(1-4): 63-82.

Rønsted, N., E. Göbel, H. Franzyk, S. R. Jensen and C. E. Olsen (2000). Chemotaxonomy of Plantago. Iridoid glucosides and caffeoyl phenylethanoid glycosides. Phytochemistry 55(4): 337-348.

Sanderson, M. J. and J. A. Doyle (2001). Sources of error and confidence intervals in estimating the age of angiosperms from $r b c L$ and $18 \mathrm{~S}$ rDNA data. American Journal of Botany 88(8): 1499-1516.

Sang, T., D. J. Crawford and T. F. Stuessy (1997). Chloroplast DNA phylogeny, reticulate evolution, and biogeography of Paeonia (Paeoniaceae). American Journal of Botany 84(8): 1120-1136.

Sanmartín, I. and F. Ronquist (2004). Southern Hemisphere biogeography inferred by event-based models: Plant versus animal patterns. Systematic Biology 53(2): 216-243.

Sanmartín, I., L. Wanntorp and R. C. Winkworth (2007). West Wind Drift revisited: testing for directional dispersal in the Southern Hemisphere using event-based tree fitting. Journal of Biogeography 34(3): 398-416. 
Schuelke, M. (2000). An economic method for the fluorescent labeling of PCR fragments. Nature Biotechnology 18(2): 233-234.

Schuettpelz, E. and S. B. Hoot (2004). Phylogeny and biogeography of Caltha (Ranunculaceae) based on chloroplast and nuclear DNA sequences. American Journal of Botany 91(2): 247-253.

Setoguchi, H., T. A. Osawa, J. C. Pintaud, T. Jaffre and J. M. Veillon (1998). Phylogenetic relationships within Araucariaceae based on $r b c L$ gene sequences. American Journal of Botany 85(11): 1507-1516.

Shaw, J., E. B. Lickey, J. T. Beck, S. B. Farmer, W. S. Liu, J. Miller, K. C. Siripun, C. T. Winder, E. E. Schilling and R. L. Small (2005). The tortoise and the hare II: Relative utility of 21 noncoding chloroplast DNA sequences for phylogenetic analysis. American Journal of Botany 92(1): 142-166.

Shaw, J., E. B. Lickey, E. E. Schilling and R. L. Small (2007). Comparison of whole chloroplast genome sequences to choose noncoding regions for phylogenetic studies in angiosperms: The tortoise and the hare III. American Journal of Botany 94(3): 275-288.

Shepherd, L. D., L. R. Perrie, B. S. Parris and P. J. Brownsey (2007). A molecular phylogeny for the New Zealand Blechnaceae ferns from analyses of chloroplast trnL-trnF DNA sequences. New Zealand Journal of Botany 45(1): $67-80$. 
Simmons, M. P., K. Müller and A. P. Norton (2007). The relative performance of indel-coding methods in simulations. Molecular Phylogenetics and Evolution 44(2): 724-740.

Smissen, R. D., I. Breitwieser and J. M. Ward (2004). Phylogenetic implications of trans-specific chloroplast DNA sequence polymorphism in New Zealand Gnaphalieae (Asteraceae). Plant Systematics and Evolution 249(1-2): 37-53.

Smissen, R. D., P. J. Garnock-Jones and G. K. Chambers (2003). Phylogenetic analysis of ITS sequences suggests a Pliocene origin for the bipolar distribution of Scleranthus (Caryophyllaceae). Australian Systematic Botany 16(3): $301-315$

Soltis, D. E., P. S. Soltis and J. A. Tate (2004). Advances in the study of polyploidy since Plant speciation. New Phytologist 161(1): 173-191.

Spence, J. R. and W. R. Sykes (1989). Are Plantago novae-zelandiae L. Moore and P. lanigera Hook. f. (Plantaginaceae) different? New Zealand Journal of Botany 27(4): 499-502.

Squirrell, J. and K. Wolff (2001). Isolation of polymorphic microsatellite loci in Plantago major and P. intermedia. Molecular Ecology Notes 1(3): 179-181. 
Stöckler, K., I. L. Daniel and P. J. Lockhart (2002). New Zealand Kauri (Agathis australis (D. don) Lindl., Araucariaceae) survives oligocene drowning. Systematic Biology 51(5): 827-832.

Strand, A. E., J. LeebensMack and B. G. Milligan (1997). Nuclear DNA-based markers for plant evolutionary biology. Molecular Ecology 6(2): 113-118.

Swenson, U., A. Backlund, S. McLoughlin and R. S. Hill (2001). Nothofagus biogeography revisited with special emphasis on the enigmatic distribution of subgenus Brassospora in New Caledonia. Cladistics-the International Journal of the Willi Hennig Society 17(1): 28-47.

Swofford, D. L. (2002). PAUP*. Phylogenetic analysis using parsimony (*and other methods). Sunderland, Massachusetts, Sinauer Associates.

Sykes, W. R. (1988). Notes on New Zealand Plantago Species. New Zealand Journal of Botany 26(2): 321-323.

Sytsma, K. J., A. Litt, M. L. Zjhra, J. C. Pires, M. Nepokroeff, E. Conti, J. Walker and P. G. Wilson (2004). Clades, clocks, and continents: Historical and biogeographical analysis of Myrtaceae, Vochysiaceae, and relatives in the Southern Hemisphere. International Journal of Plant Sciences 165(4): S85S105. 
Taberlet, P., L. Gielly, G. Pautou and J. Bouvet (1991). Universal Primers for Amplification of 3 Noncoding Regions of Chloroplast DNA. Plant Molecular Biology 17(5): 1105-1109.

Tate, J. A. (2002). Systematics and evolution of Tarasa (Malvaceae): an enigmatic Andean polyploid genus. Austin, The University of Texas. PhD.

Trewick, S. A. and M. Morgan-Richards (2005). After the deluge: mitochondrial DNA indicates Miocene radiation and Pliocene adaptation of tree and giant weta (Orthoptera : Anostostomatidae). Journal of Biogeography 32(2): 295309.

Tripp, E. A. (2007). Evolutionary relationships within the species-rich genus Ruellia (Acanthaceae). Systematic Botany 32(3): 628-649.

VanDijk, P. and T. Bakx-Schotman (1997). Chloroplast DNA phylogeography and cytotype geography in autopolyploid Plantago media. Molecular Ecology 6(4): $345-352$.

Vijverberg, K., L. Lie and K. Bachmann (2002). Morphological, evolutionary and taxonomic aspects of Australian and New Zealand Microseris (Asteraceae). Australian Journal of Botany 50(1): 127-143. 
von Hagen, K. B. and J. W. Kadereit (2001). The phylogeny of Gentianella (Gentianaceae) and its colonization of the southern hemisphere as revealed by nuclear and chloroplast DNA sequence variation. Organisms Diversity \& Evolution 1(1): 61-79.

Vriesendorp, B. and F. T. Bakker (2005). Reconstructing patterns of reticulate evolution in angiosperms: what can we do? Taxon 54(3): 593-604.

Wagstaff, S. J., I. Breitwieser, C. Quinn and M. Ito (2007). Age of origin of enigmatic megaherbs from the subantarctic islands. Nature Precedings (hdl:10101/npre.2007.1272.1).

Wagstaff, S. J., M. J. Bayly, P. J. Garnock-Jones and D. C. Albach (2002). Classification, origin, and diversification of the New Zealand Hebes (Scrophulariaceae). Annals of the Missouri Botanical Garden 89(1): 38-63.

Wagstaff, S. J., I. Breitwieser and U. Swenson (2006). Origin and relationships of the austral genus Abrotanella (Asteraceae) inferred from DNA sequences. Taxon 55(1): 95-106.

Wagstaff, S. J. and P. J. Garnock-Jones (1998). Evolution and biogeography of the Hebe complex (Scrophulariaceae) inferred from ITS sequences. New Zealand Journal of Botany 36(3): 425-437. 
Wagstaff, S. J. and P. J. Garnock-Jones (2000). Patterns of diversification in Chionohebe and Parahebe (Scrophulariaceae) inferred from ITS sequences. New Zealand Journal of Botany 38(3): 389-407.

Wagstaff, S. J., P. B. Heenan and M. J. Sanderson (1999). Classification, origins, and patterns of diversification in New Zealand Carmichaelinae (Fabaceae). American Journal of Botany 86(9): 1346-1356.

Wagstaff, S. J. and F. Hennion (2007). Evolution and biogeography of Lyallia and Hectorella (Portulacaceae), geographically isolated sisters from the Southern Hemisphere. Antarctic Science 19(4): 417-426.

Wagstaff, S. J., K. Martinsson and U. Swenson (2000). Divergence estimates of Tetrachondra hamiltonii and T. patagonica (Tetrachondraceae) and their implications for austral biogeography. New Zealand Journal of Botany 38(4): 587-596.

Wagstaff, S. J. and J. Wege (2002). Patterns of diversification in New Zealand Stylidiaceae. American Journal of Botany 89(5): 865-874.

Wanntorp, L. and H. E. Wanntorp (2003). The biogeography of Gunnera L.: vicariance and dispersal. Journal of Biogeography 30(7): 979-987. 
Webb, C. J., W. R. Sykes and P. J. Garnock-Jones (1988). Flora of New Zealand. Volume IV. Naturalised Pteridophytes, Gymnosperms, Dicotyledons. Christchurch, Botany Division DSIR.

White, T. J., T. Bruns, S. Lee and J. Taylor (1990). Amplification and direct sequencing of fungal ribosomal RNA genes for phylogenetics. PCR protocols : a guide to methods and applications $\mathrm{M}$. Innis, C. Gelfand, J. Sninsky and T. White. San Diego, Academic Press: 315-322.

Winkworth, R. C., J. Grau, A. W. Robertson and P. J. Lockhart (2002a). The origins and evolution of the genus Myosotis L. (Boraginaceae). Molecular Phylogenetics and Evolution 24(2): 180-193.

Winkworth, R. C., A. W. Robertson, F. Ehrendorfer and P. J. Lockhart (1999). The importance of dispersal and recent speciation in the flora of New Zealand. Journal of Biogeography 26(6): 1323-1325.

Winkworth, R. C., S. J. Wagstaff, D. Glenny and P. J. Lockhart (2002b). Plant dispersal NEWS from New Zealand. Trends in Ecology \& Evolution 17(11): 514-520.

Winkworth, R. C., S. J. Wagstaff, D. Glenny and P. J. Lockhart (2005). Evolution of the New Zealand mountain flora: Origins, diversification and dispersal. Organisms Diversity \& Evolution 5(3): 237-247. 
Wolfe, K. H., W. H. Li and P. M. Sharp (1987). Rates of Nucleotide Substitution Vary Greatly among Plant Mitochondrial, Chloroplast, and Nuclear DNAs. Proceedings of the National Academy of Sciences of the United States of America 84(24): 9054-9058.

Wolff, K. and M. Morgan-Richards (1999). The use of RAPD data in the analysis of population genetic structure: case studies of Alkanna (Boraginaceae) and Plantago (Plantaginaceae). Molecular systematics and plant evolution. P. M. Hollingsworth, R. M. Bateman and R. J. Gornall. New York, Taylor \& Francis.

Wolff, K. and B. Schaal (1992). Chloroplast DNA Variation within and among 5 Plantago Species. Journal of Evolutionary Biology 5(2): 325-344.

Wright, S. D., C. G. Yong, J. W. Dawson, D. J. Whittaker and R. C. Gardner (2000). Riding the ice age El Nino? Pacific biogeography and evolution of Metrosideros subg. Metrosideros (Myrtaceae) inferred from nuclear ribosomal DNA. Proceedings of the National Academy of Sciences of the United States of America 97(8): 4118-4123.

Xia, X. and Z. Xie (2001). DAMBE: Software package for data analysis in molecular biology and evolution. Journal of Heredity 92(4): 371-373.

Yoder, A. D., J. A. Irwin and B. A. Payseur (2001). Failure of the ILD to determine data combinability for slow loris phylogeny. Systematic Biology 50(3): 408424. 
Yokoyama, J., M. Suzuki, K. Iwatsuki and M. Hasebe (2000). Molecular phylogeny of Coriaria, with special emphasis on the disjunct distribution. Molecular Phylogenetics and Evolution 14(1): 11-19.

Zane, L., L. Bargelloni and T. Patarnello (2002). Strategies for microsatellite isolation: a review. Molecular Ecology 11(1): 1-16.

Zhang, L. B. and S. Renner (2003). The deepest splits in Chloranthaceae as resolved by chloroplast sequences. International Journal of Plant Sciences 164(5): S383-S392. 


\section{Appendix I: Details of sample collections}

A. Samples used in primer pair assays (Chapter two).

\begin{tabular}{|c|c|c|c|}
\hline Taxon & Collection location & $\begin{array}{l}\text { Indigenous } \\
\text { distribution }\end{array}$ & $\begin{array}{l}\text { Voucher } \\
\text { specimen }\end{array}$ \\
\hline $\begin{array}{l}\text { P. triandra } \\
\text { subsp. triandra }\end{array}$ & $\begin{array}{l}\text { Lake Sylvester, NW Nelson, New } \\
\text { Zealand }\end{array}$ & $\mathrm{NZ}$ & $\begin{array}{l}\text { WELTU20163 } \\
\text { (MLT021 et al.) }\end{array}$ \\
\hline $\begin{array}{l}\text { P. spathulata } \\
\text { subsp. spathulata }\end{array}$ & $\begin{array}{l}\text { Between Kettlehole Bog and } \\
\text { Kettlehole Tarn, Cass, New Zealand }\end{array}$ & $\mathrm{NZ}$ & $\begin{array}{l}\text { WELTU20118 } \\
(P G J 2257)\end{array}$ \\
\hline P. euryphylla & $\begin{array}{l}\text { Kosciuszko National Park, Southern } \\
\text { Tablelands, NSW, Australia }\end{array}$ & AUS & $\begin{array}{l}\text { NSW742956 } \\
(B G B 9743)\end{array}$ \\
\hline P. lanceolata & $\begin{array}{l}\text { Ponsonby Road, Karori, Wellington, } \\
\text { New Zealand }\end{array}$ & COSMO & $\begin{array}{l}\text { WELTU20184 } \\
(P G J 2551)\end{array}$ \\
\hline P. coronopus & $\begin{array}{l}\text { End of Red Rocks, Owhiro Bay, } \\
\text { Wellington, New Zealand }\end{array}$ & MED, EUR & $\begin{array}{l}\text { WELTU20183 } \\
(P G J 2549)\end{array}$ \\
\hline P. major & $\begin{array}{l}\text { Ben Burn Park, Wellington, New } \\
\text { Zealand }\end{array}$ & COSMO & $\begin{array}{l}\text { WELTU20180 } \\
(P G J 2550)\end{array}$ \\
\hline Veronica stricta & $\begin{array}{l}\text { VUW, Mount Street, Wellington, } \\
\text { New Zealand }\end{array}$ & NZ & $\begin{array}{l}\text { WELTU } \\
(\text { MLTO01) }\end{array}$ \\
\hline
\end{tabular}

Distibution: NZ = New Zealand, AUS = Australia, COSMO = cosmopolitan, MED = Mediterranean, EUR $=$ Europe. Samples collected from New Zealand are deposited in the herbarium at the herbarium of Victoria University of Wellington, Wellington, New Zealand (WELTU). Australian voucher specimens can be found at the National Herbarium of New South Wales (NSW). 
B. Species and accession numbers of ITS sequences used in molecular dating analyses (Chapter three).

\begin{tabular}{|c|c|c|}
\hline Species & Collected from & $\begin{array}{l}\text { Reference/Herbarium } \\
\text { Voucher }\end{array}$ \\
\hline Plantago "sylvester" & Lake Sylvester, Nelson, NZ & WELTU20150 \\
\hline P. alpestris & Kosciuszko National Park, NSW, AUS & NSW742962 \\
\hline P. aucklandica & Auckland Islands, NZ & In cult. Otari (2003.2037) \\
\hline P. australis & Hunua Ranges, Auckland, NZ & WELTU20181 \\
\hline P. cladarophylla & Barrington Tops National Park, NSW, AUS & NSW744803 \\
\hline P. coronopus & Island Bay, Wellington, NZ & WELTU20183 \\
\hline P. cunninhamii & Brigalow Park Nature Reserve, NSW, AUS & NSW744804 \\
\hline P. daltonii & St. Clair National Park, AUS, Tasmania & NSW743874 \\
\hline P. debilis & Barrenjoey Headland, NSW, AUS & NSW 742894 \\
\hline P. euryphylla & Kosciuszko National Park, NSW, AUS & NSW742956 \\
\hline P. glacialis & Kosciuszko National Park, NSW, AUS & NSW743813 \\
\hline P. lanceolata & Karori, Wellington, NZ & WELTU20184 \\
\hline P. lanigera (3) & Hall Range, Canterbury, NZ & WELTU20143 \\
\hline P. major & Ben Burn Park, Karori, NZ & WELTU20180 \\
\hline P. muelleri & Kosciuszko National Park, NSW, AUS & NSW743812 \\
\hline P. obconica & Cardrona Skifield, Wanaka, NZ & WELTU20121. \\
\hline P. paradoxa & St. Clair National Park, AUS, Tasmania & WELTU20187 \\
\hline P. raoulii (1) & Lake Sarah, Cass, NZ & WELTU20153 \\
\hline$P . \mathrm{sp}$. & Pukerua Bay, Wellington, NZ & WELTU20178 \\
\hline P. spathulata subsp. picta & East Cape, Gisborne, NZ & CHR439486 \\
\hline P. spathulata subsp. spathulata & Marfells Beach, Marlborough, NZ & WELTU20117 \\
\hline P. tasmanica & St. Clair National Park, AUS, Tasmania & WELTU20188 \\
\hline P. triandra subsp. masoniae & Paturau Coast, Nelson, NZ & WELTU20168 \\
\hline P. triandra subsp. triandra & Lake Sylvester, Nelson, NZ & WELTU20163 \\
\hline P. triantha & Enderby Island, AI, NZ & WELTU20177 \\
\hline P. unibracteata & Lake Sylvester, Nelson, NZ & WELTU20175 \\
\hline P. varia & Kosciuszko National Park, NSW, AUS & NSW743869 \\
\hline Aragoa. corrugatifolia (AJ548980) & Colombia & Hoggard et al. 2003 \\
\hline A. cupressina (AJ459402) & northern Andes & Bello et al. 2002 \\
\hline Littorella americana (AJ548956) & Anderson Lake & Hoggard et al. 2007 \\
\hline L. americana (AJ548958) & New Brunswick & Hoggard et al. 2007 \\
\hline L. americana (AJ548957) & Trout Lake & Hoggard et al. 2007 \\
\hline L. australis (AJ548959) & Falkland Islands & Hoggard et al. 2007 \\
\hline L. uniflora (AJ548960) & Denmark & Hoggard et al. 2007 \\
\hline L. uniflora (AJ548963) & Iceland & Hoggard et al. 2007 \\
\hline L. uniflora (AJ548961) & Sweden & Hoggard et al. 2007 \\
\hline Veronica hookeriana & Whanahuia Range, Ruahine Mts, NZ & WELTU (PGJ2458) \\
\hline Veronica salicornioides & Jacks Pass, Hanmer, Canterbury, NZ & CHR512475 \\
\hline
\end{tabular}

Locations: $\mathrm{AI}=$ Auckland Islands, AUS $=$ Australia, NSW $=$ New South Wales, NZ = New Zealand, RBG Kew $=$ Royal Botanic Gardens Kew, UK = United Kingdom. Collectors: $B G B=$ Barbara G. Briggs, $M L T=$ Mei-Lin Tay, $P B H=$ Peter Heenan, $P G J=$ Phil Garnock-Jones, $P J L=$ Peter J. Lockhart and $V T=$ Vanessa Thorn. Herbarium vouchers: WELTU $=$ H. D. Gordon Herbarium in Victoria University of Wellington, New Zealand; NSW = National Herbarium of New South Wales, Australia; and CHR = Allan Herbarium, Landcare Research, Christchurch, New Zealand. The Littorella species included here had the same sequences for replicate samples of the same species. 
Appendix II: Phylogenetic analyses

A. 50\% bootstrap consensus phylogeny of the ITS dataset recovered using Maximum Parsimony (using samples listed in Table 3.1). Tree scores range from 350-356.

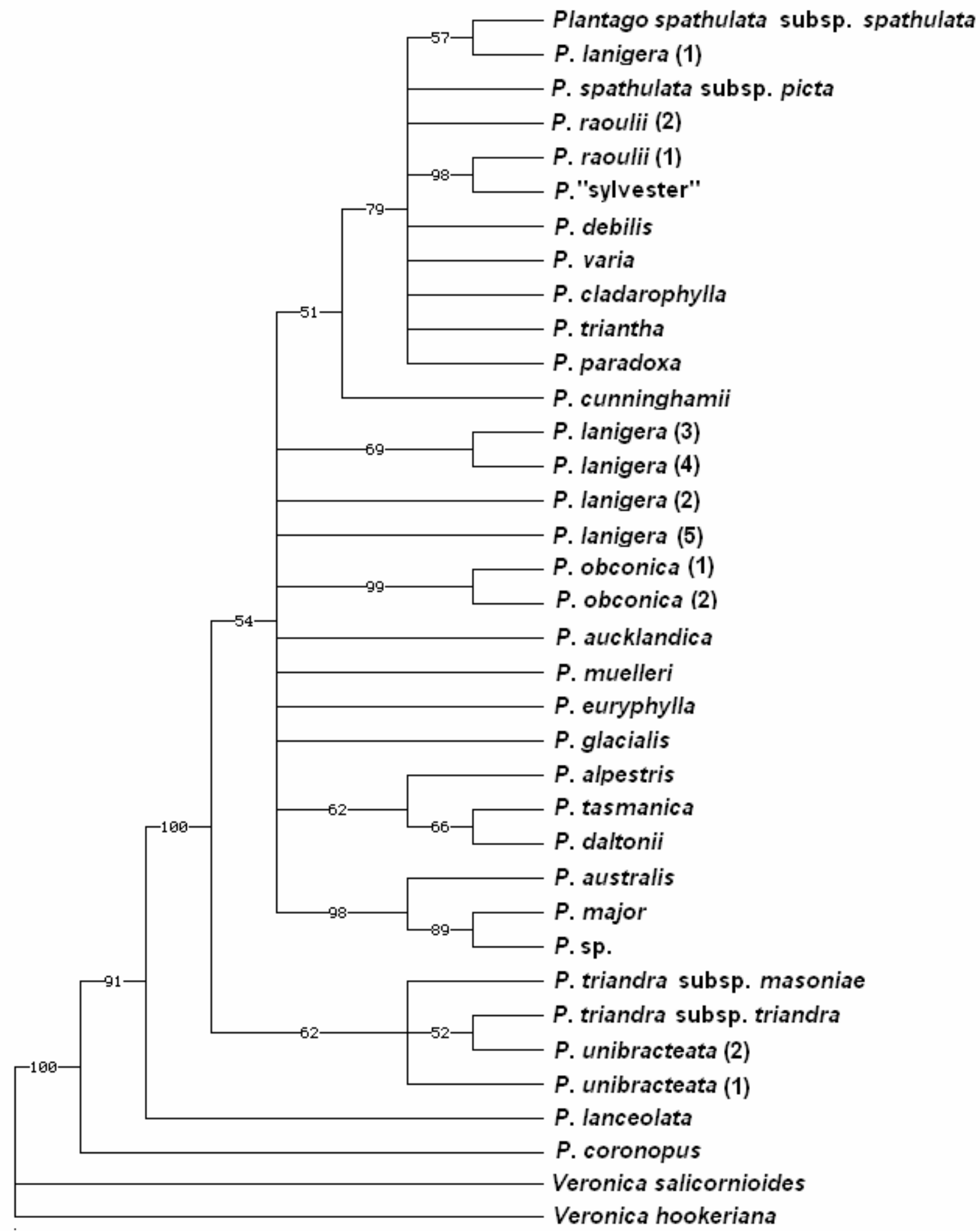


B. 50\% posterior probability consensus phylogeny of the ITS dataset recovered using Bayesian analysis (using samples listed in Table 3.1). Estimated tree likelihood score $=-2417.00$.

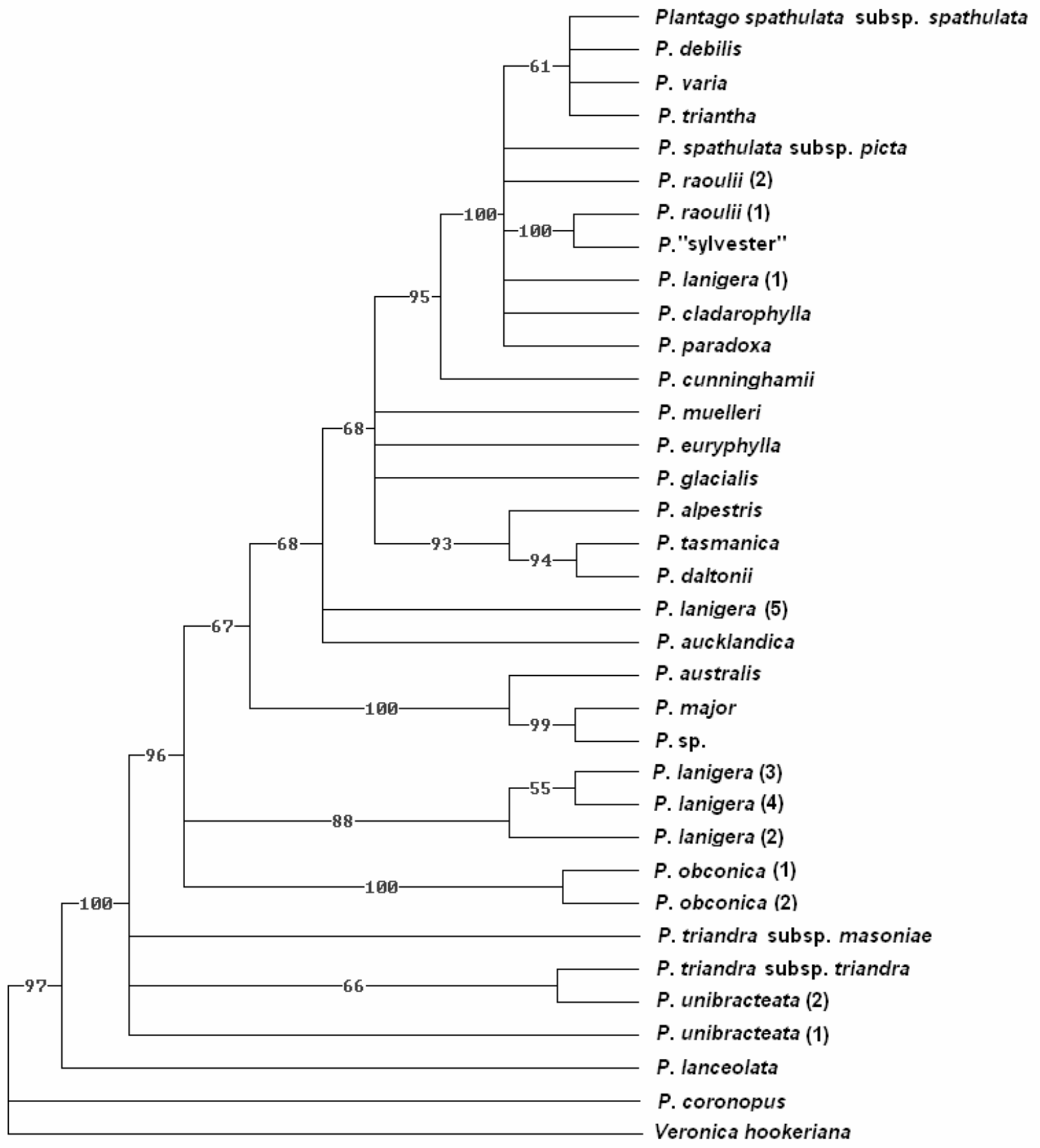


C. $50 \%$ bootstrap consensus phylogeny of the ITS dataset recovered using neighbourjoining methods (using samples listed in Table 3.1).

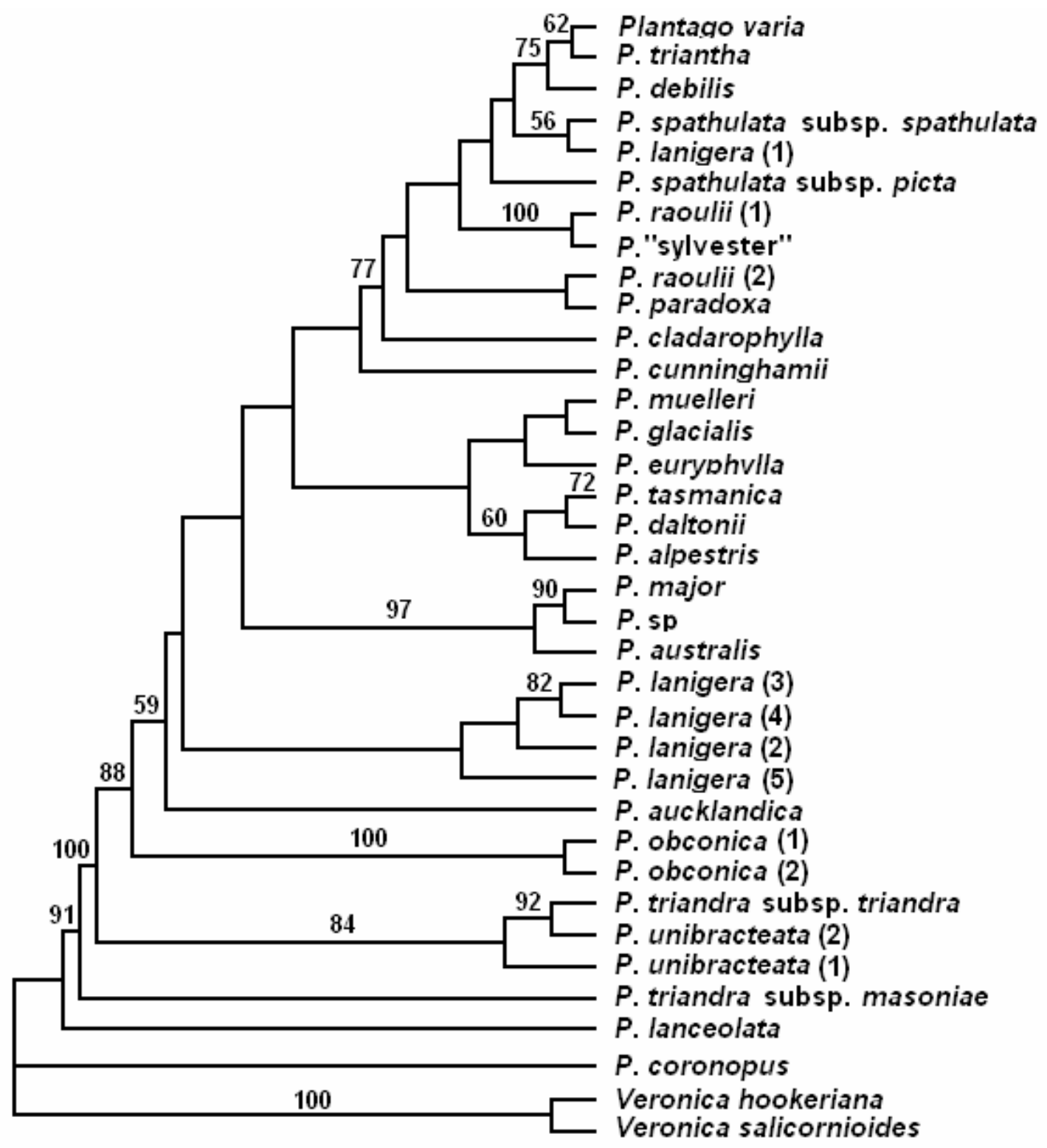


D. $50 \%$ bootstrap consensus phylogeny of the $n d h F-r p l 32$ dataset recovered using Maximum Parsimony (using samples listed in Table 3.1). Tree scores range from 496-500.

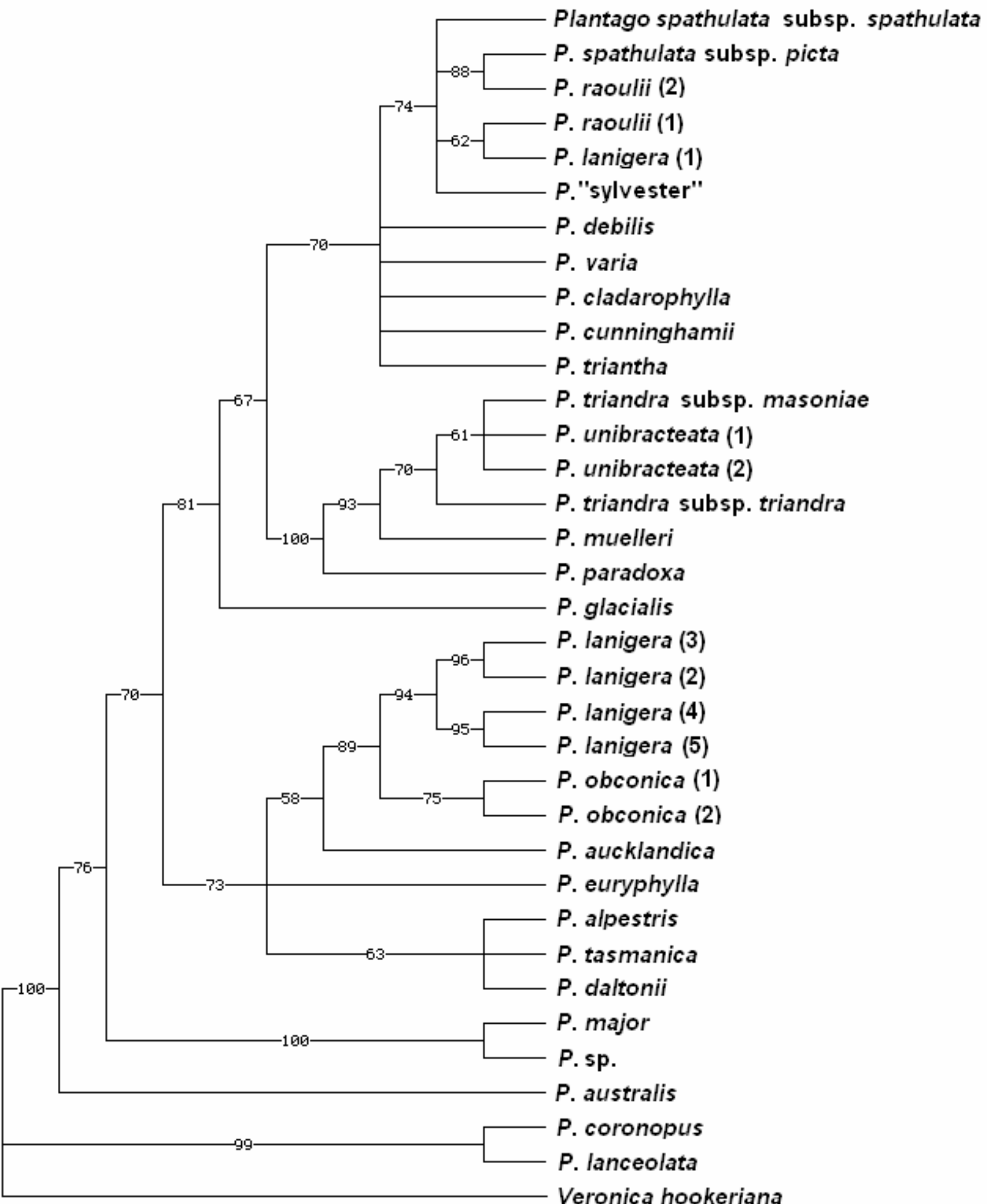


E. $50 \%$ posterior probability consensus phylogeny of the $n d h F-r p l 32$ dataset recovered using Bayesian analysis (using samples listed in Table 3.1). Estimated likelihood score $=-3079.09$.

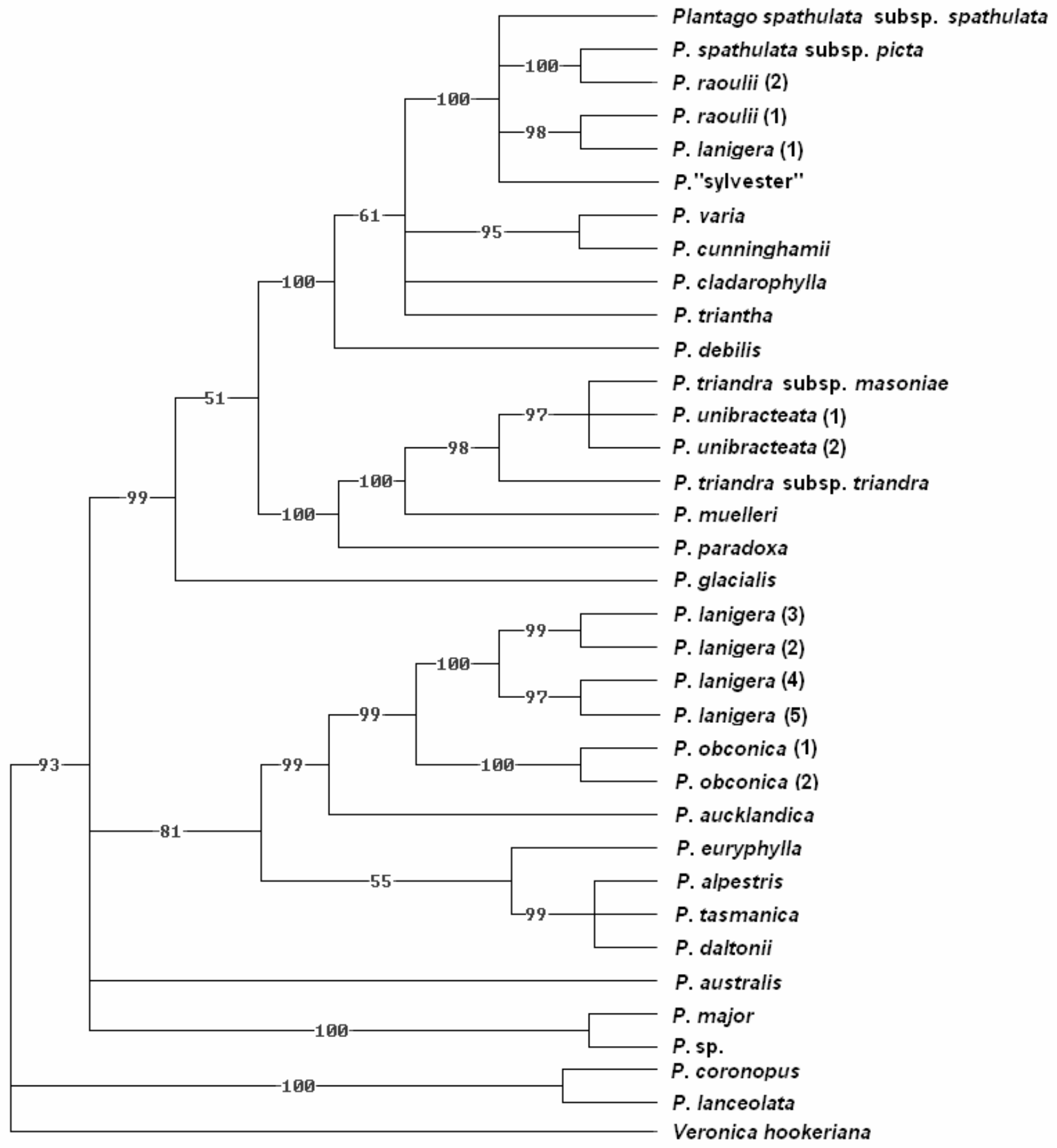


F. 50\% bootstrap consensus phylogeny of the $n d h F-r p l 32$ dataset recovered using neighbour-joining methods (using samples listed in Table 3.1).

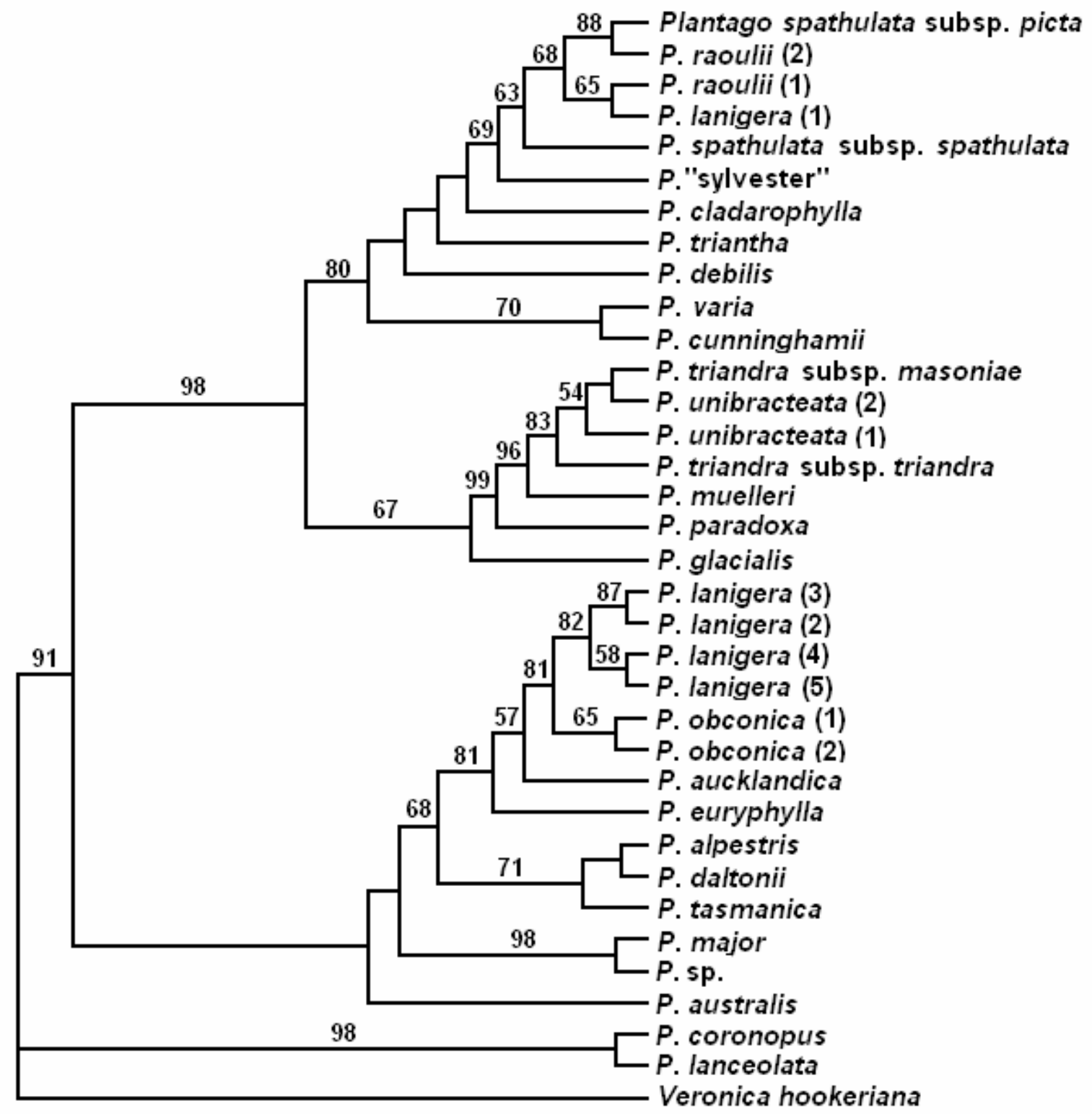


G. 50\% bootstrap consensus phylogeny of the coxl dataset recovered using Maximum Parsimony (using samples listed in Table 3.1). Tree scores range from 198-199.

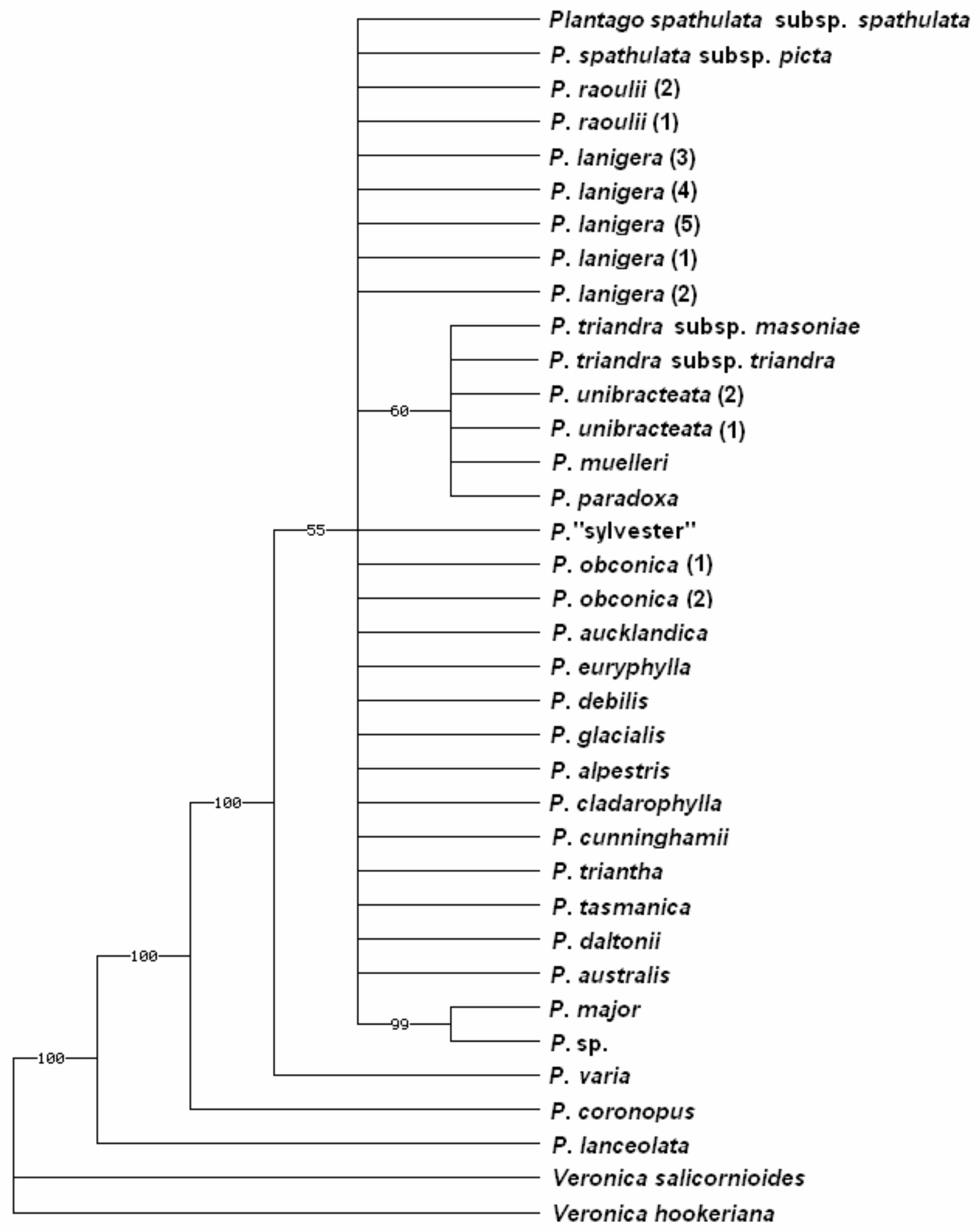


H. $50 \%$ posterior probability consensus phylogeny of the coxl dataset recovered using Bayesian analysis (using samples listed in Table 3.1). Estimated likelihood score = 1838.13.

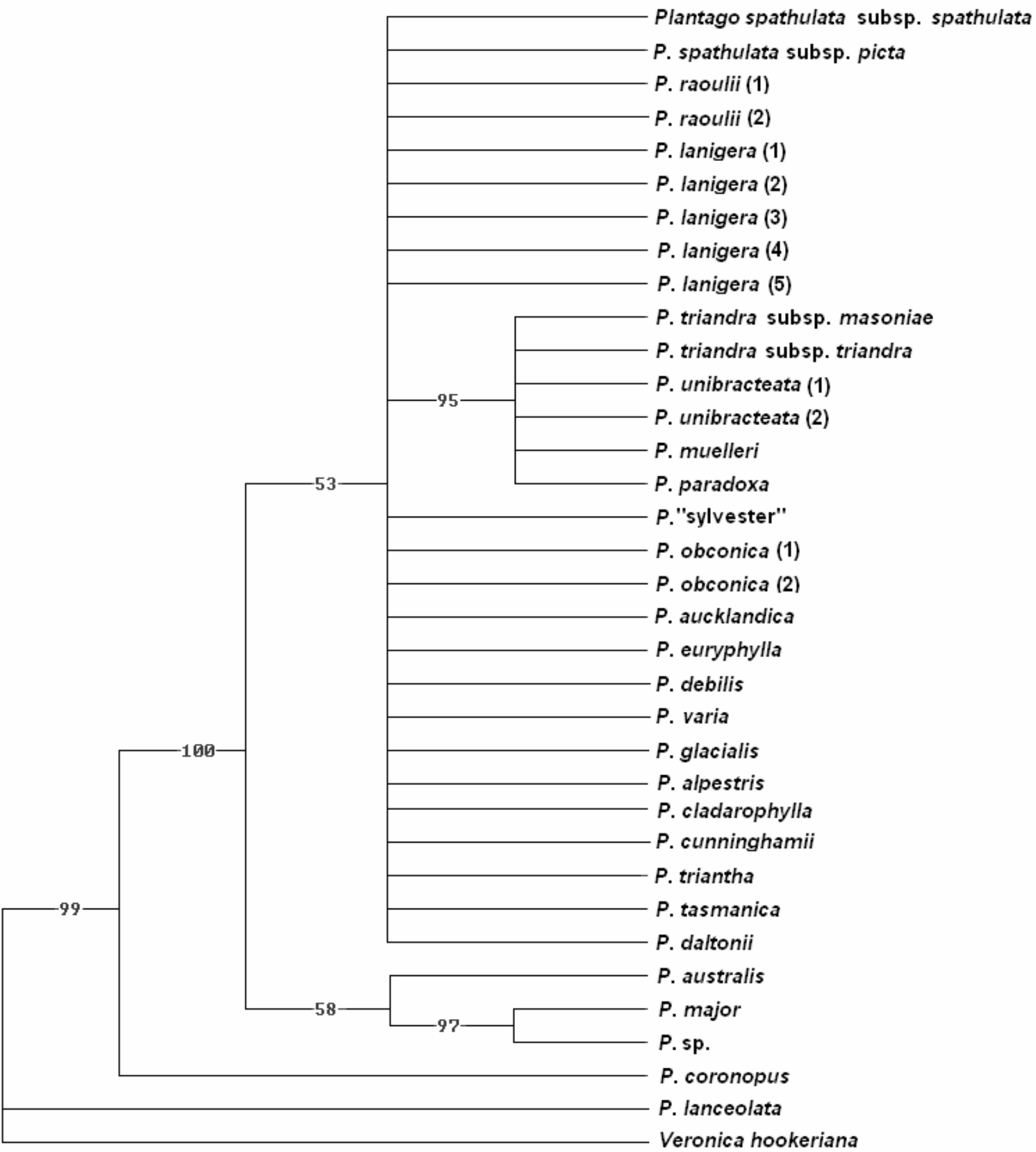


I. 50\% bootstrap consensus phylogeny of the coxl dataset recovered using neighbourjoining methods (using samples listed in Table 3.1).

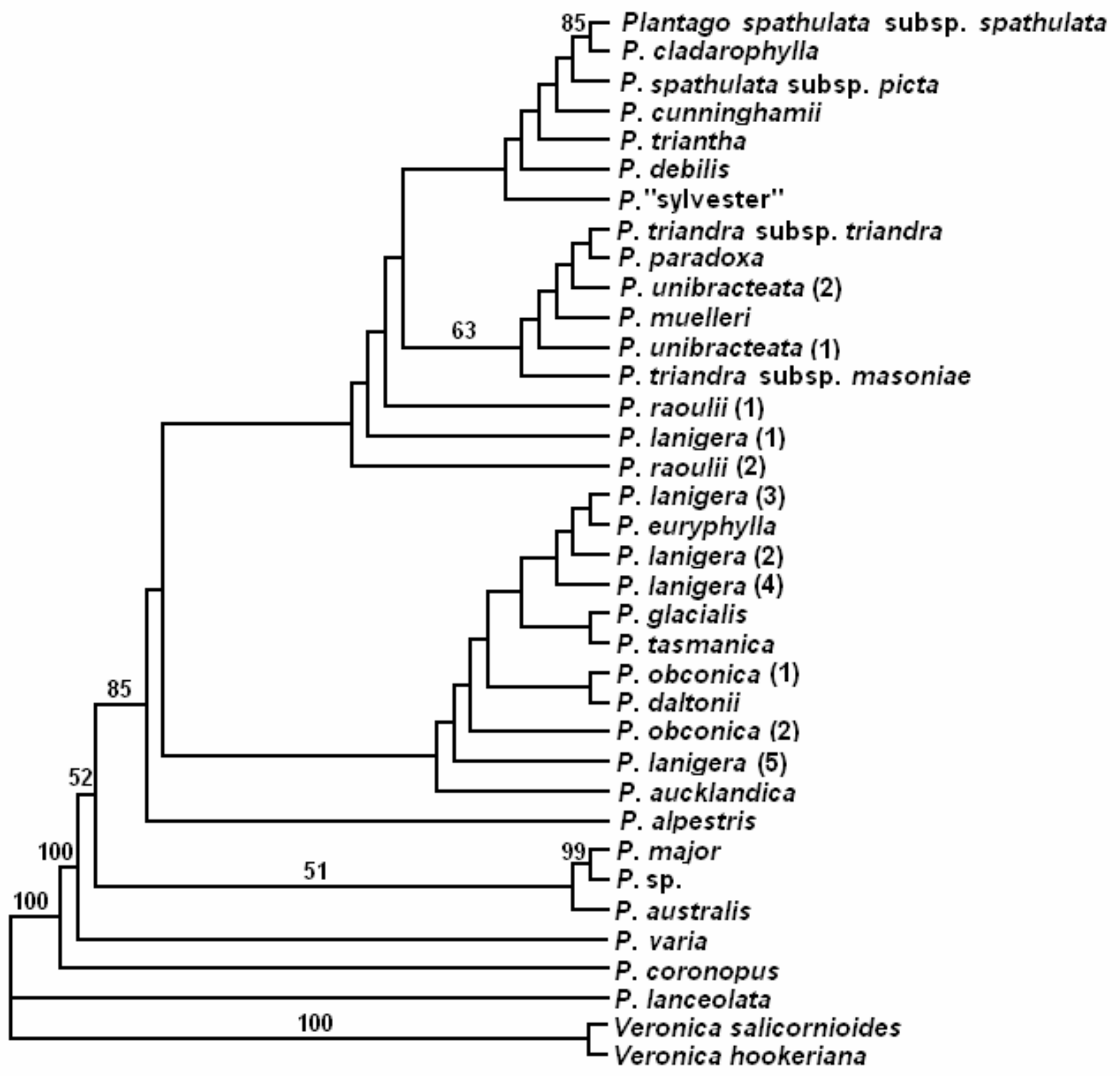


J. $50 \%$ bootstrap consensus phylogeny of the concatenated (ITS $+n d h F-r p l 32+\operatorname{coxl}$ ) dataset recovered using Maximum Parsimony (using samples listed in Table 3.1). Tree scores range from 1056-1058.

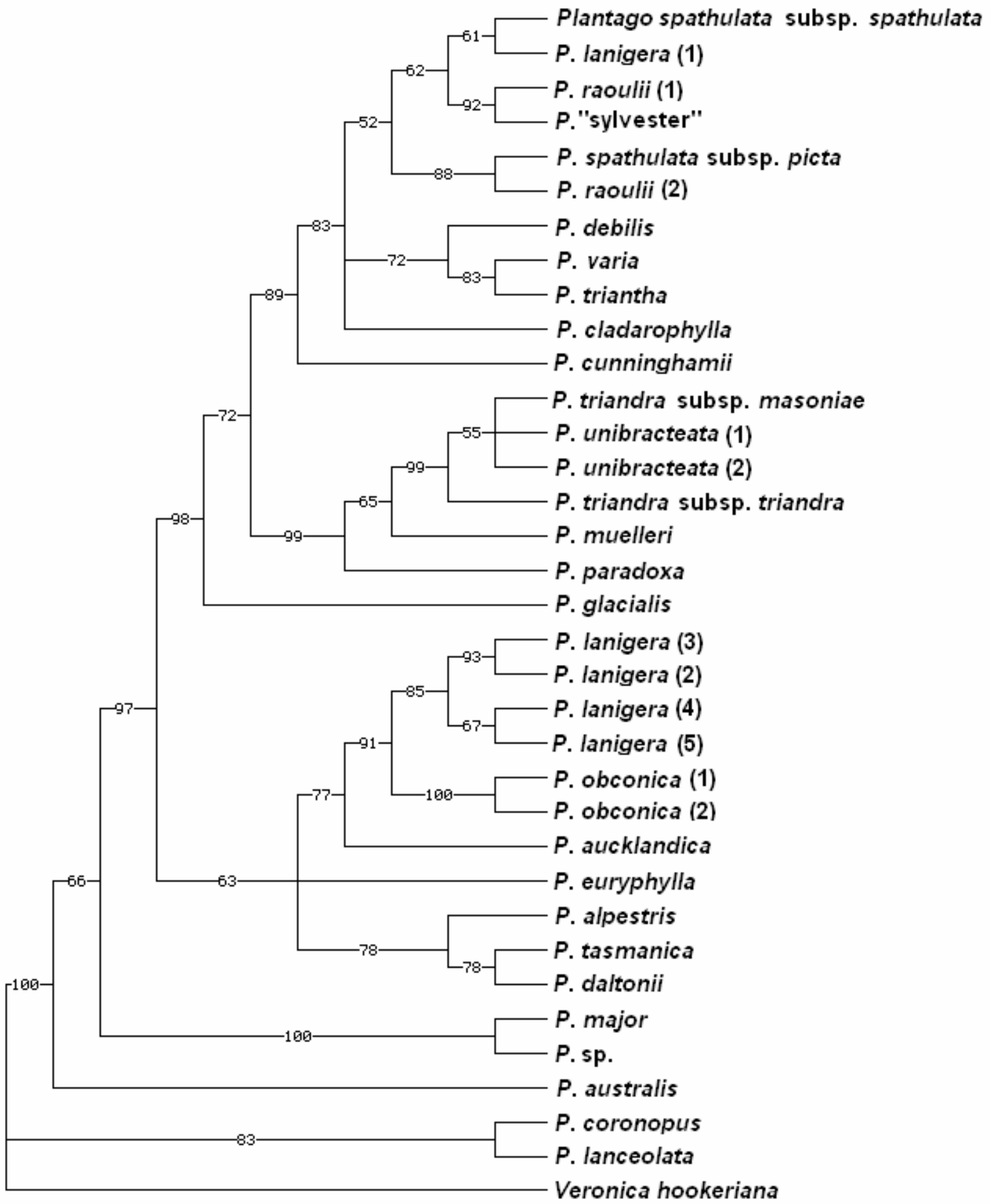


K. $50 \%$ posterior probability consensus phylogeny of the concatenated (ITS $+n d h F$ rpl32 + coxl) dataset recovered using Bayesian analysis with one model for the dataset (using samples listed in Table 3.1). Estimated likelihood score $=-7775.85$.

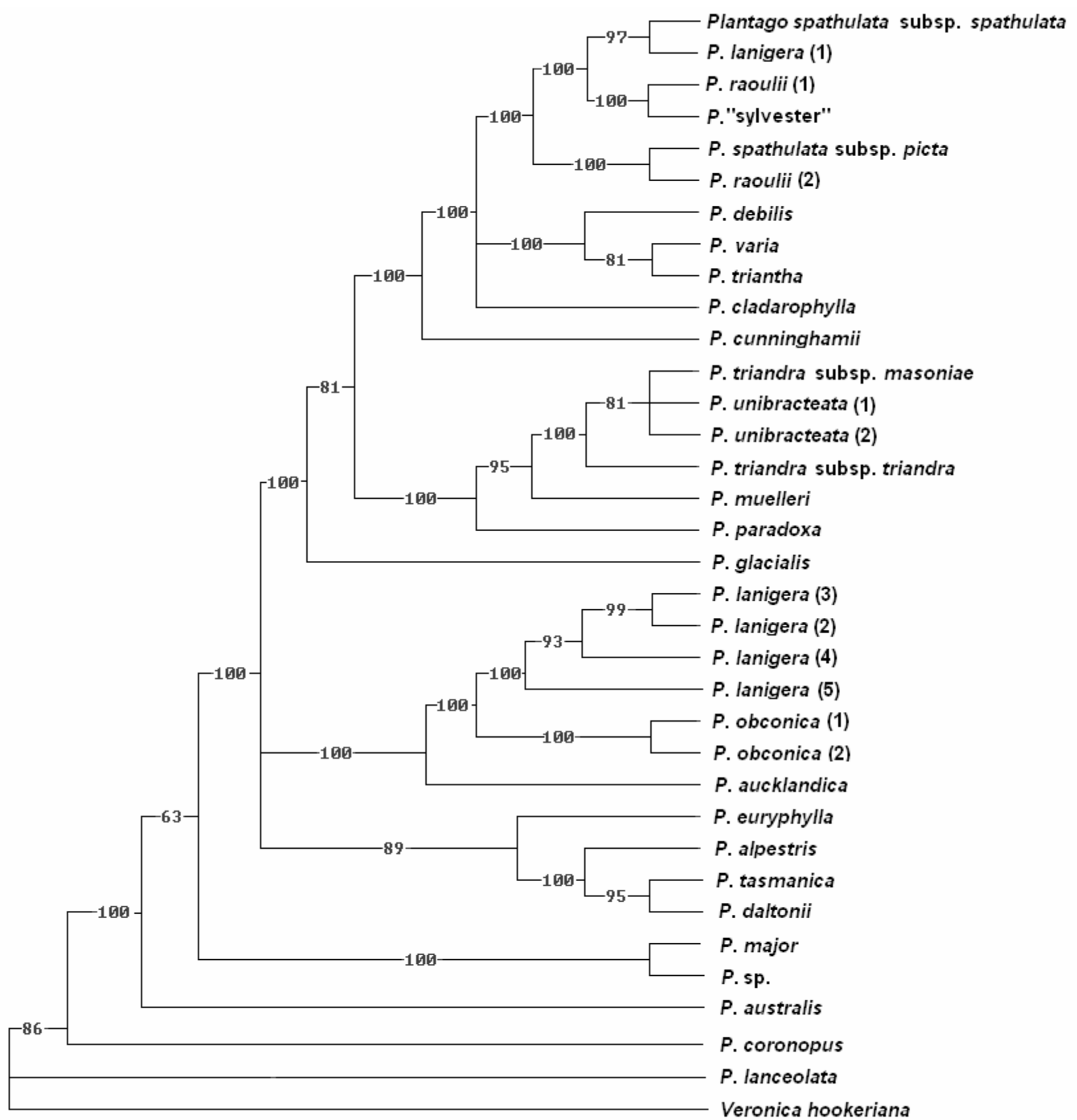


L. $50 \%$ posterior probability consensus phylogeny of the concatenated (ITS $+n d h F-$ rpl32 + coxl) dataset recovered using Bayesian analysis when the dataset was partitioned and different models were implemented for each region (using samples listed in Table 3.1). Estimated likelihood score $=-7874.62$.

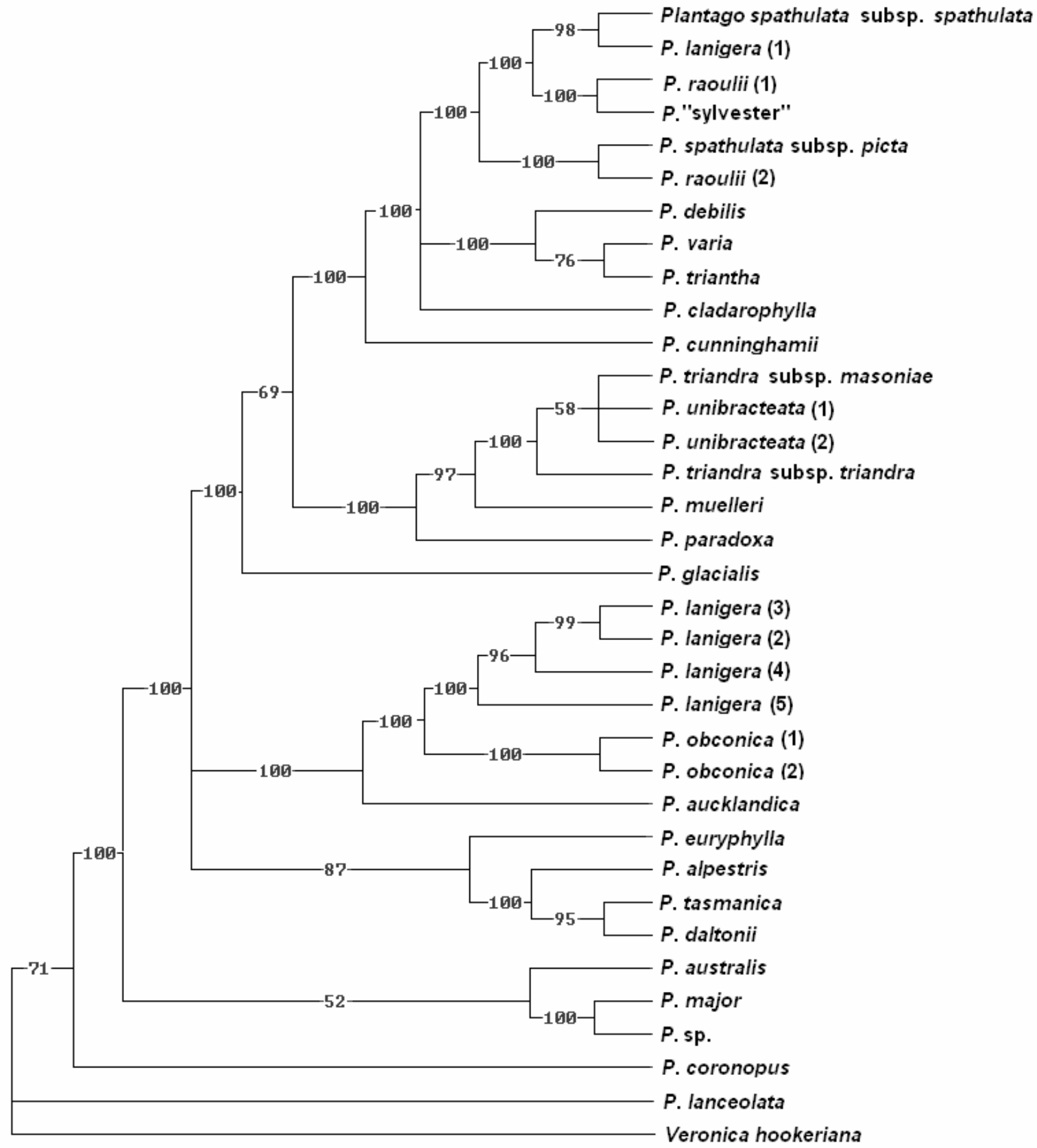


M. $50 \%$ bootstrap consensus phylogeny of the concatenated (ITS $+n d h F-r p l 32+\operatorname{cox} 1)$ dataset recovered using neighbour-joining methods (using samples listed in Table 3.1).

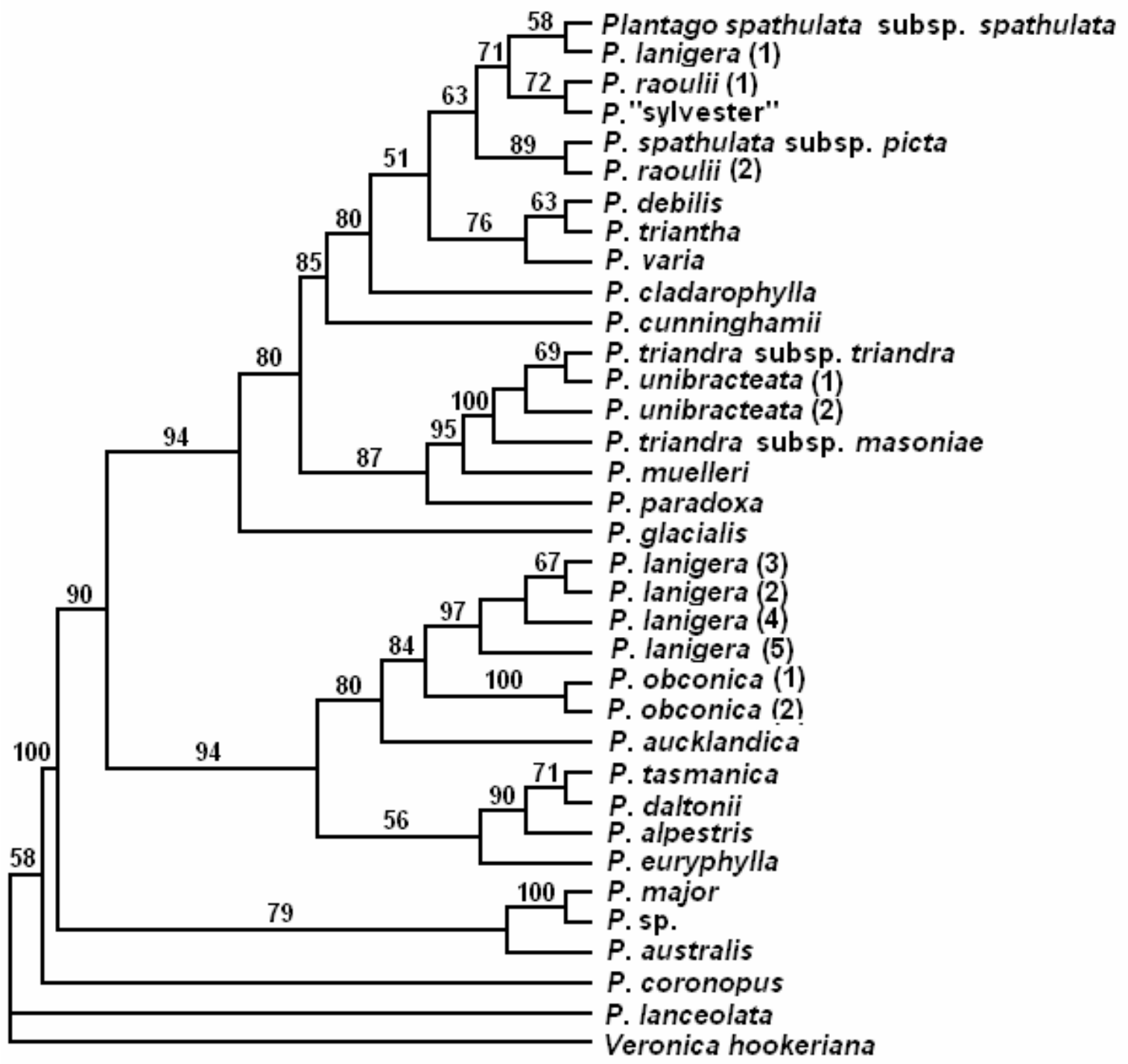


N. Neighbour-net analyses of the concatenated regions ITS, ndhF-rpl32 and coxl of the Australasian species using Splitstree v4.8 (using samples listed in Table 3.1).

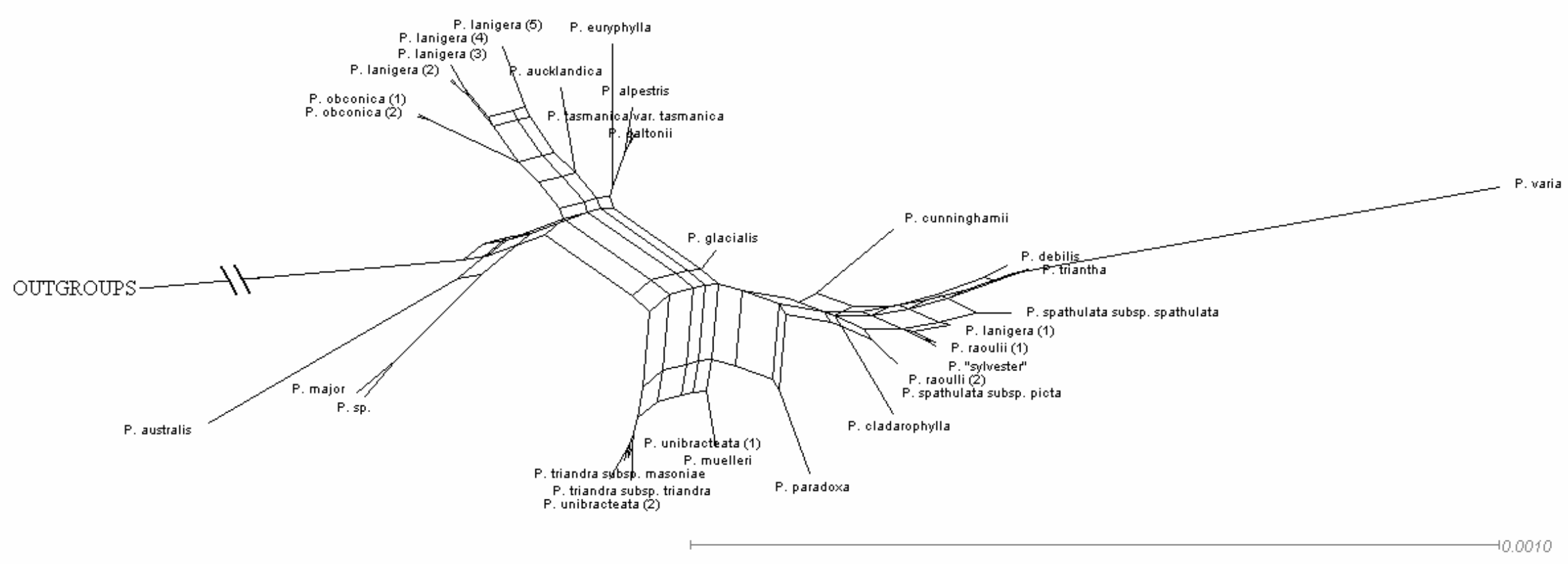


O. $50 \%$ posterior probability consensus ITS phylogeny of a worldwide Plantago dataset reconstructed using Bayesian analysis (samples listed in Table 4.1). Estimated likelihood score $=-7531.24$.

Aragoa corrugatifolia AJ548980

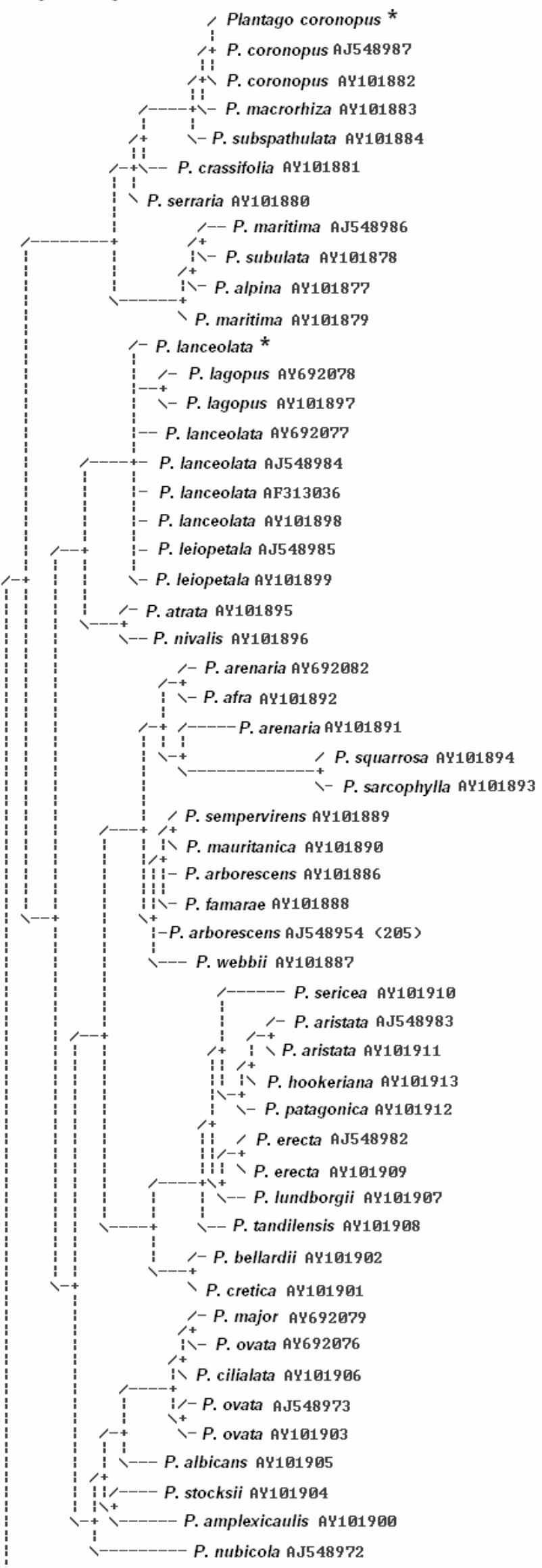


O. (continued) $50 \%$ posterior probability consensus ITS phylogeny of a worldwide Plantago dataset reconstructed using Bayesian analysis.

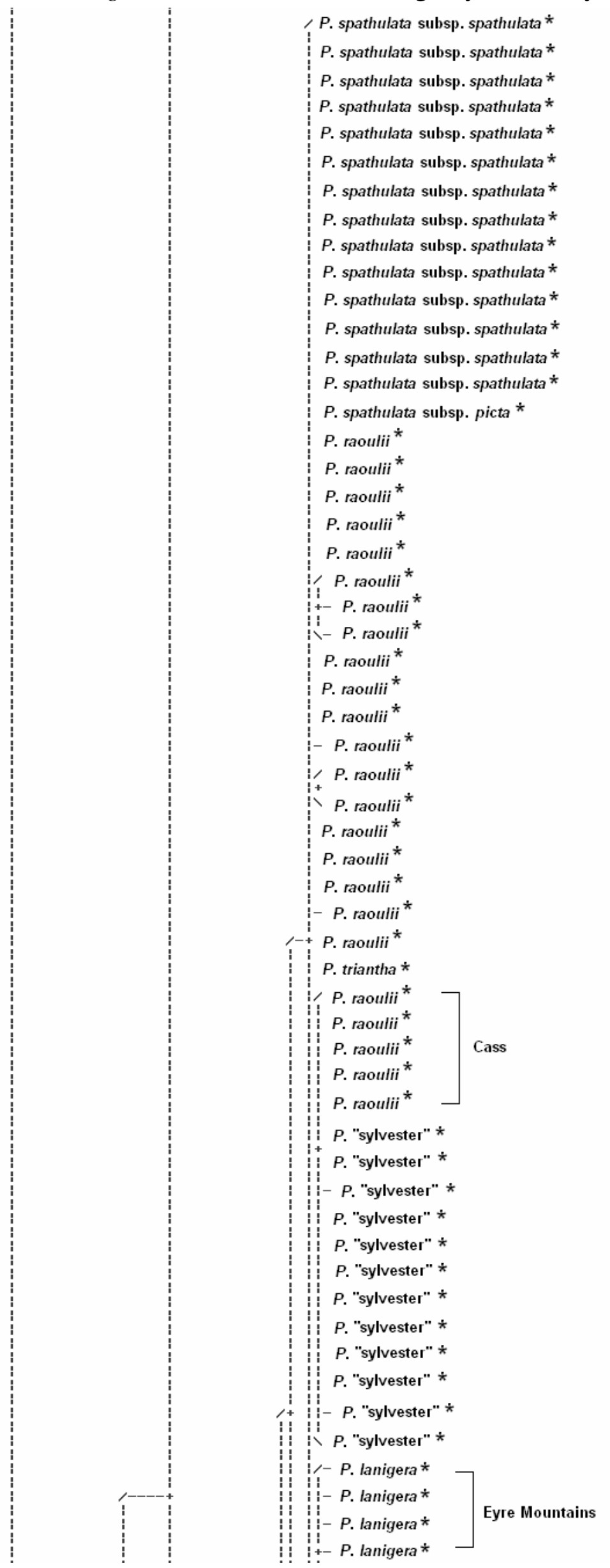


O. (continued) $50 \%$ posterior probability consensus ITS phylogeny of a worldwide Plantago dataset reconstructed using Bayesian analysis.

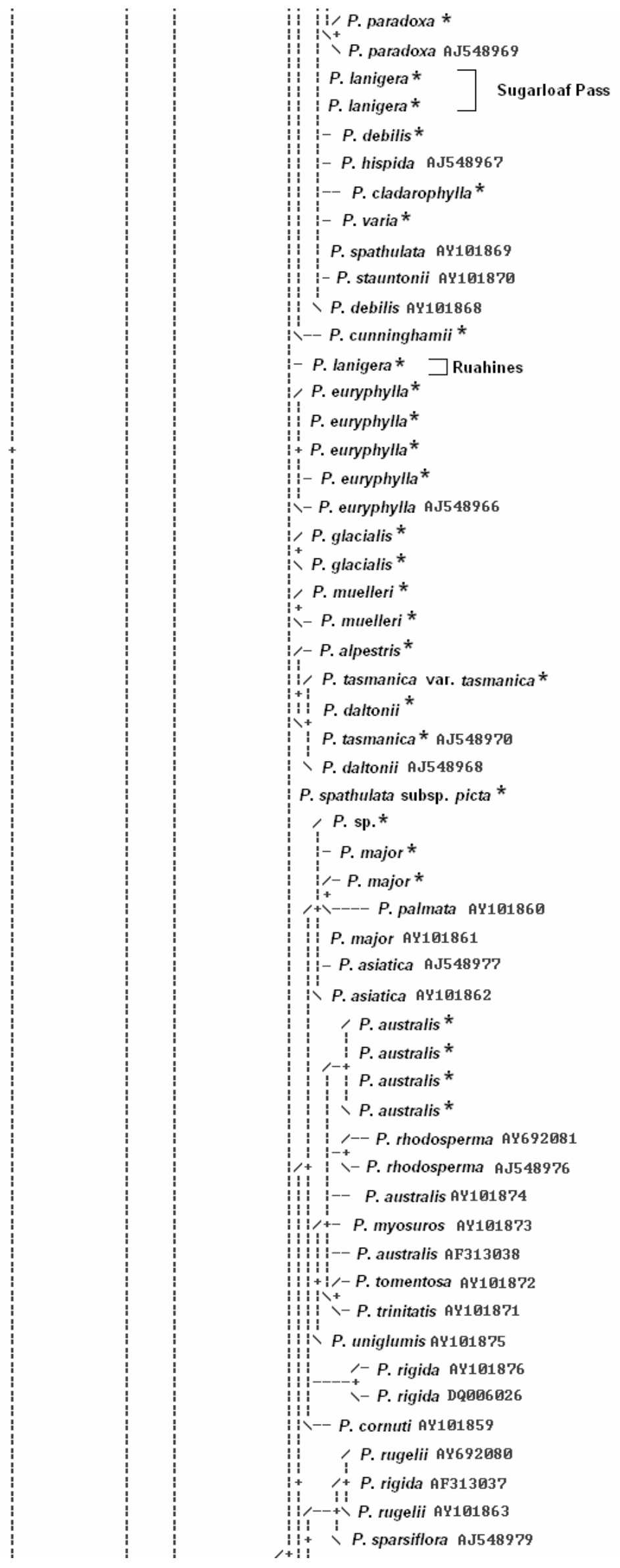


O. (continued) 50\% posterior probability consensus ITS phylogeny of a worldwide Plantago dataset reconstructed using Bayesian analysis.

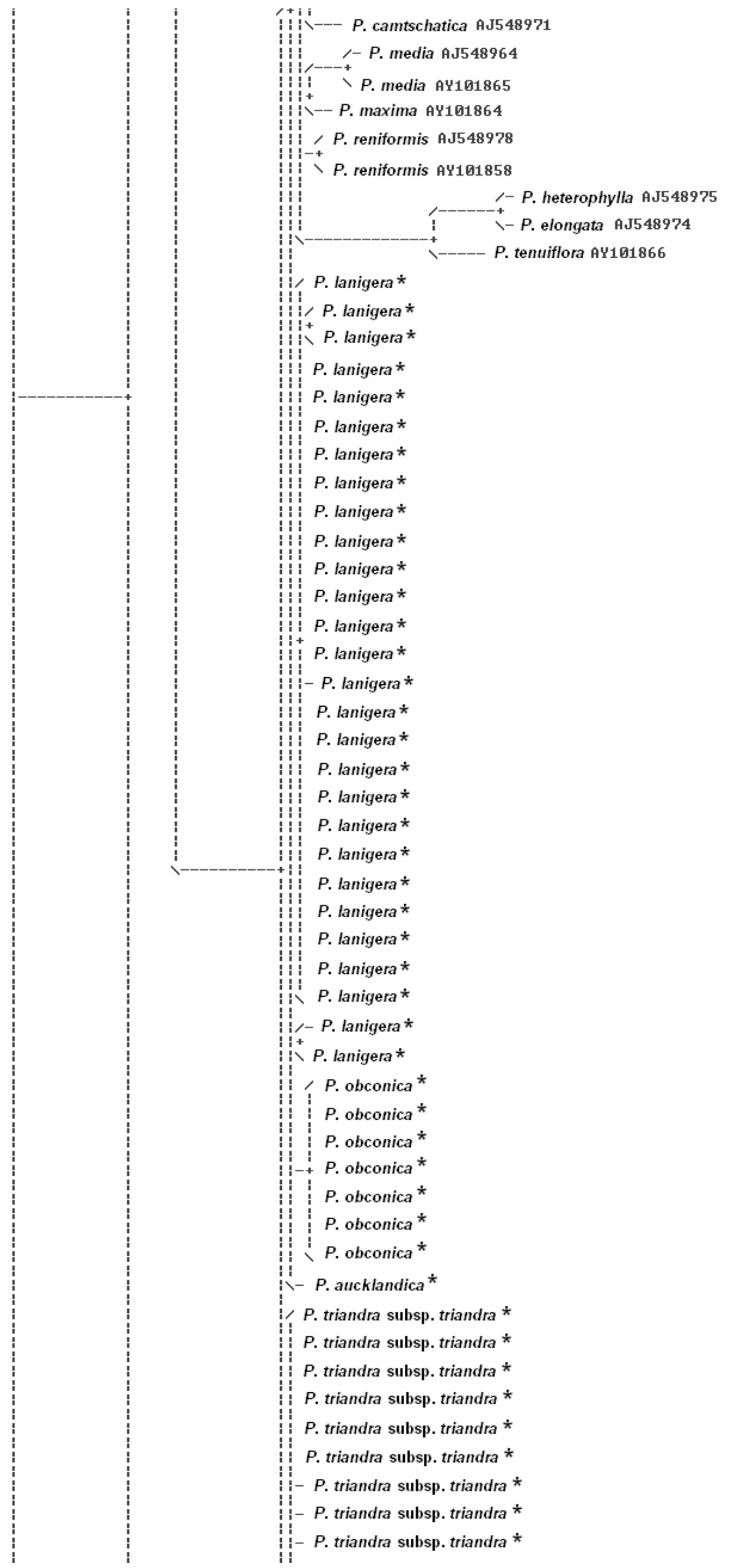


O. (continued) $50 \%$ posterior probability consensus ITS phylogeny of a worldwide Plantago dataset reconstructed using Bayesian analysis.

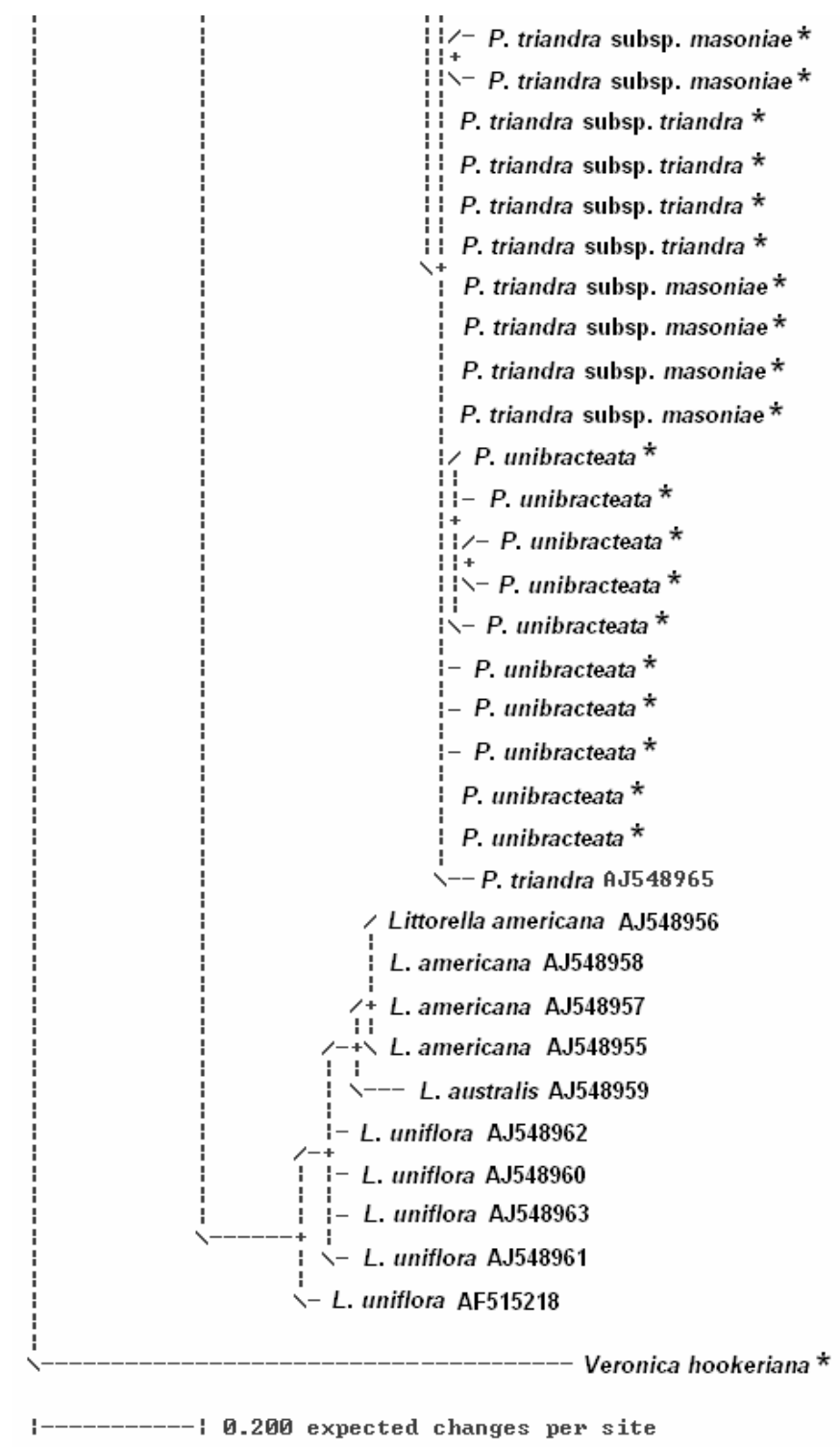




\section{Appendix III. Data statistics}

A. Data statistics for the three Australasian groups resolved in a worldwide ITS phylogeny (Fig. 4.2). Sample details can be found in Table 4.1.

\begin{tabular}{|c|c|c|c|}
\hline & Clade II & Grade B & Clade IV \\
\hline Base frequencies (all sites) & $\begin{array}{ll}\text { T- } 23.1 & \text { C- } 26.3 \\
\text { A- } 22.1 & \text { G- } 28.5\end{array}$ & $\begin{array}{ll}\text { T- } 23.0 & \text { C- } 26.0 \\
\text { A- } 22.3 & \text { G- } 28.6\end{array}$ & $\begin{array}{ll}\text { T- } 23.2 & \text { C- } 26.0 \\
\text { A- } 22.4 & \text { G- } 28.5\end{array}$ \\
\hline Base frequencies (variable sites) & $\begin{array}{ll}\text { T- } 29.4 & \text { C- } 27.9 \\
\text { A- } 22.9 & \text { G- } 19.8\end{array}$ & $\begin{array}{ll}\text { T- } 22.4 & \text { C- }-48.0 \\
\text { A- } 11.0 & \text { G- } 18.6\end{array}$ & $\begin{array}{ll}\text { T- } 22.3 & \text { C- } 41.3 \\
\text { A- } 9.3 & \text { G- } 27.1\end{array}$ \\
\hline $\begin{array}{l}\text { Variable sites and parsimony-informative } \\
\text { sites (\%) }\end{array}$ & $37(3.35 \%)$ & $31(1.98 \%)$ & $16(0.61 \%)$ \\
\hline Modeltest model & GTR + I & TIMef & $K 81+\mathrm{I}$ \\
\hline Pinvar & 0.8224 & 0 & 0.9468 \\
\hline Number of transitions (all sites) & 3 & 3 & 1 \\
\hline Number of transversions (all sites) & 3 & 2 & 2 \\
\hline Transition/transversion ratio (all sites) & 1 & 1.5 & 0.5 \\
\hline $\begin{array}{l}\text { p-value of } \chi 2 \text { of base frequencies overall } \\
\text { (variable sites) }\end{array}$ & $0.7530(0.5399)$ & $0.7530(0.0001)$ & $0.7530(0.0002)$ \\
\hline
\end{tabular}


B. Uncorrected pairwise distances of ITS sequences among Australasian species (sample details can be found in Table 4.1).

\begin{tabular}{|c|c|c|c|c|c|c|c|c|c|c|c|c|c|c|c|c|c|c|c|c|c|c|}
\hline & 1 & 2 & 3 & 4 & 5 & 6 & 7 & 8 & 9 & 10 & 11 & 12 & 13 & 14 & 15 & 16 & 17 & 18 & 19 & 20 & 21 & 22 \\
\hline 2 & 0.7 & - & & & & & & & & & & & & & & & & & & & & \\
\hline 3 & 0.8 & 0.5 & - & & & & & & & & & & & & & & & & & & & \\
\hline 4 & 2.9 & 1.5 & 2.7 & - & & & & & & & & & & & & & & & & & & \\
\hline 5 & 1.3 & 0.8 & 1.8 & 2.5 & - & & & & & & & & & & & & & & & & & \\
\hline 6 & 1.8 & 0.2 & 1.3 & 1.8 & 1.3 & - & & & & & & & & & & & & & & & & \\
\hline 7 & 1.8 & 0.5 & 1.5 & 2.3 & 1.3 & 0.8 & - & & & & & & & & & & & & & & & \\
\hline 8 & 0.5 & 0.3 & 1.0 & 2.0 & 0.5 & 0.8 & 0.8 & - & & & & & & & & & & & & & & \\
\hline 9 & 3.0 & 1.7 & 2.9 & 1.2 & 2.7 & 2.0 & 2.3 & 2.2 & - & & & & & & & & & & & & & \\
\hline 10 & 2.9 & 1.7 & 2.7 & 1.7 & 2.9 & 2.2 & 2.7 & 2.2 & 1.5 & - & & & & & & & & & & & & \\
\hline 11 & 3.2 & 1.9 & 3.0 & 0.7 & 2.9 & 2.2 & 2.7 & 2.4 & 1.3 & 1.8 & - & & & & & & & & & & & \\
\hline 12 & 3.0 & 1.7 & 2.8 & 1.5 & 2.7 & 2.0 & 2.5 & 2.2 & 1.3 & 1.8 & 1.7 & - & & & & & & & & & & \\
\hline 13 & 2.3 & 1.0 & 2.2 & 1.5 & 2.0 & 1.3 & 1.8 & 1.5 & 1.3 & 1.8 & 1.7 & 0.8 & - & & & & & & & & & \\
\hline 14 & 2.9 & 1.2 & 2.3 & 2.7 & 2.3 & 1.3 & 1.8 & 1.8 & 2.9 & 3.0 & 2.7 & 2.9 & 2.2 & - & & & & & & & & \\
\hline 15 & 2.2 & 1.0 & 2.0 & 2.3 & 2.2 & 1.5 & 2.0 & 1.5 & 2.2 & 2.3 & 2.5 & 1.8 & 1.2 & 2.3 & - & & & & & & & \\
\hline 16 & 1.5 & 1.2 & 1.0 & 3.4 & 2.3 & 2.0 & 2.2 & 1.7 & 3.6 & 3.4 & 3.7 & 3.5 & 2.9 & 2.9 & 2.7 & - & & & & & & \\
\hline 17 & 2.3 & 1.0 & 2.2 & 1.5 & 2.0 & 1.3 & 1.8 & 1.5 & 1.3 & 1.8 & 1.7 & 1.0 & 0.3 & 2.2 & 1.2 & 0.029 & - & & & & & \\
\hline 18 & 2.5 & 1.2 & 2.3 & 1.7 & 2.2 & 1.5 & 2.0 & 1.7 & 1.5 & 2.0 & 1.8 & 1.2 & 0.5 & 2.3 & 1.3 & 3.0 & 0.5 & - & & & & \\
\hline 19 & 2.7 & 1.3 & 2.5 & 1.8 & 2.3 & 1.7 & 2.2 & 1.8 & 1.7 & 2.2 & 2.0 & 1.3 & 0.7 & 2.2 & 1.5 & 3.2 & 0.7 & 0.8 & - & & & \\
\hline 20 & 2.5 & 1.2 & 2.3 & 1.7 & 2.2 & 1.5 & 2.0 & 1.7 & 1.5 & 2.0 & 1.8 & 1.2 & 0.5 & 2.2 & 1.3 & 3.0 & 0.5 & 0.7 & 0.5 & - & & \\
\hline 21 & 2.5 & 1.2 & 2.0 & 2.2 & 2.0 & 1.3 & 0.8 & 1.5 & $2 . .5$ & 3.2 & 2.9 & 2.7 & 2.0 & 2.4 & 2.5 & 2.7 & 2.0 & 2.2 & 2.3 & 2.0 & - & \\
\hline 22 & 2.5 & 1.2 & 2.3 & 1.7 & 2.2 & 1.5 & 2.0 & 1.7 & 1.5 & 2.0 & 1.8 & 1.2 & 0.5 & 2.2 & 1.3 & 3.0 & 0.5 & 0.7 & 0.5 & 0.0 & 2.0 & - \\
\hline 23 & 1.0 & 0.3 & 0.5 & 2.5 & 2.0 & 1.2 & 1.7 & 1.2 & 2.7 & 2.5 & 2.9 & 2.7 & 2.0 & 2.2 & 1.8 & 1.2 & 2.0 & 2.2 & 2.3 & 2.2 & 2.2 & 2.2 \\
\hline
\end{tabular}

$1=P$. spathulata subsp. spathulata, $2=P$. spathulata subsp. picta, $3=P$. triantha, $4=P$. triandra subspp, $5=P$. "sylvester", $6=P$. raoulii, $7=P$. lanigera $($ Eyre Mountains), $8=P$. lanigera (Sugarloaf Pass), $9=P$. lanigera, $10=P$. obconica, $11=P$. unibracteata, $12=P$. aucklandica, $13=P$. euryphylla, $14=P$. cladarophylla, $15=P$. cunninghamii, $16=P$. varia, $17=P$. glacialis, $18=P$. muelleri, $19=P$. alpestris, $20=P$. tasmanica, $21=P$. paradoxa, $22=P$. daltonii, $23=P$. debilis $\& P$. hispida. Highlighted boxes indicate relatively high p-distances found in the dataset ( $\geq 3.0 \%)$. Species with multiple shaded values are $P$. varia and $P$. spathulata subsp. picta (representatives of each species are used). 
